\title{
User Manual for AQUASTOR: A Computer Model for Cost Analysis of Aquifer Thermal Energy \\ Storage Coupled with District Heating or Cooling Systems
}

\section{Volume I - Main Text}

April 1982

Prepared for the U.S. Department of Energy under Contract DE-AC06-76RLO 1830

Pacific Northwest Laboratory Operated for the U.S. Department of Energy by Battelle Memorial Institute 


\title{
DISCLAIMER
}

This report was prepared as an account of work sponsored by an agency of the United States Government. Neither the United States Government nor any agency thereof, nor any of their employees, makes any warranty, express or implied, or assumes any legal liability or responsibility for the accuracy, completeness, or usefulness of any information, apparatus, product, or process disclosed, or represents that its use would not infringe privately owned rights. Reference herein to any specific commercial product, process, or service by trade name, trademark, manufacturer, or otherwise, does not necessarily constitute or imply its endorsement, recommendation, or favoring by the United States Government or any agency thereof. The views and opinions of authors expressed herein do not necessarily state or reflect those of the United States Government or any agency thereof.

\author{
PACIFIC NORTHWEST LABORATORY \\ operated by \\ BATTELLE \\ for the \\ UNITED STATES DEPARTMENT OF ENERGY \\ under Contract DE-AC06-76RLO 1830
}

\begin{tabular}{|c|c|}
\hline Printed in the & of America \\
\hline & \\
\hline National Tec & tion Service \\
\hline United States & f Commerce \\
\hline 5285 & oad \\
\hline Spring & 22151 \\
\hline & \\
\hline & \\
\hline & \\
\hline & Price \\
\hline Pages & Codes \\
\hline 001-025 & $\mathrm{A} 02$ \\
\hline 026-050 & $\mathrm{A} 03$ \\
\hline 051-075 & A04 \\
\hline $076-100$ & A05 \\
\hline $101-125$ & A06 \\
\hline $126-150$ & A07 \\
\hline $151-175$ & $\mathrm{~A} 08$ \\
\hline $176-200$ & $A 09$ \\
\hline $201-225$ & A010 \\
\hline $226-250$ & A011 \\
\hline $251-275$ & A012 \\
\hline $276-300$ & A013 \\
\hline
\end{tabular}


USER MANUAL FOR AQUASTOR: A COMPUTER

MODEL FOR COST ANALYSIS OF AQUIFER

THERMAL ENERGY STORAGE COUPLED WITH

DISTRICT HEATING OR COOLING SYSTEMS

VOLUME I - MAIN TEXT

H. D. Huber

D. R. Brown

R. W. Reilly

Apri1 1982

Prepared for the U.S. Department of Energy under Contract DE-ACO6-76RLO 1830

Pacific Northwest Laboratory

Richland, Washington 99352 


\section{PREFACE}

For ease of handling, the AQUASTOR User Manual was broken into two volumes. Volume I contains the main text, including introduction, program description, input data instructions, and a description of the output. Volume II contains all the appendices, including supply and distribution system cost equations and models, descriptions od pre-defined residential districts, key equations for the cooling degree-hour methodology, and a listing of the sample case output. Both volumes include the complete table of contents and lists of figures and tables. In addition, both volumes include Appendix $H$, which contains the indices for supply input parameters, distribution input parameters, and AQUASTOR subroutines. The authors hope this organization has resulted in a manual which is easier to work with. 



\section{ABSTRACT}

Pacific Northwest Laboratory has developed a computer model called AQUASTOR. The purpose of this model is to calculate the cost of district heating (cooling) using thermal energy supplied by an aquifer thermal energy storage (ATES) system. The AQUASTOR model is extremely flexible, and can simulate ATES district heating systems using stored hot water or ATES district cooling systems using stored chilled water.

AQUASTOR simulates the complete ATES district heating (cooling) system, which consists of two principal parts: the ATES supply system and the district heating (cooling) distribution system. The supply system submodel calculates the life-cycle cost of thermal energy supplied to the distribution system by simulating the technical design and cash flows for the exploration, development, and operation of the ATES supply system. This includes the construction and operation of a transmission pipeline for delivering the stored energy from the aquifer to the distribution system. The distribution system submodel calculates the life-cycle cost of heat (chill) delivered by the distribution system to the end-users by simulating the technical design and cash flows for the construction and operation of the distribution system.

AQUASTOR is a powerful analytical tool for cost analysis of district heating (cooling) systems using ATES. The model combines the technical characteristics of the supply system (such as aquifer efficiency parameters) and the technical characteristics of the distribution system (including climate, demographic factors, and thermal energy demands) with financial and tax conditions for the entities operating the two systems into one techno-economic model. This provides the flexibility to individually or collectively evaluate the impact of different economic and technical parameters, assumptions, and uncertainties on the cost of providing district heating (cooling) with an ATES system. ${ }^{(1)}$ 
PREFACE

ABSTRACT .

1.0 INTRODUCTION

2.0 DESCRIPTION OF PROGRAM

2.1 OVERVIEW OF A TYPICAL ATES DISTRICT HEATING (COOLING) SYSTEM. 2.1

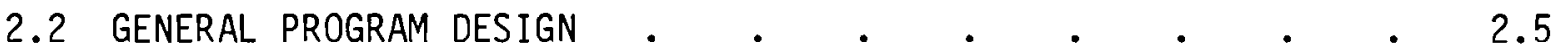

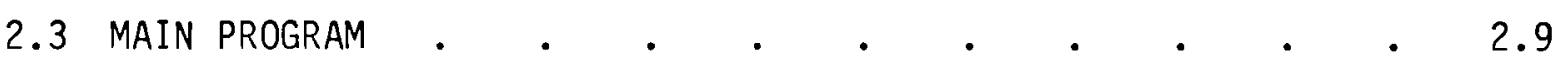

2.4 DATA INPUT SUBMODEL • • • • • • • • • • • 2.11

2.5 EXECUTIVE ROUTINE FOR SUPPLY SYSTEM AND DISTRIBUTION

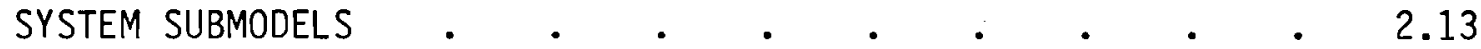

2.6 SUPPLY SYSTEM SUBMODEL (Technical Design and Costs) • . 2.26

2.6.1 Heat Exchangers at Interface with External

Energy Source and Distribution System . . . . 2.26

2.6.2 Fluid Transmission to and from Aquifer Wellfields . 2.36

2.6 .3 Aquifer. . . . . . . . . . . . . . 2.42

2.7 DISTRIBUTION SYSTEM SUBMODEL (Technical Design and Costs) • 2.43

2.8 DISCOUNTED CASH FLOW SUBMODEL FOR SUPPLY SYSTEM $\quad \cdot \quad \cdot \quad \cdot 2.58$

2.9 DISCOUNTED CASH FLOW SUBMODEL FOR DISTRIBUTION SYSTEM • $\quad 2.62$

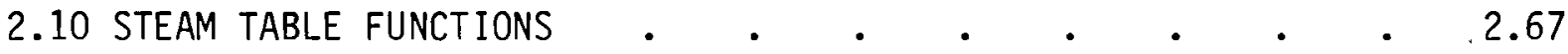

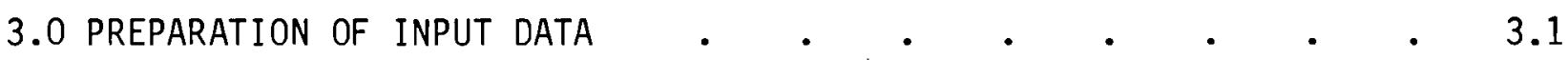

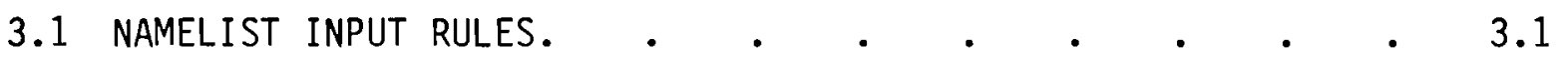

3.2 INPUT INSTRUCTIONS AND SAMPLE CASE INPUT $. \quad . \quad . \quad \cdot 3.3$

3.3 SUPPLY SYSTEM INPUT DATA •

3.3.1 Supply Energy Source . . . . . . . 3.16

3.3 .2 Supply Heat Exchanger . . . . . . . 3.20

3.3.3 Wellfield and Aquifer Description . . . . 3.23

3.3.4 Supply Transmission Piping and Pumps . $. \quad . \quad 3.25$ 


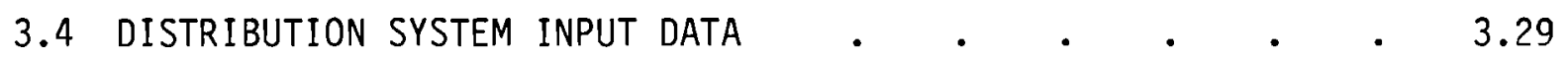

3.4 .1 Operational Mode . . . . . . . . . 3.30

3.4.2 Climatic Parameters for Heating Mode . . . . 3.31

3.4.3 Climatic Parameters for Cooling Mode . . . . 3.36

3.4.4 Distribution Heat Exchanger . . . . . . . 3.44

3.4 .5 Districts . . . . . . . . . . . 3.46

3.4.5.1 District Geometry . . . . . . 3.47

3.4.5.2 District Type Characteristics . . . 3.51

3.4.6 Distribution System Piping Design . . . . . 3.54

3.4.7 Point Demand . . . . . .3 .58

3.4.8 Branching Mains Network for Multi-Residential 3.59

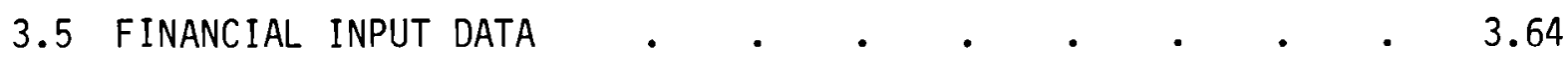

3.5.1 Supply System Financial Data . . . . . . 3.65

3.5.2 Aquifer Well Drilling Costs . . . . . . 3.66

3.5.3 Distribution System Financial Data . . . . $\quad . \quad 3.69$

3.5.4 Distribution System Trenching Costs . . . . 3.70

3.5.5 General Economic Parameters . . . . . . 3.72

$\begin{array}{lll}\text { 3.5.5.1 Base Year of Capital and O\&M Costs } & & \\ \text { and Depreciation Options } & \text {. } & 3.72\end{array}$

3.5.5.2 Inflation and Escalation . $. \quad . \quad .3 .75$

3.5.5.3 Cost of Supplemental Heat, Pumping
Efficiency, and Pumping Electrical costs . 3.77

3.5.6 Supply System Pre-Development, Development, and
Operation Time Schedules and Costs . . 3.79

3.6 OUTPUT SELECTION OPTIONS • • • • • • • • • • 3.86

4.0 DESCRIPTION OF OUTPUT

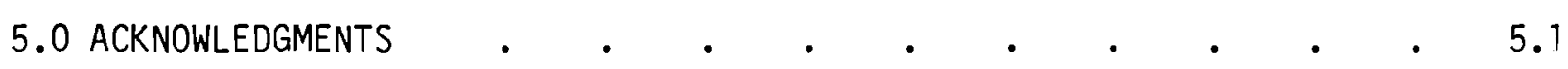

6.0 REFERENCES . . . . . . . . . . . . . . . 6.1

APPENDIX A - Pre-Development, Development, and Operation
Cost Equations for ATES Supply System . . . . A.1

APPENDIX B - Capital and Operating Cost Models for Distribution System B.1

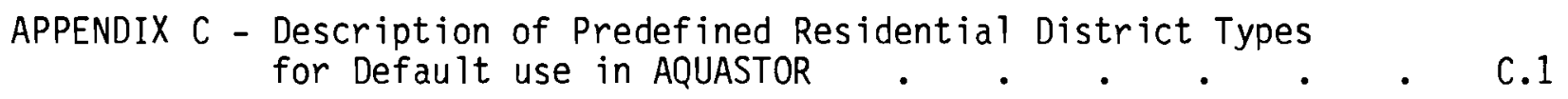

APPENDIX D - Capital Cost Models for ATES Supply System . . . . D.1

APPENDIX E - Key Equations for Cooling Degree Hour Methodology . . E.1 


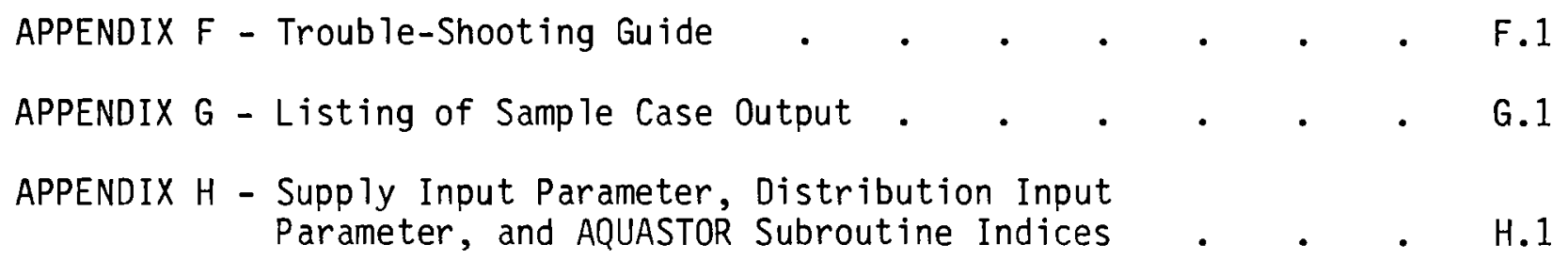




\section{FIGURES}

1. Overview of Technical and Economic Simulation for ATES

District Heating (Cooling) System • • • • . • . 1.2

2. Schematic of Major Elements of ATES Installation for

District Heating (Cooling) System • • • • • • • 2.2

3. Major Submodels and Order of Execution in AQUASTOR . $\quad$. 2.6

4. Flow Diagrams for AQUASTOR with Submodels and Subroutines

5. Sequence of Subroutines Called by the Executive Routine NODEPR to Simulate the ATES Elements . . . . . . 2.15

6. Well Layout Design and Routing of Fluid Transmission Lines . . 2.38

7. Layout for a District with 22 Buildings. . . . . 2.52

8. Steam Table Subregions as a Function of Temperature and Pressure. 2.70

9. Layout of Residential Districts in Richland, Washington . . 3.9

10. Nomenclature for the Temperature Distribution in the Supply Heat Exchanger at the Energy Source . . . . . 3.22

11. Nomenclature for the Temperature Distribution in the Distribution Heat Exchanger . . • • • • • . 3.45

12. Examples of Main Configurations Servicing Multi-Residential Districts . . • . • • . . 3.50

13. Physical Layout of Buried Pipe Trenches Used in
the Trenching Cost Model. . . . . . . . . 3.71

14. Default Time Sequences of Supply System Pre-Development,
Development, and Operation Activities

15. Storage Wellfield Nodes and Exiting Temperature Degradation

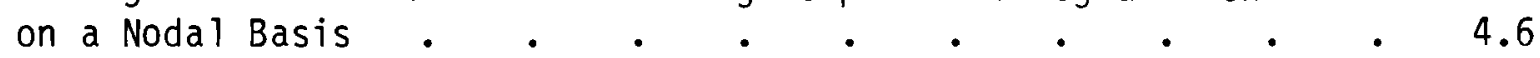

16. Layout for District 7 with 54 Buildings in Sample Case. .. . 4.9

B-1. District Heating (Cooling) System Two-Pipe Network • • • B.2

C-1. Plan of Suburban Residential House $54 \times 30 \mathrm{ft}$. . . . . C.2 
C-2. P1an for High-Density Single-Family Home . . . . . C.3

C-3. Plan for Garden Apartment Unit . . . . . . . . C.4

C-4. Plan for Townhouse Unit. . . . . . . . . C.5

C-5. Plan for High-Rise Apartment Unit Twelve Apartments per Floor . C.6 


\section{$\underline{\text { TABLES }}$}

1. ASME Steam Table Single-Valued Functions . . . . . 2.68

2. ASME Steam Table Multiple-Valued Functions . . . . . . 2.69

3. Sample Case Input for ATES District Heating in Richland, WA. $\quad 3.5$

4. ATES Supply System Input Parameters for City of Richland

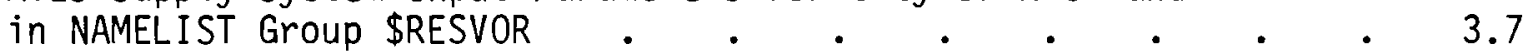

5. Summary of District Input Data for ATES Installation at Richland, Washington . . . . . . . . 3.10

6. Distribution System Input Parameters for City of Richland

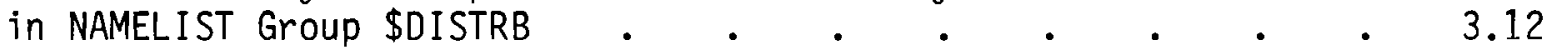

7. Branching Main Matrix DNET for ATES Installation at Richland, Washington . . . . . . . . . 3.15

8. District Type Characteristics of the Default District
Types in AQUASTOR. . . . . . . . 3.52

9. Matrix Examples for Branching Mains Network . . . . . 3.63

10A. Activities and Input Costs for Supply System Pre-Development, Development, and Operation . . . . . . . 3.80

10B. Activities, Input Times, and Success Ratios for Supply System 3.81

11. Subgrouping of Supply System Activities Occurring

Parallel in Time. . . . . . . . 3.82

12A. Subgrouping of Supply System Activities by Decision Points . $\quad 3.85$

12B. Description of Decision Points . . . . . . . 3.86

13. Summary of Computer Output from AQUASTOR . . . . . 4.2

B-1. Distribution System Capital Cost Coefficients . . . . B.8

B-2. Operating Cost Models . . . . . . . . . B.10

B-3. Calcium Silicate Insulation Cost Equations . . . . . . B.11

B-4. Valves, FRP Fittings, and Carbon Steel Fittings . . . . B.12

B-5. Steet Casing Fitting . . . . . . . . . B.13 
B-6. PVC Casing Fitting . . . . . . . . . . B.14

B-7. Meter . . . . . . . . . . . . B.15

B-8. Cost Factors . . . . . . . . . . . B.16

C-1. Design Basis for Suburban Residential House $54 \times 30 \mathrm{ft}$. $\quad$ C.2

C-2. Design Basis for High-Density Single-Family Home . . . . C.3

C-3. Design Basis for Garden Apartment Unit . . . . . . C.4

C-4. Design Basis for Townhouse Unit . . . . . . . C.5

C-5. Design Basis for High-Rise Apartment Unit . . . . . C.6

D-1. Categorization of Transmission System Components

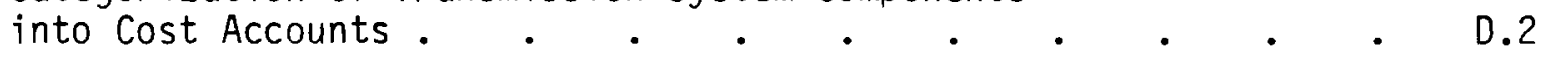

D-2. Transmission System Capital Cost Coefficients . . . . D.3

D-3. Transmission System Pipe Schedules . . . . . . . . 0.4 


\section{USER MANUAL FOR AQUASTOR}

\subsection{INTRODUCTION}

This user manual describes a computer simulation model called AQUASTOR. The purpose of this model is to calculate the cost of district heating (cooling) using thermal energy supplied by an aquifer thermal energy storage (ATES) system coupled to a seasonal energy source. The model was developed in support of the Underground Energy Storage Program at the Pacific Northwest Laboratory (PNL), the lead laboratory for underground energy storage research for the U.S. Department of Energy. Funding was provided by the Office of Energy Systems Research within the Department of Energy.

The objective of this user manual is to provide users of the AQUASTOR code with a basic understanding of the code operation and its capabilities. This manual presents a general description of the computer code, the details of the submodels and subroutines used to simulate the ATES district heating (cooling) system, a detailed description of the input instructions and input data for using the code, the input for a sample problem, and a description and listing of the corresponding computer output.

The AQUASTOR model is extremely flexible, and can simulate ATES district heating systems using stored hot water or ATES district cooling systems using stored chilled water. The model combines a simulation of the technical design, construction, and operation of the ATES district heating (cooling) system with a detailed cash flow simulation to estimate the cost of ATES delivered heat (chill) to the end-user. The cost is expressed in dollars per million British thermal units of delivered energy (\$/MBtu). The block diagram in Figure 1 shows an overview of the technical and economic simulation used to calculate the cost of an ATES district heating (cooling) system.

The AQUASTOR model is a powerful analytical tool for district heating (cooling) cost analysis using ATES systems. The model provides the flexibility to individually or collectively evaluate the impact of many technical and economic parameters on the cost of ATES delivered heat (chill) to the end-user. This includes the technical characteristics of the ATES supply system (such as aquifer efficiency characteristics, well drilling costs, and the distance of 


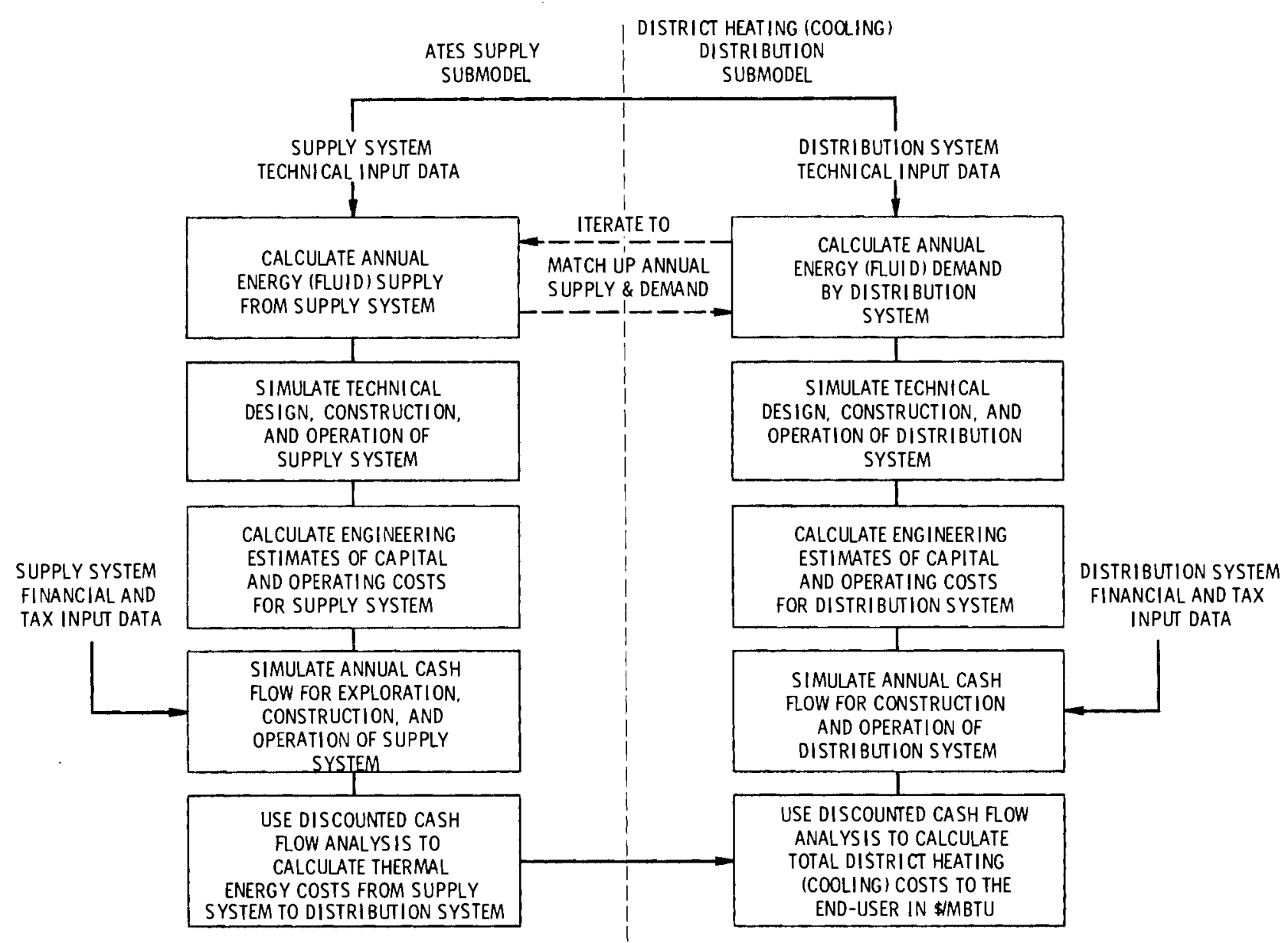

FIGURE 1. Overview of Technical and Economic Simulation for ATES District Heating (Cooling) System

the aquifer to the district heating (cooling) distribution system), the technical characteristics of the distribution system (including climate, population, and thermal energy demands) and financial and tax conditions.

The model is composed of two principal parts: an ATES supply submodel and a district heating (cooling) distribution submodel. The ATES supply submodel simulates the storage of thermal energy from a seasonal energy source using hot (chilled) water in an aquifer and the subsequent recovery and delivery of the thermal energy to a distribution system for district heating (cooling). AQUASTOR calculates the life-cycle cost of thermal energy supplied to the distribution system by simulating the technical design and cash flows for the exploration, development, and operation of the ATES supply system. This 
includes the construction and operation of a transmission pipeline for delivering the energy from the aquifer to the distribution system.

The district heating (cooling) distribution submodel simulates the delivery of the hot (chilled) water supplied by the ATES supply system to the endusers for district heating (cooling). AQUASTOR calculates the life-cycle cost of heat (chill) delivered by the distribution system to the end-user by simulating the technical design and cash flows for the construction and operation of the distribution system.

AQUASTOR uses discounted cash flow analysis to calculate the unit cost of thermal energy to the distribution system and the unit cost of heat (chill) to the end-user. The calculations are based on the principle that the present worth of the revenues must equal the present worth of the expenses, including investment return, over the economic life of the supply and distribution systems. The model can simulate nearly any financial and tax structure through varying the rates of return on debt and equity, the debt-equity ratios, tax rates, and depreciation schedules. Both private enterprise and municipal utility systems can be simulated. The companies operating the ATES supply system and the district heating (cooling) distribution system may have the same or differing financial structures and costs of capital.

The model provides the flexibility to update capital and operating cost estimates of the ATES supply system and district heating (cooling) distribution system to present year dollars. Currently, the default value is January, 1980 dollars. This updating feature is extremely important to prevent obsolescence of the cost estimates generated by using the code in future years. Of course, radical changes in ATES technology or construction in future years, e.g., changes affecting the aquifer, well drilling, downhole pumps, heat exchangers, or piping systems, would require modifications to the subroutines in the code calculating the cost of these elements.

The model also provides the flexibility to include the effects of inflation and price escalation in calculating the capital and operating costs over the simulated lifetime of the ATES supply system and district heating (cooling) distribution system. The user can operate the code to perform either current 
dollar analysis with inflation and price escalation or constant dollar analysis without inflation and price escalation.

This user manual is comprised of six sections and eight appendices. Section 1.0 introduces the user to the background and purpose of the code and the scope of the manual. Section 2.0 provides a general description of the AQUASTOR code, including the details of the submodels and of the subroutines that carry out the computations arising from the submodels. Section 3.0 describes in detail the preparation of the input data and a sample input problem. Section 4.0 describes the computer output corresponding to the sample input problem. Sections 5.0 and 6.0 list the acknowledgments and references respectively. The reader who wants to rapidly learn to use the code can simply read Section 2.1 (Overview), Section 2.2 (General Program Design), Section 3.0 (Preparation of Input Data), and Section 4.0 (Description of Output).

Appendices $A$ through $G$ describe the following items: $A$ ) cost equations for the pre-development, development, and operation of the ATES supply system; B) capital and operating cost models stored in the code for the distribution system; C) pre-defined residential district types stored in the code for the distribution system; D) capital cost models stored in the code for the ATES supply system; E) key equations for the cooling degree hour methodology; F) a trouble-shooting guide in case the code fails to execute properly; and G) a listing of the sample computer output corresponding to the sample data input. The manual concludes with an index to the input parameters and an index to the subroutines to aid the code user in locating the descriptions of the input parameters and subroutines in this manual. 


\subsection{DESCRIPTION OF PROGRAM}

\subsection{OVERVIEW OF A TYPICAL ATES DISTRICT HEATING (COOLING) SYSTEM}

An ATES installation for district heating (cooling) is based on the concept of storing thermal energy in an aquifer until recovery at some later time for space or process heating (cooling). This technology requires that a source of thermal energy such as cogenerated heat, climate-related energy (e.g., winter chill in the form of cold surface water), or industrial waste heat be available for storage. This is energy that would otherwise have been wasted or unavailable without seasonal storage, because no demand existed for it at the time of availability. The AQUASTOR model assumes that thermal energy is available from a seasonal energy source in a liquid medium (water) and is extracted through a liquid-to-liquid heat exchanger located at the energy source. The thermal energy is purchased from the external energy source on a $\$ / M B t u$ basis.

The diagram in Figure 2 shows the layout of a typical ATES installation for district heating (cooling) purposes. The ATES installation consists of two principal parts: 1) an ATES supply system for storing thermal energy in an aquifer and supplying it when needed, and 2) a distribution system for delivering the thermal energy supplied by the ATES supply system to the end-user for space or process heating (cooling). The ATES supply system is comprised of the following major elements represented symbolically by nodes and legs in Figure 2.

Node 1 - External energy source, a heat exchanger, and pumps at the tubeside and shell-side inlets to the heat exchanger

Leg 1 - Surface transmission pipeline and series of surface pumps to deliver the fluid from Node 1 to Node 2

Node 2 - Set of storage wells drilled into a suitable aquifer, downhole pumps, and surface wellfield piping

Leg 2 - Surface transmission pipeline and series of surface pumps to deliver the fluid from Node 2 to Node 3.

Leg 3 - Surface transmission pipeline and series of surface pumps to deliver the fluid from Node 3 to Node 4

Node 4 - Set of supply wells drilled into the same aquifer, downhole pumps, and surface wellfield piping 


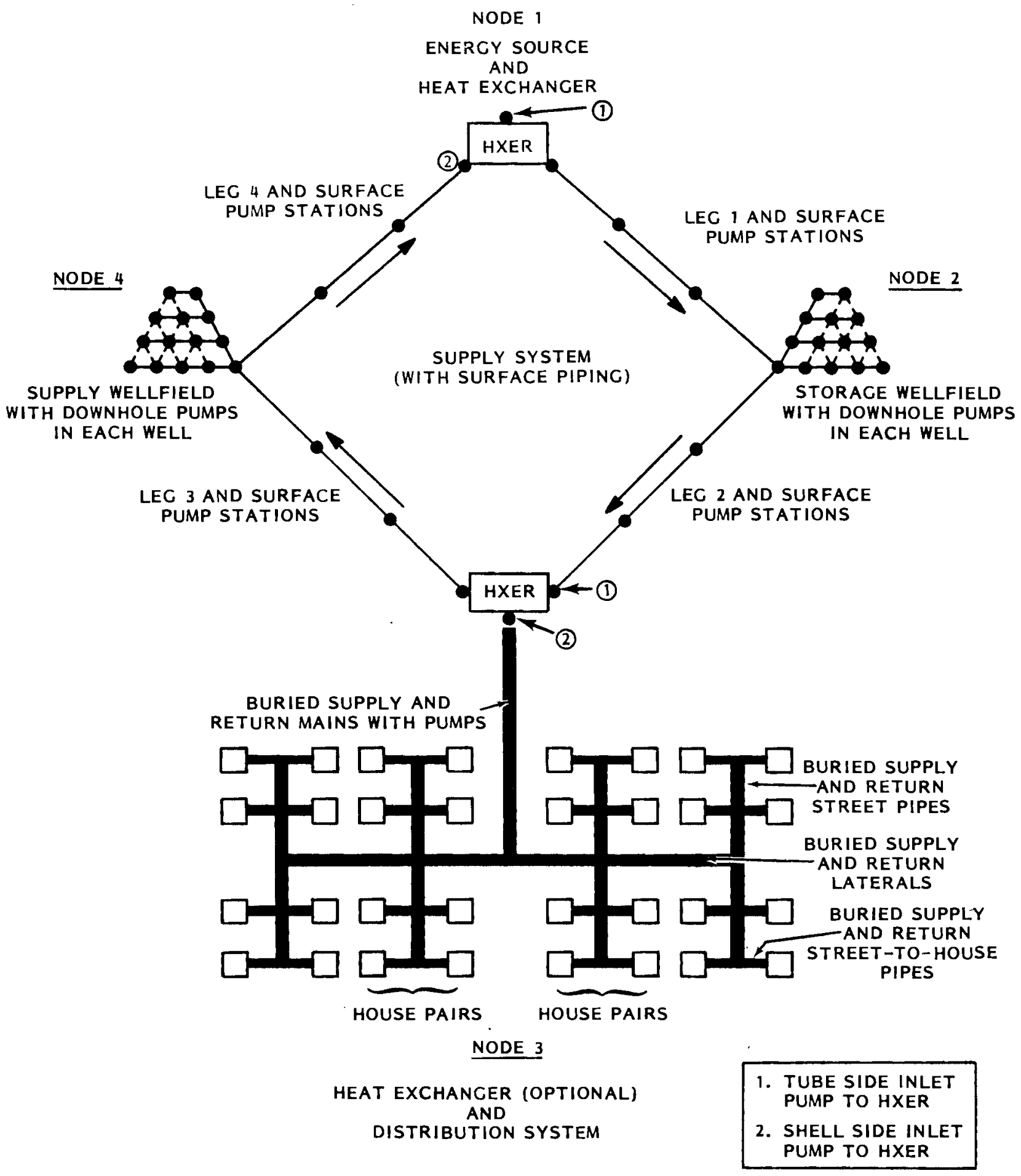

FIGURE 2. Schematic of Major Elements of ATES Installation for District Heating (Cooling) System 
Leg 4 - Surface transmission pipeline and series of surface pumps to deliver the fluid from Node 4 to Node 1.

The district heating (cooling) distribution system is represented symbolically by Node 3 in Figure 2. It consists of an optional heat exchanger with pumps at the tube-side and shell-side inlets to the heat exchanger, surface pumps, and a buried distribution piping system for delivering the hot (chilled) water to the end-user.

During operation, the ground water is withdrawn from the supply wells, heated (chilled) in the heat exchanger at the external energy source, and then returned to the same aquifer through the storage wells. The two sets of wells are horizontally separated to ensure that the storage bubble is unaffected by operations at the supply wells. Thermal energy is stored in the aquifer until needed. At recovery, the storage wells are pumped, and the hot (chilled) water is pumped through an optional heat exchanger at the inlet to the distribution system or directly pumped into this system to deliver the stored energy for space or process heating (cooling). The water from the storage wells is then returned to the aquifer through the supply wells to complete the cycle.

The technical design, operation, and costs of the ATES elements are simulated in the code by an executive routine called NODEPR, the supply submodel, and the distribution submodel. These submodels are described in Sections 2.5 through 2.7. The executive routine NODEPR and the supply submodel employ the energy source characteristics, aquifer efficiency parameters, and peak/annual flow requirements to design the ATES supply system and calculate its capital and operating costs. The executive rout ine NODEPR iterates between the supply and distribution submodels (see Section 3.3.1) in an attempt to match up the annual energy supply with annual energy demand in designing the supply and distribution systems. This involves a triple set of nested iterations to design heat exchangers, pipelines, and wellfields, and balance mass and thermal flows between the supply and distribution (demand) portions of the system. These iterations take into account water and thermal losses in the aquifer and in all pipelines.

The supply submodel does not attempt to simulate fluid or thermal flow within the aquifer. Instead, the salient aquifer characteristics are 
represented by three input parameters: fluid recovery fraction (ratio of annual water volume recovered to annual volume injected), thermal storage efficiency (ratio of annual energy recovery to annual energy injection), and discovery (natural) aquifer temperature. Only the steady state situation is modeled and aquifer thermal efficiency is assumed constant over time.

The executive routine NODEPR and the distribution submodel design the hot (chilled) water distribution system and calculate its capital and operating costs. Climatic parameters are used to determine peak and average heat demands, load factors, and supplemental heat requirements (if any). The peak demand is then used in conjunction with material and design options for pipe, insulation, and casing to design the fluid transmission lines. The pipe sizes and insulation thicknesses are automatically optimized to a lowest total cost based upon the mix of capital, thermal loss, and pumping energy costs.

The input data for the distribution system defines energy demand characteristics for a single point demand (e.g., a large commercial building or factory), residential districts, or a multi-district city. Each district is a contiguous area consisting of buildings of similar heat (chill) demand and uniform density. Five residential district types, representing typical residential areas, and one point demand are defined in the distribution submodel; variations of the district types or other district types (including commercial districts) can be added to the input data as required.

After the executive routine NODEPR completes processing the iterative calculations between the supply and distribution submodels, the capital and operating costs of the two systems are combined with financial and tax input parameters in discounted cash flow submodels for the two systems. These submodels simulate the annual cash flows for all capital and operating costs over the lifetimes of the supply and distribution systems. Discounted cash flow analysis is used to calculate the unit cost of thermal energy sold to the distribution system by the supply system and the unit cost of heat (chill) sold to the end-user by the distribution system. These costs (expressed in \$/MBtu) are the prices that must be charged to recover all costs of production, including capital investment, purchased thermal energy, operating expenses, and taxes, as we 11 as a specified rate of return on investment. 


\subsection{GENERAL PROGRAM DESIGN}

AQUASTOR is designed in modular fashion with 85 technical and economic subroutines. In addition to the standard FORTRAN library functions, 63 subroutines comprising the 1967 ASME Steam Tables $(2,3)$ are used to calculate thermodynamic and physical properties of pure water, including pressure, temperature, enthalpy, specific volume, density, viscosity and fluid quality. AQUASTOR and the steam tables contain approximately 16,000 and 4000 FORTRAN statements respectively.

AQUASTOR and the ASME Steam Tables are programmed in ASCII FORTRAN using all double precision and are operational on the UNIVAC 1100/44 computer with EXEC level 36 operating system. The overall program requires 30 minutes to compile on the ASCII FORTRAN level 8R1 compiler without optimization on the UNIVAC 1100/ 44 computer. The entire program requires approximately 150,000 decimal words of computer memory for execution. The sample case described in Section 3.2 required 44 seconds of CPU time for execution on the UNIVAC 1100/44 computer.

The source code for AQUASTOR and the ASME Steam Tables, the sample data input described in Section 3.2, and the sample computer output in Appendix G are available from the Argonne Code Center on one reel of magnetic tape. The program can be converted to other UNIVAC computer facilities with a minimal set of basic control cards required to compile, load, and execute a FORTRAN source program from tape. Numerous comment cards are provided in the source code to facilitate understanding of the logic in the code. It is recommended that the user initialize computer memory to 0 with an appropriate control card before executing the AQUASTOR code.

The block diagram in Figure 3 shows the computational flow through the major submodels of AQUASTOR. Figure 4 shows the detailed, logical layout of the subroutines in each major submodel and serves as the basis for the operational description of the major sequence of calculations in AQUASTOR.

The major submodels and their associated subroutines in AQUASTOR are discussed in Sections 2.3 through 2.9 in the order of their execution in the computer code. The code user may refer to Figures 3 and 4 to help read the following descriptions of the submodels and their subroutines. The submodels are as follows: 


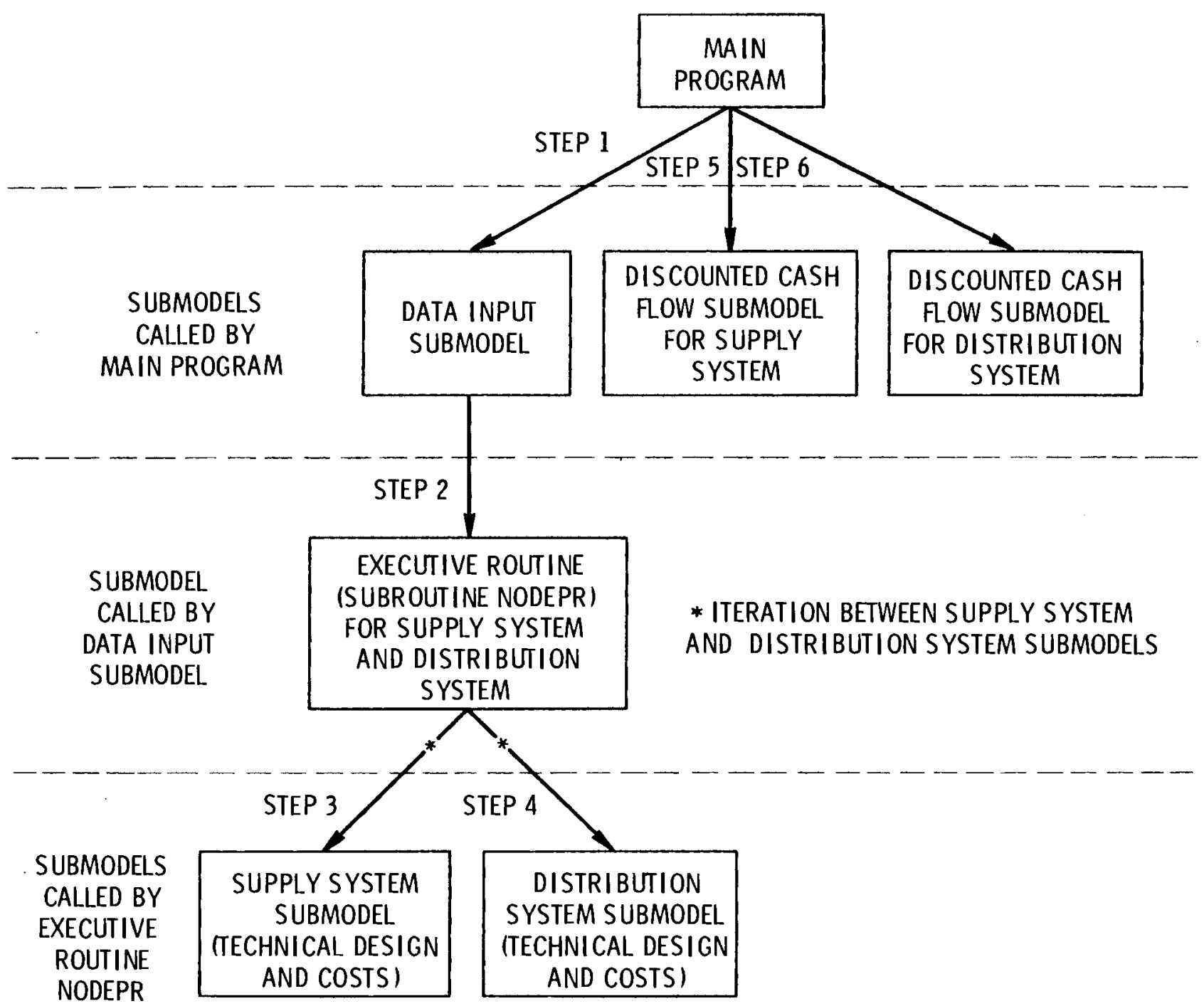

FIGURE 3. Major Submodels and Order of Execution in AQUASTOR 


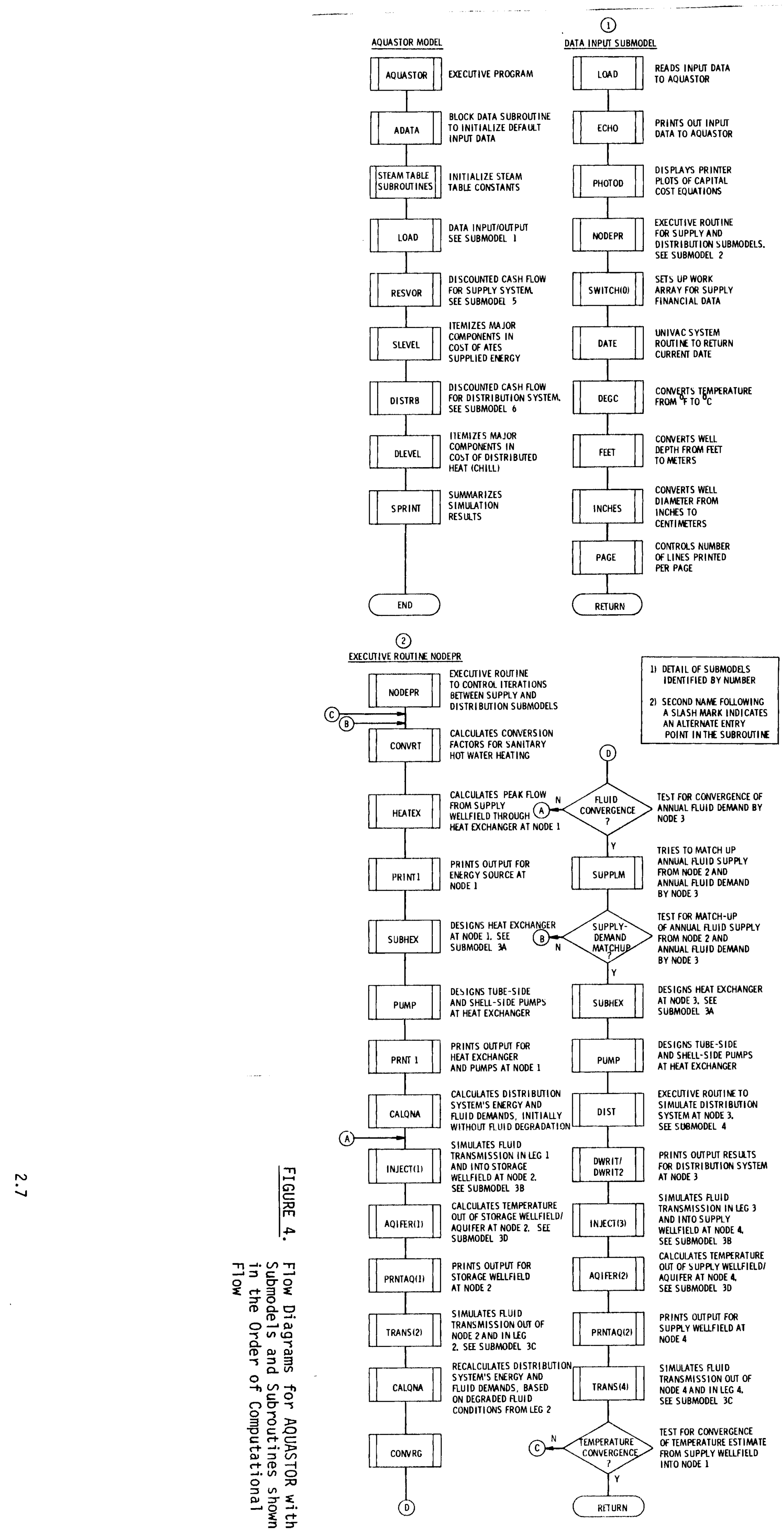




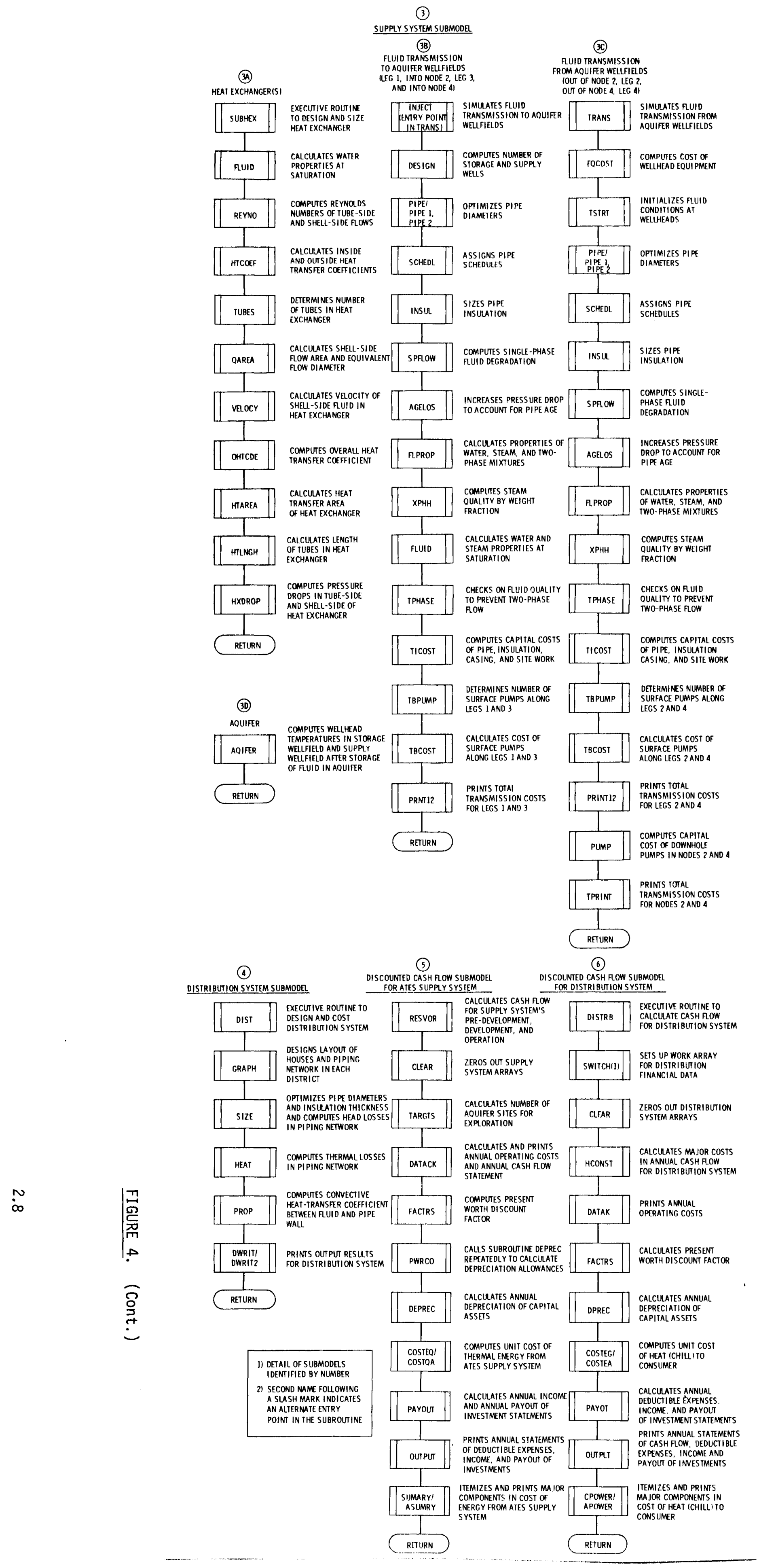


- Main Program

- Data Input Submode 1

- Executive Routine for Supply System and Distribution System Submodels

- Supply System Submode 1

- Distribution System Submode1

- Discounted Cash Flow Submodel for Supply System

- Discounted Cash Flow Submodel for Distribution System

The ASME Steam Table functions are called from many subroutines in AQUASTOR, but are not shown in Figure 4 for the sake of brevity. These functions are summarized in Section 2.10 following the descriptions of the submodels and their subroutines.

\subsection{MAIN PROGRAM}

The main program controls the sequence of processing by the major submodels to simulate the technical design and calculate the economic costs of the ATES district heating (cooling) system. As previously noted, Figure 3 shows the major submodels called directly or indirectly by the main program. As the first step to set up the initialization, the main program calls the BLOCK DATA subroutine ADATA to initialize default values for the technical and economic input parameters (see Figure 4 ). This is followed by a series of calls to subroutines from the ASME Steam Tables to initialize constants required by the steam table functions.

The main program then calls the data input submodel simulated by subroutine LOAD and its associated subroutines to allow the code user to override the default values for the input parameters and input new values using the NAMELIST feature. The data input submodel in turn calls the executive routine NODEPR to initiate and control the iterations between the supply system and distribution system submodels. This iterative process designs the supply and distribution systems and calculates their capital and operating costs.

Using these cost estimates, the main program calls the discounted cash flow submodel for the supply system (simulated by subroutine RESVOR and its associated subroutines) to calculate the life-cycle, levelized unit cost of 
thermal energy from the supply system, deflated to base year dollars. Subroutine SLEVEL is called to break down the cost of thermal energy from the supply system into four basic components: 1) capital costs, 2) 0\&M costs, 3) purchased thermal energy costs, and 4) pumping electricity costs.

The main program next calls the discounted cash flow submodel for the distribution system (simulated by subroutine DISTRB and its associated subroutines) to calculate the life-cycle, levelized unit cost of heat (chill) from the distribution system (to the end-user), deflated to base year dollars. Subroutine DLEVEL is called to break down the cost of heat (chill) from the distribution system into the same four basic components as was previousiy performed for the supply system by subroutine SLEVEL.

Finally, the main program calls subroutine SPRINT to print a summary of the technical and economic results from the simulation. Subroutine LOAD is then called again to read in the input data for the next simulation case and execution is terminated if there are no more cases.

The subroutines called by the main program are described below in the order of their execution in the code.

ADATA The BLOCK DATA subroutine that initializes default values for the input parameters when the code is loaded into computer memory.

CCSR1, CCSR2 Subroutines from the ASME Steam Tables that initialize steam CCSR3, CCBLL constants required in calculations by the steam table functions. and COMALL

LOAD

Subroutine $L O A D$ and its associated subroutines described in Section 2.4 comprise the data input submodel. This subroutine reads the input data using the NAMELIST feature to override the default values initialized in BLOCK DATA. Subroutine LOAD also calls supporting subroutines to echo back a record of the input data and generate printer plots of key capital cost equations stored in the code for the distribution system. Finally, subroutine LOAD calls the executive routine NODEPR which initiates and controls the iterative process between the supply system and distribution system submodels. 
RESVOR Subroutine RESVOR and its associated subroutines described in Section 2.8 comprise the discounted cash flow submodel for the supply system. This submodel generates the cash flow associated with the pre-development, development, and operation of the supply system and uses discounted cash flow analysis to calculate the unit cost of thermal energy from the supply system.

SLEVEL - Subroutine SLEVEL breaks down the unit cost of thermal energy from the supply system in base year dollars into four basic components: 1) capital costs, 2) 0\&M costs, 3) purchased therma 1 energy costs, and 4) pumping electricity costs.

DISTRB Subroutine DISTRB and its associated subroutines described in Section 2.9 comprise the discounted cash flow submodel for the distribution system. This submodel generates the cash flow associated with the design, construction, and operation of the distribution system and uses discounted cash flow analysis to calculate the unit cost of heat (chill) from the distribution system.

DLEVEL The second half of subroutine SLEVEL, defined by the entry point DLEVEL, breaks down the unit cost of heat (chi11) from the distribution system in base year dollars into the four basic components previously mentioned in the description of subroutine SLEVEL.

SPRINT Subroutine SPRINT prints a summary of the key technical and economic results at the end of the simulation run.

\subsection{DATA INPUT SUBMODEL}

The data input submodel is comprised of subroutine LOAD and nine supporting subroutines. This submodel performs the following six activities in the code:

1) initializes default values for several of the input parameters

2) reads in new values for the input parameters using the NAMELIST feature 
3) performs scale conversions for several of the input parameters for internal usage in the code

4) prints a record of the input data at the beginning of the simulation run

5) generates optional printer plots of several of the key capital cost equations stored in the code for the distribution piping system

6) calls the executive routine NODEPR to initiate and control the iterations between the supply system and distribution system submodels.

After the iterations between the supply system and distribution system submodels are completed in subroutine NODEPR, subroutine LOAD returns control back to the main program. The main program then calls the discounted cash flow submodels for the supply and distribution systems to complete the economic processing.

The input data and default values for the supply and distribution systems are described in Section 3.0. The subroutines called by subroutine LOAD to read, convert, and print the input data are described below in the order of their execution in the code.

ECHO Prints out a comprehensive record of the input data and its units at the beginning of the simulation run.

PHOTOD Calls subroutine TOLP to generate printer plots of key capital cost equations stored in the code for estimating the capital costs of various components of the distribution piping system, including pipes, insulation, and casing, over a wide range of pipe diameters. The capital cost equations, that are described in Appendix B, constitute an internal data base stored in the code. The coefficients in the capital cost equations described in Appendix $B$ for the distribution system are defined in subroutines DATA, SIZE, DIST, and PHOTOD of the code. Future changes to these coefficients, if needed, can be made through these four subroutines.

SWITCH(0) Stores the first 35 values of the DINPUT array defining input financial and tax data for the supply system (see Section 3.5.1) into an internal work array, $\mathrm{D}(\mathrm{N}), \mathrm{N}=1, \ldots, 35$. SWITCH(1) stores 
the second set of 35 values of the DINPUT array, DINPUT(N), $\mathrm{N}=36, \ldots, 70$, defining input financial and tax data for the distribution system (see Section 3.5.3) into the same work array, $D(N), N=1, \ldots, 35$. The common work array has similar definitions for the supply and distribution systems, although the individual elements transferred from the first and second set of 35 values in the DINPUT array can have different numerical values.

DATE

DEGC Subroutine DATE is a system routine on the UNIVAC computer that returns the current date in the form 'MM/DD/YY' where: $M M=$ the current month of the year $D D=$ the current day of the month $Y Y=$ the current year.

DEGC

FEET

INCHES

Returns Centigrade temperature expressed as a positive number when Fahrenheit temperature is input as a negative number. Centigrade temperature input as a positive number is returned unchanged.

FET

Returns meters expressed as a positive number when feet are input as a negative number. Meters input as a positive number are returned unchanged. The input parameter that can use this option is the aquifer well depth, $\operatorname{STRATA}(2,1)$.

Returns centimeters expressed as a positive number when inches are input as a negative number. Centimeters input as a positive number are returned unchanged. The input parameter that can use this option is the aquifer well diameter, DIA.

PAGE Controls the number of lines printed per page, prints an input title at the top of the page, and numbers pages. This routine is called from various subroutines throughout the code.

\subsection{EXECUTIVE ROUTINE FOR SUPPLY SYSTEM AND DISTRIBUTION SYSTEM SUBMODELS}

The executive routine NODEPR is a key subroutine in the AQUASTOR code. It initiates and controls the iterations between the subroutines comprising the components of the ATES supply and distribution submodels. This iterative 
procedure simulates the design and calculates the capital and operating costs of the supply and distribution system. Subroutine NODEPR simulates the ATES elements represented symbolically by nodes and legs in Figure 2 in the clockwise direction of fluid flow, starting with node 1 , followed by leg 1 , node 2 , etc., and preceeding to node 4 , leg 4 , and back to node 1 to complete the cycle. The major subroutines called by subroutine NODEPR in simulating the elements of the ATES supply and distribution systems are shown in Figure 5 in the order in which they are called.

The executive routine NODEPR is summarized below by a walk through of its operational logic, followed by a brief description of the major subroutines in Figure 5 called by subroutine NODEPR. Since these subroutines simulate the components of the ATES supply and distribution systems, a more detailed description of the subroutines is given in the descriptions of the supply and distribution system submodels in Sections 2.6 and 2.7 respectively. The computational steps performed by subroutine NODEPR are as follows:

1) The fluid temperature entering the heat exchanger at node 1 from the supply wellfield is initially estimated. The estimate is recomputed below in successive iterations until it converges.

2) Several conversion factors used in computing the heat demand required for sanitary hot water heating in district heating are calculated by subroutine CONVRT.

3) The peak fluid supply (lb/hr) circulating from the supply wellfield through the shell-side of the heat exchanger at node 1 is calculated by subroutine HEATEX. The peak fluid supply is determined based on the thermal energy available for transfer on the tube-side (external energy side) of the heat exchanger and the stipulated change in thermal energy desired on the shell-side (supply wellfield side). The equation is given in the description of subroutine HEATEX below. The peak flow rate from the external energy source may be adjusted by subroutine SUPPLM below to try to match up the annual energy supply with annual energy demand. The rationale is described in Section 3.3.1. This adjustment will, of course, also adjust the peak flow rate circulating from the supply wellfield through the shell-side of the heat exchanger. 


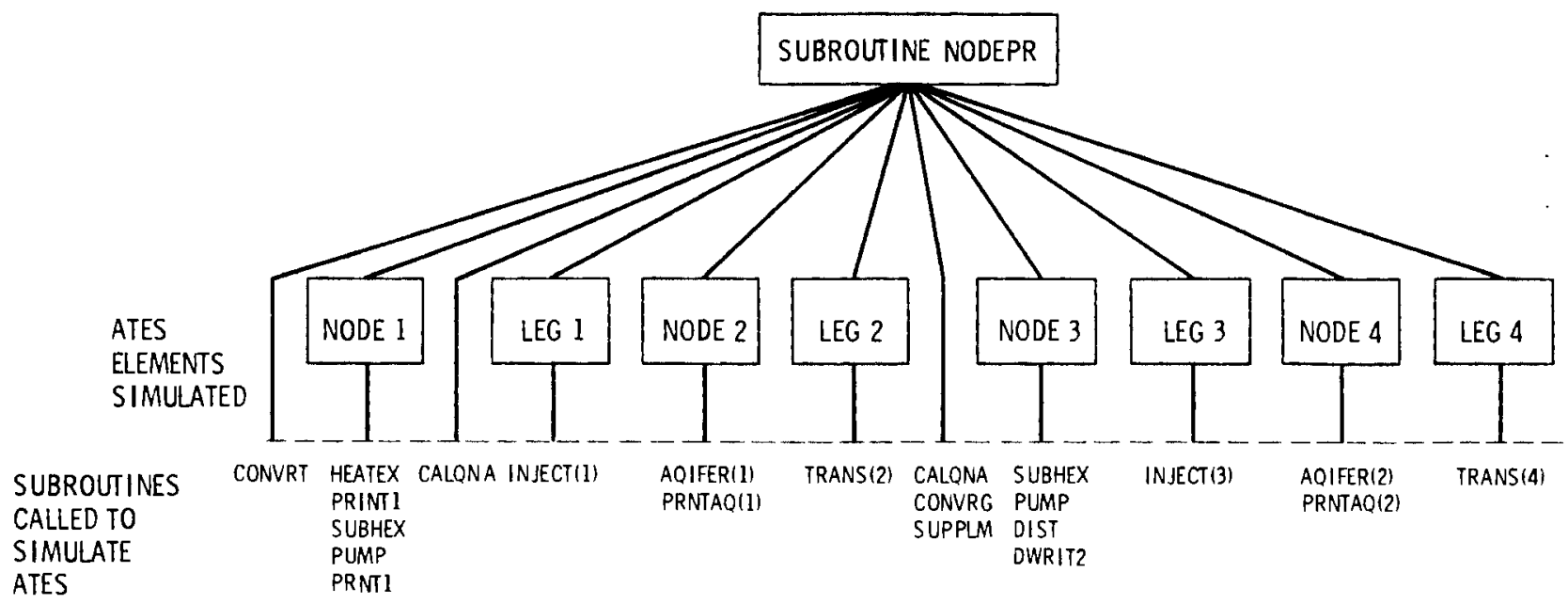

ELEMENTS

\section{DESCRIPTION OF SUBROUTINES}

CONVRT - Calculate conversion factors for sanitary hot water heating

HEATEX - Calculate peak flow from supply wellfield through heat exchanger at node 1

PRINT1 - Print output for energy source at node 1

SUBHEX - Design heat exchanger at node 1 and optionally at node 3

PUMP - Calculate tube-side and she11-side pumps at heat exchangers

PRNT1 - Print output for heat exchanger and pumps at node 1

CALQNA - Calculate distribution system energy and fluid demand

INJECT - Simulate fluid transmission in leg 1 and into node 2 or in leg 3 and into node 4

AQIFER(1) - Calculate average temperature out of storage wellfield at node 2

PRNTAQ(1) - Print output for storage wellfield at node 2

TRANS - Simulate fluid transmission out of node 2 and in leg 2 or out of node 4 and in leg 4

CONVRG - Test for convergence of flow requirements between node 2 and node 3

SUPPLM - Try to match up annual fluid supply and annual fluid demand

DIST - Simulate distribution system at node 3

DWRIT2 - Print output for distribution system at node 3

AQIFER(2) - Calculate average temperature out of supply wellfield at node 4

PRNTAQ(2) - Print output for supply wellfield at node 4

FIGURE 5. Sequence of Subroutines Called by the Executive Routine NODEPR to Simulate the ATES Elements 
4) The characteristics of the external energy source and the fluid conditions at the heat exchanger are printed by subroutine PRINTI.

5) The design characteristics of the heat exchanger, including the heat transfer coefficients, heat transfer area, and number of tubes, are calculated by subroutine SUBHEX. This subroutine also calls subroutine HXDROP to calculate and print the pressure drops in the tube-side and shell-side of the heat exchanger.

6) The capital cost and electrical usage of pumps located at the tube-side and shell-side inlets of the heat exchanger are calculated and printed by subroutine PUMP.

7) The capital and operating costs of the heat exchanger are calculated based on the heat transfer area using the equations in Appendix $B$. The heat exchanger design and costs are then printed by subroutine PRNT1 (an entry point in subroutine PRINT1).

8) The peak and annual fluid demands required by the distribution system from the storage aquifer in node 2 are calculated by subroutine CALQNA assuming no fluid degradation (in the first iteration only) between nodes 1,2 and 3. Thus, the fluid conditions at the heat exchanger outlet in node $I$ are used without degradation as the initial estimate of the fluid conditions entering the distribution system (in the first iteration only between nodes 1,2 and 3 ). This procedure is used simply to obtain an initial estimate of the peak fluid demand. The equations for calculating the peak fluid demand, both with and without a heat exchanger at the distribution system, are described in Section 2.7. The output results from subroutine CALQNA are printed by subroutine PRNTCQ depending upon the print options selected in Section 3.6.

9) The pipe diameters, schedules, insulation thickness, thermal losses, pressure drops, pumping requirements, capital costs and operating costs for leg 1 are calculated by subroutine INJECT(1) based upon the peak fluid supply $(1 \mathrm{~b} / \mathrm{hr})$. Subroutine INJECT(1) also calculates the number of wells in the storage wellfield, wellfield layout, the pipe diameters, schedules, and insulation thickness of the wellfield piping, and the thermal losses, pressure drops, and pumping requirements of the fluid entering the storage wellfield. The number of wells and pipe sizes in the storage wellfield 
piping are based upon the peak system flow, either the peak fluid supply $(1 \mathrm{~b} / \mathrm{hr}$ ) into the storage aquifer or the peak fluid demand ( $1 \mathrm{~b} / \mathrm{hr}$ ) from the storage aquifer. The booster pump heads throughout the ATES supply system are initially set sufficiently high in subroutines INJECT and TRANS to prevent two-phase flow, and then minimized during the iterations. However, the final pump heads are still high enough to prevent two-phase flow. Finally, subroutine INJECT(1) prints the fluid conditions and costs for leg 1 and the fluid conditions entering into the storage wellfield piping in node 2 .

10) The average temperature of the fluid out of the aquifer at the storage wellfield is calculated by subroutine AQIFER based upon a simple enthalpy balance and three input parameters described in Section 2.6.3: fluid recovery fraction, thermal storage efficiency, and discovery (natural) aquifer temperature.

11) The characteristics of the storage wellfield, such as the number of wells and well spacing, and the average fluid conditions exiting the wells are printed by subroutine PRNTAQ(1).

12) The thermal losses, pressure drops, and pumping requirements of the fluid exiting the storage wellfield and the capital and operating costs for the piping system in the storage wellfield (including downhole pumps) are calculated by subroutine TRANS(2). Observe that step 9 designs and sizes the piping system in node 2 whereas step 12 calculates its capital and operating costs based upon the design and size calculated in step 9. Electrical pumping costs to restore frictional pressure drops are calculated for entering the wellfield in step 9 and for leaving the wellfield in step 12. Subroutine TRANS(2) also calculates the pipe diameters, schedules, insulation thickness, thermal losses, pressure drops, pumping requirements, capital costs, and operating costs for leg 2. Finally, subroutine TRANS(2) prints the fluid conditions exiting the storage wellfield, the costs of the piping system (including downhole pumps), the fluid conditions in leg 2, and the costs of the piping system for leg 2.

13) The peak and annual fluid demands required by the distribution system from the storage aquifer in node 2 (calculated assuming no fluid degradation in the first iteration on ly in step 8 ) are now recalculated by subroutine 
CALQNA based upon the fluid degradation computed by subroutines INJECT(1), AQIFER(1), and TRANS(2). The fluid degradation occurs as the fluid from node 1 passes through leg 1 , into and out of node 2, and through leg 2. The output results from subroutine CALQNA are printed by subroutine PRNTCQ depending upon the print options selected in Section 3.6.

14) The fluid demands computed for the distribution system based upon the degraded fluid conditions (temperature and enthalpy) in the current iteration are compared in subroutine CONVRG with the fluid demands computed in the previous iteration. The convergence criterion requires that the new fluid demand requirement differ by less than $2 \%$ from the fluid demand requirement in the previous iteration. If the fluid demand requirement has not yet converged, subroutine NODEPR returns to step 9 to recalculate the piping system for leg 1 , node 2, and leg 2, the number of wells in node 2, and the fluid conditions, capital costs, and operating costs for leg 1 , node 2 and leg 2 . The recomputed fluid demands based upon the recomputed fluid degradation are then again tested for convergence in step 14. After convergence of the computed fluid demands, subroutine NODEPR proceeds to step 15 . Failure to converge within 20 iterations results in an abnormal termination and printout of an appropriate error message.

15) After the calculation of the fluid demand has converged in step 14, subroutine SUPPLM is called to test if the annual fluid supply, after allowing for fluid losses in the storage aquifer and transmission piping, matches up within $1 \%$ of the annual fluid demand. If the fluid supply and demand match, subroutine NODEPR proceeds to step 16. If they do not match, subroutine SUPPLM may adjust the peak hourly, daily, and annual flow rates from the external energy source (thereby adjusting the analogous supply flow rates as shown by the equation in subroutine HEATEX below) to try to automatically match up the annual fluid supply and demand. If the annual supply is in excess, it is simply reduced to match up with the annual fluid demand. However, if the annual supply is currently insufficient, it can be automatically increased only if the peak hourly flow rate from the external energy source can be increased (i.e., is not already at its absolute peak value represented by the input parameter SMXFLW). The procedure is discussed in Section 3.3.1. If the annual 
supply can not be sufficiently increased to match up within $1 \%$ of the annual demand, the supply shortfall in the heating case is met by calculating annual supplemental heating requirements in subroutine SUPPLM. In the cooling case, the supply shortfall is printed in the output results, but is not met by supplemental cooling. The rationale is discussed in Section 3.3.1. If the annual fluid supply is not adjusted, subroutine NODEPR proceeds to step 16. If it is adjusted, subroutine NODEPR returns to the simulation of node 1 in step 3 and repeats steps 3 through 15 . Subroutine SUPPLM prints out the annual fluid supply, after fluid losses in the storage aquifer and transmission piping, the annual fluid demand, their difference and ratio, and the annual supplemental heating (if any) requirements. For the purposes of brevity, only the equations for the annual fluid demand and annual fluid supply from the storage aquifer for space heating (assuming a heat exchanger at the inlet to the distribution system) are given below. These equations, as well as those for space heating and sanitary hot water heating or space cooling, are well commented internally in subroutines CALQNA, CONVRT, and SUPPLM.

Derivation of Annual Fluid Demand (1b/yr) from Storage Aquifer

a) Annual Heat Demand (MBtu/yr) in District(I) = [Number of Buildings in District(I)] * [Unit Heat Demand per Building in District(I) per Degree Day] * [Number of Design Degree Days in the Year] (4)

b) Annual Heat Demand (MBtu/yr) in District(I) = $\operatorname{DENSE}(\mathrm{J}) * \operatorname{AREA}(\mathrm{I}) *\left[\frac{\mathrm{HQ}(\mathrm{J}) * 24 . * \operatorname{DDGDAY}(1)}{(65-\operatorname{TDES}(1))}\right]$

c) Annual Fluid Demand ( $1 \mathrm{~b} / \mathrm{yr})$ inside Distribution System $=$ Number of Districts

$$
\sum_{I=1}
$$
(Annual Heat Demand of District(I)) * $1 . E 6$ * (1. + WLEAK $) /[($ Temperature Drop across Distribution System) * (Fraction of Heat Not Lost In Distribution Piping System * Sp Heat]

d) Annual Fluid Demand (1b/yr) from Storage Aquifer (Tube-Side of Heat Exchanger $)=$ (Annual Fluid Demand (1b/yr) inside Distribution System) * (Temperature Rise across She11-Side)/(Temperature Drop Across TubeSide) 
Derivation of Annual Fluid Supply (1b/yr) from Storage Aquifer

a) Annual Fluid Supply $(1 \mathrm{~b} / \mathrm{yr})=$ (Peak Supply Flow from Heat Exchanger at External Energy Source in $1 \mathrm{~b} / \mathrm{hr}$ ) * 24. * 365.25 * (Annual Supply Load Factor) * (Aquifer Fluid Recovery Fraction)

b) Annual Fluid Supply $($ lb/yr) $=$ FLOWHX * 24 * 365.25 *

$$
\frac{\text { SAFLOW }}{\text { SMFLOW } \star 24 . \star 365.25} \star \text { STFREC }
$$

c) Annual Fluid Supply $(1 \mathrm{~b} / \mathrm{yr})=$ FLOWHX $* \frac{\text { SAFLOW }}{\text { SMFLOW }}$ * STFREC

The terms in the above equations are defined in detail in Sections 2.7, 3.3, and 3.4. The terms are summarized briefly below.

AREA(I) = Area of district number I, sq miles.

$\operatorname{DENSE}(\mathrm{J})=$ Density of buildings in district type $\mathrm{J}$, bldgs/sq mile. The district type of district number $I$ is $J$.

$\mathrm{HQ}(\mathrm{J})=$ Peak heat demand for space heating in district type J, MBtu/ hr-bldg.

$\operatorname{DDGDAY}(1)=$ Design heating degree days per year, ${ }^{0} \mathrm{~F}$-days $/ \mathrm{yr}$.

$\operatorname{TDES}(1)=$ winter design outdoor temperature, ${ }^{\circ} \mathrm{F}$. The indoor design temperature for heating is set in the code at $65^{\circ} \mathrm{F}$.

WLEAK = Fraction of fluid leakage in the piping system.

$\mathrm{Sp} \mathrm{Heat} \mathrm{=} \mathrm{Specific} \mathrm{heat} \mathrm{of} \mathrm{water,} \mathrm{assumed} \mathrm{to} \mathrm{be} 1$ above.

FLOWHX $=$ Peak flow rate $(\mathrm{lb} / \mathrm{hr})$ from the supply wellfield circulating through the shell-side of the heat exchanger at the external energy source.

SMFLOW = Peak flow rate $(\mathrm{lb} / \mathrm{hr})$ from the external energy source.

SAFLOW = Annual flow rate ( $1 \mathrm{~b} / \mathrm{yr}$ ) from the external energy source.

STFREC = Aquifer fluid recovery fraction for the storage wellfield.

16) If the optional heat exchanger at the distribution system is not employed, subroutine NODEPR proceeds to step 18. If it is employed, the design characteristics of the heat exchanger are calculated by subroutine SUBHEX. This subroutine also calls subroutine HXDROP to calculate and print the pressure drops in the tube-side and shell-side of the heat exchanger. 
17) The capital cost and electrical usage of pumps at the tube-side and she11side inlets of the heat exchanger are calculated and printed in subroutine PUMP.

18) The detailed, technical design of the distribution system and its capital and operating costs are calculated by subroutine DIST. The output for the distribution system is printed by subroutines DIST and DWRIT2.

19) This step is analogous to step 9; subroutine INJECT(3) is called to simulate the fluid transmission system and costs for leg 3 , the supply wel1field in node 4 , and the fluid transmission entering the supply wellfield. The peak flow rate used in leg 3 is the peak fluid demand from the storage aquifer, after a slight reduction to account for fluid losses in the transmission or distribution piping.

20) This step is analogous to step 10; subroutine AQIFER(2) is called to calculate the average temperature out of the aquifer at the supply wellfield.

21) This step is analogous to step 11; subroutine PRNTAQ(2) is called to print the characteristics and fluid conditions of the supply wellfield.

22) This step is analogous to step 12; subroutine TRANS(4) is called to simulate the fluid transmission system and costs exiting the supply wellfield in node 4 and the fluid transmission system and costs for leg 4 .

23) Subroutine NODEPR tests for convergence of the estimated in let temperature to the heat exchanger at node 1 from the supply wellfield. The degraded fluid temperature from the supply we17field calculated in step 22 in the current iteration is compared with the estimate of the in let temperature to the heat exchanger in the previous iteration. If the new estimate does not differ by more than $1 \%$ from the old estimate, the convergence test is satisfied, and subroutine NODEPR proceeds to step 24 . If the convergence test fails, the new estimate of the inlet temperature to the heat exchanger is the current degraded temperature from the supply wellfield, and subroutine NODEPR returns to the simulation of node 1 in step 3 and repeats steps 3 througn 23. A maximum of 5 iterations is permitted in step 23 before the execution of the code is terminated with an appropriate message.

24) Subroutine NODEPR returns control back to the main program. In turn, it calls the discounted cash flow submodels to combine the computed capital and operating costs for the supply and distribution systems with their 
financial input data to simulate the detailed cash flow over the lifetime of the project.

The major subroutines in Figure 5 simulating the elements of the ATES district heating (cooling) system in Figure 2 are described below in the order of their execution in the executive routine NODEPR.

Calculates conversion factors used in computing the heat demand required for sanitary hot water heating.

HEATEX

Performs a heat transfer balance across the heat exchanger at the external energy source to calculate the peak flow rate of water from the supply wellfield that can be heated (chilled) in the heat exchanger to the specified outlet temperature. The equation is given below, with the specific heat of water assumed to be 1 .

where:

$$
\text { FLOWHX }=\frac{\text { SMFLOW } \star(T S R I N-\text { TSROUT }) \star \text { Specific Heat }}{(\text { THXOUT }- \text { TSUPAQ }) \star \text { Specific Heat }}
$$

FLOWHX = peak hourly flow rate $(1 \mathrm{~b} / \mathrm{hr})$ of water from the supply wellfield that can be heated (chilled) to the specified outlet temperature THXOUT at the heat exchanger outlet.

SMFLOW = peak hourly flow rate $(1 \mathrm{~b} / \mathrm{hr})$ from the energy source. This parameter is defined in the input data but can be adjusted up or down by subroutine SUPPLM to try to match up the annual energy supply with the annuat energy demand as described in Section 3.3.1.

TSRIN = inlet temperature $\left({ }^{\circ} \mathrm{F}\right)$ entering the heat exchanger from the energy source (defined in the input data). TSROUT = outlet temperature $\left({ }^{\circ} \mathrm{F}\right)$ exiting the heat exchanger back to the energy source (defined in the input data).

TSUPAQ = in let temperature $\left({ }^{O} F\right)$ entering the heat exchanger from the supply wellfield (initially estimated internally in subroutine NODEPR and then calculated through successive iterations). 
THXOUT = specified temperature of water from the supply wellfield desired at heat exchanger outlet (specified through the approach parameter APPHX described in Section 3.3.2).

PRINT1

SUBHEX

PUMP Called from subroutine NODEPR with its argument type ITYPE set

CALQNA

This subroutine also has an entry point PRNT1. Subroutine PRINT1 prints the output describing the characteristics of the external energy source and heat exchanger at node 1 in Figure 2.

Calculates the design characteristics and size of the heat exchanger at the external energy source and of the optional heat exchanger at the inlet to the distribution system. Subroutine SUBHEX and its supporting routines are described in Section 2.6.1. to 1 and 2 to calculate the pumping requirements at the tubeside and shell-side inlets respectively to the heat exchanger. Subroutine PUMP calculates the capital cost of the pumps in base year dollars and their electrical usage.

Calculates the following demand quantities for the distribution system: annual average heat (chill) demand and peak heat (chill) demand in MBtu/hr, the distribution system load factor, annual fluid flow requirements in $1 \mathrm{~b} / \mathrm{yr}$, and peak fluid flow requirements in $\mathrm{lb} / \mathrm{hr}$. Subroutine CALQNA is described in Section 2.7.

INJECT(1), Simulates the technical design and calculates the capital and $\operatorname{INJECT}(3)$ operating costs of the following parts of the fluid transmission system in Figure 2: INJECT(1) - fluid transmission in leg 1 and into the storage wellfield in node 2 and INJECT(3) - fluid transmission in leg 3 and into the supply wellfield in node 4 . Subroutine INJECT and its supporting routines are described in Section 2.6.2.

AQIFER

Called from subroutine NODEPR with its argument type NAQFER set to 1 and 2 to perform an enthalpy balance to calculate the average temperature of the fluid out of the aquifer through the 
PRNTAQ

TRANS (2), TRANS (4)

CONVRG

SUPPLM storage and supply wellfields respectively. Subroutine AQIFER is discussed in Section 2.6.3.

Called from subroutine NODEPR with its argument type NAQFER set to 1 and 2 to print the output results for the storage and supply wellfields respectively at the aquifer.

Simulates the technical design and calculates the capital and operating costs of the following parts of the fluid transmission system in Figure 2: TRANS(2) - fluid transmission out of the storage wellfield in node 2 and in leg 2 and TRANS(4) - fluid transmission out of the supply wellfield in node 4 and in leg 4. Subroutine TRANS and its supporting routines are described in Section 2.6.2.

Compares the flow requirements computed for the distribution system demand (by subroutine CALQNA) based upon the degraded fluid conditions delivered by the fluid transmission system from the storage aquifer to the distribution system in the current iteration, with the flow requirements calculated in the previous iteration. As the temperature degradation of the fluid converges in successive iterations, the increased flow required in successive iterations will also converge. The convergence criterion in subroutine CONVRG requires that the new flow requirement computed for the distribution system demand differ by less than $2 \%$ from the flow requirement computed in the previous iteration.

Tries to match up the annual fluid supply delivered to the distribution system by the ATES supply system, after allowing for fluid losses in the aquifer and in the transmission piping, within $1 \%$ of the annual fluid demand requirement of the distribution system. Subroutine SUPPLM may adjust up or down the peak hourly flow rate from the energy source depending upon the input parameters described in Section 3.3.1 to try to match up the annual fluid supply with the annual fluid demand. The iterations to try to match up the annual fluid supply with the 
DIST

annual fluid demand are controlled by the executive routine NODEPR. If the annual fluid supply cannot be sufficiently increased to match up within $1 \%$ of the annual fluid demand, the supply shortfall is met by supplemental heat in the district heating case. In the district cooling case, the supply shortfall (if any) is not met by supplemental chil1. The rationale is described in Section 3.3.1.

Simulates the detailed, technical design and calculates the capital and operating costs of the district heating (cooling) distribution system represented by node 3 in Figure 2 . Subroutine DIST and its supporting routines are described in Section 2.7 .

DWRIT2 Subroutine DWRIT2, an entry point in subroutine DWRIT, prints the output for the district heating (cooling) distribution system.

Finally, there are two other subroutines called by the executive routine NODEPR and by many other subroutines in the code. These routines update the costs calculated in the code to present (base) year dollars and allow for price escalation of the costs to current (inflated) dollars in each year over the simulated lifetime of the ATES district heating (cooling) system. These subroutines are described below.

UPDATE Subroutine UPDATE updates the capital and operating costs calculated in the code to present (base) year dollars as described in Section 3.5.5.1. The default update is to January, 1980 dollars.

ESCALT Subroutine ESCALT escalates the capital and operating costs calculated in the code at a compound rate in each year over the simulated lifetime of the ATES district heating (cooling) system. Input parameters define price escalation rates that reflect a combination of inflation, supply/demand, and other price effects for four generic categories in the supply and distribution systems: capital equipment, O\&M expenses, electrical expenses for pumps, and purchased thermal energy. The parameters are described in Section 3.5.5.2. 


\subsection{SUPPLY SYSTEM SUBMODEL (Technical Design and Costs)}

The supply system submodel simulates the design and calculates the capital and operating costs of the ATES supply system shown in Figure 2. The supply system delivers water from a set of supply wells drilled into a suitable aquifer to a heat exchanger interfacing to an external energy source. Here the water is heated (chilled), and then returned to the same aquifer through a storage wellfield. Thermal energy in the form of hot (chilled) water is stored in the aquifer until it is needed. At recovery, the storage wells are pumped and the hot (chilled) water is delivered to the distribution system (which may optionally have a heat exchanger of its own) to recapture the stored energy. The water is then returned to the aquifer through the supply wellfield to complete the cycle.

As previously described in Section 2.5, the executive routine NODEPR calls the subroutines comprising the supply system submodel to simulate the design, operation, and cost of the major elements of the supply system. This includes the heat exchanger interfacing with the external energy source, the fluid transmission systems to and from the storage and supply wellfields, and the aquifer. The set of subroutines that simulate each of these elements are described in the following three sections.

\subsubsection{Heat Exchangers at Interface with External Energy Source and Distribution System}

AQUASTOR assumes that thermal energy is transferred in a liquid medium (water) from an external energy source through a heat exchanger to circulating water from the supply wellfield. The water from the energy source is pumped through the tube-side and the circulating water from the supply wellfield is pumped through the she11-side of the heat exchanger. After being heated (coo)ed) in the heat exchanger, the water from the supply wellfield is transmitted to the storage wellfield for seasonal storage in the aquifer and subsequent recovery of the stored thermal energy for use in the distribution system.

An option for a heat exchanger is also provided at the end of the transmission line from the storage aquifer (inlet to the distribution system). This heat exchanger can be used both to protect the aquifer from environmental damage and to protect the expensive distribution system from corrosion. Heat 
(chi11) is transferred from the storage aquifer water to circulating clean water for use in the distribution system. The aquifer water is pumped through the tube-side and the circulating clean water is pumped through the shell-side of the heat exchanger.

The heat exchangers are modeled as counterflow, single-pass, she 11 and tube units constructed of carbon steel with an equilateral triangular tube configuration. The design characteristics and size of the heat exchangers are determined in subroutine SUBHEX and its associated subroutines. As previously mentioned in Section 2.5, the pumps at the tube-side and she11-side inlets to the heat exchangers are simulated in subroutine PUMP, called by the executive routine NODEPR.

Subroutine SUBHEX and its associated subroutines are used with different flow rates and temperature conditions to design and size both the heat exchanger at the external energy source and the optional heat exchanger at the inlet to the distribution system. In the first case, subroutine SUBHEX is called from the executive routine NODEPR in designing the supply system (see node 1 in Figure 5). The input parameters and temperature profiles in the heat exchanger at the external energy source are described in Section 3.3.2. In the second case, subroutine SUBHEX is called from the executive routine NODEPR in designing the distribution system (see node 3 in Figure 5). The input parameters and temperature profiles in the heat exchanger at the in let to the distribution system are described in Section 3.4.4.

The capital and operating costs of the two heat exchangers are calculated in subroutine NODEPR and included in the supply system and distribution system costs respectively. The equations for the costs of the heat exchangers are given in Appendix B. The description of subroutine SUBHEX and its associated subroutines is given below.

SUBHEX Calculates the basic design characteristics and size of a liquidto-liquid heat exchanger based upon a counterflow; single-pass, she11 and tube unit constructed of carbon steel with an equilateral triangular tube configuration.

The input conditions to subroutine SUBHEX are: 

a) Tube-side and she11-side flow rates, $1 \mathrm{~b} / \mathrm{hr}$
b) Tube-side fluid temperatures at the heat exchanger in let and outlet, ${ }^{0} \mathrm{~F}$
c) Shel1-side fluid temperatures $\left({ }^{\circ} \mathrm{F}\right)$ and enthalpies (Btu/lb) at the heat exchanger in let and outlet
d) Inside and outside fouling factors, $\mathrm{hr}-\mathrm{ft} \mathrm{t}^{2}-{ }^{0} \mathrm{~F} / \mathrm{Btu}$
e) Inside and outside tube diameters, ft
f) Tube-side fluid velocity, ft/hr.

The basic characteristics calculated for the heat exchanger are:

a) Inside and outside heat transfer coefficients, Btu/hr-ft ${ }^{2}{ }^{{ }_{F}} \mathrm{~F}$

b) Overall heat transfer coefficient, Btu/hr-ft ${ }^{2}-{ }^{0} \mathrm{~F}$

C) Number of heat exchanger tubes

d) Total flow area $\left(\mathrm{ft}^{2}\right)$ and equivalent flow diameter ( $\mathrm{ft}$ ) for the shell side

e) Heat exchanger area, $\mathrm{ft}^{2}$

f) Heat exchanger length, $f t$.

The characteristics of the heat exchanger are calculated in steps described below, first for the tube-side and then for the shellside.

1) The average of the inlet and outlet temperatures is calculated for the tube-side fluid and shell-side fluid respectively for use in computation of physical properties.

2) The thermal conductivity, density, and viscosity of the tubeside fluid are calculated at the average tube-side fluid temperature in Step 1 using function FLUID.

3) The Reynolds number of the tube-side fluid is calculated in function REYNO. The Prandt 1 number is calculated in subroutine SUBHEX based on the specific heat $c_{p}$, viscosity $\mu$, and thermal conductivity $k$ of the tube-side fluid:

$$
\operatorname{Pr}=\frac{c_{p^{\star \mu}}}{k}
$$


4) The inside or tube-side heat transfer coefficient is determined in function HTCOEF.

5) The number of tubes required for the tube-side fluid is calculated in function TUBES.

6) The total flow area and equivalent flow diameter for the shell side are determined in subroutine QAREA.

7) The specific heat, thermal conductivity, density, and viscosity of the shell-side fluid are calculated at the average shell-side fluid temperature in Step 1 using function FLUID.

8) The velocity of the fluid in the tubes is set in the input data. The velocity of the fluid in the heat exchanger shell is calculated in function VELOCY.

9) The Reynolds number of the shell-side fluid is calculated in function REYNO. The Prandtl number is calculated in subroutine SUBHEX based on the specific heat, viscosity, and thermal conductivity of the shell-side fluid.

10) The outside or shell-side heat transfer coefficient is determined in subroutine HTCOEF.

11) The inside and outside heat transfer coefficients are combined with the thermal conductivity of the tube wall and the fouling factors to determine the overall heat transfer coefficient in function OHTCOE.

12) Knowing the amount of overall heat transfer desired, the heat transfer area and heat transfer length are calculated in functions HTAREA and HTLNGH respectively.

The subroutines called by subroutine SUBHEX to calculate the basic characteristics of the heat exchanger are described below. Function FLUID, which is the first routine called by subroutine SUBHEX, is also called from some of the other subroutines in Figure 4 to calculate physical properties of pure water. 
Correlates physical properties of 10 different fluids to temperature at saturation. In AQUASTOR, function FLUID is called only to calculate physical properties of pure water.

Each physical property for a particular fluid is expressed as a polynomial function of temperature in the elementary form:

$$
\text { Property value }=K_{0}+K_{1} T+K_{2} T^{2}+K_{3} T^{3} \text { for } T_{x}<T<T_{y}
$$

These expressions were correlated to available data in the temperature range $T_{x}$ to $T_{y}$. The data were acquired through a search of numerous reference texts and publications. $(5,6,7)$

Within the specified temperature range, there is good agreement between the actual and predicted values. A warning message is printed if the input temperature requires extrapolating the polynomials beyond the temperature range $T_{x}$ to $T_{y}$ specified in function FLUID for a given equation.

The polynomial functions are used to predict the following physical properties as a function of temperature at saturation: specific heat, thermal conductivity, density, viscosity, heat of vaporization, and surface tension. Critical pressure, critical temperature, and molecular weight are included as constants. When a physical property is desired, the following statement is made:

$$
\text { Property Value }=\text { FLUID }(I, J, T)
$$

where $\mathrm{T}=$ temperature at which the property is required, ${ }^{0} \mathrm{~F}$

$$
\begin{aligned}
I= & 1,13 \text { - Property Index } \\
& \left.1 \text { - specific heat (liquid) (Btu/lb- }{ }^{\circ} \mathrm{F}\right) \\
& 2 \text { - thermal conductivity (liquid) }\left(\mathrm{Btu} / \mathrm{hr}-\mathrm{ft}-{ }^{\circ} \mathrm{F}\right) \\
& 3 \text { - density (1iquid) }\left(1 \mathrm{~b} / \mathrm{ft}^{3}\right) \\
& 4 \text { - viscosity (1iquid) }\left(1 \mathrm{~b}_{\mathrm{m}} / \mathrm{ft}-\mathrm{hr}\right) \\
& 5 \text { - specific heat (gas) }\left(\mathrm{Btu} / 1 \mathrm{~b}-{ }^{\mathrm{O}} \mathrm{F}\right) \\
& 6 \text { - thermal conductivity (gas) }\left(\mathrm{Btu} / \mathrm{hr}-\mathrm{ft}-{ }^{\circ} \mathrm{F}\right)
\end{aligned}
$$




$$
\begin{aligned}
& \left.7 \text { - density (gas) ( } 1 \mathrm{~b} / \mathrm{ft} \mathrm{t}^{3}\right) \\
& 8 \text { - viscosity (gas) }\left(1 b_{m} / f t-h r\right) \\
& 9 \text { - heat of vaporization (Btu/lb) } \\
& 10 \text { - critical pressure (psia) } \\
& 11 \text { - critical temperature }\left({ }^{O} \mathrm{~F}\right) \\
& 12 \text { - surface tension }\left(1 b_{f} / f t\right) \\
& 13 \text { - molecular weight (1b/1b mole } \\
& J=1,10-\text { Fluid Index } \\
& 1 \text { - water (only fluid used in AQUASTOR) } \\
& 2 \text { - isobutane } \\
& 3 \text { - n-butane } \\
& 4-R-11 \\
& 5-R-12 \\
& 6-\mathrm{R}-21 \\
& 7-R-22 \\
& 8-R-113 \\
& 9-R-114 \\
& 10 \text { - ammonia }
\end{aligned}
$$

REYNO Calculates the Reynolds number based upon the fluid density $\rho$, $v$ iscosity $\mu$, velocity $V$, and flow diameter $D$ :

$$
\operatorname{Re}=\frac{\rho D V}{\mu}
$$

HTCOEF Calculates inside and outside heat transfer coefficients based on the Dittus-Boelter equation for fully developed turbulent flow in smooth tubes. Subroutine HTCOEF is called by subroutine SUBHEX to calculate the inside heat transfer coefficients for the tubeside fluid and the outside heat transfer coefficients for the shell-side fluid in the heat exchanger. The Dittus-Boelter equation is summarized below:

$$
h_{\text {conv }}=0.023 \operatorname{Re}_{d}^{0.8} \operatorname{Pr}^{x} \frac{k}{d}
$$


where:

$$
\begin{aligned}
h_{\text {conv }}= & \text { convective heat transfer coefficient, } \\
& \text { Btu/hr-ft }{ }^{2}-{ }^{0} F \\
d= & \text { tube diameter, } f t \\
k= & \text { thermal conductivity, Btu/hr-ft }-{ }^{0} F \\
\operatorname{Pr}= & \text { Prandtl number } \\
\operatorname{Re}_{d}= & \text { Reynolds number based on tube diameter } \\
x= & 0.4 \text { when fluid is being heated, } \\
& 0.3 \text { when fluid is being cooled. }
\end{aligned}
$$

TUBES

Determines the number $N$ of tubes required in the heat exchanger based on the tube-side fluid mass flow rate $Q$, velocity $V$, density $\rho$, and flow diameter $D$. Fractional values of $N$ are increased to the next largest integer. The basic relationship is:

$$
N=\frac{(Q / \rho)}{V * \frac{\pi D^{2}}{4}}
$$

where:

$(Q / \rho)$ is the total required volumetric flow rate of tubeside fluid, $\frac{\pi D^{2}}{4}$ is the cross-sectional flow area per tube, $v * \frac{\pi D^{2}}{4}$ is the volumetric flow rate per tube.

QAREA Calculates the total cross-sectional flow area $A$ and equivalent flow diameter $D_{e}$ for the shell-side fluid in the heat exchanger. An equilateral triangular pitch is assumed for the tube configuration, as shown below. 


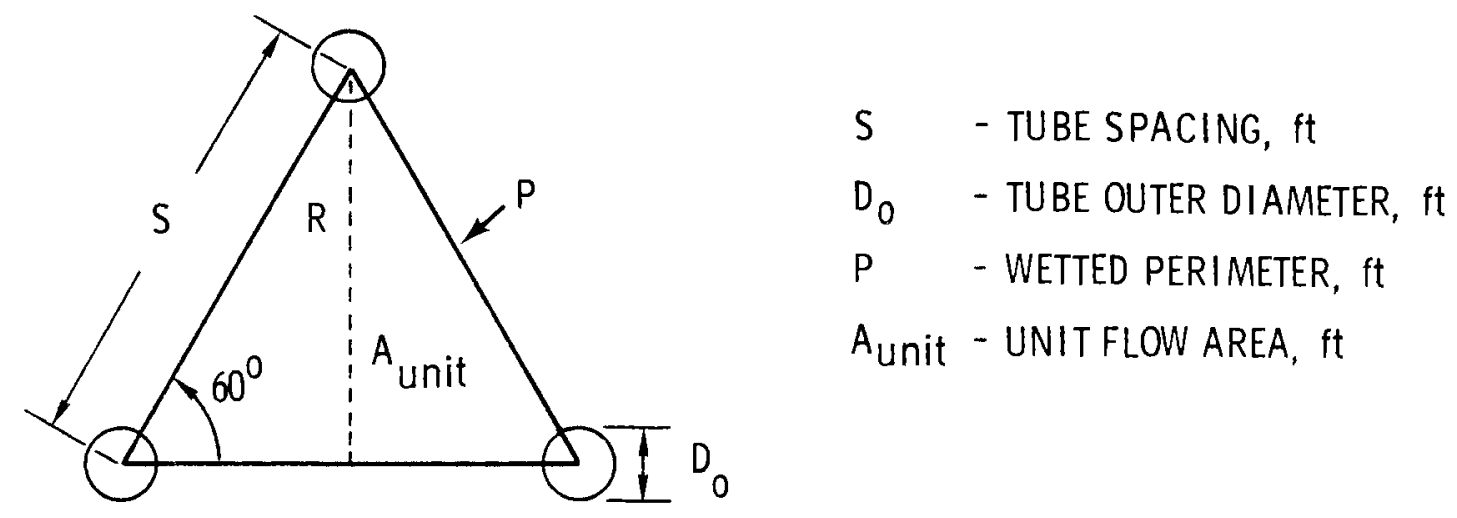

The tube spacing $S$ is assumed to be 1.75 times the tube outer diameter $D_{0}$. Based on the área for an equilateral triangle, the unit flow area for the shell-side fluid is calculated by the following equation.

$$
A_{\text {unit }}=\frac{S R}{2}-\frac{3}{6} * \frac{\pi D^{2}}{4}
$$

where:

$$
\begin{aligned}
& R=S * \sin 60^{\circ}, \\
& \frac{S R}{2}=\text { area of the equilateral triangle, } \\
& \frac{3}{6} * \frac{\pi D^{2}}{4}=\begin{array}{l}
\text { area of the } 3 \text { pie shapes in the } 3 \text { tubes that are } \\
\text { not included in the flow area for the shell-side } \\
\text { fluid. }
\end{array}
\end{aligned}
$$

The total cross-sectional flow area $A$ is calculated as the number of tubes times the unit flow area $A_{\text {unit. }}$ The equivalent flow diameter $D_{e}$ for the shell-side is calculated as:

$$
D_{e}=\frac{4 * A_{\text {unit }}}{\text { wetted perimeter }}
$$

The wetted perimeter $P$ is calculated as:

$$
P=3\left(S-D_{0}\right)+\frac{3 \pi D_{0}}{6}
$$


VELOCY Calculates the fluid velocity $V$ as a function of the mass flow rate $Q$, fluid density $\rho$, and total cross-sectional flow area $A$ as follows:

$$
V=\frac{(Q / P)}{A}
$$

where:

$(Q / D)$ is the volumetric flow rate.

OHTCOE Combines the inside and outside heat transfer coefficients with the thermal resistance of the heat exchanger tube walls and the fouling factors. This yields an overall heat transfer coefficient on the basis of the following equation:

$$
U=\frac{1}{\frac{A_{0}}{A_{i}} \star \frac{1}{h_{i}}+\frac{A_{0} \ln \left(r_{0} / r_{i}\right)}{2 \pi K L}+\frac{1}{h_{0}}+f_{i}+f_{0}}
$$

where:

$U=$ overall heat transfer coefficient, Btu/hr-ft ${ }^{2}-{ }^{\circ} \mathrm{F}$

$A_{0}=$ outside tube surface area, $\mathrm{ft}^{2}$

$A_{j}=$ inside tube surface area, $\mathrm{ft}^{2}$

$h_{i}=$ inside heat transfer coefficient, Btu/hr-ft ${ }^{2}-{ }^{0} F$

$h_{0}=$ outside heat transfer coefficient, Btu/hr-ft ${ }^{2}-{ }^{0} F$

$r_{i}=$ inside tube radius, $\mathrm{ft}$

$r_{0}=$ outside tube radius, $\mathrm{ft}$

$\mathrm{K}=$ thermal conductivity for the tube wall, Btu/hr-ft- ${ }^{\circ} \mathrm{F}$

$L=$ tube length, $\mathrm{ft}$

$f_{i}=$ inside fouling factor, $h r-f t^{2}-{ }^{0} F /$ Btu

$f_{0}^{i}=$ outside fouling factor, $h r-f^{2}-{ }^{0} F / B t u$

The fouling factors reduce the overall heat transfer coefficient to allow for the accumulation of corrosion deposits on the heat transfer surfaces. 
HTAREA Calculates the heat transfer area A for the heat exchanger. The calculation is based on the shell-side fluid flow rate $Q$, enthalpies of the shell-side fluid at the inlet and outlet, $\mathrm{H}_{1}$ and $\mathrm{H}_{2}$, overall heat transfer coefficient $U$, and the logarithmic mean temperature difference LMTD in the following equation:

$$
A=\frac{Q *\left(H_{1}-H_{2}\right)}{U *(\text { LMTO })}
$$

The logarithmic mean temperature difference between the tube-side fluid and shell-side fluid is based on the temperature difference at the two ends of the heat exchanger.

$$
\text { LMTD }=\frac{\Delta T_{\text {in }}-\Delta T_{\text {out }}}{\ln \left(\Delta T_{\text {in }} / \Delta T_{\text {out }}\right)}
$$

where:

$$
\begin{aligned}
\Delta T_{\text {in }}= & \text { temperature difference }\left({ }^{O} \mathrm{~F}\right) \text { between the tube-side } \\
& \text { fluid and shell-side fluid at the shell-side fluid } \\
& \text { inlet to the heat exchanger. } \\
\Delta T_{\text {out }}= & \text { temperature difference }\left({ }^{O} \mathrm{~F}\right) \text { between the tube-side } \\
& \text { fluid and shell-side fluid at the shell-side fluid } \\
& \text { out let from the heat exchanger. }
\end{aligned}
$$

HTLNGH Calculates the tube length $L$ in the heat exchanger. The calculation is based on the heat transfer area $A$, tube outer diameter $D_{0}$, and number $N$ of tubes in the heat exchanger.

$$
L=\frac{A}{\pi D_{0} N}
$$

HXDROP Calculates the pressure drop in the tube-side and shell-side of the heat exchanger, including entrance and exit effects.

\section{Tube or She11-Side Pressure Losses}

$$
\Delta P=f \frac{L}{D} \quad \rho \frac{v^{2}}{2 g_{C}} \quad \frac{1}{144} \quad \text { (Darcy-Weisbach equation) }
$$


where:

$$
\begin{aligned}
\Delta P & =\text { pressure drop, } p s i \\
f & =\text { friction factor, approximated as } 0.16 * \mathrm{Re}^{-.16} \\
R e & =\text { Reynolds number, computed as } \rho V d / \mu \\
\rho & =\text { fluid density, } 1 b_{\mathrm{m}} / \mathrm{ft}^{3} \\
\mu & =\text { fluid viscosity, } 1 b_{\mathrm{m}} / \mathrm{ft}-\mathrm{sec} \\
V & =\text { average fluid velocity, ft/sec } \\
d & =\text { tube internal diameter or she } 11 \text { equivalent diameter, ft } \\
L & =\text { tube length, ft } \\
g_{C} & =\text { gravitational constant, } 32.174 \mathrm{ft} / \mathrm{sec}^{2}
\end{aligned}
$$

Entrance Loss

$$
\Delta P_{i n}=\frac{K_{c} v^{2}}{\left(2 g_{c}\right)(144)}
$$

where:

$$
\begin{aligned}
& \Delta P_{i n}= \text { pressure drop at entrance, } p \text { si } \\
& K_{C}= \text { coefficient, computed as } 0.5 * \text { CSAREA/EAREA }+0.5 \\
& \text { CSAREA = } \text { cross-sectional flow area of tube or she11-side, } \\
& \mathrm{ft}^{2} \\
& \text { EAREA = entrance area to heat exchanger, } \mathrm{ft}^{2}
\end{aligned}
$$

Exit Loss

$$
\Delta P_{\text {out }}=\frac{v^{2}}{2 g_{c} 144} \cdot\left(1-\frac{\text { CSAREA }}{\text { EAREA }}\right)^{2} \text { (Borda-Carnot Eq.) }
$$

where:

$$
\begin{aligned}
\Delta \mathrm{P}_{\text {out }} & =\text { pressure drop at exit, psi } \\
\Delta \mathrm{P}_{\text {total }} & =\Delta \mathrm{P}+\Delta \mathrm{P}_{\text {in }}+\Delta \mathrm{P}_{\text {out }}
\end{aligned}
$$

\subsubsection{Fluid Transmission to and from Aquifer Wellfields}

As shown in Figure 5 , the executive routine NODEPR calls subroutines INJECT and TRANS to simulate the technical design and calculate the capital and operating costs of the fluid transmission system to and from the aquifer 
wellfields respectively. Referring to Figure 2, subroutine INJECT (an entry point in subroutine TRANS) calls supporting subroutines described below to simulate fluid transmission in leg 1 and into the storage wellfield in node 2 and fluid transmission in leg 3 and into the supply wellfield in node 4 . This set of subroutines calculates the following quantities: the number of storage and supply wells required, the storage and supply wellfield layout, optimum pipe diameters, schedules, insulation and casing, surface pumping requirements, and capital and operating costs for the piping system and surface pumps.

Since all ATES wells serve as both injection and withdrawal wells, the total number of storage wells required is determined by the peak system flow, either into or out of the storage wellfield, the flow capacities of the well during injection and withdrawal, and the fraction of excess wells desired. Subroutine INJECT uses an analogous calculation to determine the number of supply wells. The pipe diameters inside the supply and storage wellfields are also determined by the peak system flow, either into or out of the wellfields. The thermal losses and pressure drops of the fluid are modeled based on fluid transmission in a compressed liquid state throughout the transmission pipe lines and wellfield piping.

Subroutine TRANS calls supporting subroutines described below to simulate fluid transmission out of the storage wellfield in node 2 and in leg 2 and out of the supply wellfield in node 4 and in leg 4 . This set of subroutines calculates the following quantities: optimum pipe diameters, schedules, insulation and casing, surface and downhole pumping requirements, and capital and operating costs for the piping system and pumps. The thermal losses and pressure drops of the fluid are also modeled based on compressed liquid flow.

The subroutines called by either subroutine INJECT or subroutine TRANS are described below. The description indicates whether subroutine INJECT, subroutine TRANS, or both call each subroutine.

DESIGN Subroutine DESIGN is called only by subroutine INJECT. It calculates the number of storage and supply wells based on the peak system flow, either into or out of the wellfields, the flow capacities of each well during injection and withdrawal, and the 
fraction of excess wells desired. The wells are located at the vertices of equilateral triangles (nodes in a triangular lattice) as shown in Figure 6 , with pipe runs parallel to the horizontal $X$ axis. The fluid transmission system has a manifold pipeline for gathering the fluid from all horizontal rows of wells.

The input well area in acres (WELSPC) encompassed by each well (shaded area in Figure 6 ) is equal to the area of two equilateral triangles.

Subroutine DESIGN calculates the pipe length (meters) between wells based on the equation for the area of an equilateral triangle as follows:

$$
\text { Pipe length }(\mathrm{m})=(0.3048006 \mathrm{~m} / \mathrm{ft})(5280 \mathrm{ft} / \mathrm{mile})^{\star}
$$

$$
\sqrt{\frac{\text { WELSPC (acres) }}{(0.86603)(640 \text { acres/sq mi })}}
$$

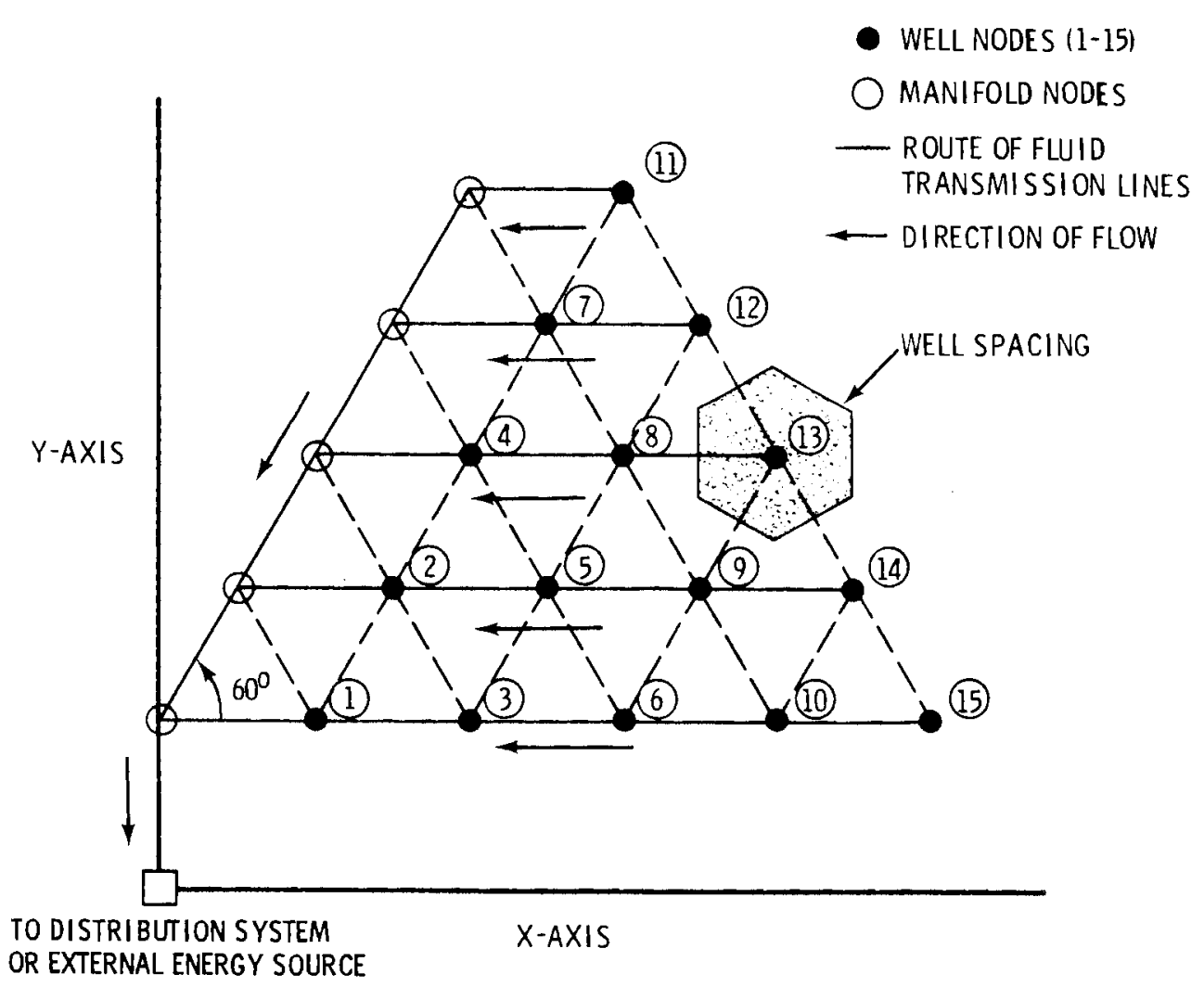

FIGURE 6. Well Layout Design and Routing of Fluid Transmission Lines 
EQCOST Subroutine EQCOST is called only by subroutine TRANS. It calculates the cost of valves, instrumentation, and solid separators at the wellheads.

TSTRT

Subroutine TSTRT is called only by subroutine TRANS. It initializes fluid conditions (temperature and pressure) previously computed in subroutine AQIFER at all wellhead nodes in the storage wellfield. All wellhead nodes are initialized with the same average temperature conditions. Subroutine TSTRT also initializes fluid conditions at all wellhead nodes in the supply wellfield. of course, the fluid conditions computed in subroutine AQIFER for the supply wellfield are different than those of the storage wellfield.

PIPE Subroutine PIPE has two other entry points, PIPE1 and PIPE2. This subroutine is called by both subroutines INJECT and TRANS. It calculates the optimum pipe diameters for the transmission legs and all wellfield piping. The calculation is based on the fluid mass flow rate, fluid density and viscosity, and economic trade-offs between the components comprising the cost function for the fluid transmission system: capital cost of the pipe, annual value of lost thermal energy, and capital and electrical operating costs of pumps to restore frictional pressure drops. The cost function for each section of pipe in the fluid transmission system is minimized with respect to internal pipe diameter $D$ by setting its derivative with respect to $D$ to zero. An iterative solution based upon the Newton-Raphson algorithm is obtained for the optimum pipe diameter in each section of pipe from the resultant equation.

SCHEDL Subroutine SCHEDL is called by both subroutines INJECT and TRANS. It selects the pipe schedule for each section of pipe by selecting the smallest schedule from a range of 10 to 160 that can withstand the maximum fluid pressure in each section of pipe. The maximum pressure each schedule can accomodate is a function of the fluid temperature and ranges from about 350 psia 
for schedule 10 up to 2900 psia for schedule 160, with temperature from $50^{\circ} \mathrm{C}$ to $300^{\circ} \mathrm{C}$. The pipe schedule and diameter are used to calculate the cost of piping and installation.

INSUL Subroutine INSUL is called by both subroutines INJECT and TRANS. It sizes the pipe insulation for each section of pipe as a function of the fluid temperature, nominal outer pipe diameter, insulation thickness availability, and cost, using two types of insulation. Calcium silicate is used for the inner layers of insulation, and (if required) polyurethane is used for the outer layers. Subroutine INSUL calculates both the cost of the insulation and the protective casing.

SPFLOW Subroutine SPFLOW is called by both subroutines INJECT and TRANS. It calculates the fluid degradation (thermal losses and pressure drops) during single-phase flow in the piping. Fluid degradation is calculated in one step equal to the distance of the pipe section. Calculations with smaller step size increments, such as 50 $\mathrm{ft}$, showed no significant differences in the computed fluid degradation. However, smaller step size increments can be used by changing the parameter NSTEP in the BLOCK DATA subroutine if desired. The thermal losses are calculated using equations for convective and conductive thermal transfer between the fluid inside an insulated, cylindrical pipe and the ambient air. The pressure drops are calculated using the Darcy-Weisbach equation for turbulent flow in a new, cylindrical pipe. The fluid pressure is continuously maintained at or above saturation (i.e., in a compressed liquid state) to prevent two-phase flow in the piping.

AGELOS Subroutine AGELOS is called by both subroutines INJECT and TRANS. It multiplies the pressure drop computed in subroutine SPFLOW for new pipe by an age factor defined in the input data (see parameter AGFACT in Section 3.4.6). This increases the pressure drop to take into account the increase in relative roughness and deterioration of the pipes with age. 
FLPROP Subroutine FLPROP is called by both subroutines INJECT and TRANS. It identifies the fluid state in the transmission pipeline as compressed liquid, saturated liquid, two-phase mixture, saturated vapor or superheated steam. Actually, only the compressed liquid state should ever be encountered in the AQUASTOR code. This subroutine is called for each section of pipe. The fluid state is identified based upon the pressure and enthalpy by querying subroutine XPHH and the ASME Steam Table functions. After identification of the fluid state at a particular node, subroutine FLPROP calls the appropriate ASME Steam Table function to compute the specific volume, density, viscosity, temperature, or enthalpy as requested by subroutines INJECT and TRANS.

XPHH Subroutine XPHH is called by subroutine FLPROP to calculate the fluid quality by weight fraction as a function of pressure and enthalpy. It returns 0 for saturated and compressed liquid, 1 for saturated vapor and superheated steam, and values in between for two-phase mixtures of steam and water at saturation.

TPHASE Subroutine TPHASE is called by both subroutines INJECT and TRANS. It tests whether or not the fluid quality in the pipeline has become unacceptable due to two-phase flow, in which case the code terminates execution with an appropriate error message.

TICOST Subroutine TICOST is called by both subroutines INJECT and TRANS. It calculates the capital costs of pipe, insulation, casing, and site work for each section of pipe in base year dollars.

TBPUMP Subroutine TBPUMP is called by both subroutines INJECT and TRANS. It calculates the number of required surface pumps and their boosted discharge pressures for all four transmission legs. The surface pumps are located along the transmission legs to restore frictional pressure drops and maintain the water in a compressed liquid state at all times. The number of surface pumps along each transmission leg is determined based on the criteria of avoiding unnecessary high pump discharge pressures and therefore 
high pipe schedules, but subject to the constraint that the pumps be located at least one mile apart.

TBCOST

Subroutine TBCOST is called by both subroutines INJECT and TRANS. It calculates the cost in base year dollars of a series of surface booster pumps and their electrical usage for each of the four transmission legs.

PRNT12 Subroutine PRNT12 is called by both subroutines INJECT and TRANS. It prints the total fluid transmission system costs for the four transmission legs in Figure 2.

PUMP Subroutine PUMP is called with its argument ITYPE set to 4 by subroutine TRANS. In this mode, it calculates the capital cost in base year dollars and the electrical usage of the downhole pumps in nodes 2 and 4 in Figure 2 .

TPRINT Subroutine TPRINT is called only by subroutine TRANS. It prints the total fluid transmission system costs for nodes 2 and 4 in Figure 2 .

\subsubsection{Aquifer}

AQUASTOR does not have a geohydrologic model to simulate fluid and thermal flow within the aquifer. Instead, the salient characteristics of the aquifer are represented by three input parameters: fluid recovery fraction, thermal storage efficiency, and discovery (natural) aquifer temperature. The fluid recovery fraction is simply the ratio of the water volume recovered from the storage wellfield to the previously injected volume. It can vary from a fraction to greater than one, depending upon the nature of the aquifer being simulated, the temperature differential between the injected water and the in-situ water, and heating system response to temperature degradation. Some users may shut down when the temperature of the recovered water starts to degrade; others may be able to continue operation by increasing flow rates, or by employing supplemental energy sources.

Only the fluid recovery fraction of the storage wellfield is input. The fluid recovery fraction of the supply wellfield is already controlled in the 
code by the ratio of withdrawn water (annual supply) to reinjected water (annual demand, modified for transmission fluid losses). In general, the fluid recovery fraction for the supply wellfield will be the reciprocal of the fluid recovery fraction input for the storage wellfield, modified for transmission fluid losses.

The thermal storage efficiency is similarly the ratio of the energy recovered to energy injected, both defined with respect to the discovery (natural) water temperature of the aquifer. Defining storage efficiency in this manner isolates aquifer storage efficiency from the characteristics of the aboveground equipment. The storage and supply wellfields may have different thermal storage efficiencies in the input data because of different injection temperatures and fluid recovery fractions.

More thermal energy will be lost to the aquifer during early cycles of injection and withdrawal than during the later cycles when the aquifer has been "conditioned" by lost thermal energy. However, AQUASTOR treats only the steady state condition and aquifer thermal efficiency is assumed constant over time.

AQUASTOR calls subroutine AQIFER to determine the average temperature of water recovered from the aquifer through the storage and supply wellfields. The wellfield and transmission pipeline systems are designed based upon this average temperature. Subroutine AQIFER uses a simple enthalpy balance to determine the average temperature of water recovered from the aquifer through the storage and supply wellfields based upon the values for the natural aquifer temperature, fluid recovery fraction, thermal storage efficiency, and computed injection temperature into the aquifer. The total fluid flow that can be recovered from the aquifer is calculated as the total flow delivered into the aquifer times the fluid recovery fraction.

\subsection{DISTRIBUTION SYSTEM SUBMODEL (Technical Design and Costs)}

The distribution system submodel simulates the design and calculates the capital and operating costs of the district heating (cooling) distribution system. The distribution system can serve a single point demand (e.g., a large commercial building or factory), residential districts, or a multi-district 
city. The input data to the distribution system submodel is described in Section 3.4. It consists of the climatic conditions, characteristics of the served districts, design options for the distribution piping, insulation, and casing, and special options and adjustment factors for the distribution system. The description of the distribution system submodel is given below in its most general form for a multi-district city.

The city is defined by its distance from the storage and supply wel1fields, climatic conditions, and the number and type of districts within the city. The distance from the storage wellfield to the city is used in designing the fluid transmission line to the city and calculating the fluid temperature and enthalpy entering the distribution system. The climatic parameters are used in determining the annual heat (chi11) demand, peak heat (chi11) demand, average heat (chi11) demand, the load factor, and supplemental heat requirements.

The city is described by disaggregating it into districts, the basic elements of the distribution system submodel. Each district is a contiguous area consisting of buildings of relatively similar heat (chill) demand and uniform density. Most of the details needed for design of the distribution piping system are derived from the definitions of the districts. Fluid requirements are computed, and the piping networks are designed for each district. Material requirements, capital costs, operating costs, and maintenance costs are also calculated for each district and totaled for the city.

Districts are defined by two types of input parameters: district geometry and district type characteristics. District geometry parameters define the size and location of the districts and the district type characteristics define the demand density. A comprehensive list of these parameters is given in Section 3.4.5. The primary parameters used to define each district are the district type, the density of buildings, peak space heating (cooling) demand, sanitary hot water demand, the area of the district, and two parameters (length and width) describing a rectangular grid used to approximate the shape of the district.

Five district types, representing typical residential areas, are identified and defined in Sections 3.4 .5 and 3.4.5.2. Most residential areas in the 
United States can be described by one of these district types. A sixth district type is used to represent a single point demand, i.e., a district consisting of one point of heat (chill) demand such as a single commercial building or factory. Variations of the predefined district types or additional district types can also be defined through the district type parameters in the NAMELIST input data.

The distribution system submode 1 is decomposed into its component subroutines in Figure 4 and consists of subroutine CALQNA, subroutine DIST, and its associated subroutines: GRAPH, SIZE, HEAT, PROP, and DWRIT.

As previously noted in Section 2.5, the annual and peak fluid flows are established in the iteration between the distribution demand subroutine CALQNA and the supply system submodel. Subroutine CALQNA calculates the annual and peak fluid requirements to meet the heat (chi11) demands [space heating (cooling) and sanitary hot water] of the city based on the area, building density, space heating (cooling) demand, sanitary hot water demand, thermal losses in the fluid, and the climatic data for all districts in the city. The total city requirement is the sum of the district requirements.

Subroutine DIST calls the associated subroutines shown in Figure 4 to determine the design and cost of the distribution system. Subroutine GRAPH is called to design the piping network for each district in the city based on the area, building density, heat (chill) demand, climatic data, and a rectangular grid used to approximate the shape of the district. Heat (chill) demand data and climatic data are used to determine the fluid requirements of each building. Proceeding down the piping network, the fluid requirements are used in subroutine SIZE as a basis for selecting the economic pipe size and insulation thickness and calculating pressure drops for each segment of the piping network. Thermal losses are determined for each segment of the piping network by subroutines HEAT and PROP.

Material requirements for the distribution system are calculated in subroutines DIST and SIZE. Capital costs, operating costs, and maintenance costs for the piping network, pumps, meters, and control equipment are derived based on the distribution system design options in subroutine DIST and the capital 
and operating cost models described in Appendix B. The output results summarizing the material requirements and costs of the distribution system are printed by subroutines DIST, DWRIT, and DWRIT2 (an entry point in subroutine DWRIT).

Each subroutine of the distribution system submodel is described below in the order of execution illustrated in Figure 4. Numerous comment cards are also provided in the FORTRAN code for these subroutines to facilitate understanding of the logic in the distribution system submodel.

CALQNA Calculates the distribution system's annual average heat (chi11) demand and peak heat (chill) demand in MBtu/hr, the system load factor, the annual fluid flow requirements in $1 \mathrm{~b} / \mathrm{yr}$, and the peak fluid flow requirements in $\mathrm{lb} / \mathrm{hr}$. The degree-day method is used for evaluating heat demand for space heating; the degree-hour method is used for evaluating chill demand for space cooling. The remainder of the discussion given below for subroutine CALQNA focuses on the methodology for space heating and sanitary hot water heating. The methodology for space cooling is described in Section 3.4.3 and Appendix E. No sanitary hot water heating is currently possible with space cooling (see Section 3.4.1).

The following equation is used to calculate the annual average heat demand $A D(M B t u / h r)$ for space heating and sanitary hot water heating:

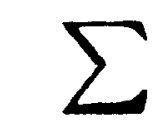

No. of Districts
Density (bldg/sq mile) * Area (sq mile) *

Peak Heat Demand at Design Outdoor Temperature (MBtu/bldg $\cdot h r) *$ Number of Heating Degree Days $\left({ }^{\mathrm{F}} \cdot\right.$ days $\left./ \mathrm{yr}\right) /[365$ (days $/ \mathrm{yr}) *(65$ - Design Outdoor Temperature $\left.)^{0} \mathrm{~F}\right]$

Daily Sanitary Hot Water Demand (gal/bldg • day)*

$$
\left.3.631 \mathrm{E}-5 \frac{\mathrm{MBtu} / \mathrm{hr}}{\mathrm{ga} 1 / \mathrm{day}}\right\}
$$

The indoor design temperature for space heating is currently fixed at $65^{\circ} \mathrm{F}$ in the code. 
The conversion factor of $3.631 \mathrm{E}-5$ is based on heating water for sanitary usage from $50^{\circ} \mathrm{F}$ to $140^{\circ} \mathrm{F}(\mathrm{a})$ using a small heat

exchanger at the hot water tank.

Heat Demand for Sanitary Hot Water Heating (MBtu/bldg $\cdot \mathrm{hr}$ ) = [Daily Sanitary Hot Water Demand (gal/bldg - day) * .1337 $\left(\mathrm{ft}^{3} / \mathrm{gal}\right) * 61.37\left(1 \mathrm{~b} / \mathrm{ft}^{3}\right) * 1 \mathrm{Btu} /\left({ }^{\mathrm{O}} \mathrm{F} \cdot \mathrm{lb}\right) *(140-50)^{0} \mathrm{~F} *$

1.E-6 MBtu/Btu]/24 (hr/day)

This yields the equation:

Heat Demand for Sanitary Hot Water Heating (MBtu/bldg $\cdot h r)=$ Daily Sanitary Hot Water Demand (gal/bldg • day)* $3.0769 \mathrm{E}-5\left(\frac{\mathrm{MBtu} / \mathrm{hr}}{\mathrm{ga} / \mathrm{day}}\right)$

Assuming an $18 \%$ heat loss (fixed in the code) from the hot water storage heater, the equation becomes:

Heat Demand for Sanitary Hot Water Heating (MBtu/bldg $\cdot h r)=$ Daily Sanitary Hot Water Demand (gal/bldg - day) * 3.0769E-5*1.18, i.e., Daily Sanitary Hot Water Demand $($ gal/bldg $\cdot$ day $) \star 3.631 E-5\left(\frac{\text { MBtu/hr }}{\text { gal/day }}\right)$

The following equation is used to calculate the annual peak heat demand PD (MBtu/hr) for space heating and sanitary hot water heating:

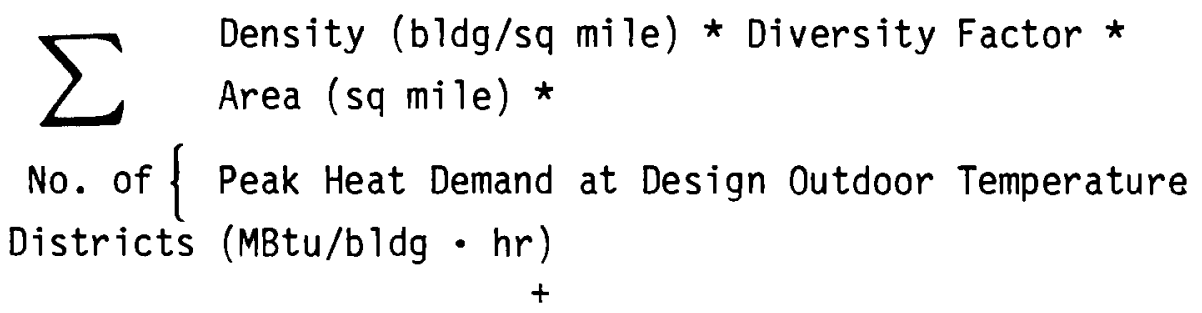

(a) This discussion pertains to the default values of cold and hot water temperatures for sanitary hot water heating in the city. The cold and hot water temperatures and conversion factors used in calculations for sanitary hot water heating in the city are generalized in the code to handle the values specified by the user in the NAMELIST input data. See Section 3.4.2 for definition of the cold water temperature (TWATC) and hot water temperature (TWATH) in the input data. 
Peak Heat Demand for Sanitary Hot Water Heating (MBtu/ bldg $\cdot h r)\}$.

The calculation of the peak heat demand for sanitary hot water heating (MBtu/bldg $\cdot \mathrm{hr}$ ) is as follows:

Daily Sanitary Hot Water Demand (gal/bldg - day) * 738.47E-6

$\left(\frac{\text { MBtu/day }}{\text { gal/day }}\right) *(1 / 7)$, where the assumption is that the peak

sanitary hot water demand in $1 \mathrm{hr}$ represents about $1 / 7$ th

that of the average daily demand for sanitary hot water in

$24 \mathrm{hrs}$.

The system load factor PF is calculated as follows:

$\mathrm{PF}=$ Annual Average Heat Demand (AD)/

Annual Peak Heat Demand (PD)

Subroutine CALQNA considers the optional heat exchanger at the inlet to the distribution system in calculating the peak flow rate required to meet the peak space and sanitary hot water heating demands of the distribution system. Two peak flow rates are calculated.

First, the required peak flow rate QDIS ( $1 \mathrm{~b} / \mathrm{hr}$ ) inside the distribution system is calculated as follows:

\{Peak Heat Demand at Design Outdoor Temperature

$\left.\sum(\mathrm{MBtu} / \mathrm{b}) \mathrm{dg} \cdot \mathrm{hr}\right)+$ Peak Heat Demand for Sanitary Heating $(\mathrm{MBtu} / \mathrm{b} 7 \mathrm{dg} \cdot \mathrm{hr})\}$ *

No. of 1.E6 Btu/MBtu * Density (bldg/sq mile) * Diversity

Districts Factor * Area (sq mile)/ \{Temperature Drop of the Fluid Inside the Distribution System $\left({ }^{\circ} \mathrm{F}\right)$ * Specific Heat of the Fluid Inside the Distribution System * $0.95\}$

The diversity factor is used to reduce the magnitude of the peak flow rate by recognizing that the peak heat demand does not occur simultaneously for all buildings in a district (see Section 3.4.5.2). 
Without a heat exchanger, the fluid temperature drop inside the distribution system is calculated as the computed fluid temperature at the inlet to the distribution system minus the fluid temperature at the outlet of the building heating system (the latter defined as TREJ(N) in Section 3.4.5.2). With a heat exchanger at the inlet to the distribution system, the fluid temperature drop inside the distribution system is calculated as the circulating water temperature out of the heat exchanger (described in Section 3.4.4) minus the circulating water temperature out of the building heating system.

The above equation for the peak flow rate QDIS inside the distribution system is derived from the following heat transfer equation:

Required Heat at Peak Demand $(B t u / h r)=$ Temperature Drop $\left({ }^{0} \mathrm{~F}\right) \star$ Specific Heat $1 \mathrm{Btu} / 1 \mathrm{~b} \cdot{ }^{\circ} \mathrm{F}$ * $0.95 *$ QDIS $(1 \mathrm{~b} / \mathrm{hr})$

The peak flow rate QDIS is used to size the distribution main pipe connecting to the in let of the distribution system. The factor 0.95 (fixed in the code) is used to approximate for average thermal losses between the inlet to the distribution system and the individual buildings. The specific heat of the fluid (water) is assumed to be 1 in the above equation. The peak flow rates for all sections of pipe inside the distribution system are calculated in subroutine DIST described below.

The required peak flow rate QTRANS (1b/hr) from the storage we11field is calculated next. The peak flow rate QTRANS is used as one of two peak flow rates in calculating the required number of aquifer wells. Since all ATES wells serve as both injection and withdrawal wells, the total number of wells required is determined by the peak system flow, either into or out of the aquifer. The peak flow rate QTRANS is also used to size the transmission pipe from the storage wellfield to the distribution system. 
After a slight reduction to allow for fluid losses in the transmission and distribution piping, QTRANS is used for sizing the transmission pipe from the distribution system to the supply wellfield.

Without a heat exchanger, the peak flow rate QDIS inside the distribution system and the peak flow rate QTRANS from the storage wellfield are the same. With a heat exchanger, the peak flow rate QTRANS ( $\mathrm{lb} / \mathrm{hr}$ ) from the storage wellfield is calculated from a heat transfer balance across the heat exchanger as follows:

QTRANS $=$ [QDIS $(\mathrm{Tb} / \mathrm{hr}) *$ Temperature Rise of the Circulating Water Across the Heat Exchanger $\left({ }^{\circ} \mathrm{F}\right)$

* Specific Heat $\left.\left(\frac{1 \mathrm{Btu}}{\mathrm{ib} \cdot 0_{\mathrm{F}}}\right)\right] /$ [Temperature Drop of the

Storage Wellfield Water Across the Heat Exchanger $\left({ }^{0} \mathrm{~F}\right)$ * Specific Heat $\left.\left(\frac{1 \mathrm{Btu}}{\mathrm{Ib} \cdot{ }^{\mathrm{O}} \mathrm{F}}\right)\right]$

The calculation of the temperature changes across the heat exchanger are discussed in Section 3.4.4. The specific heat of the fluid (water) is assumed to be 1 in the above equation in the calculations by the code.

Both peak flow rates QDIS and QTRANS are increased to factor into consideration the fraction WLEAK of fluid lost due to leakage in the piping systems:

$$
\begin{aligned}
& \text { QDIS }=\text { QDIS * }(1 .+ \text { WLEAK }) \\
& \text { QTRANS }=\text { QTRANS * }(1 .+ \text { WLEAK })
\end{aligned}
$$

The variable WLEAK is specified by the program user in the input data (see Section 3.4.6).

DIST Calls the subroutines comprising the distribution system submodel in Figure 4 to simulate the design and calculate the capital costs, operating costs, and maintenance costs of the district heating (cooling) distribution system. The design, material 
requirements, and costs of the distribution system are calculated separately in steps 1-11 below for each district and then totaled over all districts in the city.

1) The network of pipes from buildings to streets, down streets connecting buildings, across the lateral connecting with the midpoint of the streets, and up the main connecting with the midpoint of the lateral is designed for each district using subroutine GRAPH. An example layout of a piping network is illustrated in Figure 7. The piping network is laid out symmetrically about the main and lateral pipes as described in the description of subroutine GRAPH.

2) The required peak fluid flow rate per building is calculated based on the peak space heating (cooling) demand and peak sanitary hot water demand specified in the input data for this district type and the specified temperature drop (rise if cooling) of the fluid. Based on the peak fluid flow rate, the pipe size and insulation thickness are optimized and the head loss is calculated for pipe sections in the supply pipes beginning from the building to the street, down streets, across the lateral, and up the main using subroutine SIZE. Due to the symmetry in the piping network, only a few pipe sections need to be considered to size the whole network for the district. The size of the return pipes is set equal to the size of the supply pipes.

3) The thermal losses in the sections of the supply pipes starting with the main, across the lateral, up the street, and from the street to the building are calculated using subroutine HEAT.

4) The thermal losses in the sections of the return pipes starting from building to street, down the street, across the lateral, and up the main are calculated using subroutine HEAT. 


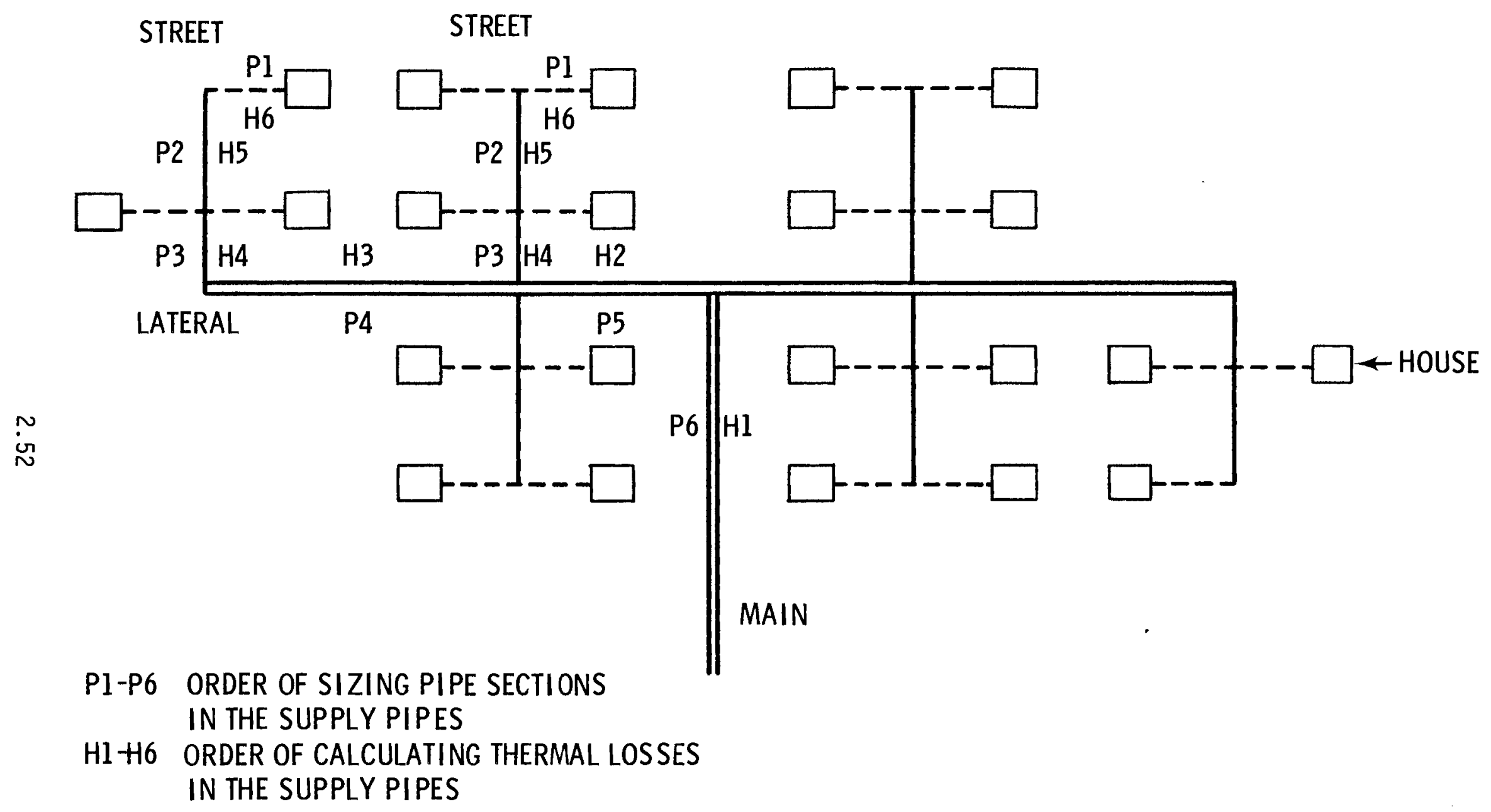

FIGURE 7. Layout for a District with 22 Buildings (The piping network is symmetrical about the main and the lateral.) 
5) The output illustrated by the sample output on page G-33 is printed. This summarizes the flow rate, thermal loss, supply and return temperatures, head loss, nominal outer pipe diameter, and insulation thickness in the sections of pipe from building to street, down a street, across the lateral, and up the main. Because of the symmetry of the piping network, it is necessary to print only the pipe sections from one building to the street, pipe sections connecting pairs of buildings down a half-street (either above or below the lateral), and pipe sections connecting streets across a halflateral (either to the right or left of the main).

6) The total head loss and thermal loss in the piping network are calculated for the district. Based on the total head loss, the required pumping capacity and capital cost of the pumps are calculated.

7) The material requirements and capital costs of the piping network are calculated based on the material and configuration options specified for pipes, insulation, and casing and the capital cost models described in Appendix B. The length of pipe, number of fittings, valves, and expansion loops, and the capital costs of pipes, fittings, valves, insulation, casing, expansion loops, and trenches are tabulated by up to 23 categories of nominal outer pipe diameter sizes that can be used throughout the piping network. These costs are then summed over all pipe sizes and combined with the cost of meters, pumps, and retrofitting of buildings to handle ATES heating (cooling) to obtain total capital costs for the district piping system.

8) The output illustrated by the sample output on page G-34 is printed. This summarizes the material requirements and capital costs calculated in step 7 by up to 23 categories of nominal outer pipe diameter sizes and also summarizes the total capital costs for the district piping system. 
9) The annual average heat (chill) demand (space heating and sanitary hot water heating) in MBtu/yr is calculated for the district based on the peak heat (chill) demand, climate, density, area, and daily sanitary hot water demand. The annual peak heat (chill) demand (space heating and sanitary hot water) in MBtu/hr is calculated for the district based on the peak heat (chill) demand, peak sanitary hot water demand, density, area, and diversity factor. The peak sanitary hot water demand is assumed to be $1 / 7$ of the daily sanitary hot water demand, occurring at the same time as the hourly peak heat demand. The diversity factor defined in Section 3.4.5.2 is used to reduce the size of laterals and mains supplying a district by considering that the peak loads for all buildings in a district will not occur simultaneously. The annual average heat (chill) demand and annual peak heat (chill) demand are also summed over all districts in the city.

10) The return temperature for each district is weighted by the mass flow rate for each district to calculate an average return temperature from the city distribution system.

11) The peak supplemental heat requirements (MBtu/hr) are calculated for each district based on the peak heat demand, climate, density, and area of the district.

12) The output illustrated by the sample output on page G-69 is printed. This summarizes the flow rate, thermal loss, supply and return temperatures, head loss, nominal outer pipe diameter, and insulation thickness for the mains to the districts.

13) The design parameters and capital cost of the heat exchanger are printed if the option to use a heat exchanger at the interface between the transmission line from the storage wellfield and distribution main is simulated. 
14) The output illustrated by the sample output on page G-71 is printed. This summarizes the total material requirements and capital costs for the entire city distribution system by up to 23 categories of nominal outer pipe diameters. The total capital costs summed over all pipe sizes and the total operating expenses are also printed for the entire city distribution system.

15) The total supplemental heat requirements (MBtu/yr) are calculated for the city based on the annual average heat demand calculated in step 9 for the city and the climate. The cost of providing the total supplemental heat requirements is also calculated. No supplemental chill is provided in the case of cooling.

Designs the layout of the piping network for the distribution system in each district based upon the area, building density, length, and width which the user can approximate from a map of the district. Subroutine GRAPH calculates the number of buildings in a given district (area * density) and places them on a rectangular grid such that the ratio of rows to columns is equal to the ratio of width to length of the district. The rectangular grid defaults to a square with length and width equal to $1 \mathrm{mile}$ if these two parameters are not defined in the NAMELIST input data.

An example layout designed by subroutine GRAPH for a district with 22 buildings and with ratio of length to width equal to 2 is shown in Figure 7. Pairs of columns of houses are assigned by subroutine GRAPH to streets. A lateral pipe, located at the midpoint of the streets, connects all of the street pipes. A main pipe connects with the midpoint of the lateral. If a street cannot be completely filled out with buildings, these remaining buildings are placed on 2 short streets, one at each end of the lateral, so that the resulting network is symmetrical both about the lateral and main. 
Optimizes the pipe diameter (meters) and insulation thickness (meters) and calculates the pressure drop (meters of $\mathrm{H}_{2} \mathrm{O}$ ) for each section of pipe in the distribution piping network. Since all pipes from building to street are identical in a given district, and since the piping network is symmetrical about the main and lateral pipes, only a few pipe sections need to be considered to size the whole network in a given district. The optimal pipe diameter for each pipe section is determined by searching a set of feasible pipe sizes to find the size that will minimize the sum of the annualized capital cost of pipe, insulation, casing, valves, fittings, expansion loops, trenches, and pumps and the annual costs of thermal loss and pumping power costs. The optimal insulation thickness is determined by minimizing the sum of the annualized capital cost of insulating the pipes, valves, fittings, and expansion loops, annualized costs of casing and trenching, and annual value of lost thermal energy.

The material and configuration options for pipes, insulation, and casings used in subroutine SIZE are specified in the input described in Section 3.4.6. These design options include: single pipe systems, various two-pipe systems, use of steel or fiberglass reinforced plastic pipes, use of calcium silicate or polyurethane foam insulation, and use of steel, plastic (PVC), or field-constructed concrete casings. Material requirements including pipe, insulation, casing, valves, fittings, expansion loops, and trenches are accumulated by size at each section in the distribution piping network. The capital cost models used in subroutine SIZE are based on the design options specified in the input data and are described in Appendix $B$.

Calculates the radial thermal losses (joules/sec meter) through a composite series of walls (pipe, insulation, annular air space and ground) due to convection and conduction for fluid flow in a cylindrical pipe buried below the ground. Subroutine HEAT is called by both subroutines SIZE and DIST. 
DWRIT

(entry

point

DWRIT2)

Prints the output entitled "Definition of Distribution Districts" with results in both English and metric units and the output entitled "District Populations" illustrated in the sample output on pages $\mathrm{G}-30$ to $\mathrm{G}-32$. This output consists principally of the input data defining the districts and district types in the distribution system described in Section 3.4.5. Subroutine DWRIT (entry point OWRIT2) also prints the output entitled "Distribution System Description" with results in both English and metric units. This output summarizes the calculated heat (chill) demands, fluid temperatures, fluid flow rates, and costs by district for the distribution system. The output is illustrated in the sample output on page G-72.

PROP Calculates the convective heat-transfer coefficient for fluid flow in a cylindrical pipe based on the Dittus-Boelter equation as follows:

$$
h_{\text {conv }}=\frac{.0225 * K \star R e^{0.8} * \mathrm{Pr}^{0.4}}{D}
$$

where:

$$
\begin{aligned}
h_{\text {conv }}= & \text { convective heat-transfer coefficient, joules/sec } \cdot \\
& \text { meter }{ }^{2} \cdot{ }_{K} \\
K= & \text { thermal conductivity of the fluid, joules/sec } \\
& \text { meter } \cdot{ }^{O_{K}} \\
\operatorname{Re}= & \text { Reynolds number } \\
\operatorname{Pr}= & \text { Prandtl number } \\
D= & \text { inside pipe diameter, meters }
\end{aligned}
$$

Subroutine PROP is called by subroutine HEAT in order to calculate the portion of radial thermal losses due to convection for fluid flow in a cyclindrical pipe. 


\subsection{DISCOUNTED CASH FLOW SUBMODEL FOR SUPPLY SYSTEM}

As previously shown in Figure 3, the main program in AQUASTOR calls the discounted cash flow submodel for the supply system after the iterations to complete the technical design of the supply and distribution systems are completed in the executive routine NODEPR. This submodel is simulated by subroutine RESVOR and its associated subroutines; it determines the cash flow associated with the pre-development, development, and operation of the supply system from the beginning of exploration through its operational life. The discounted cash flow submodel allows the code user to escalate the annual costs of capital and interim capital replacements, O\&M expenses, electricity expenses, and purchased thermal energy for the supply system using the price escalation rates defined for these four generic categories in Section 3.5.5.2.

The exploration process simulated in subroutine RESVOR identifies and evaluates potential aquifer sites by a series of discrete steps, each of which can occur either sequentially in time or with some specified time overlap. Each step has an activity description, time period, associated cost, and success ratio (finding rate). The major steps are: 1) identification of target aquifer sites, 2) preliminary reconnaissance, 3) detailed reconnaissance, 4) preparation of environmental impact statement, 5) aquifer characterization, 6) exploratory drilling, 7) development of the aquifer wellfields and fluid transmission system, and 8) operation of that system. The steps are described in detail in Section 3.5.6.

All pre-developmental costs for the supply system are first capitalized and then amortized on a straight-line basis. The developmental and operational costs are based upon the size of the heat exchanger at the external energy source, the number of wells in the aquifer wellfields, and the size of the fluid transmission system, all of which are determined in the iterative calculations in subroutine NODEPR matching up the annual energy (fluid) supply from the supply system with the annual energy (fluid) demand by the distribution system.

The developmental costs of the supply system include the drilling costs based upon the required number of aquifer supply and storage wells and the unit 
drilling costs per well (either input or calculated by the drilling model), the capital cost of the heat exchanger at the external energy source calculated in subroutines NODEPR and SUBHEX, and the capital cost of the fluid transmission system to and from the aquifer wellfields calculated in subroutine TRANS (with entry point INJECT). The annual operating costs for the supply system include: replacement well drilling, purchased thermal energy from the external energy source, we 11 abandonment, well maintenance, overhead and management, replacement of downhole pumps, operation of the heat exchanger at the external energy source, pumping electricity cost, and maintenance of the fluid transmission system.

Using discounted cash flow analysis, the unit cost of thermal energy from the supply system is calculated by equating the present worth of the revenues and expenses from the beginning of exploration of the supply system through its operational life. Descriptions follow of the subroutines associated with subroutine RESVOR and the discounted cash flow submodel for the supply system.

CLEAR Clears consecutive locations in memory for initializing arrays in various subroutines to zero.

TARGTS Calculates the number of prospective aquifer sites to explore in each of the successive discrete steps comprising the aquifer exploration process, based upon the success ratios (finding rates) input for each step. The successive reduction in the number of aquifer sites to explore at each step culminates in a single successful site at the last step, completing the exploration process.

DATACK Calculates and prints the annual operating costs and the annual cash flow statement for the supply system from exploration through its operating lifetime. The annual operating costs printed include the following: 0\&M Costs, pumping electricity costs, purchased thermal energy from the external energy source, general management, replacement well drilling, and the sum of these five costs. The annual cash flow statement lists the year, the distribution system load factor (or fraction of annual time the distribution system is operating at full capacity), and the 
FACTRS

PWRCO

DEPREC

COSTEQ and

Entry Point COSTQA annual cash flows for the following items: identification of target aquifer sites, remaining aquifer pre-development activities beginning with preliminary reconnaissance, supply system development, supply system operation, property taxes and insurance, interim capital replacements for the fluid transmission system, the sum of these costs, and investment tax credits.

Calculates the present worth discount factor based on the cost of capital from both debt (bond) and equity (stock) financing, using the effective bond interest rate after taxes. A11 expenses and revenues are assumed to be incurred at midyear. If year-end discounting is desired, the variable TIMD appearing in subroutine FACTRS should be reset from 0.5 to 1.0 in the BLOCK DATA subroutine. Subroutine FACTRS is called by both the supply and distribution discounted cash flow submodels as shown in Figure 4. Subroutine PWRCO repeatedly calls subroutine DEPREC to calculate the depreciation allowances for the following capitalized items: aquifer wells, replacement wells, the fluid transmission system (including the heat exchanger at the external energy source and the downhole pumps), and all interim capital replacements. Subroutine PWRCO also amortizes the pre-development costs of the supply system on a straight-line basis. The depreciation allowances are printed by subroutine OUTPUT in the statement of annual deductible expenses.

Calculates the annual depreciation of the capital assets of the supply system, including interim capital replacements. The input parameter LL2 selects one of two available options: the straight line method (LL2 = 1) or double declining balance with switch over to straight line $(L L 2=3)$.

Calculates the unit cost of thermal energy from the supply system by setting the present worth of the revenues equal to the present worth of the expenses from the beginning of exploration through the operating life of the supply system. 
Unit cost of energy (dollars/MBtu) $=$ (present worth of the expenses - present worth of tax credits)/[(present worth of energy supplied $)$ * $(1$ - state gross revenue tax rate $) *(1$ combined federal and state income tax rate)]

The present worth of thermal energy supplied takes into account the distribution system load factor.

The first half of subroutine COSTEQ calculates the unit cost of thermal energy on a constant dollar basis (no inflation or price escalation); the second half, defined by the entry point COSTQA, calculates the unit cost of thermal energy on a current dollar basis (with inflation and price escalation).

PAYOUT Calculates the annual income statement and annual payout of investments for the supply system. This includes the total energy sales (gross revenues), state and federal income taxes, revenue taxes, royalty payments, and the changes in capitalization: outstanding bonds, bonds repaid, unrecovered equity, equity recovered, bond interest, and earnings on unrecovered equity.

OUTPUT Prints the statements of annual deductible expenses, income, and payout of investments for the supply system from the beginning of exploration through the operating life of the supply system. The statement of annual deductible expenses lists the items: year, present worth factor for that year, operating expenses, bond interest, well depreciation, amortization and transmission system depreciation, total deductible operating expenses, and state income taxes. The statement of annual income lists the items: year, trillion Btu of energy supplied, energy sales, revenue taxes, royalty payments, total tax deductible expenses, taxable income (federal), and federal income tax. The statement of payout of investments lists the items: year, net cash flow, outstanding bonds, equity capital not recovered, bond interest, earnings on unrecovered equity, bonds repaid, and recovery of equity. 
SUMARY The first half of subroutine SUMARY calculates and prints the and breakdown of the life cycle levelized unit cost of thermal energy Entry Point from the supply system (on a constant dollar basis) in ASUMRY dollars/MBtu and equivalent annual costs in millions of dollars. These costs are itemized by components as follows: identification and exploration, development, operating costs, revenue taxes, state income taxes, royalty payments, federal income taxes and bond interest. In another set of calculations, the taxes, royalty payments, and bond interest are reallocated to the direct cost components (identification and exploration, development, and operating costs) for the supply system. The rate of return on investment is included in the distributed energy cost for each component. The deductible nature of the bond interest causes this expense to be partially included in the rate of return (the part that is included in the present worth factor) and the remainder to be accounted for separately.

The second half of subroutine SUMARY, defined by the entry point ASUMRY, calculates the annual unit cost of thermal energy in current dollars using four different bases: 1) full cost recovery basis, 2) out-of-pocket cost basis, 3) purchased thermal energy and operating cost basis, and 4) purchased thermal energy cost basis. In addition, the equivalent life cycle levelized cost of thermal energy for the full cost recovery basis is also calculated in deflated base year dollars (January PRINDX dollars) as defined in Section 3.5.5.1. The calculations use the after-tax discount rate computed in subroutine FACTRS and the general inflation rate defined in Section 3.5.5.2.

\subsection{DISCOUNTED CASH FLOW SUBMODEL FOR DISTRIBUTION SYSTEM}

As previously shown in Figure 3 , the main program in AQUASTOR completes the calculations in the code by calling the discounted cash flow submodel for the distribution system, simulated by a small executive routine DISTRB and its associated subroutines. This submodel combines the thermal energy cost from 
the supply system with the capital and operating costs of the distribution system and generates the cash flow associated with the design, construction, and operation of the distribution system throughout its useful life. Note that the annual revenue of the supply system is an annual operating cost to the distribution system. The discounted cash flow submodel allows the code user to escalate the annual costs of capital and interim capital replacements, 0\&M expenses, electricity expenses, and purchased thermal energy for the distribution system using the price escalation rates defined for these four generic categories in Section 3.5.5.2.

The required revenue and unit cost of heat (chill) from the distribution system are determined by using discounted cash flow analysis, and equating the present worth of the revenues and expenses over the operational life of the distribution system. Descriptions of the subroutines called by the small executive routine DISTRB to simulate the discounted cash flow submodel for the distribution system follow.

HCONST Calculates the following costs appearing in the annual cash flow statement for the distribution system: capital costs, operating costs, interim capital replacements, property taxes and insurance, the sum of all these costs with the thermal energy cost from the supply system, and investment tax credits. The total capital cost of the distribution system for the construction period (NYC years, specified in the input data) is calculated in subroutine DIST according to the component capital cost models in Appendix B. This cost includes the following items: pipe, insulation, casing, fittings, expansion loops, trenches, valves, meters, pumps, metering and control equipment, buildings and land use, building retrofit (optional), heat exchanger (optional), and engineering and administration. Subroutine HCONST apportions the capital cost by year over the number of years (NYC) input for distribution system construction. The apportionment is based on the following function:

$$
c(t)=\frac{100}{\left[1+e^{k(a-t)}\right]}
$$


where:

$C(t)$ is the cumulative percent expenture at time $t$.

$k$ is a constant, 0.0847 .

$a$ is the $50 \%$ expenditure point in time, currently set to the $60 \%$ point in the construction schedule.

$t$ is the time in years from beginning of construction.

Annual operating costs are calculated in subroutine DIST according to the operating cost models in Appendix $B$. This includes the following items: personnel costs for operating the distribution system and for administrative functions, routine repair and maintenance of the distribution system, pump operating costs, meter readers, supplemental heating costs, and operation of a heat exchanger (optional).

Interim capital replacements are calculated as a fraction of construction period capital costs.

Interim capital replacements $(\$)=$ [input fraction DINPUT (53), with default value 0.0035$]$ * (construction period capital cost)

Property taxes and insurance are calculated annually as a fraction of total capital costs (construction period capital costs plus all interim capital replacements) up to the year of interest in the calculation.

Property $\operatorname{tax}(\$)=$ [input fraction $\operatorname{DINPUT}(52)$, with default value 0.0250$]$ * (total capital cost up to the year of interest in the calculation)

Property insurance $(\$)=$ input fraction DINPUT(54), with default value 0.0012$]$ * (total capital cost up to the year of interest in the calculation)

Investment tax credits in the first year of operation are calculated as a fraction of total construction period capital costs and interim capital replacements during the first year of operation. 
Investment tax credit $(\$)=[0.01$ * input percentage PIVTCP, with default value 0]* (total construction period capital costs and interim capital replacements in the first year of operation). Investment tax credits in subsequent years of operation are calculated as a fraction of the interim capital replacements.

Investment tax credit $(\$)=[0.01$ * input percentage PIVTCP, with default value 0] * (interim capital replacements in the year of interest)

Subroutine HCONST (together with subroutine DIST) also calculates the annual net production of usable heat or chill (after allowance for thermal losses in the distribution system piping) in units of Btu/yr and MBtu/yr.

DATAK Prints the following annual operating costs for the distribution system: 0\&M costs, pumping electricity costs, purchased supplemental heat (discussed in Section 3.5.5.3), and the sum of these three costs.

DPREC Calculates the annual depreciation of the distribution system capital assets, including interim capital replacements. The input parameter LL2 selects one of two available options: the straight line method (LL2 = 1) or double declining balance with switch over to straight line (LL2 $=3)$.

COSTEG Calculates the unit cost of heat (chill) from the distribution and entry point system by setting the present worth of the revenues equal to the COSTEA present worth of the expenses throughout the economic life of the distribution system.

Unit cost of heat (chill) (dollars/MBtu) = (present worth of expenses - present worth of tax credits)/[(present worth of heat production $)$ * $(1$ - state gross revenue tax rate $)$ * $(1$ - combined federal and state income tax rate)].

The present worth of heat (chill) production takes into account the distribution system load factor. 
The first half of subroutine COSTEG calculates the unit cost of heat (chill) on a constant dollar basis (no inflation or price escalation); the second half, defined by the entry point COSTEA, calculates the unit cost of heat (chill) on a current dollar basis (with inflation and price escalation).

PAYOT Calculates the distribution system's annual tax deductible expenses, annual income statement, and annual payout of investments. This includes the total heat (chili) sales (gross revenues), total tax deductible expenses, taxable income (federal), state and federal income taxes, revenue taxes, and the changes in capitalization: outstanding bonds, bonds repaid, unrecovered equity, equity recovered, bond interest, and earnings on unrecovered equity.

OUTPLT Prints the statements of annual cash flow, annual tax deductible expenses, annual income, and annual payout of investments from the beginning of distribution system construction through its economic life. The statement of annual cash flow lists these items: year, distribution system load factor, capital costs, energy costs from the supply system, distribution operating costs, interim capital replacements, property taxes and insurance, the sum of these costs and investment tax credits. The statement of annual tax deductible expenses lists these items: year, present worth factor for that year, operating expenses, bond interest, depreciation, total deductible operating expenses, and state income taxes. The statement of annual income lists these items: year, trillion Btus of heat (chill) sold, heat (chi11) sales, revenue taxes, total tax deductible expenses, taxable income (federal), and federal income tax. The statement of payout of investments lists these items: year, net cash flow, outstanding bonds, equity capital not recovered, bond interest, earnings on unrecovered equity, bonds repaid, and recovery of equity. 
CPOWER

and

entry point

APOWER
The first half of subroutine CPOWER calculates and prints the breakdown of the life cycle levelized unit cost of heat (chi11) from the distribution system (on a constant dollar basis) in dollars/MBtu and equivalent annual costs in millions of dollars. These costs are itemized by components as follows: distribution system capital costs, interim capital replacements, energy supply from the supply system, operating expenses, property taxes and insurance, revenue taxes, state income taxes, federal income taxes, and bond interest. The difference between the unit cost for energy supply at the distribution system and the unit cost of energy from the supply system calculated in subroutine COSTEQ is caused by thermal losses in the distribution system piping. In another set of calculations, the taxes and bond interest are reallocated to the direct cost components (capital costs, interim capital replacements, energy supply, operating expenses, and property taxes and insurance) for the distribution system.

The second half of subroutine CPOWER, defined by the entry point APOWER, calculates the annual unit cost of heat (chill) in current dollars using four different bases: 1) full cost recovery basis, 2) out-of-pocket cost basis, 3) energy supply and operating cost basis, and 4) energy supply cost basis. In addition, the equivalent life cycle levelized cost of heat (chill) for the full cost recovery basis is also calculated in deflated base dollars (January PRINDX dollars), as defined in Section 3.5.5.1. The calculations use the after-tax discount rate computed in subroutine FACTRS and the general inflation rate defined in Section

\section{5 .5 .2 .}

\subsection{STEAM TABLE FUNCTIONS}

Tables 1 and 2 give the 1967 ASME Steam Table functions used to calculate thermodynamic and physical properties of water and steam, their arguments, and the temperature-pressure subregions in which they are applicable. The subregions are illustrated relative to the saturation line on the temperature- 
TABLE 1. ASME Steam Table Single Valued Functions

State Unknown

(either wet (two-phase) or superheated)

Saturation Line and Wet Steam

\begin{tabular}{|c|c|c|}
\hline $\begin{array}{l}\text { FORTRAN } \\
\text { Code Name }\end{array}$ & Function & Subregion \\
\hline HPS & $h=f(p, s)$ & $2,3,4$ \\
\hline SPH & $s=f(p, h)$ & 2,3 \\
\hline VPH & $v=f(p, h)$ & 2,3 \\
\hline VPS & $v=f(p, s)$ & $2,3,4$ \\
\hline TPH & $t=f(p, h)$ & $2,3,4$ \\
\hline TPS & $t=f(p, s)$ & $2,3,4$ \\
\hline THS & $t=f(h, s)$ & $2,3,4,6$ \\
\hline PHS & $p=f(h, s)$ & $2,3,4,6$ \\
\hline XPH & $x=f(p, h)$ & \\
\hline XPS & $x=f(p, s)$ & \\
\hline
\end{tabular}

\begin{tabular}{lllll}
$\begin{array}{c}\text { FORTRAN } \\
\text { Code Name }\end{array}$ & & Function & & Subregion \\
\cline { 1 - 1 } HPSW & & $h=f(p, s)$ & & 6 \\
SPHW & & $s=f(p, h)$ & & 6 \\
VPHW & & $v=f(p, h)$ & & 6 \\
VPSW & & $v=f(p, s)$ & & 6 \\
TSL /TSATP & $t=f(p)$ & & Sat. Line \\
PHSW & & $p=f(h, s)$ & & 6 \\
PSL/PSATT & & $p=f(t)$ & Sat. Line
\end{tabular}

Superheated Steam

Compressed Liquid

$\begin{array}{llllll}\text { HPSD } & h=f(p, s) & 2,3,4 & \text { HPTL } & h=f(p, t) & 1,3,4 \\ \text { HPTD } & h=f(p, t) & 2,3,4 & \text { SPTL } & s=f(p, t) & 1,3,4 \\ \text { SPHD } & s=f(p, h) & 2,3,4 & \text { VPTL/VCL } & v=f(p, t) & 1,3,4 \\ \text { SPTD } & s=f(p, t) & 2,3,4 & \text { TPHL } & t=f(p, h) & 1,4 \\ \text { VPHD } & v=f(p, h) & 2,3,4 & \text { TPSL } & t=f(p, s) & 1,4 \\ \text { VPSD } & V=f(p, s) & 2,3,4 & \text { VISL } & \mu=f(p, t) & 1,2,3,4 \\ \text { VPTD } & V=f(p, t) & 2,3,4 & \text { CONDL } & k=f(p, t) & 1 \\ \text { TSUPH/TPHD } & t=f(p, h) & 2 & \text { PRLIQ } & P r=f(p, t) & 1 \\ \text { TSUPS/TPSD } & t=f(p, s) & 2,3,4 & & & \\ \text { THSD } & t=f(h, s) & 2,3,4 & & \\ \text { PHSD } & p=f(h, s) & 2,3,4 & & \\ \text { VISV } & \mu=f(p, t) & 2,3,4 & & \\ \text { CONDV } & k=f(p, t) & 2,3,4 & & & \\ \text { PRSTM } & \text { Pr }=f(p, t) & 2,3,4 & & \end{array}$

Saturated Vapor

Saturated Liquid

$\begin{array}{llllll}\text { HGP } & h=f(p) & \text { Sat. Line } & \text { TSLH } & t=f(h) & \text { Sat. Line } \\ \text { HGT } & h=f(t) & \text { Sat. Line } & \text { HFP } & h=f(p) & \text { Sat. Line } \\ \text { SGP } & S=f(p) & \text { Sat. Line } & \text { HFP/HSL } & h=f(t) & \text { Sat. Line } \\ \text { SGT } & S=f(t) & \text { Sat. Line } & \text { SFP } & s=f(p) & \text { Sat. Line } \\ \text { VGP } & V=f(p) & \text { Sat. Line } & \text { SFT/SSL } & s=f(t) & \text { Sat. Line } \\ \text { VGT } & V=f(t) & \text { Sat. Line } & \text { VFP } & V=f(p) & \text { Sat. Line } \\ \text { PSV } & p=f(s) & \text { Sat. Line } & \text { VFT/VSL } & V=f(t) & \text { Sat. Line }\end{array}$

Some subroutines have been given two names separated by a slash (/) mark. When calling these subroutines, the names can be used interchangeably. 
TABLE 2. ASME Steam Table Multiple Valued Functions

FORTRAN

Code Name

Function

HSSISS

HPSISS

HSS

HSV

HCL

HSSICL

SSSISS

SPSISS

SSICL

CRFLO

CRVEL

\begin{tabular}{l}
\multicolumn{1}{c}{ Function } \\
\hline$h, t, v, x=f(p, s)$ \\
$h, t, v, x=f(p, s)$ \\
$h, s, v=f(p, t)$ \\
$h, t, s, v=f(p)$ \\
$h, s=f(p, t)$ \\
$h, t=f(p, s)$ \\
$s, t, v, x=f(p, h)$ \\
$s, t, v, x=f(p, h)$ \\
$s, t=f(p, h)$ \\
$f c,{ }^{\circ} s=f(p, h)$ \\
$v c, \gamma=f(p, h)$
\end{tabular}

Isentropic Drop Subroutines

ZSDT

$$
\begin{aligned}
& h_{1}, s_{1}, x_{1}, v_{1}, t_{2}, x_{2}, v_{2}, h_{2} \\
& =f\left(p_{1}, p_{2}, t_{1}\right)
\end{aligned}
$$

ZSDH

$$
\begin{aligned}
& t_{1}, s_{1}, x_{1}, v_{1}, t_{2}, x_{2}, v_{2}, h_{2} \\
& =f\left(p_{1}, p_{2}, h_{1}\right)
\end{aligned}
$$

ZSRT

$$
h_{1}, s_{1}, t_{2}, h_{2}=f\left(p_{1}, p_{2}, t_{1}\right) \quad \text { Compressed Liquid }
$$

ZSRH

Compressed Liquid

$$
t_{1}, s_{1}, t_{2}, h_{2}=f\left(p_{1}, p_{2}, h_{1}\right) \quad \text { Compressed Liquid }
$$

Wet or Superheated Steam

Superheated Steam

Superheated Steam

Saturated Vapor

Compressed Liquid

Wet or Superheated Steam

Superheated Steam

Compressed Liquid

Wet or Superheated Steam

Wet or Superheated Steam

Wet or Superheated Steam

Wet or Superheated Steam

pressure diagram in Figure 8. Subregion 6 is the area just above and below the saturation line. When calculations of properties are needed near the critical point in subregion 5, the accuracy of the functions used should be checked against the individual requirements since the properties vary rapidly in this area. Definitions for the symbols used in Tables 1 and 2 follow.

$$
\begin{aligned}
& p \text { - Pressure, psia } \\
& t \text { - Temperature, }{ }^{o_{F}} \\
& \text { h - Specific Enthalpy, Btu/lb } \\
& \text { s - Specific Enthalpy, Btu/1b- }{ }^{\circ} F
\end{aligned}
$$




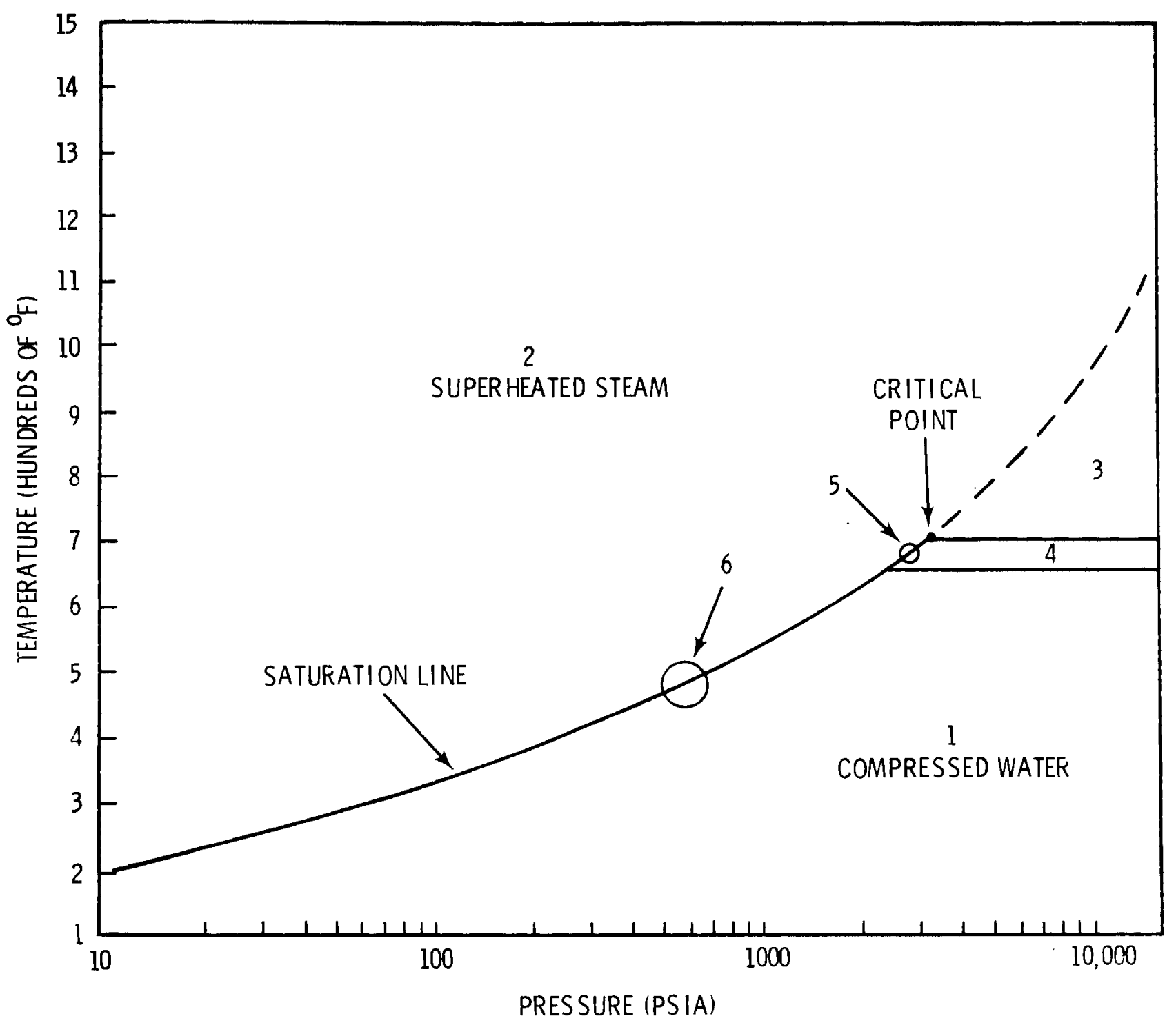

FIGURE 8. Steam Table Subregions as a Function of Temperature and Pressure 


$$
\begin{aligned}
& v \text { - Specific Volume, } \mathrm{ft}^{3} / 1 \mathrm{~b} \\
& \text { x - Quality by weight fraction, } \% / 100 \\
& \mu \text { - Viscosity, lb/ft-sec } \\
& k \text { - Thermal conductivity, Btu/hr-ft- }{ }^{\circ} \mathrm{F} \\
& \mathrm{Pr} \text { - Prandtl number } \\
& V c \text { - Critical velocity, ft/sec } \\
& F c \text { - Critical flow, lb/hr-in }{ }^{2} \\
& Y \text { - Isentropic exponent (pv } \gamma=\text { Constant) } \\
& { }_{s} \text { - Degrees superheat }
\end{aligned}
$$

Many of the functions are interdependent. Consequently, if the use of a function is desired the majority of the steam table functions must be loaded into computer memory.

AQUASTOR initially calls the following subroutines in the steam tables to initialize steam table constants appearing in labeled common: CCSR1, CCSR2, CCSR3, CEBLL, and COMALL. 

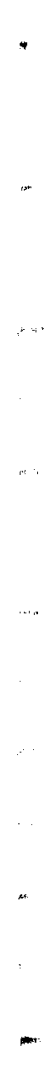


\subsection{PREPARATION OF INPUT DATA}

\subsection{NAMELIST INPUT RULES}

The first card required in the input data for AQUASTOR specifies a Hollerith title of 80 characters or less for identifying the simulation printout. The remaining data cards permit the user to override default values initialized for the input parameters in the BLOCK DATA subroutine. These cards are input using the NAMELIST statement, which permits input of numerical values for parameters and arrays preceded by the identifying parameter or array names. No format specification is used. This section gives a brief description of the NAMELIST rules for the UNIVAC computer, which are applicable to most other machines with minor variations. The reader may wish to consult the FORTRAN manual available at his/her installation for a more detailed discussion. A sample case illustrating the NAMELIST input is given in the next section. The reader may find it helpful to refer to the sample input during the following discussion. The definitions of the NAMELIST input parameters and their default values in AQUASTOR are given following the sample input.

The NAMELIST input to AQUASTOR is composed of two sets of data: 1) the ATES supply system data, and 2) the distribution system data. The ATES supply system data begin in column 2 of the second data card (the first card is the title card mentioned above) with the NAMELIST group name \$RESVOR. The distribution system data begin in column 2 of the data card following the ATES supply system data with \$DISTRB. Each NAMELIST group name is separated by one or more spaces from its succeeding list of parameters, array names, and their numerical values.

Input parameters and arrays may be defined in three ways.

- parameter = constant

- array name = constant, ..., constant,

- array name (integer constant subscript) = constant, ..., constant,

Commas separate each definition from succeeding definitions. Constants can be preceded by a repetition number and an asterisk, as for example, array name $=$ $3 * 1.0$. This sets the first three locations in the array to the values 1.0 . 
In defining arrays, the number of constants, including repetitions, given for an array name should not exceed the number of elements in the array. The number of elements in the AQUASTOR arrays are given accompanying the definition of the input parameters and their default values following the sample input case. When data are input using the definition, array name (integer constant subscript) $=$ constant,..., constant, the array elements are defined consecutively beginning with the location given by the integer constant subscript. The number of constants need not equal, but may not exceed, the remaining number of elements in the array.

Integer or real constants are converted to the type of the parameter or array in the code. A11 input parameters to AQUASTOR beginning with the letters I through $N$, except the parameters IO and KINS, are integer. The paramters IO and KINS are declared real (floating point) parameters in AQUASTOR. All other input parameters are real.

The parameters, array names, and their numerical values succeeding the NAMELIST group name \$RESVOR or \$DISTRB are read until the characters \$END are encountered to complete the definition of the input data for the ATES supply system or distribution system respectively. Parameters may be in any order. $B$ lanks may be used freely to improve readability except between $\$$ and RESVOR or $\$$ and DISTRB, or within array names and parameter names, or within numerical values.

A minimum of three data cards is needed to define the input data for a simulation case. The first column of each card is ignored and should not contain any data. All cards except the last for a NAMELIST group name must end with a constant (optionally followed by a comma). The last card for each NAMELIST group must end with the characters \$END.

Consecutive simulation cases can be set up in the input data. Each new simulation case requires the following cards: 1) a title card, 2) a \$RESVOR card and, when necessary, continuation cards defining the NAMELIST input parameters to be changed from the preceding simulation case for the ATES supply system, and 3) a \$DISTRB card and, when necessary, continuation cards defining the NAMELIST input parameters to be changed from the preceding simulation case for the distribution system. The last card for each NAMELIST group name must end 
with the characters \$END. The input data for a simulation case may consist of any subset of the NAMELIST input parameters. In setting up consecutive simulation cases in the input data, only the input parameters with values differing from the preceding simulation case require redefinition. The values of parameters and arrays not included in the input data for a particular simulation case remain unchanged from:

- The default values in BLOCK DATA for the first simulation case.

- The values from the preceding simulation case for cases after the first case.

If no values are to be changed from the default values in BLOCK DATA in the first simulation case, the input data consists of: 1) a title card, 2) a card with \$RESVOR \$END beginning in column two, and 3) a card with \$DISTRB \$END beginning in column two.

\subsection{INPUT INSTRUCTIONS AND SAMPLE CASE INPUT}

The data input to AQUASTOR consists of the following three types of cards:

- A title card of 80 characters of less to identify the simulation printout.

- Data cards defining values for the ATES supply system input parameters beginning in column two with \$RESVOR according to NAMELIST input rules.

- Data cards defining values for the distribition system input parameters beginning in column two with \$DISTRB according to NAMELIST input rules.

The following steps are suggested for preparing the data input:

Step 1. Review the NAMELIST input rules summarized in the preceding section.

Step 2. Prepare a title card of 80 characters or less.

Step 3. Prepare cards defining the technical and economic input parameters for the ATES supply system following the NAMELIST input rules.

Step 4. Prepare cards defining the technical and economic input parameters for the distribution system following the NAMELIST input rules. 
Al1 input parameters and their default values are defined in Sections 3.3, $3.4,3.5$, and 3.6. Those input parameters not included in the list of parameters in the data cards for a given case are left set to the default values.

To illustrate the data input, the AQUASTOR model was used to determine the cost of residential space heating and sanitary hot water heating in Richland, Washington using an ATES district heating system. The ATES district heating concept was previously depicted in Figure 2 of Section 2.1. The reader may wish to refer to Figure 2 in following the description of the ATES installation simulated for the city of Richland.

The sample case input for the ATES installation of the city of Richland is shown in Table 3. The parameters set to override the default values for the ATES supply and distribution systems are defined in the NAMELIST groups \$RESVOR and \$OISTRB respectively. The parameters are listed within each NAMELIST group in Table 3 in the chronological order of their description in the user manual. The sections that describe the parameters are also shown in Table 3 . Al1 input parameters not shown were left set to their default values. The ATES installation simulated for the city of Richland is described briefly below.

During the summer, groundwater is withdrawn from a supply wellfield drilled into a suitable aquifer and pumped approximately 6 mi les (9600 meters) via an above-ground pipeline to an industrial heat source. The groundwater is heated by the industrial waste heat to $307.5^{\circ} \mathrm{F}$ using a liquid-to-liquid heat exchanger and then pumped 6 miles back to the same aquifer and through the storage wellfield.

The industrial waste heat is available as hot water at a peak flow rate of $3,565,100 \mathrm{lb} / \mathrm{hr}$ for 24 hours per day and 120 days per year (summer months). It is assumed that the peak flow rate from the industrial heat source passing through the heat exchanger can be increased as needed to extract the necessary thermal energy. The exact peak flow rate needed is calculated by the code. The purchased thermal energy from the industrial heat source is assumed to cost $\$ 3 / 10^{6}$ Btu.

Thermal energy is stored in the aquifer at a depth of 1312 feet ( 400 meters) until needed. In the winter, the storage wellfield is pumped and the 
TABLE 3. Sample Case Input for ATES District Heating in Richland, WA

ATES UISTRICT MEATING TEST CASE FOH RICHLAND, WASHINGTON

SRE SVUH

SHCOST $=3 .$, SMFLOW=3.56ל1E6, SOFLOW=8.5563E 1, SAFLOW=1.0267E10,

Section

SHCOST $=3.9$ SMFLOW $=3.5651 E 6$, SOFLOW $=8.5$
SMXFLW $=1 . E 99$, TSRIN $=325$, TSHUUT $=117 .$,

APPHX $=17.5$.

3.1

FLORAT $=150000 \ldots$ WELSPC $=23 \ldots$ STRATA $(2,1)=400 \ldots$ STADEF $=.60$.

3.3 .2

SPADEF $=.85$, STFHEC $=.90$, TACIF $=35.0$

PLNGTH $=4 \$ 9600, P L M A N F=1$.

DINPUT $(4)=1 \ldots$ DINPUT $(5)=.10, \operatorname{DINPUT}(6)=0 \ldots$ DINPUT $(7)=\pi \ldots$

DINPUT $(15)=0.9$ DI NHUT $(17)=0$. .

DCPW $=100000$

PIFCSH $=6.9$

ACRES $=1000$

IPLOT $=1$.

DERID

\$DISTRHS

ADGDAY $(1)=5267 \ldots$ DUGOAY $(1)=5109 .$.

HTE $\times O P=1$. U UAPIN $=17.5$, UAPOUT $=17.5$,

NDTR $=18$,

IUTF $=4,3,3,3,3,3,4,3,2,3,2,2,3 \cdot 2,2,5,4,1$,

$\triangle H E A=.078, .29, .08, .06, .20, .04, .140, .15, .26, .68, .14, .16, .023, .14$,

$45, .034, .049, .14$.

WIDTH $=.12, .62, .18, .27, .51, .15, .27, .42, .23, .53, .40, .39, .21, .48, .28$. $24, .09, .16$

XLNGTH=.62,..70,.611,.32,.58,.40,.4H,.53.1.49,2.02,.58,.61,..26,.57,

$2.35, .30 \cdot .42,1.71$,

DUTR=.41,1.59,1.48,.43..56,.58,.45,.50,.42,1.27,.43,.43,.56,.40,

$.40, .21, .51, .87$.

$H \cap=.053, .044, .034, .48, .034,340 .$,

$H W=60.60,600.1200,040.030000$

DENSE $=1368, .2093 .3837 .376 . .7898 ., 3 * 0 \ldots$

DIVF $=540.72,340 .$.

TRE J $=5 \$ 100,3 \% 0.0$

POPHSH $=2.66,2.66,2.66,56.86,2.66,3 * 0.9$

CRIF $=3 \% 1000,21000,01000,340 \ldots$

$P O=1 \ldots$ TA $=0 \ldots$ VMBTU=3., AGFACT $=1 \ldots 1 \ldots 1 \ldots$

UNET $=11 * 1,2,2 * 0,15 * 0,2 * 2,3 * 0,14 * 1,2,5 * 0,3 * 2,17 * 0,3 * 0,10 * 1,2,6 * 0$,

$8 \$ 0,3 \$ 2,7 \$ 0,3 \$ 0,3 \$ 1,2 \$ 2.12 \$ 0,5 \$ 0,2,14 \$ 0,3 \$ 0,2 \$ 2,15 \$ 0,220 \$ 0$.

DINPUT $(39)=1 \ldots$ DINPUT $(40)=.10$, DINPUT $(41)=0$, DINPUT $(42)=0$.

3. 3.3

3. 3.4

3.5 .1

3.5 .2

3.5 .5 .2

3.5 .6

3.6

3.4 .2

3.4.4.

3.4.5.1

DINPUT $(50)=0 .$, DINPUT $(52)=0$.

$L L 2=1$.

CSBTI $=6$, COPIIMP $=. \cup 2$,

SEND 
hot water is transported 6 miles for circulation through a heat exchanger at the boundary of the city to recapture the stored energy. The spent aquifer water is then returned 6 miles to the aquifer through the supply wellfield.

The circulating water inside the city distribution system is heated to $204.5^{\circ} \mathrm{F}$ at the heat exchanger and then pumped through a network of buried, insulated pipes for residential space heating and sanitary hot water heating in the city of Richland. The used water is rejected from the individual residences at $100^{\circ} \mathrm{F}$ and recirculated through the heat exchanger at the boundary of the city.

A municipal utility is assumed to construct and operate both the ATES supply system and district heating distribution system within the city of Richland. Financing for the project is assumed to be provided by the sale of municipal bonds at an interest rate of 10 percent.

The definitions of the parameters set to override the default values for the ATES supply system are given in Table 4. All costs are in January, 1980 dollars. The descriptions of all parameters for the ATES supply system and their default values are given in Section $3.3,3.5$, and 3.6 .

To simulate the distribution system, the city of Richland was divided into 18 residential heating districts as follows:

1 single-family, low-density district

5 single-family, medium-density districts

7 single-family, high-density districts

3 multiple-family apartment districts

2 trailer courts

Figure 9 shows the layout of the 18 heating districts in Richland. The AQUASTOR code requires that all districts have rectangular shapes, so the actual city of Richland zoning map was modified to conform with this requirement. The width, length, and area of each of the 18 districts were determined from the zoning map and input to the code. The geometric description and characteristics of each district are shown in Table 5 .

The climate affects district heating costs through two factors--the minimum extreme temperature and the heating degree-days. The minimum temperature 
TABLE 4. ATES Supply System Input Parameters for City of Richland in NAMELIST Group \$RESVOR

\begin{tabular}{|c|c|c|c|}
\hline Parameter & Section & Description & Value \\
\hline SHCOST & 3.3 .1 & $\begin{array}{l}\text { Cost of purchased thermal energy } \\
\text { from the industrial energy source }\end{array}$ & $\$ 3 / \mathrm{MBtu}$ \\
\hline SMFLOW & 3.3 .1 & $\begin{array}{l}\text { Peak hourly flow rate from the } \\
\text { industrial energy source }\end{array}$ & $3,565,100 \mathrm{lb} / \mathrm{hr}$ \\
\hline SDFLOW & 3.3 .1 & $\begin{array}{l}\text { Daily flow rate from the industrial } \\
\text { energy source operating } 24 \text { hours } \\
\text { per day }\end{array}$ & $\begin{array}{l}85,563,700 \\
1 \mathrm{~b} / \text { day }\end{array}$ \\
\hline SAFLOW & 3.3 .1 & $\begin{array}{l}\text { Annual flow rate from the industrial } \\
\text { energy source operating } 120 \text { days } \\
\text { per year }\end{array}$ & $\begin{array}{l}10,267,000,000 \\
\text { lb/year }\end{array}$ \\
\hline SMXFLW & 3.3 .1 & $\begin{array}{l}\text { Upper bound on the peak hourly flow } \\
\text { rate from the industrial energy source }\end{array}$ & 1.E99 $\mathrm{lb} / \mathrm{hr}(\mathrm{a})$ \\
\hline TSRIN & 3.3 .1 & $\begin{array}{l}\text { In let temperature entering the heat } \\
\text { exchanger from the industrial } \\
\text { energy source }\end{array}$ & $325^{\circ} \mathrm{F}$ \\
\hline TSROUT & 3.3 .1 & $\begin{array}{l}\text { Outlet temperature exiting the heat } \\
\text { exchanger back to the industrial } \\
\text { energy source }\end{array}$ & $117^{\circ} \mathrm{F}$ \\
\hline APPHX & 3.3 .2 & $\begin{array}{l}\text { Approach to the heat exchanger at } \\
\text { the inlet of the industrial energy } \\
\text { source (outlet of the circulating } \\
\text { water from the supply wellfield) }\end{array}$ & $17.5^{\circ} \mathrm{F}$ \\
\hline FLORAT & 3.3 .3 & $\begin{array}{l}\text { Withdrawal flow rate capacity of } \\
\text { each aquifer we } 11\end{array}$ & $150,000 \mathrm{lb} / \mathrm{hr}$ \\
\hline WELSPC & 3.3 .3 & Aquifer well spacing & 25 acres \\
\hline $\begin{array}{l}\text { STRATA } \\
(2,1)\end{array}$ & 3.3 .3 & Aquifer well depth & 400 meters \\
\hline STAQEF & 3.3 .3 & $\begin{array}{l}\text { Aquifer thermal storage efficiency } \\
\text { of storage wellfield }\end{array}$ & 0.60 \\
\hline
\end{tabular}

\footnotetext{
(a) The value of 1. Eg9 indicates that the hourly flow rate from the industrial energy source can be increased by the code to whatever value is necessary to match up the annual energy supply with annual energy demand.
} 
TABLE 4. (Continued)

\begin{tabular}{|c|c|c|c|}
\hline Parameter & Section & Description & Value \\
\hline SPAQEF & 3.3 .3 & $\begin{array}{l}\text { Aquifer thermal storage efficiency } \\
\text { of the supply wellfield }\end{array}$ & 0.85 \\
\hline STFREC & 3.3 .3 & $\begin{array}{l}\text { Aquifer fluid recovery fraction } \\
\text { for the storage wellfield }\end{array}$ & 0.90 \\
\hline TAQIF & 3.3 .3 & $\begin{array}{l}\text { Discovery (natural) aquifer tem- } \\
\text { perature of both the supply and } \\
\text { storage wellfields }\end{array}$ & $55^{\circ} \mathrm{F}$ \\
\hline $\begin{array}{l}\text { PLNGTH(I) } \\
I=1,4\end{array}$ & 3.3 .4 & $\begin{array}{l}\text { Length of transmission leg } I \text {, } \\
I=1,4 \text {, shown in Figure } 2 \text { of } \\
\text { Section } 2.1\end{array}$ & 9600 meters \\
\hline PLMANF & 3.3 .4 & $\begin{array}{l}\text { Distance from the manifold pipe } \\
\text { nodes ( } J=1 \text { in Figure } 15 \text { of Section } \\
4.0) \text { to the first column of well } \\
\text { nodes }(J=2) \text { in the matrix of sup- } \\
\text { ply and storage wells }\end{array}$ & 1 meter \\
\hline DINPUT (4) & 3.5 .1 & $\begin{array}{l}\text { Fraction of investment in bonds by } \\
\text { owner of ATES supply system }\end{array}$ & 1.0 \\
\hline DINPUT (5) & 3.5 .1 & Bond interest rate (fraction) & 0.10 \\
\hline DINPUT ( 6$)$ & 3.5 .1 & $\begin{array}{l}\text { Earning rate on equity after taxes } \\
\text { (fraction) }\end{array}$ & 0. \\
\hline DINPUT(7) & 3.5 .1 & Federal income tax rate (fraction) & 0 . \\
\hline DINPUT (15) & 3.5 .1 & State income tax rate (fraction) & 0. \\
\hline DINPUT(17) & 3.5 .1 & Property tax rate (fraction) & 0 . \\
\hline DCPW & 3.5 .2 & Cost of drilling each aquifer well & $\$ 100,000 /$ we 11 \\
\hline PIFCSB & 3.5 .5 .2 & $\begin{array}{l}\text { Annual escalation rate for the cost } \\
\text { of purchased thermal energy over } \\
\text { the simulated project lifetime }\end{array}$ & $6 \% /$ year \\
\hline ACRES & 3.5 .6 & $\begin{array}{l}\text { Size of aquifer site leased for } \\
\text { initial exploration }\end{array}$ & 1000 acres \\
\hline IPLOT & 3.6 & $\begin{array}{l}\text { Print switch to display printer } \\
\text { plots of capital costs calculated } \\
\text { by the code for pipes, insulation, } \\
\text { and casing of the distribution piping } \\
\text { system }\end{array}$ & 1 (yes) \\
\hline
\end{tabular}


RESIDENTIAL DISTRICT TYPE

SINGLE-FAMILY, LOW-DENSITY

ZZ SINGLE-FAMILY, MEDIUM-DENSITY

$\square$ SINGLE-FAMILY, HIGH-DENSITY

MULTIPLE-FAMILY APARTMENTS

$\square$ TRAILER COURTS

- district CENTER (1-18)

- MAIN NUMBER (1-9)

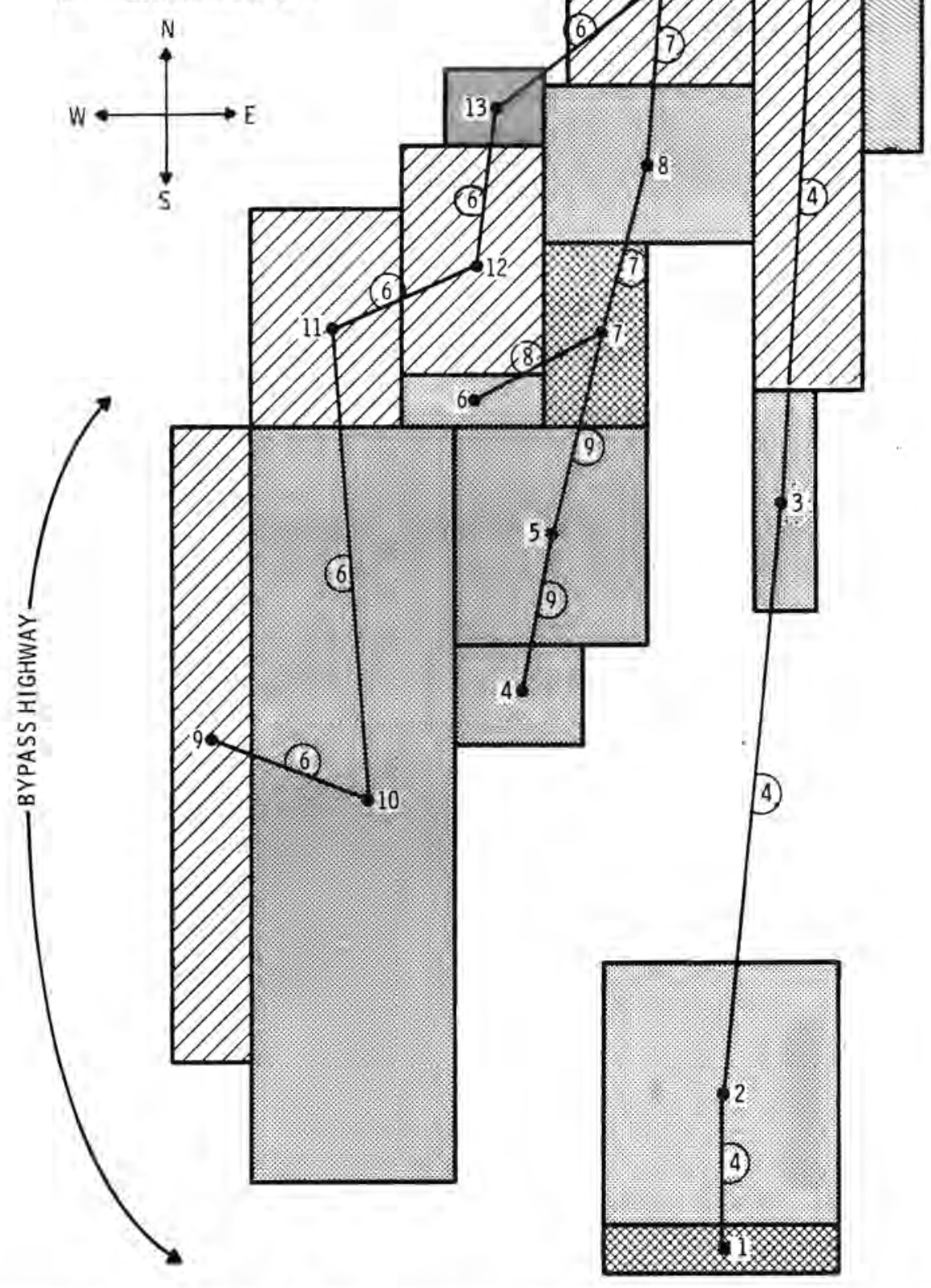

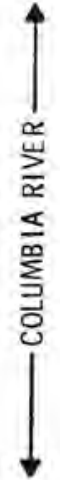

FIGURE 9. Layout of Residential Districts in Richland, Washington 
TABLE 5. Summary of District Input Data for ATES Installation at Richland, Washington

\section{District Geometric Parameters}

\begin{tabular}{|c|c|c|c|c|c|}
\hline $\begin{array}{l}\text { District } \\
\text { Number }\end{array}$ & $\begin{array}{c}\text { District } \\
\text { Type } \\
\end{array}$ & $\begin{array}{l}\text { Area } \\
\text { (sq mi) }\end{array}$ & $\begin{array}{l}\text { Width } \\
(\mathrm{mi}) \\
\end{array}$ & $\begin{array}{c}\text { Length } \\
(\mathrm{mi})\end{array}$ & $\begin{array}{l}\text { Main Length Serving } \\
\text { the District (mi) }\end{array}$ \\
\hline 1 & 4 & .078 & .12 & .62 & .41 \\
\hline 2 & 3 & .29 & .62 & .70 & $\begin{array}{r}.41 \\
1.59\end{array}$ \\
\hline 3 & 3 & .08 & .18 & .60 & 1.48 \\
\hline 4 & 3 & .06 & .27 & 32 & .43 \\
\hline 5 & 3 & .20 & .51 & .58 & .56 \\
\hline 6 & 3 & .04 & .15 & .40 & .38 \\
\hline 7 & 4 & .146 & .27 & .48 & .45 \\
\hline 8 & 3 & .15 & .42 & .53 & .50 \\
\hline 9 & 2 & .26 & .23 & 1.69 & .42 \\
\hline 10 & 3 & .68 & .53 & 2.02 & 1.27 \\
\hline 11 & 2 & .14 & .40 & .58 & .43 \\
\hline 12 & 2 & .16 & .39 & .61 & .43 \\
\hline 13 & 5 & .023 & .21 & .26 & .56 \\
\hline 14 & 2 & .14 & .48 & .57 & .40 \\
\hline 15 & 2 & .45 & .28 & 2.35 & .40 \\
\hline 16 & 5 & .034 & .24 & .30 & .21 \\
\hline 17 & 4 & .049 & .09 & .42 & .51 \\
\hline 18 & 1 & .19 & .16 & 1.71 & .87 \\
\hline
\end{tabular}

\section{District Type Parameters}

\begin{tabular}{|c|c|c|c|c|c|c|}
\hline District Type & $\begin{array}{l}\text { Density } \\
\text { (Bldg/ } \\
\text { sq mi) } \\
\end{array}$ & $\begin{array}{c}\text { Peak Heat } \\
\text { Demand/B /dg } \\
\text { (MBtu/hr) } \\
\end{array}$ & $\begin{array}{l}\text { Hot Water } \\
\text { Demand } \\
\text { (gal/day) }\end{array}$ & $\begin{array}{c}\text { Diversity } \\
\text { Factor }\end{array}$ & $\begin{array}{l}\text { Reject } \\
\text { Temp } \\
(\mathrm{F}) \\
\end{array}$ & $\begin{array}{l}\text { Retrofit } \\
\text { Cost ( } \$ 1 \\
\text { (B1dg) } \\
\end{array}$ \\
\hline $\begin{array}{l}1 \text { Single-family } \\
\text { low-density }\end{array}$ & 1568 & .053 & 60. & 0.72 & 100 & 1000 \\
\hline $\begin{array}{l}2 \text { Single-family } \\
\text { medium density }\end{array}$ & 2093 & .044 & 60. & 0.72 & 100 & 1000 \\
\hline $\begin{array}{c}3 \text { Single-family } \\
\text { high-density }\end{array}$ & 3837 & .034 & 60. & 0.72 & 100 & 1000 \\
\hline $\begin{array}{l}4 \text { Multiple- } \\
\text { family apts. }\end{array}$ & 376 & .48 & 1260. & 0.72 & 100 & 21000 \\
\hline 5 Tralier courts & S 7898 & .034 & 60. & 0.72 & 100 & 1000 \\
\hline
\end{tabular}


establishes the peak-load heating requirements and thus determines the size and cost of the pipes. Lower extreme temperatures require more flow and larger pipes. Larger pipes increase the capital cost of the system. For economic reasons, district heating systems are usually designed to meet less than the peak demand. The peak heating requirements are then met with supplemental heat. The minimum temperature used to design the Richland system was the default value of $-5^{\circ} \mathrm{F}$ [TDES(1) $=-5^{\circ} \mathrm{F}$, as described in Section 3.4.2].

The number of heating degree-days establishes the annual energy usage for residential space heating. Richland has a total of 5,267 heating degree-days. The ATES district heating system was designed to supply 92 percent of the annual residential space heating demand (i.e., $\operatorname{DDGDAY}(1)=5,109^{\circ} \mathrm{F}$-days, which is $92 \%$ of $\operatorname{ADGDAY}(1)=5,267^{\circ} \mathrm{F}$-days in Table 6 ), with supplemental heat providing the remaining annual space heating demand ( 8 percent).

The housing densities used in the simulation are based on the city of Richland's zoning ordinances. The peak heat demands for space heating and sanitary hot water heating are based on ASHRAE design recommendations (Appendix C) and the minimum outdoor design temperature of $-5^{\circ} \mathrm{F}$. The simulation consisted of 8,460 single-family dwellings, 103 apartment buildings containing a total of 2,155 apartment units, and 450 mobile homes. This represents a total population of about 29,435 , assuming 2.66 people per house according to the 1970 census.

The cost of the ATES district heating system must also include the capital costs of building retrofit. We have assumed a retrofit cost of $\$ 1,000$ per dwelling unit in the Richland simulation. Retrofit costs should be only about $\$ 500$ for houses that already have hot-water or forced-air heating systems. For houses that require major modifications of existing heating systems, retrofit costs could be as high as $\$ 2,000$ per house or more. Thus, the assumption of $\$ 1,000$ per house is considered reasonable. In a more detailed analysis, a comprehensive survey of existing heating systems could be undertaken to determine retrofit costs more accurately.

The network of buried, branching mains used to transport the hot water from the heat exchanger at the boundary of the city to the 18 districts is shown in Figure 9. The layout of the mains is a somewhat arbitrary choice. As 
TABLE 6. Distribution System Input Parameters for City of Richland in NAMELIST Group \$DISTRB

\begin{tabular}{|c|c|c|c|}
\hline Parameter & Section & Description & Value \\
\hline $\operatorname{ADGDAY}(1)$ & 3.4 .2 & $\begin{array}{l}\text { Annual heating degree-days based } \\
\text { on weather data at simulated site }\end{array}$ & $5267^{\circ} \mathrm{F}$-days \\
\hline $\operatorname{DDGDAY}(1)$ & 3.4 .2 & $\begin{array}{l}\text { Design heating degree-days used to } \\
\text { size ATES supply and distribution } \\
\text { systems }\end{array}$ & $5109^{\circ} \mathrm{F}$-days \\
\hline HTEXOP & 3.4 .4 & $\begin{array}{l}\text { Option for a heat exchanger at the } \\
\text { inlet to the distribution system }\end{array}$ & 1 (yes) \\
\hline UAPIN & 3.4 .4 & $\begin{array}{l}\text { Approach temperature to distribu- } \\
\text { tion heat exchanger at inlet of } \\
\text { aquifer water from storage wellfield }\end{array}$ & $17.5^{\circ} \mathrm{F}$ \\
\hline UAPOUT & 3.4 .4 & $\begin{array}{l}\text { Approach temperature to distribu- } \\
\text { tion heat exchanger at out let of } \\
\text { aquifer water from heat exchanger }\end{array}$ & $17.5^{\circ} \mathrm{F}$ \\
\hline NDTR & 3.4 .5 .1 & $\begin{array}{l}\text { Number of districts at simulated } \\
\text { site }\end{array}$ & 18 \\
\hline IDTYPE & 3.4 .5 .1 & $\begin{array}{l}\text { Generic type of districts at simu- } \\
\text { lated site }(1=\text { residential })\end{array}$ & 1 \\
\hline $\operatorname{IDTR}(M)$ & 3.4 .5 .1 & $\begin{array}{l}\text { District type } N \text { of district number } \\
\text { D }\end{array}$ & Table 5 \\
\hline $\operatorname{AREA}(M)$ & 3.4 .5 .1 & Area of district number $M$ & Table 5 \\
\hline WIDTH(M) & 3.4 .5 .1 & Width of district number $M$ & Table 5 \\
\hline XLNGTH(M) & 3.4 .5 .1 & Length of district number $M$ & Table 5 \\
\hline $\operatorname{DDTR}(M)$ & 3.4 .5 .1 & $\begin{array}{l}\text { Length of main serving district } \\
\text { number } M\end{array}$ & Table 5 \\
\hline$H Q(N)$ & 3.4 .5 .2 & $\begin{array}{l}\text { Peak space heat demand per build- } \\
\text { ing in district type } \mathrm{N}\end{array}$ & Table 5 \\
\hline$H W(N)$ & 3.4 .5 .2 & $\begin{array}{l}\text { Daily sanitary hot water demand } \\
\text { per building in district type } \mathrm{N}\end{array}$ & Table 5 \\
\hline $\operatorname{DENSE}(N)$ & 3.4 .5 .2 & $\begin{array}{l}\text { Density of buildings in district } \\
\text { type } N\end{array}$ & Table 5 \\
\hline $\operatorname{DIVF}(N)$ & 3.4 .5 .2 & $\begin{array}{l}\text { Diversity factor in district } \\
\text { type } N\end{array}$ & Table 5 \\
\hline
\end{tabular}


TABLE 6 (Continued)

\begin{tabular}{|c|c|c|c|}
\hline Parameter & Section & Description & Value \\
\hline $\operatorname{TREJ}(N)$ & 3.4 .5 .2 & $\begin{array}{l}\text { Temperature of return water in } \\
\text { district type } N\end{array}$ & Table 5 \\
\hline POPHSE (N) & 3.4 .5 .2 & $\begin{array}{l}\text { Number of people per building in } \\
\text { district type } N \text { (used only for } \\
\text { printout purposes) }\end{array}$ & Table 5 \\
\hline $\operatorname{CRTF}(N)$ & 3.4 .5 .2 & $\begin{array}{l}\text { Retrofit cost per building in dis- } \\
\text { trict type } N\end{array}$ & Table 5 \\
\hline DNET & 3.4 .8 & Branching main matrix & Table 6 \\
\hline PO & 3.4 .6 & Pipe option (see Section 3.4.6) & 1 \\
\hline TA & 3.4 .6 & Casing annular air space & 0 meters \\
\hline VMBTU & 3.4 .6 & $\begin{array}{l}\text { Value of } 1 \text { MBtus of heat (used } \\
\text { in optimization of insulation } \\
\text { thickness) }\end{array}$ & $\$ 3 / \mathrm{MBtu}$ \\
\hline $\begin{array}{l}\operatorname{AGFACT}(\mathrm{I}) \\
I=1,3\end{array}$ & 3.4 .6 & $\begin{array}{l}\text { Age factor to multiply friction } \\
\text { losses in pipes due to age. }\end{array}$ & $1 ., 1 ., 1$ \\
\hline DINPUT( 39$)$ & 3.5 .3 & $\begin{array}{l}\text { Fraction of investment in bonds } \\
\text { by owner of distribution system }\end{array}$ & 1.0 \\
\hline DINPUT (40) & 3.5 .3 & Bond interest rate (fraction) & 0.10 \\
\hline DINPUT (41) & 3.5 .3 & $\begin{array}{l}\text { Earned rate on equity after } \\
\text { taxes (fraction) }\end{array}$ & 0 \\
\hline DINPUT (42) & 3.5 .3 & Federal income tax rate (fraction) & 0. \\
\hline DINPUT (50) & 3.5 .3 & State income tax rate (fraction) & 0. \\
\hline DINPUT ( 52$)$ & 3.5 .3 & Property tax rate (fraction) & 0 \\
\hline LL2 2 & 3.5 .5 .1 & $\begin{array}{l}\text { Depreciation option } \\
(1=\text { straight line })\end{array}$ & 1 \\
\hline CSBTU & 3.5 .5 .3 & Cost of supplemental heat & $\$ 6 / \mathrm{MBtu}$ \\
\hline COPUMP & 3.5 .5 .3 & Electrical pumping cost & $\$ .02 / \mathrm{kWh}$ \\
\hline
\end{tabular}


shown in Figure 9, we used a total of 9 mains in the simulation. The layout of the mains serving the districts was determined from the city of Richland zoning map. The matrix DNET (district number, main number) input to the code to define the network of branching mains serving the 18 districts is shown in Table 7.

The code lays out lateral pipes, street pipes, and street-to-house pipes inside each district as shown in Figure 2 of Section 2.1 and Figure 7 of Section 2.7. The distribution piping system inside the city of Richland was designed as a two-pipe system in which the used water from individual residences is returned to the heat exchanger at the boundary of the city through the return piping. The design features of the distribution piping system used in the Richland simulation are:

1) A two-pipe system, only supply pipes insulated, with supply and return pipes in a common casing, using schedule 40 carbon steel pipe (default system)

2) Calcium silicate insulation (default insulation type)

3) Prefabricated steel casing with no annular air spacing between the insulation and casing (default casing type with annular air spacing $T A=$ 0)

4) Casing buried 0.5 meters deep in a dirt and rock mixture (default trenching conditions described in Section 3.5.4)

The definitions of the parameters set to override the default values for the distribution system are given in Table 6. All costs are in January, 1980 dollars. The description of all parameters for the distribution system and their default values are given in Sections 3.4, 3.5, and 3.6.

The output corresponding to the sample case input is listed in Appendix G and described in Section 4.0. The output shows the input data, printer plots of key capital cost equations for the distribution system, the final technoeconomic iteration between the ATES supply and distribution systems, ful1 economic output (cash flows) for the supply and distribution systems, and the technical and financial summaries of the simulation results for the ATES installation at the city of Richland. 
TABLE 7. Branching Main Matrix DNET for ATES Installation at Rich land, Washington

Matrix DNET (District Number, Main Number) Defining the Districts Served by the Mains

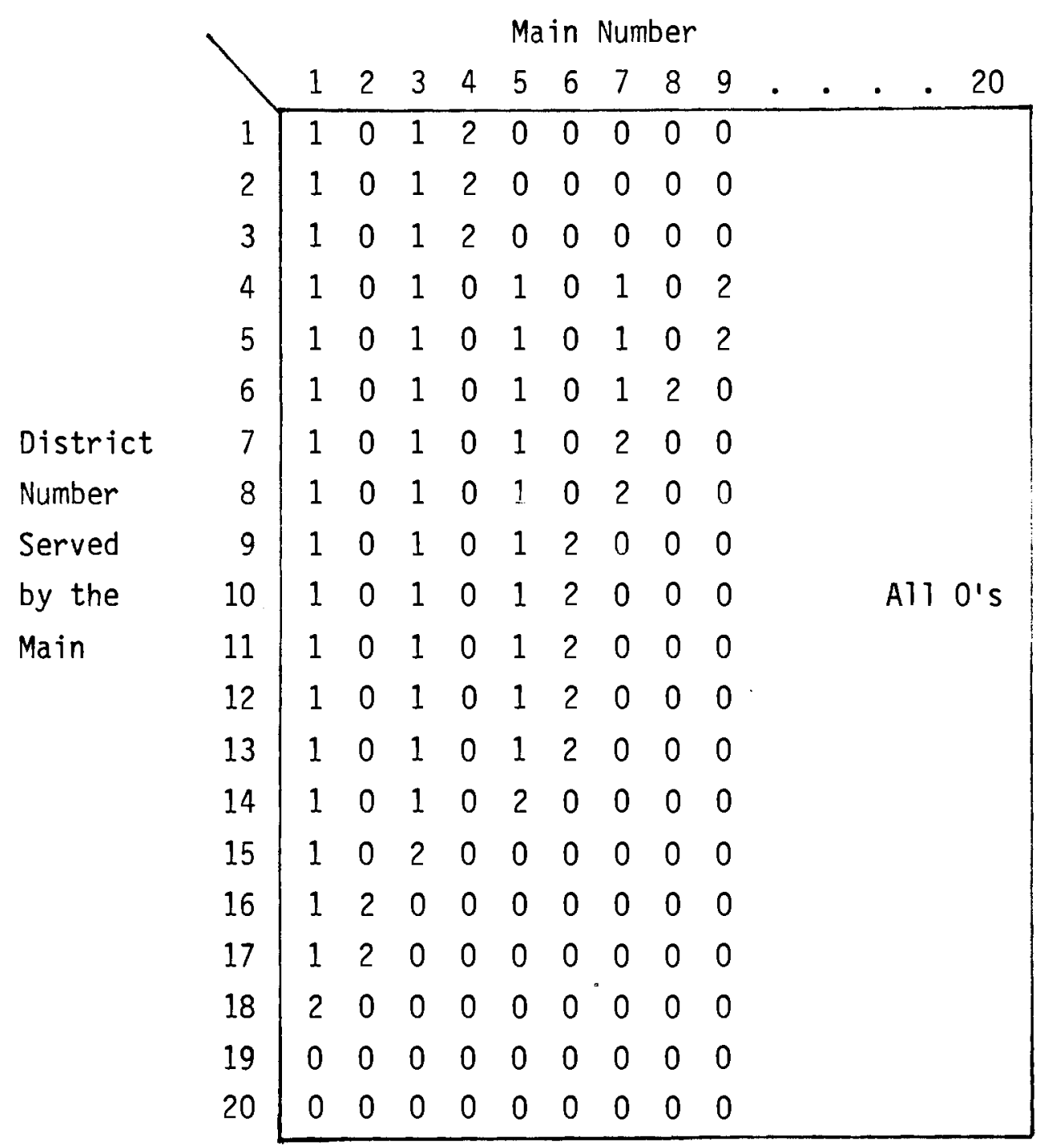

\section{Definition of Matrix Entries DNET (District M, Main MM)}

0 - Main MM does not transport flow to district $M$ in any way.

1 - Main MM transports flow to district $M$ but does not connect directly to district $M$.

2 - Main MM connects directly to district M. 


\subsection{SUPPLY SYSTEM INPUT DATA}

This section describes the technical input parameters used by AQUASTOR to design and size the supply system of an ATES installation linked to a distribution system. The supply system extracts thermal energy from an external energy source in the form of heated (chilled) water and then stores this energy in an aquifer. The water is later pumped from the aquifer for transmission to the distribution system for district or process heating or cooling.

The major components comprising the supply system in AQUASTOR are an external energy source, the heat exchanger at the energy source, the storage and supply wellfields drilled into the aquifer, and the transmission piping and pumping network. The technical parameters used in defining the various components of the ATES supply system are described in the following subsections:

\begin{tabular}{cll} 
Subsection & & Components of ATES Supply System \\
\cline { 1 - 1 } 3.3 .1 & & Supply Energy Source \\
3.3 .2 & & Supply Heat Exchanger \\
3.3 .3 & & Wellfields and Aquifer \\
3.3 .4 & & Supply Transmission Piping and Pumps
\end{tabular}

The default values initialized for the input parameters are also defined in each subsection. New values for the parameters in this section overriding the default values can be input through the NAMELIST group \$RESVOR.

\subsubsection{Supply Energy Source}

AQUASTOR assumes that thermal energy (in the form of hot or chilled water) is available for purchase from an external energy source for heating or cooling applications using an ATES system. The thermal energy is transferred through a liquid-to-liquid heat exchanger to circulating water from a set of supply wells drilled into an aquifer. The heated (chilled) water from the heat exchanger is then transmitted to a set of storage wells drilled into the same aquifer for seasonal storage.

AQUASTOR models only the storage of energy from a seasonal energy source and assumes that all of the energy is stored in the aquifer before delivery to the end user. The code further assumes that the water from the energy source enters the heat exchanger at a constant flow rate and temperature when the 
energy source is in operation. In actual practice an ATES system should be able to handle small transients, but a surge tank system should be employed for variable sources. Systems with continuous or near-continuous energy sources will be able to supply some energy directly and so only a portion of their energy would need to be stored underground. Energy costs for such systems would be less than those estimated by AQUASTOR since these systems would require less pumping energy, smaller pipe sizes and fewer wells, and have lower thermal energy losses within the aquifer. Therefore, the estimates obtained from AQUASTOR for seasonal energy sources can be considered a ceiling for the cost of continuous or near-continuous energy sources linked to an ATES system.

The seasonal energy source is characterized by seven input parameters defining the cost of purchased thermal energy, the flow rates, and the temperatures at the energy source. The seven parameters and their default values in the code are defined below followed by a discussion of their interdependency and usage in the code. The parameters are input through the NAMELIST group \$RESVOR.

SHCOST Cost of purchased thermal energy from the energy source, \$/MBtu. The default is 0 .

SMFLOW Peak hourly water flow rate from the energy source, $1 \mathrm{~b} / \mathrm{hr}$. The default is $500,000 \mathrm{lb} / \mathrm{hr}$.

SDFLOW Daily water flow rate from the energy source, 1b/day. The default is $12,000,000.1 \mathrm{~b} /$ day, which represents an energy source operating at full capacity 24 hours per day at the default value above for the peak hourly flow rate.

SAFLOW Annual water flow rate from the energy source, 1b/yr. The default is $2,191,500,0001 \mathrm{~b} / \mathrm{yr}$, which represents an energy source operating at full capacity for half of the year at the default value above for the daily flow rate. The code assumes 365.25 days per year over long project lifetimes to take into account leap years.

SMXFLW Upper bound on the peak hourly water flow rate from the energy source, $1 \mathrm{~b} / \mathrm{hr}$. This parameter allows the code to increase the 
input value for the peak hourly flow rate (SMFLOW), if necessary, to try to match up the annual fluid supply with annual fluid demand. The default is 1.E99, which is simply used to represent an unlimited fluid (energy) supply from the energy source.

TSRIN Inlet temperature entering the heat exchanger from the energy source, ${ }^{\circ} \mathrm{F}$. The default is $200^{\circ} \mathrm{F}$.

TSROUT Outlet temperature exiting the heat exchanger back to the energy source, ${ }^{\circ} \mathrm{F}$. The default is $80^{\circ} \mathrm{F}$.

The following steps are suggested for determining the input flow rates to the code:

Step 1. Determine an input value for the peak hourly flow rate (SMFLOW) from the energy source in $\mathrm{lb} / \mathrm{hr}$ which represents the actual peak or a reasonable estimate of it. The code automatically adjusts this flow rate up or down to try to match annual fluid supply with demand. The extent to which this flow rate can be adjusted upward is controlled by the input parameter SMXFLW, which represents an upper bound on the peak hourly flow rate available from the energy source. The equations used by the code to calculate the annual fluid supply and demand are described in Section 2.5. The calculations for the annual energy (fluid) supply allow for thermal losses in the transmission piping and storage aquifer and fluid losses in the storage aquifer. The calculations for the annual energy (fluid) demand allow for thermal losses and fluid losses in the transmission piping from the storage aquifer to the distribution system and in the distribution system piping.

Step 2. Based upon the daily availability of the energy source (hrs/day), determine the daily flow rate (SDFLOW) in lbs/day as follows: SDFLOW = Daily Source Availability (hrs/day) * SMFLOW (1bs/hr)

Step 3. Based upon the annual availability of the energy source (days/yr), determine the annual flow rate (SAFLOW) in lbs/yr as follows: 
SAFLOW = Annual Source Availability (days/yr) * SDFLOW (lbs/day)

Step 4. Determine an upper bound (SMXFLW) in $1 \mathrm{~b} / \mathrm{hr}$ for the peak hourly flow rate (SMFLOW). The code will increase the input value for SMFLOW (up to SMXFLW) as necessary to match up annual fluid supply with demand. If SMFLOW is already at its upper bound, set SMXFLW equal to SMFLOW, in which case the code will not increase SMFLOW. Otherwise, set SMXFLW to the upper bound. For applications where the heat (chill) energy supply is relatively limited, the parameter SMXFLW is usually set to some upper bound. For applications where the heat (chill) energy supply is relatively unlimited (compared to the prospective demand), the parameter SMXFLW is frequently set to a large number such as 1.E99 to represent an unlimited fluid (energy) supply from the energy source.

The user should be careful to note that the daily and annual source availabilities and load factors are actually fixed in the code by these input flow rates as follows:

1) Daily Source Availability (hrs/day) $=\frac{\text { SDFLOW }}{\text { SMFLOW }}$ and Daily Source Load Factor $=\frac{\text { SDFLOW }}{\text { SMFLOW } \star 24}$

2) Annual Source Availability (days/yr) $=\frac{\text { SAFLOW }}{\text { SDFLOW }}$ and

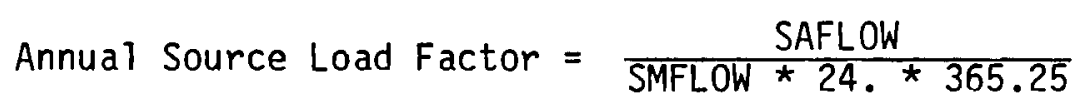

In adjusting the peak hourly flow rate (SMFLOW), the code also adjusts the daily flow rate (SDFLOW) and annual flow rate (SAFLOW) using Equations 1 and 2 above to hold the daily and annual source availabilities and load factors fixed.

If the annual fluid supply exceeds the annual fluid demand, the code automatically reduces the input value for the peak hourly flow rate (SMFLOW) to match up annual fluid supply with demand. In this case, the supply system is designed based upon the fluid demand. This applies to both heating and cooling applications. 
If the annual fluid supply is less than the demand and cannot be sufficiently increased due to the upper bound on the peak hourly flow rate (SMXFLW), the code designs the supply system based upon the fluid supply using the upper bound SMXFLW for the peak hourly flow rate. For heating applications, the annual shortfall in the fluid (energy) supply is met by supplemental heat in the distribution system. However, for cooling applications, supplemental cooling is not provided to meet a fluid (energy) supply shortfall. This reflects the assumption that chill sources provided by winter weather, such as river water or water cooled by winter air will usually be limited only by the size of the chill gathering equipment. On the other hand, energy sources such as cogeneration or industrial waste heat are more likely to be available at a fixed supply level. A second condition requiring supplemental heat in heating applications arises from undersizing the distribution system to meet less than the peak energy demand for economic considerations. This condition is described in Section 3.5.5.3.

A fluid (energy) supply shortfall could be met by reducing the size of the annual fluid (energy) demand, e.g., reduce the number of residential districts in a city served by an ATES system. In this approach, the user would likely eliminate the less dense districts that have higher capital costs per MBtu of delivered heat (chill). This approach is currently not automated in the code. The code does print out the final ratio of annual fluid supply to demand. Thus, the user can examine the simulation run, manually remove some districts from the input data, and rerun the code to obtain a better matchup between fluid (energy) supply and demand.

\subsubsection{Supply Heat Exchanger}

AQUASTOR assumes that thermal energy is available in a liquid medium (water) from an external energy source and is transferred through a liquid-toliquid heat exchanger to circulating water from the supply wellfield. As previously illustrated in Figure 2, the heated (chilled) water from the supply wellfield is transmitted to the storage wellfield for seasonal storage in the aquifer. The heat exchanger is modeled as a counterflow, single-pass, she11and-tube unit constructed of carbon steel with an equilateral triangular tube configuration. The water from the energy source is pumped through the tube 
side and the circulating water from the supply wellfield is pumped through the she 11 side of the heat exchanger. The extraction of thermal energy from a gaseous medium, such as steam, air, or industrial waste gases is not an option of AQUASTOR.

The nomenclature used in defining the temperature distribution in the supply heat exchanger is illustrated in Figure 10. The temperature difference between the energy source water entering the heat exchanger and the circulating water from the supply wellfield exiting the heat exchanger is defined as the approach (APPHX) to the heat exchanger.

Referring to the nomenclature in Figure 10, the temperature rise (drop) of the supply wellfield water in the heat exchanger is calculated by the code in the heating (cooling) mode as follows:

Heating: Aquifer Water Temperature Rise $\left({ }^{\circ} \mathrm{F}\right)=($ TSRIN - APPHX) - TSUPAQ Cooling: Aquifer Water Temperature Drop $\left({ }^{\circ} \mathrm{F}\right)=$ TSUPAQ $-($ TSRIN + APPHX) Three of the above four parameters are input into the code. This includes the energy source water temperature (TSRIN) entering the heat exchanger, the energy source water temperature (TSROUT) exiting the heat exchanger, and the heat exchanger approach temperature (APPHX). The fourth parameter TSUPAQ, which represents the temperature of the circulating water entering the heat exchanger from the supply wellfield, is calculated by the code in an iterative fashion.

The input parameters TSRIN and TSROUT were previously described for the energy source in Section 3.3.1. The approach APPHX is defined as a positive temperature $\left({ }^{\circ} \mathrm{F}\right)$ throught the NAMELIST group $\$ R E S V O R$. Its default value is $5^{\circ} \mathrm{F}$. Several other input parameters are used by the code in designing the supply heat exchanger that are common to both the supply heat exchanger and the optional distribution heat exchanger. These parameters, which are input through the NAMELIST group \$DISTRB, are defined in Section 3.4 .4 for the distribution heat exchanger and are summarized below:

DIAL and Inner and outer tube diameters (ft) of the heat exchanger. The DIAOL default values are DIAL $=0.1 \mathrm{ft}$ and DIAOL $=0.1104 \mathrm{ft}$.

FOULFI and Inside and outside fouling factors for the heat exchanger. The FOULF0 default values for FOULFI and FOULFO are $0.001 \mathrm{hr}-\mathrm{ft}{ }^{2}-{ }^{\circ} \mathrm{F} / \mathrm{Btu}$. 

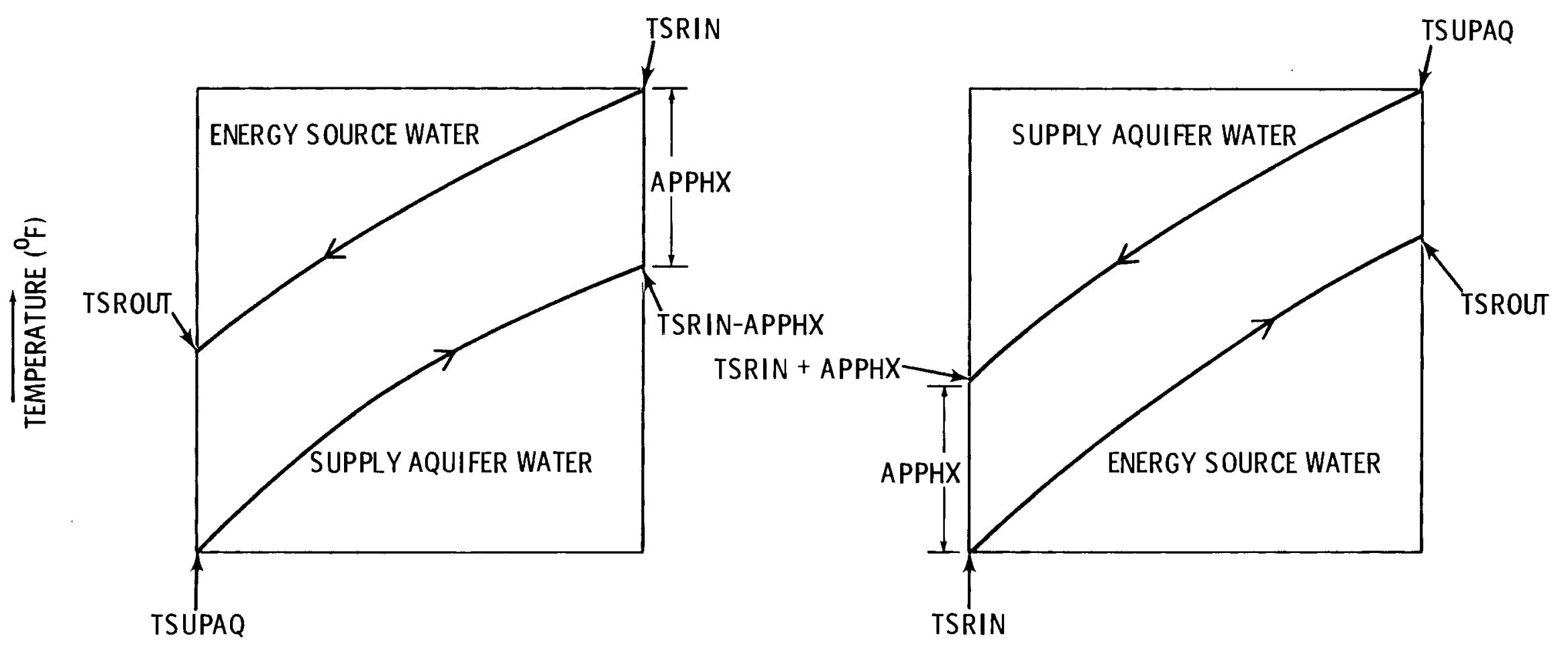

TEMPERATURE NOMENCLATURES

TSRIN = Entering temperature $\left({ }^{0} \mathrm{~F}\right)$ from energy source

APPHX $=$ Approach $\left({ }^{O} \mathrm{~F}\right)$ to heat exchanger

TSRIN-APPHX = Heated temperature $\left({ }^{{ }_{F}}\right)$ to storage wellfield

TSRIN+APPHX = Chilled temperature $\left({ }^{O} \mathrm{~F}\right)$ to storage wellfield

TSUPAQ = Temperature $\left({ }^{O} \mathrm{~F}\right.$ ) from supply wellfield (calculated by code)

TSROUT = Exiting temperature $\left({ }^{\circ} \mathrm{F}\right)$ to energy source

FIGURE 10. Nomenclature for the Temperature Distribution in the Supply Heat Exchanger at the Energy Source 
WVELL Velocity $(\mathrm{ft} / \mathrm{hr}$ ) of the water in the heat exchanger tubes. The default is $28,800 \mathrm{ft} / \mathrm{hr}$ (i.e., $8 \mathrm{ft} / \mathrm{sec}$ ).

\subsubsection{Wellfield and Aquifer Description}

This section describes the input parameters used to define the wellfield and aquifer characteristics in an ATES installation. This description is preceeded by first reviewing the layout and operation of the wellfield and aquifer. In general, AQUASTOR assumes that a set of supply and storage wells are drilled into an aquifer. The two sets of wells are horizontally separated to ensure that the storage bubble is unaffected by operations at the supply wells. The layout of the wells was previously illustrated in Figure 2 of Section 2.1 and Figure 6 of Section 2.6.2.

During operation, water is withdrawn from the supply wells, heated (chilled) in a heat exchanger, and then returned to the same aquifer through the storage wells. At recovery, the storage wells are pumped and the heated (chilled) water is circulated through a heat exchanger to recapture the stored energy and then returned to the same aquifer through the supply wells to complete the cycle.

The characteristics of the wells are basically defined by eight input parameters: average well life, the flow capacities of the well during withdrawal and injection, the number of excess wells desired, well spacing, and well depth. The other input parameters are the fraction of well cased and the type of rock hardness in which the well is drilled. These two parameters are used by the code only if. the well drilling model discussed in Section 3.5.2 is employed.

Since all ATES wells serve as both injection and withdrawal wells, the total number of wells required is determined by the peak system flow, either into or out of the aquifer. The number of wells required is determined in the code by the maximum of these two rates, the flow capacities of the well during injection and withdrawal, and the fraction of excess wells desired.

Well spacing is dependent upon the quality of the aquifer. The distance between wells in meters is calculated from the input well spacing in acres as previously described in Section 2.6.2. Well flow rate and depth are used by the code to size the capacity of the downhole pumps and calculate their 
required pumping energy. Well diameter, well depth, fraction of well cased, and the type of rock hardness in which the well is drilled, are all used by the well drilling model discussed in Section 3.5.2 if it is employed to calculate the well drilling cost.

AQUASTOR does not have a geohydrologic model to simulate fluid and thermal flow within the aquifer. Instead, the salient aquifer characteristics are represented by three input parameters: aquifer fluid recovery fraction, aquifer thermal storage efficiency, and discovery (natural) aquifer temperature. These three parameters were defined and their relationship discussed previously in Section 2.6.3.

The input parameters used to define the wellfield and aquifer characteristics are defined below. The parameters are input through the NAMELIST group \$RESVOR.

AVGWL Average well life (years). The default is 30 years.

CASFRC Fraction of each well cased. The default is 1.

DIA Average diameter (centimeters if positive, inches if negative) of each we 11. The default is 22.225 centimeters ( 8.75 inches).

FLORAT Withdrawal flow rate capacity $(1 \mathrm{~b} / \mathrm{hr})$ of each well. The default is $500,000 \mathrm{lb} / \mathrm{hr}$.

FRCEPW Fraction excess wells to provide spare wells. The default is 0. PRDRAT Ratio of injection-to-withdrawal flow rate capacity of each we11. The default is 1 .

WELSPC Aquifer well spacing (acres). The default is 1 acre.

NUMTYP Number of different generic types of rock hardness comprising the strata encountered in drilling the entire depth of each well. The parameter NUMTYP should be left preset to its default value of 1 , indicating one hardness for the entire depth of the well.

STRATA $(M, N)$ Stratigraphic data array defining the type of rock hardness to be $M=1,2 ;$ drilled $(M=1)$ and the depth $(M=2$, positive if meters, $N=1,10$ negative if feet) of each type of strata (N) encountered in 
drilling the well. The possible values of $\operatorname{STRATA}(1, N)$ are:

$1=$ soi $1,2=$ soft, $3=$ medium, $4=$ hard, and $5=$ very hard. The default values are as follows:

$\operatorname{STRATA}(1,1)=3$, indicating that the rock type to drill is medium for the entire depth of the well.

$\operatorname{STRATA}(2,1)=300$, total well depth in meters.

SPAQEF Aquifer thermal storage efficiency (fraction) of the supply wellfield. The default is 0.80 .

STAQEF Aquifer thermal storage efficiency (fraction) of the storage wellfield. The default is 0.80 .

STFREC Aquifer fluid recovery fraction for the storage wellfield. The default is 0.90 .

TAQIF Discovery (natural) aquifer temperature $\left({ }^{\circ} F\right.$ ) of both the supply and storage wellfields. The default is $55^{\circ} \mathrm{F}$.

\subsubsection{Supply Transmission Piping and Pumps}

The description of the input parameters in this section is preceeded by first reviewing the transmission piping and pumping network used for the supply system in the code. The layout of the piping and pumping network for the supply system was previously illustrated in Figure 2 of Section 2.1. Recall from Section 2.6.2 that the transmission piping network consists of a connected series of above-ground pipes optimally sized on peak flow rates that circulate water among the four components of the ATES system: the supply wellfield, energy source, storage wellfield, and distribution system. During periods of seasonal heat (chill) storage, the water from the matrix of supply wells is transported to the heat exchanger at the energy source to be heated (cooled) and then transported to a matrix of storage wells for storage. During periods of seasonal heat (chili) usage, the heated (chilled) water is transported from the storage wells to the distribution system or its optional heat exchanger and then back to the supply wells to complete the cycle.

The pumping network consists of both downhole and surface pumps. The default operation of the code assumes that downhole pumps are located at the bottom of the supply and storage wells. Pumping energy is conservatively based 
on a head equal to the full depth of the we11s, neglecting both the natural static head and wel1 drawdown. The downhole pumps provide the vertical lift and restore the frictional pressure drop in the wells and in the surface piping connecting the matrix of wells. Water pressure is maintained above the saturation pressure at all times (i.e., in a compressed liquid state).

The surface pumps are located at the tube and shell-side inlets to the heat exchangers and along the four transmission legs to restore frictional pressure drop and maintain the water in a compressed liquid state. The code calculates the number of surface pumps along the transmission legs based on avoiding unnecessarily high pressures requiring large pipe schedules, subject to the constraint that the pumps be located at least one mile apart. The pipe schedules are calculated by the code as a function of the discharge water pressures as described in Appendix 0 . The discharge pressures from the downhole pumps and surface pumps are initially estimated by the code and then minimized during the iterations between the supply and distribution systems. At al1 times the water pressure is maintained above one atmosphere of pressure (15 psia).

The first set of input parameters in this section allow the user to define the lengths of the four transmission legs and the lengths of the piping manifold nodes from the well nodes as illustrated in Figure 6 of section 2.6.2. The piping layout between the well nodes is based on the well spacing which is dependent on the quality of the aquifer. The well spacing, which is input by the user, was previously defined in Section 3.3.3.

The default operation of the code optimizes the pipe diameters and insulation thickness to a lowest cost based upon the mix of capital costs, thermal losses, and required pumping energy. The insulation is covered by an aluminum casing for protection. However, to provide maximum flexibility, a set of input parameters is defined below to allow the user to override the default operation and directly input the insulation thickness or even entirely delete the insulation and casing.

Thermal losses and pressure drops are calculated for each section of pipe in the entire transmission piping network. Two parameters included in this section define the average ambient air temperatures during the heating and cooling seasons for use by the code in calculating the thermal losses from the surface 
transmission piping to the surrounding air. Another parameter AGFACT(I), I = 1 to 3, defined in Section 3.4.6 for the distribution piping system, also affects the pressure drop calculations for the transmission system. This parameter increases the pressure drop calculated for new pipe to take into account the increase in relative roughness and the deterioration of pipes with age.

Two parameters are used to define the pumps. The first parameter allows the user the flexibility of using surface pumps at the aquifer wellheads and piping manifold nodes in place of downhole pumps in the unlikely event that the natural artesian pressure of the aquifers is sufficient to produce the desired pressure and flow rate at the wellhead. The second parameter defines the service life of the downhole pumps and has economic implications in the code. If the lifetime is less than one year, the pump replacement is treated as an expensed item. If the lifetime is one year or more, the pump replacement is treated as an interim capital replacement. This parameter does not apply to the replacement of the surface pumps. Their replacement is lumped as part of the interim capital replacement rate for the transmission system that is defined in Section 3.5.1. Another parameter (ETA) defines the combined motor and pump efficiency for both the transmission and distribution pumps, and is discussed in Section 3.5.5.3.

The parameters defined below are input through the NAMELIST group \$RESVOR. PLNGTH(1) Length (meters) of transmission leg 1 from the heat exchanger at the energy source to the storage wellfield. The default is 2500 meters.

PLNGTH(2) Length (meters) of transmission leg 2 from the storage wellfield to the inlet of the distribution system or its optional heat exchanger. The default is 2500 meters.

PLNGTH(3) Length (meters) of transmission leg 3 from the distribution system or its optional heat exchanger to the supply wellfield. The default is 2500 meters.

PLNGTH(4) Length (meters) of transmission leg 4 from the supply wellfield to the heat exchanger at the energy source. The default is 2500 meters. 
Distance (meters) from the manifold pipe nodes $(J=1)$ to the first column of well nodes ( $J=2$ in Figure 15) in the matrix of supply and storage wells. The default value is 0 , in which case subroutine TRANS sets this distance identical to the distance between we 11 nodes. To override the default value, set PLMANF to the desired distance in meters in the input data.

TRINSL Option to directly input or allow the code to calculate the insulation thickness on all transmission system piping.

-1. (default value). AQUASTOR calculates the insulation thickness in subroutine INSUL, beginning with $1 / 2$ inch increments of calcium silicate up to a maximum of 2 inches. Above 2 inches, polyurethane insulation is used in $1 / 2$ inch increments until the calculated insulation thickness is reached.

$\geq 0$. (only multiples of $1 / 2$ inches of calcium silicate allowed, e.g., 0., 0.5, 1., 1.5, 2.0, up to a maximum of 2 inches). User directly inputs the insulation thickness as a multiple of $1 / 2$ inch thick layers of calcium silicate, up to a maximum of 2 inches. No polyurethane insulation is used with this option.

TRCASE

Option to delete the casing or allow the code to use 0.016 inch aluminum jacket casing to cover all transmission system insulation.

-1. (default value). AQUASTOR covers all transmission system insulation with aluminum jacket casing and calculates the cost of the casing in subroutine INSUL.

0 . No casing is used to cover the transmission system insulation and the casing costs are set to zero in subroutine INSUL.

$\operatorname{TENVR}(1) \quad$ Average ambient air temperature $\left({ }^{\circ} \mathrm{F}\right)$ during thermal energy storage in the heating mode and during thermal energy delivery in the cooling mode. The default is $70^{\circ} \mathrm{F}$. 
TENVR(2) Average ambient air temperature $\left({ }^{\circ} F\right)$ during thermal energy delivery in the heating mode and during thermal energy storage in the cooling mode. The default is $35^{\circ} \mathrm{F}$.

IPUMP Type of transmission system pumps.

1 = one surface pump at each aquifer wellhead and at each piping manifold node together with a series of surface pumps on the four transmission legs.

$2=$ one downhole pump at the bottom of each aquifer we 11 together with a series of surface pumps on the four transmission legs. The depth of the aquifer wells is given by the parameter STRATA $(2,1)$ defined in Section 3.3.3. The default of IPUMP is 2 .

PMLIFE Service life (years) of the downhole pumps in the aquifer wells before replacement is needed. The default is 10 years.

\subsection{DISTRIBUTION SYSTEM INPUT DATA}

This section describes the technical input parameters used by AQUASTOR to design and size the distribution system. The distribution system is very flexible and can simulate many designs for district heating or district cooling systems ranging from a single point demand or a single residential district to multi-residential districts comprising an entire city. The design features include an optional heat exchanger at the inlet to the distribution system and various material and configuration options for piping, insulation, and casing.

The technical parameters for the distribution system are logically grouped into major categories that are listed below along with the subsection describing the parameters in each category. 
Subsection Category of Technical Parameters for Distribution System

3.4.1 Operational Mode

3.4.2 Climatic Parameters for Heating Mode

3.4.3 Climatic Parameters for Cooling Mode

3.4.4 Distribution Heat Exchanger

3.4.5 Districts

- 3.4.5.1 -- District Geometry

- 3.4.5.2 -- District Type Characteristics

3.4.6 Distribution System Piping Design

3.4.7 Point Demand

3.4.8 Branching Mains Network for Multi-Residential Districts

The default values initialized for the input parameters are also defined in each subsection. New values for the parameters in this section overriding the default values can be input through the NAMELIST group \$DISTRB.

\subsubsection{Operational Mode}

AQUASTOR can be operated to simulate annual heating or cooling of either residential districts or a single point demand. A residential district is defined as a contiguous area consisting of multiple buildings of uniform density and relatively similar heat demand. A point demand is defined as an entire district consisting of one point of heat or chill demand such as a single commercial building or factory instead of many individual buildings.

Five residential district types representing typical residential areas in cities of the United States and one point demand type are defined in the code.

1) Suburban

2) High-Density Single Family

3) Garden Apartments

4) Townhouse or Row Houses

5) High-Rise Apartments

6) Single Point Demand

Most residential areas in the United States can be described by these district types. Variation of the district types or additional district types (including commercial districts) can also be defined through the input data. The residential 
part of an entire city can be simulated by disaggregating it into multiple residential district types as described in Section 3.4.5. Operation of the code with one or multiple residential district types is described in Sections 3.4.5 -3.4.8. Operation with a single point demand is described in Section 3.4.7.

The operational mode for simulating heating or cooling of either residential districts or a single point demand is selected through the input parameter MODE described below.

\section{MODE $=0$ - Heating Mode}

This mode simulates residential space heating using annual heating degree days ${ }^{(8)}$ with or without sanitary hot water heating. This is the default mode of operating the code. This mode can also be used to simulate pointdemand space heating or point-demand process heating without sanitary hot water heating.

MODE $=1-$ Cooling Mode

This mode simulates residential space cooling using annual cooling degree hours ${ }^{(9)}$ without sanitary hot water heating. No sanitary hot water heating is currently possible in the cooling mode since chilled water is distributed throughout the distribution system ${ }^{(a)}$. This mode can also be used to simulate point-demand space cooling or point-demand process cooling without sanitary hot water heating.

\subsubsection{Climatic Parameters for Heating Mode}

AQUASTOR calculates the annual residential heating demands based on the annual heating degree days at the geographic site of interest. The number of degree days used to size the supply and distribution systems is usualiy set below the annual heating degree days based on temperature data. The peak heating demands are trimmed to improve the system load factor. The default value for the design heating degree days used to size the system is $92 \%$ of the

(a) Sanitary hot water heating could be provided in the cooling mode if hot water was available from the distribution system and absorption chillers were located at each building for cooling purposes. This ability could be added to the code with a few modifications. 
annual heating degree days based on temperature data. AQUASTOR provides for supplemental heating to meet the percentage of annual heating degree days not included in the design degree days.

The key climatic parameters input to AQUASTOR for defining the residential heating demand characteristics are the annual heating degree days, design heating degree days, indoor design temperature, winter outdoor design temperature, and peak heat demand of a typical building at the indoor and outdoor design temperatures in each of the different district types used to represent the simulated site. Several of these input parameters are interdependent. The annual heating degree days depend on the value selected for the indoor design temperature and are obtained from degree-day tables that are traditionally based on an indoor design (reference) temperature of $65^{\circ} \mathrm{F}$. Currently, the value of the indoor design temperature for heating is fixed in the code at its default value of $65^{\circ} \mathrm{F}$ and can not be varied.

The peak heat demand of a building is defined as the MBtu/hr of heat required to maintain the building (i.e., offset its hourly heat loss) at the indoor design temperature when the outside temperature is at the winter outdoor design temperature. Clearly, the peak heat demand required by a typical building in each simulated district type depends on the values selected for the indoor design temperature and the winter outdoor design temperature. Increasing (decreasing) the winter outdoor design temperature from its default value of $-5^{\circ} \mathrm{F}$ will cause AQUASTOR to decrease (increase) the peak heat demand of a typical building in each simulated district type.

The input parameters for calculating the heating energy requirements for residential heating and sanitary hot water heating are defined in detail below. ADGDAY(1) Annual heating degree-days based on temperature data between the indoor design temperature $\left(65^{\circ} \mathrm{F}\right)$ and the minimum ambient temperature (TMIN) for the simulated geographic site. The default value is $6500^{\circ} \mathrm{F}$-days.

DDGDAY(1) Annual design heating degree-days based on temperature data between the indoor and outdoor design temperatures for the simulated geographic site. Annual design heating degree-days are 
used to size the supply and distribution systems. The default value is $6000^{\circ} \mathrm{F}$-days or $92 \%$ of $\operatorname{ADGDAY}(1)$. The user should realize that DDGDAY(1) is dependent on both the indoor design temperature TINDES(1) and the outdoor design temperature $\operatorname{TDES}(1)$. Note that DDGDAY(1) will equal ADGDAY(1) if $\operatorname{TDES}(1)$ equals TMIN. In the normal sequence of defining the input parameters, the user would first select TDES(1) and then determine the corresponding value of $\operatorname{DDGDAY}(1)$.

Two methods for estimating the value of $\operatorname{DDGDAY}(1)$, given $\operatorname{TDES}(1)$ and TINDES(1), are discussed here. ADGDAY(1) for a geographic site is calculated by summing the difference between TINDES(1) and the mean daily temperature, summing over all days of the year when this difference is positive. The mean daily temperature is simply the average of the maximum and minimum daily temperatures. A value for DDGDAY(1) can be estimated by limiting the value for any minimum daily temperature to values $\geq \operatorname{TDES}(1)$ when employing the method described above.

A second method for estimating $\operatorname{DDGDAY}(1)$ is based on the relation between heating degree-days and heating degree-hours. Heating degree-hours are calculated in a manner similar to that for heating degree-days, except the difference is between TINDES(1) and the mean hourly temperature and the sum is over all the hours when the difference is positive. The advantage of using heating degree-hours is the availability of this type of data from the U.S. Department of Commerce. The disadvantage is that heating degree-hours divided by 24 does not equal heating degree-days. The two parameters do not directly correspond because it is possible for heating degree-hours to occur during a day for which there are no heating degree-days. This problem can be mediated by adjusting the number of heating degree-hours at TDES(1) by the ratio of annual heating degree-days to annual heating degreehours. The equation describing this relation is given below. 


$$
\operatorname{DDGDAY}(1) \cong \operatorname{DDGHRS}(1) * \frac{\operatorname{ADGDAY}(1)}{\operatorname{ADGHRS}(1)}
$$

Supplemental heating is represented by the difference between $\operatorname{ADGDAY}(1)$ and DDGDAY(1).

The annual supplemental heating requirements (MBtu/yr), used in calculating the annual cost of supplemental heating, are calculated by the code as follows:

Annual Heat Demand Totaled Over All Districts (MBtu/yr) * [ADGDAY(1) - DDGDAY(1)]/DDGDAY (1)

$\mathrm{HQ}(\mathrm{N})$ $\mathrm{N}=1,8$

Peak heat demand in MBtu/hr-bldg for a typical building in district type $\mathrm{N}$ based on an indoor design temperature TINDES(1) of $65^{\circ} \mathrm{F}$ and a winter outdoor design temperature TDES(1) of $-5^{\circ} \mathrm{F}$. The default values of $H Q(N)$ were calcuated by designing typical residential units for each district type and calculating the heat loss according to ASHRAE procedures assuming $-5^{\circ} \mathrm{F}$ outside temperature, $65^{\circ} \mathrm{F}$ inside temperature, and a $15 \mathrm{mph}$ wind. The physical layout of the residential units in each of the district types is described in Appendix $C$. The default values of $\mathrm{HQ}(\mathrm{N})$ are as follows:

$\begin{array}{lll}\text { N } & \frac{\text { District Type }}{\text { Suburban }} & \begin{array}{c}\text { (MBtu/hr-bldg } \\ 1\end{array} \\ 2 & \begin{array}{l}\text { High-Density } \\ \text { Single Family }\end{array} & 0.053 \\ 3 & \text { Garden Apartments } & 0.034 \\ 4 & \text { Townhouse or Row Houses } & 0.900 \\ 5 & \text { High-Rise Apartments } & 1.728 \\ 6 & \text { Point Demand } & 1.0\end{array}$

District types 7 and 8 are available for definition by the user. The default values of $\mathrm{HQ}(7)$ and $\mathrm{HQ}(8)$ were arbitrarily set to zero since these two districts do not have a default description. 
If the winter outdoor temperature TDES(1) is input at some value other than its default value of $-5^{\circ} \mathrm{F}$, AQUASTOR automatically prorates the peak heat demands $H Q(N)$ for residential (but not point demand) districts.

Subroutine LOAD calculates a new peak heat demand for each building type according to the following equation:

$$
H Q(\text { new })=H Q(\text { input }) \star \frac{65 .- \text { TDES }(\text { input })}{65 .- \text { TDES (defaut })}
$$

For example, if $\mathrm{HQ}$ (input) is input at $1 \mathrm{MBtu} / \mathrm{hr}-\mathrm{b} / \mathrm{dg}$ and TDES (input) is input at $0^{\circ} \mathrm{F}$, then $H Q$ (new) is prorated in subroutine $L O A D$ as follows:

$$
\begin{aligned}
& H Q(\text { new })=1 . * \frac{65 .-0 .}{65 .-(-5 .)}=1 . * \frac{65 .}{70 .} \\
& \text { i.e., } \\
& H Q(\text { new })=0.9286 \mathrm{MBtu} / \mathrm{hr}-\mathrm{b} 1 \mathrm{dg} .
\end{aligned}
$$

The user should carefully note that this equation prorates input values of $\mathrm{HQ}(\mathrm{N})$ for residential districts as well as the default values of $\mathrm{HQ}(\mathrm{N})$. Thus, if the outdoor design temperature of $H Q(N)$ is identical to the input value of $\operatorname{TDES}(1)$, but $\operatorname{TDES}(1)$ is different from its default value of $-5^{\circ} \mathrm{F}$, this equation will still prorate the input value for $H Q(N)$.

TINDES(1) Indoor design temperature $\left({ }^{0} \mathrm{~F}\right)$ for heating each building type. The default value is $65^{\circ} \mathrm{F}$. This parameter currently can not be varied. The user must be careful that the indoor reference temperature used in determining the peak heating energy requirements $H Q(N)$ and the annual heating degree-days ADGDAY(1) is the same as the indoor design temperature TINDES(1) in the code (fixed at $65^{\circ} \mathrm{F}$ ).

TDES(1) Winter design outdoor dry-bulb temperature $\left({ }^{\circ} \mathrm{F}\right)$ used for calculating the peak heat demands $H Q(N)$ in MBtu/hr-bldg for each building in district type $N$. The default value is $-5^{\circ} \mathrm{F}$. The user should review the description of $H Q(N)$ above to assess the impact 
of changing TDES(1) from its default value upon the values of the peak heat demand $\mathrm{HQ}(\mathrm{N})$ for each building in district type $\mathrm{N}$.

TMIN Minimum winter outdoor temperature for heating. The default value is $-15^{\circ} \mathrm{F}$. This value is currently used by the code only to calculate and print out peak supplemental heating requirements (MBtu/hr) but is not used in any cost calculations.

TWATC

Cold water temperature in the sanitary hot water tank. This water is heated by the circulating water from the distribution system through a small heat exchanger at the hot water tank. The default value is $50^{\circ} \mathrm{F}$.

TWATH Hot water temperature from the sanitary hot water tank after heating. The default value is $140^{\circ} \mathrm{F}$.

\subsubsection{Climatic Parameters for Cooling Mode}

AQUASTOR calculates annual residential cooling demand using annual cooling degree-hours based on hourly data. The input parameter MCOOL provides the flexibility for the user to either directly input the following two climatic cooling parameters or have the code calculate them.

- $C Q(N)$, the peak cooling energy requirement for each building in district type $N$ corresponding to the input values for the indoor design temperature, the ambient summer outdoor design temperature, and outdoor absolute humidity. This.parameter includes all residences in the building and is expressed in MBtu/hr-bidg of chill.

- ACDGHR, the annual cooling degree hours based on hourly cooling degree data at the simulated geographic site. The reference temperature of the hourly data must be the same as the indoor design temperature input into the code. This parameter is expressed ${ }^{0} \mathrm{~F}$-hours/year.

Specifically, the parameter MCOOL is defined to provide flexibility as follows: MCOOL $=0 \quad$ The two parameters $C Q(N)$ and ACDGHR are calculated internally in the code (subroutine COOLHR) according to equations 1 and 2 in Appendix E. This is the default value of MCOOL. 
1 The parameters $\mathrm{CQ}(\mathrm{N})$ is calculated internally in the code (subroutine COOLHR) but parameter ACDGHR is directly input by the user.

2 Both parameters $C Q(N)$ and ACDGHR are directly input by the user.

The parameters that must be input for each value of MCOOL in order for AQUASTOR to calculate the cooling energy requirements are listed below ${ }^{(a)}$.

\begin{tabular}{|c|c|c|c|c|c|}
\hline \multirow{5}{*}{$\begin{array}{l}\text { MCOOL }= \\
\begin{array}{l}\text { User must } \\
\text { input param- } \\
\text { eters on } \\
\text { right }\end{array}\end{array}$} & \multicolumn{2}{|c|}{$0($ default $)$} & \multicolumn{2}{|l|}{1} & \multirow{2}{*}{$\frac{2}{\text { TINDES }(2)}$} \\
\hline & TINDES (2) & Used by & TINDES (2) & Used by & \\
\hline & $\operatorname{TDES}(2)$ & code to & TDES (2) & code to & $\operatorname{TDES}(2)$ \\
\hline & HDES (2) & internally & $\operatorname{HDES}(2)$ & internally & $\mathrm{CQ}(\mathrm{N})$ \\
\hline & $\operatorname{NRESD}(\mathrm{N})$ & calculate & $\operatorname{NRESD}(\mathrm{N})$ & calculate & \\
\hline & NTMINT & Used by & ACDGHR & & ACDGHR \\
\hline & TWIDTH & code to & & & \\
\hline & TAOD $(K)$ & internally & & & \\
\hline & HROD(K) & calculate & & & \\
\hline & & ACDGHR & & & \\
\hline
\end{tabular}

The definitions of these parameters are summarized below.

TINDES(2) Indoor design temperature $\left({ }^{\circ} \mathrm{F}\right)$ for cooling each building type. The default value is $78^{\circ} \mathrm{F}$. The indoor design temperature must be the same as the indoor reference temperature upon which the peak cooling energy requirements $C Q(N)$ for each building in district type $N$ and the annual cooling degree hours ACDGHR are based. This equality occurs automatically in equations 1 and 2 of Appendix $E$ when the calculation of $C Q(N)$ and ACDGHR is left to

(a) When simulating a single point demand district (i.e., district number one defined as district type (6), the value of MCOOL is ignored. The user must input the peak heat demand $H Q(6)$ or peak chill demand $C Q(6)$ together with the load factor PF as described in Section 3.4.7. 
the code (e.g., with MCOOL set to its default value of 0 ). However, if the user directly inputs $C Q(N)$ or ACDGHR, the user must check that the indoor design temperature $\operatorname{TINDES(2)}$ is identical to the indoor reference temperature upon which $\mathrm{CQ}(\mathrm{N})$ and $A C D G H R$ are based.

TDES(2) Summer design outdoor dry-bulb temperature $\left({ }^{\circ} \mathrm{F}\right)$ used to calculate peak cooling demands in MBtu/hr of chill for each building type. The default value of TDES(2) is $99^{\circ} \mathrm{F}$.

It is recommended that the peak cooling load of each building type be calculated at a design outdoor temperature TDES(2) some percentage below the actual peak summer temperature to improve the system load factor. For example, the user may opt to select the ASHRAE design dry-bulb temperature read at the 2.5\% level ${ }^{(10)}$ as the outdoor design temperature $\operatorname{TDES}(2)$. This value represents a temperature that is equaled or exceeded by $2.5 \%$ of the 2,928 hours during the four summer months (June through September). Thus, 73.2 hours ( 0.6 hours per day) would be at or above the outdoor design temperature during the four summer months. (a)

HDES(2) Absolute humidity (1bs $\mathrm{H}_{2} \mathrm{O} / \mathrm{lb}$ air) at the summer design outdoor dry-bulb and wet-bulb temperatures. (11) The default value is $0.0125 \mathrm{lbs} \mathrm{H}_{2} \mathrm{O} / \mathrm{lb}$ air. The absolute humidity is used to calculate the peak chill demand for each building type in Equation 1 of Appendix E.

NRESD(N) Number of residences in each building of district type $N$. The $N=1,8$ default values are as follows:

\footnotetext{
(a) No supplemented cooling is provided in AQUASTOR for the hours above the outdoor design temperature.
} 


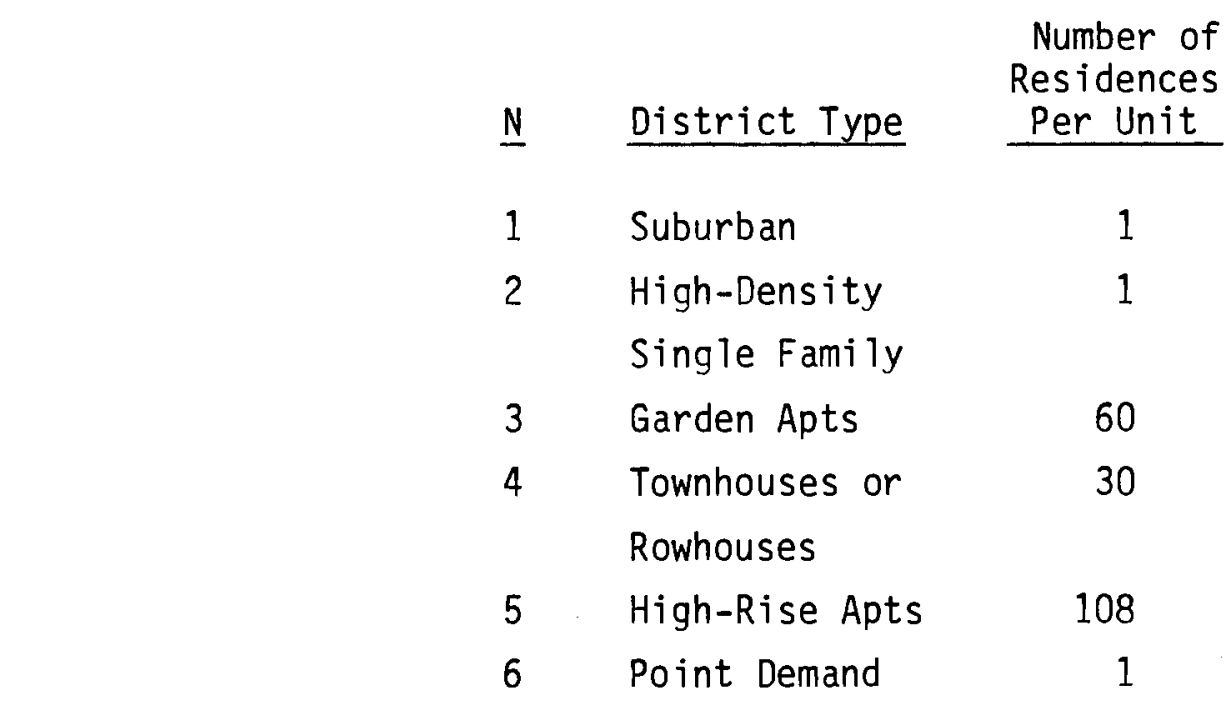

$\mathrm{CQ}(\mathrm{N})$

$\mathrm{N}=1,8$

This parameter is used in Equation 1 of Appendix $E$ (programmed in subroutine COOLHR of the code) in calculating the peak chill demand $C Q(N)$ for each building in district type $N$ when MCOOL is set to 0 or 1 . If MCOOL is set to 2, the user must include the number of residences in the external determination of $\mathrm{CQ}(\mathrm{N})$ before inputting $\mathrm{CQ}(\mathrm{N})$ into the code.

Peak cooling demand in MBtu/hr-bldg of chill for each building in district type N. This parameter is input only if MCOOL is set to 2. It is automatically calculated in subroutine COOLHR when MCOOL is set to 0 or 1 according to equation 1 in Appendix $E$. If MCOOL is set to 2, the user has the flexibility to directly input the values of $\mathrm{CQ}(\mathrm{N})$ or use the default values. However, trhe user must be careful that the peak chill demands $\mathrm{CQ}(\mathrm{N})$ are based on the values of the indoor design temperature TINDES(2) and the outdoor design temperature TDES(2) input into the code. In contrast to the peak heat demand $H Q(N)$, described in Section 3.4.2, no adjustment (prorating) is applied to the peak chill demand $\mathrm{CQ}(\mathrm{N})$ in the code.

The default values of $C Q(N)$ are based on equation 1 in Appendix $E$ with the indoor reference temperature TINDES(2) set to $78^{\circ} \mathrm{F}$, the outdoor design dry-bulb temperature $\operatorname{TDES}(2)$ set to $99^{\circ} \mathrm{F}$, the absolute humidity $\operatorname{HDES}(2)$ set to 0.0125 lbs $\mathrm{H}_{2} \mathrm{O} / \mathrm{lb}$ air, and 
the number of residences per building type set to their default values above. The default values of $C Q(N)$ are as follows:

$\begin{array}{llll}N & \text { District Type } & & \begin{array}{c}\text { Building Peak } \\ \text { Chill Demand } \\ \text { (MBtu/hr bldg) }\end{array} \\ 1 & \text { Suburban } & & 0.020911 \\ 2 & \text { High-Density } & 0.015530 \\ 3 & \text { Single Family } & \\ 4 & \text { Garden Apts } & 0.663936 \\ 5 & \text { Townhouses or } & 0.391980 \\ 6 & \text { High-Rise Apts } & 1.019909 \\ \text { Point Demand } & 1.0\end{array}$

District types 7 and 8 are available for definition by the user. The default values of $C Q(7)$ and $C Q(8)$ were arbitrarily set to zero since these two districts do not have a default description. For simulating point demand (district type 6 ), the value of MCOOL is ignored and the user must directly input CQ(6).

NTMINT Number of outdoor dry-bulb ambient temperature intervals used in hourly calculations of cooling energy requirements. The defalut value is 10 . If more than 10 intervals are required, the dimensions of $\operatorname{TAOD}(10)$ and $\operatorname{HROD}(10)$ must be increased in the code.

TWIDTH The width of outdoor temperature intervals grouping annual hourly temperature data at a simulated geographic site into temperature intervals spanning the range from the indoor design temperature to the peak outdoor summer temperature. The default value is $5^{\circ} \mathrm{F}$. This parameter is used when MCOOL is set to 0 to calculate the annual cooling degree-hours in equation 2 of Appendix $E$. The temperature intervals are determined from the values input for the midpoint $\operatorname{TAOD}(K)$ of each temperature interval and the interval width TWIDTH by subroutine COOLHR as follows:

$$
(T A O D(K)-T W I D T H / 2 \text {., TAOD(K) + TWIDTH/2.) }
$$


$\operatorname{TAOD}(K)$, $K=1$, NTMINT

The user has the flexibility to input any temperature interval width for which data of annual hourly temperature groupings (temperature histograms) are available. The default value of $5^{\circ} \mathrm{F}$ represents the width of the temperature intervals in the hourly temperature groupings provided by the National Oceanic and Atmospheric Administration (NOAA). (a) It is assumed that the temperature intervals in the NOAA data actually run half a degree below the printed temperature interval to half a degree above in order to make the temperature scale cont inuous, i.e., 70-74 actually represents the $5^{\circ} \mathrm{F}$ temperature interval 69.5-74.5. Midpoints $\left({ }^{\circ} F\right)$ of the outdoor dry-bulb temperature intervals (numbering NTMINT in a11) grouping annual hourly temperature data into temperature intervals spanning the range from the indoor design temperature to the peak outdoor summer temperature. The temperature midpoints are defined in increasing order as $K$ increases; the first temperature interval must either include the indoor design temperature or lie below it. (b) If this rule is violated, the code will print an appropriate error message and stop execution.

The default values of the temperature midpoints and their corresponding temperature intervals which subroutine COOLHR constructs from the default midpoints and default value of the interval width TWIDTH are based on the NOAA data as follows:

(a) NOAA Environmental Data Service, National Climatic Center, Asheville, NC.

(b) If any temperature interval lies below the indoor design temperature TINDES(2), subroutine COOLHR in AQUASTOR automatically sets the cooling degree hours for that interval to 0 . If a temperature interval includes the indoor design temperature, subroutine COOLHR assumes a uniform temperature distribution in the interval and automatically prorates the hours in the interval to include only that portion of the hours that require cooling in the reduced temperature interval between the indoor design temperature and the upper boundary of the interval. 


\begin{tabular}{|c|c|c|c|}
\hline$\underline{K}$ & $\begin{array}{c}\text { Temperature } \\
\text { Midpo ints } \\
\text { TAOD(K) } \\
\end{array}$ & $\begin{array}{l}\text { Corresponding } \\
\text { Temperature } \\
\text { Intervals (OF) }\end{array}$ & $\begin{array}{l}\text { NOAA Rounded } \\
\text { Temperature } \\
\text { Intervals }(\mathrm{OF}) \\
\end{array}$ \\
\hline $\begin{array}{r}1 \\
2 \\
3 \\
4 \\
5 \\
6 \\
7 \\
8 \\
9 \\
10\end{array}$ & $\begin{array}{l}77 . \\
82 . \\
87 . \\
92 . \\
97 . \\
102 . \\
107 . \\
112 . \\
117 . \\
122 .\end{array}$ & $\begin{array}{l}(74.5,79.5) \\
(79.5,84.5) \\
(84.5,89.5) \\
(89.5,94.5) \\
(94.5,99.5) \\
(99.5,104.5) \\
(104.5,109.5) \\
(109.5,114.5) \\
(114.5,119.5) \\
(119.5,124.5)\end{array}$ & $\begin{array}{l}(75,79) \\
(80,84) \\
(85,89) \\
(90,94) \\
(95,99) \\
(100,104) \\
(105,109) \\
(110,114) \\
(115,119) \\
(120,124)\end{array}$ \\
\hline
\end{tabular}

Note that for the default temperature intervals, the default value for the indoor design temperature TINDES(2) of $78^{\circ} \mathrm{F}$ lies within the first temperature interval.

HROD(K) Number of hourly temperature observations per year at a $K=1$, NTMINT geographic site which lies in the temperature interval represented by its midpoint temperature $\operatorname{TAOD}(K)$ and interval width TWIDTH, i.e., in the temperature interval:

$$
\text { (TAOD(K) - TWIDTH/2., TAOD(K) + TWIDTH/2.). }
$$

The default values for $\operatorname{HROD}(K)$ are as follows:

$\begin{array}{ccc}\begin{array}{c}\text { Temperature } \\ \text { Midpoints } \\ \text { TAOD }(\mathrm{K})\end{array} & \begin{array}{c}\text { NOAA Temperature } \\ \text { Intervals (OF) }\end{array} & \begin{array}{c}\text { Hours/Year in that } \\ \text { Temperature Interval } \\ \text { HROD }(\mathrm{K})\end{array} \\ \begin{array}{c}\text { 77. } \\ \text { 82. }\end{array} & (75,79) & 982 . \\ 87 . & (80,84) & 788 . \\ 92 . & (85,89) & 596 . \\ 97 . & (90,94) & 440 . \\ 102 . & (95,99) & 246 . \\ 107 . & (100,104) & 0 . \\ 112 . & (105,109) & 0 . \\ 117 . & (110,114) & 0 . \\ 122 . & (115,119) & 0 .\end{array}$

If one or more of the NTMINT temperature intervals do not have any hourly temperatures occurring in those intervals for a given site, the user must set the corresponding values of $\operatorname{HROD}(K)$ to 0 
for those intervals. Otherwise, the code will pick up the above default number of hours for those intervals. Note that the hours per year, $\operatorname{HROD}(K)$, in temperature intervals above the outdoor design temperature (with default value of $99^{\circ} \mathrm{F}$ ) should be set to 0 in the input data. This follows from the rationale that the ATES system is being designed to provide cooling only between the indoor design temperature TINDES(2) and the summer outdoor design temperature TDES(2). No supplemental cooling is provided in AQUASTOR for the hours above the outdoor design temperature $\operatorname{TDES}(2)$.

ACDGHR

Annual cooling degree hours per year $\left({ }^{0} \mathrm{~F}-\mathrm{hrs} / \mathrm{yr}\right)$ based on hourly temperature data between the indoor design temperature TINDES(2) and the summer outdoor design temperature TDES(2) at the simulated geographic site. This parameter is input only if MCOOL is set to 1 or 2 . The default value is $19,571^{\circ} \mathrm{F}-\mathrm{hrs} / \mathrm{yr}$. The user must be sure that the indoor reference temperature of the data is the same as the indoor design temperature TINDES(2). This occurs automatically when MCOOL is set to 0 since subroutine COOLHR uses the input parameter TINDES(2) to calculate the annual cooling degree-hours according to equation 2 in Appendix $E$.

If MCOOL is set to 1 or 2 , the user has the flexibility to directly input the value of ACDGHR or use the default value. The default value of ACDGHR is based on an indoor design temperature TINDES(2) of $78^{\circ} \mathrm{F}$, an outdoor summer design temperature TDES(2) of $99^{\circ} \mathrm{F}$, and the default hourly temperature observations (default values of $\operatorname{TAOD}(K)$ and $\operatorname{HROD}(K)$ ), and is calculated according to equation 2 in Appendix $E$.

When directly inputting the value of ACDGHR, the user should be aware that multiplying data that is originally in terms of cooling degree-days by 24 hours/day will not yield results comparable to actual cooling degree hour data unless the degree-day data is based on hourly observations. 


\subsubsection{Distribution Heat Exchanger}

An option for a liquid-to-liquid heat exchanger is provided in both heating and cooling modes at the inlet to the distribution system. (a) The heat exchanger may be used either to protect the aquifer from environmental damage and/or to protect the expensive distribution system from corrosion. Heat (chill) is transferred from the storage aquifer water to circulating clean water for use in the distribution system. The heat exchanger is modeled as a counterflow, single-pass, shell- and tube-unit constructed of carbon steel with an equilateral triangular tube configuration. The aquifer water is pumped through the tube side and the circulating clean water is pumped through the shell side of the heat exchanger.

The nomenclature used in defining the temperature distribution in the distribution heat exchanger is illustrated in Figure 11 . The temperature difference between the storage aquifer water entering the heat exchanger and the distribution circulating water exiting the heat exchanger is defined as the inlet approach (UAPIN) to the heat exchanger. The temperature difference between the exiting aquifer water and the distribution circulating water entering the heat exchanger is defined as the outlet approach (UAPOUT) to the heat exchanger.

Referring to the nomenclature in Figure 11, the temperature drop (rise) of the storage aquifer water in the heat exchanger is calculated by the code in the heating (cooling) mode as follows:

Heating: Aquifer water Temperature Drop $\left({ }^{\circ} \mathrm{F}\right)=$ TAQ - (TREJ + UAPOUT) Cooling: Aquifer water Temperature Rise $\left({ }^{\circ} F\right)=$ (TREJ - UAPOUT) - TAQ The temperature rise (drop) of the circulating water in the heat exchanger is calculated by the code in the heating (cooling) mode as follows:

Heating: Circulating Water Temperature Rise $\left({ }^{\circ} \mathrm{F}\right)=($ TAQ - UAPIN $)-$ TREJ Cooling: Circulating water Temperature Drop $\left({ }^{\circ} F\right)=$ TREJ $-($ TAQ + UAPIN)

(a) The current version of the code assumes that the supply system always has a liquid-to-liquid heat exchanger for transferring heat (chill) from the energy source to the water from the supply wellfield. 
HEATING MODE

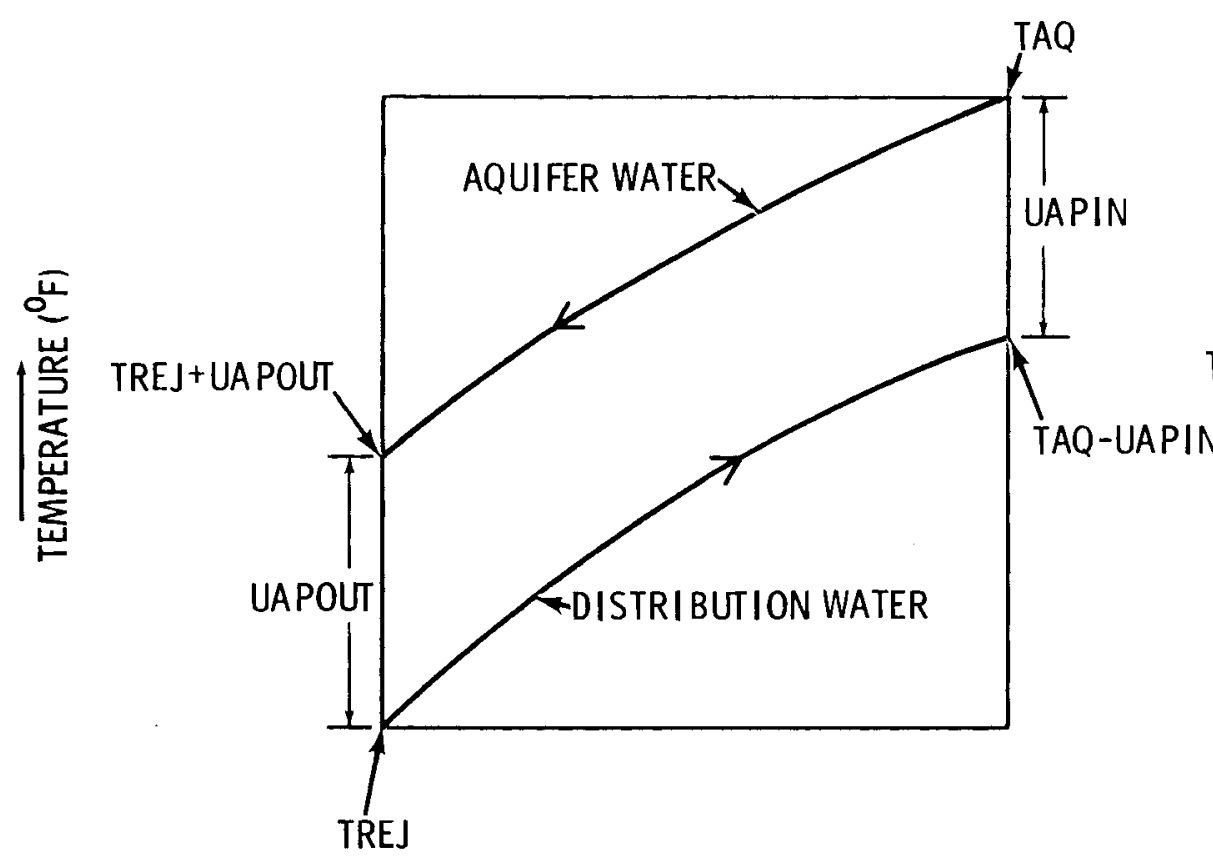

COOLING MODE

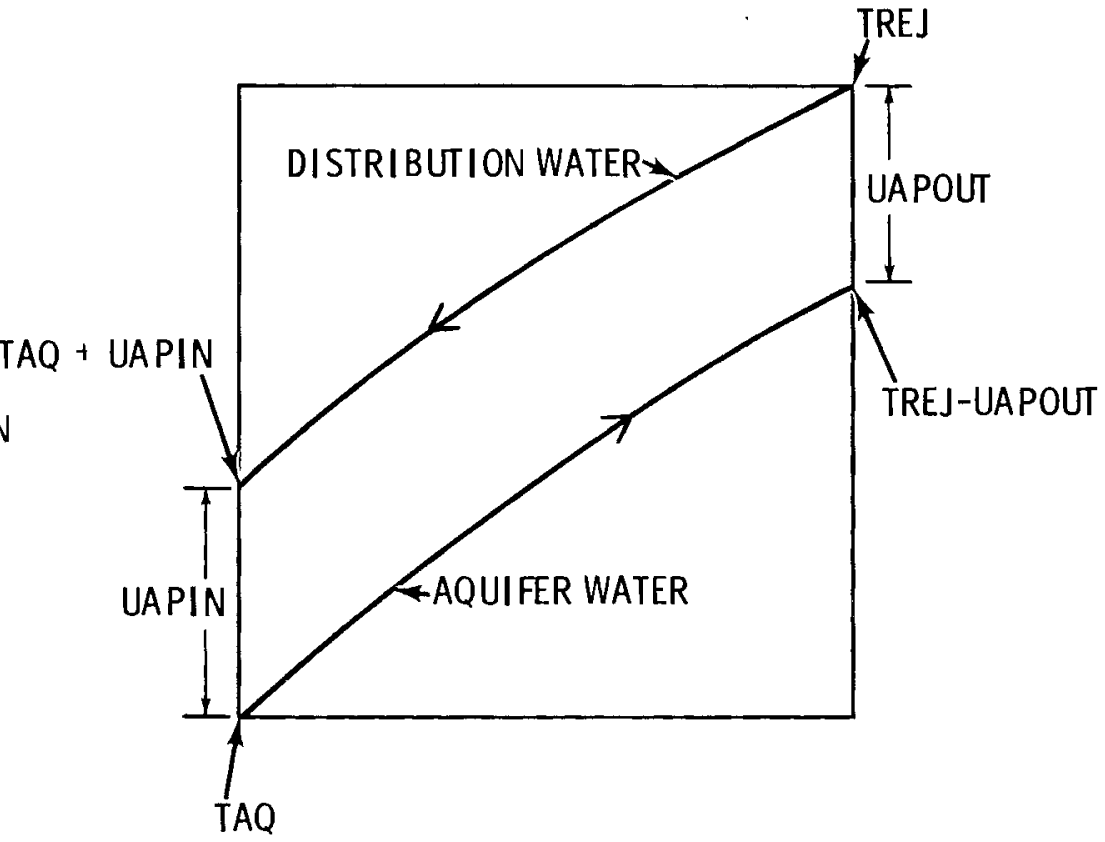

TEMPERATURE NOMENCLATURES

TAQ = Entering temperature $\left({ }^{\circ} \mathrm{F}\right)$ from storage aquifer (calculated by code)

UAPIN = In let approach $\left({ }^{\circ} \mathrm{F}\right)$ to heat exchanger

TAQ-UAPIN = Heated temperature $\left({ }^{O_{F}}\right)$ to distribution system

TAO+IJAPIN = Chilled temperature $\left({ }^{O} \mathrm{~F}\right)$ to distribution system

TREJ = Temperature $\left({ }^{O} F\right)$ from distribution system

UAPOUT $\quad=$ Out let approach $\left({ }^{O} F\right)$ to heat exchanger

TREJ+UAPOUT $=$ Reduced temperature $\left({ }^{\circ}\right)$ to supply wellfield

TREJ-UAPOUT = Increased temperature $\left({ }^{O} \mathrm{~F}\right)$ to supply wellfield

FIGURE 11. Nomenclature for the Temperature Distribution in the Distribution Heat Exchanger 
The input parameters for defining the distribution heat exchanger are defined be low:

HTEXOP Option for a centralized heat exchanger at the end of the transmission leg from the storage aquifer (i.e., at the inlet to the distribution system).

$0 .=$ No heat exchanger (default value).

1. = Heat exchanger.

DIAL, Inner and outer tube diameters ( $f t$ ) of the heat exchanger. The DIAOL default valves are:

$$
\begin{aligned}
& \text { DIAL }=0.1 \mathrm{ft} \\
& \text { DIAOL }=0.1104 \mathrm{ft}
\end{aligned}
$$

FOULFI, Inside and outside fouling factors for the heat exchanger. These FOULFO factors reduce the overall heat transfer coefficient in subroutine OHTCOE to allow for the accumulation of corrosion deposits on the inside (tube side) and outside (shell side) heat transfer surfaces. The default values are:

FOULFI $=0.001 \mathrm{hr}-\mathrm{ft} \mathrm{t}^{2}-{ }^{0} \mathrm{~F} / \mathrm{Btu}$

FOULFO $-0.001 \mathrm{hr}-\mathrm{ft}^{2}-{ }^{0} \mathrm{~F} /$ Btu

UAPIN Inlet approach temperature $\left({ }^{\circ} \mathrm{F}\right)$ to distribution heat exchanger as $i l l u s t r a t e d$ in Figure 11 . The default is $5^{\circ} \mathrm{F}$.

UAPOUT Out let approach temperature $\left({ }^{0} \mathrm{~F}\right)$ from distribution heat exchanger as illustrated in Figure 11. The default is $5^{\circ} \mathrm{F}$.

WVELL Velocity ( $\mathrm{ft} / \mathrm{hr}$ ) of the water from the storage aquifer in the heat exchanger tubes. The default is $28,800 \mathrm{ft} / \mathrm{hr}$ (i.e., $8 \mathrm{ft} / \mathrm{sec}$ ).

\subsubsection{Districts}

Districts are the basic elements of the distribution system submodel. Recall that a residential district is defined as a contiguous, rectangular area consisting of multiple buildings of relatively similar heat or chill demand and uniform density. A point demand is defined as a district consisting of one point of heat or chill demand such as a single commercial building or factory. Many of the details needed for designing the distribution piping system are 
derived from the definitions of the districts. Fluid requirements are computed and the piping networks are designed for each district.

Districts are defined by two types of input parameters: District geometric parameters and district type parameters. The geometric parameters define the area, shape, and relative location of the rectangular districts. The geometric parameters are described in Section 3.4.5.1.

District type parameters define the characteristics of the districts. Five residential district types representing typical residential areas in cities of the United States and one point demand type are defined in the code:

1) Suburban

2) High-Density Single Family

3) Garden Apartments

4) Townhouse or Row Houses

5) High-Rise Apartments

6) Single Point Demand

Each of the district types has district type parameters assigned to it that define the peak heat (chill) demand and daily hot water demands of typical building units, the density of buildings, a reject temperature, number of residences per building, and number of people per building. The code is extremely flexible with regard to district types. Variation of the district type parameters defining the district types or additional district types (including commercial districts) can be defined through the input data. The district type parameters are defined in Section 3.4.5.2.

Most residential areas in the United States can be defined by use of these district types. Zoning maps of cities can be used to describe the residential part of an entire city by disaggregating it into residential district types. Figure 9 in Section 3.2 shows the physical layout of 18 different districts used to simulate the residential districts in the city of Richland, WA. Note that simulation of additional district types is illustrated in Figure 9.

\subsubsection{District Geometry}

The initial step in describing the district geometry is to define the number of districts at the simulated site. Current code dimensions permit up to 
20 residential districts to be simulated. Each district is then assigned an integer from 1 to 8 which defines its type and appends the district type parameters to the district as described in Section 3.4.5.2.

Three parameters are used to define the area, length, and width of the rectangular shape of each district. The relative distance between adjoining districts is defined by the length of the main pipes required to connect the centers of the adjoining districts. Other parameters allow for definition of the elevation of the districts above the inlet to the distribution system and the degree of crookedness of its streets.

The district geometric parameters are defined below. The majority of these parameters are arrays where the Mth element is part of the definition of the Mth district.

NDTR

Number of districts at the simulated site. The default is 1 .

IDTYPE

The generic type of the districts at the simulated site. This parameter is used only for printout purposes.

1 = residential districts

2 = single point demand

The default is 1 .

IDTR(M) Type of district, an integer from 1 to 8 , defined as follows:

$M=1,20$

1 = Surburban

2 = High-Density Single Family

$3=$ Garden Apartments

4 = Townhouses or Rowhouses

$5=$ High-Rise Apartments

6 = Single Point Demand

This parameter appends the peak heat (chill) demand and daily hot water demands of typical building units, the density of buildings, diversity factor, reject temperature, number of residences per building, number of people per building, and retrofitting cost, i.e., the district type characteristics described in Section 3.4.5.2, to the description of district M. Variation of the district type parameters defining these district types or 
additional district types 7 and 8 can be defined through the input data.

Only $\operatorname{IDTR}(1)$ is assigned a default value, which is currently set to 1 designating suburban. A single point demand is selected by setting IDTR(1) to 6 . District type 6 is reserved in the code for simulating a single point demand and should not be redefined as a residential district through the input data. District types 1 through 5 and 7 to 8 are available for use as residential district types. Use of more than 8 different district types would require increasing the dimensions of some of the arrays in the code.

AREA(M) Area of district $M$ in square miles. The default value of $A R E A(1)$ $M=1,20$ only is 1 square mile.

WIDTH(M) Width of district $M$ in miles. The default value of WIDTH(1) only $M=1,20$ is $1 \mathrm{mile}$.

XLNGTH(M) Length of district $M$ in miles. The default value of XLNGTH(1) $M=1,20$ only is 1 mile. The width and length parameters are used to determine the approximate shape of the district. Thus, when the graph for the district is created in subroutine GRAPH, the ratio of rows to columns in the rectangular grid used to approximate the shape of the district is the same as the ratio of width to length. The user can approximate the width and length of a district from a map of the district or by judgment.

$\operatorname{DDTR}(M) \quad$ Length of the main pipe serving district $M$ in miles. The default $M=1,20$ value of $\operatorname{DDTR}(1)$ only is 1 mile. Lengths are measured from either the end of the transmission line (inlet to the distribution system) or the last junction in the main to the center of district M. Illustrations are given in Section 3.4.8 and Figure 12.

ELDIFF(M) Elevation of district $M$ above the end of the transmission line $M=1,20$ (inlet to the distribution system) in feet. This parameter alters the sizing of the pumps and the calculation of pumping requirements for district $M$. The default is 0 for all 20 districts. 
CONFIGURATION 1

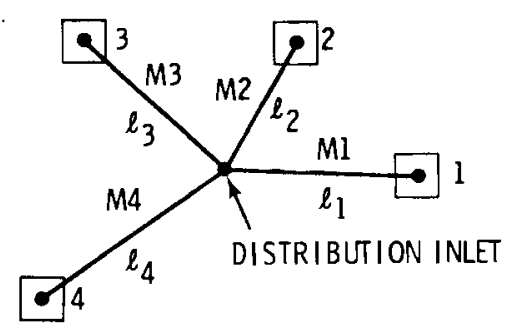

OPTION 2: AT LEAST ONE MAIN SERVES MORE THAN ONE DISTRICT

CONFIGURATION 2

SERIES

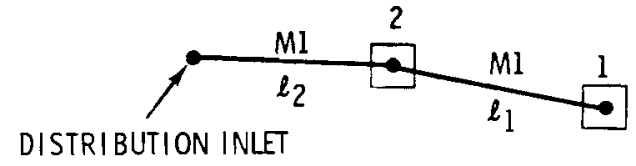

DISTRIBUTION INLET

CONFIGURATION 3

BRANCHES

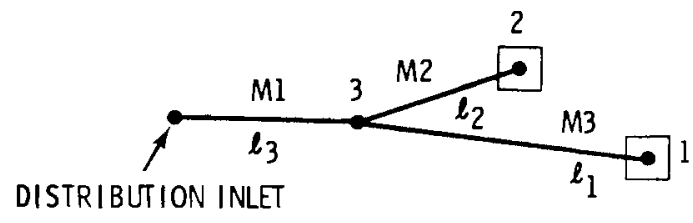

CONFIGURATION 4 COMBINATION OF SERIES AND BRANCHES

DISTRIBUTION INLET

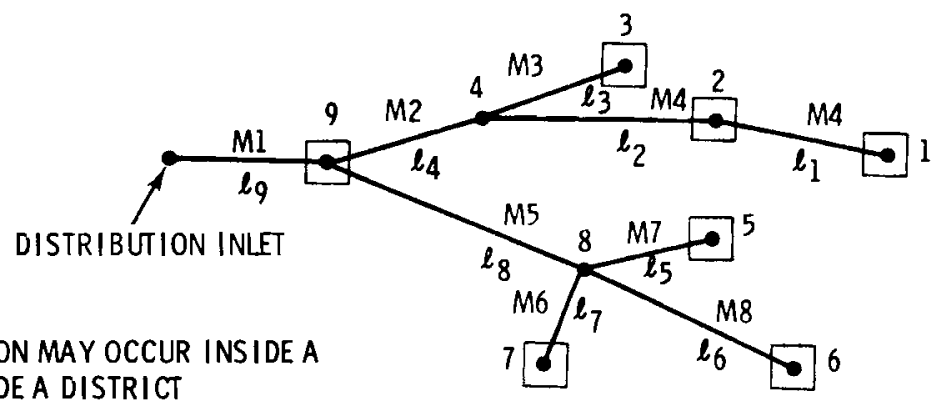

WATER PUMPED FROM DISTRI BUTION INLET TO OUTLYING DISTRICTS

- MAIN INTERSECTION

$\square$ DISTRICT

Mi MAIN NUMBER i

$\operatorname{DDTR}(\mathrm{j})=\ell_{\mathrm{j}}$ LENGTH OF MAIN SERVING DISTRICT j

FIGURE 12. Examples of Main Configurations Servicing Multi-Residential Districts 
CSF (M) Crooked street factor. This factor serves to increase (multiply) $M=1,20$ the lengths of the lateral, street, and house pipes, but not the main pipe, in the piping network for the district. The default is 1 for all 20 districts.

\subsubsection{District Type Characteristics}

District type parameters are used to define the characteristics of each district: the peak heat (chill) demand and daily hot water demand of typical building units, the density of buildings, the diversity factor, reject temperature, number of residences per building, number of people per building, and the retrofitting cost per building. Up to eight different district types can be defined through the input data. The description of the six default district types in the code and the default values of their characteristics are given in Table 8.

District type parameters are arrays where the Nth element is part of the description of the characteristics of the Nth district type. When the user specifies that the district type IDTR(M) for district $M$ is equal to $N$ as described in Section 3.4.5.1, the Nth element of each district type array below is associated with district $M$.

$\mathrm{HQ}(\mathrm{N}) \quad$ Peak heat demand in MBtu/hr-bldg for a typical building in $\mathrm{N}=1,8$ district type $\mathrm{N}$, based on the indoor design temperature TINDES(1) for heating and the winter outdoor design temperature TDES(1). $H Q(N)$ is also described in Section 3.4.2 because of its dependency on these two design temperatures. The user should also read the description of this relationship in Section 3.4.2.

CQ(N) Peak chill demand in MBtu/hr-bldg for a typical building in $\mathrm{N}=1,8$ district type $N$, based on the indoor design temperature TINDES(2) for cooling and the summer outdoor design temperature TDES(2). $\mathrm{CQ}(\mathrm{N})$ is also described in Section 3.4 .3 because of its dependency on these two design temperatures. The user should also read the description of this relationship in Section 3.4.3.

HW(N) Daily hot water demand in gal/day-bldg for a typical building in $\mathrm{N}=1,8$ district type $\mathrm{N}$. The peak hot water demand in one hour is 


\section{TABLE 8. District Type Characteristics of the Default District Types in AQUASTOR}

\begin{tabular}{|c|c|c|c|c|c|c|c|c|c|c|c|}
\hline & & $\mathrm{HQ}(\mathrm{N})$ & $\mathrm{CQ}(\mathrm{N})$ & & DENSE $(N)$ & DIVF(N) & $\operatorname{TREJ}(\mathrm{N})$ & $\operatorname{TREJC}(\mathrm{N})$ & NRESD(N) & POPHSE (N) & \\
\hline & $\begin{array}{cc} & \\
\text { District } & \mathrm{He} \\
\text { Type N } & \text { (M } \\
\end{array}$ & $\begin{array}{l}\text { B1dg Peak } \\
\text { teat Demand(a) } \\
\text { (MBtu/hr-bldg) }\end{array}$ & $\begin{array}{l}\text { Bldg Peak } \\
\text { Chill Demand (b) } \\
\text { (MBtu/hr-bldg) }\end{array}$ & $\begin{array}{l}\text { Hot } \\
\text { Water Demand }(c) \\
\text { (gal/day) }\end{array}$ & $\begin{array}{c}\text { Density } \\
\text { (bldg/sq mi) }\end{array}$ & $\begin{array}{l}\text { Diversity } \\
\text { Factor } \\
\text { (fraction) } \\
\end{array}$ & $\begin{array}{l}\text { Heating Reject } \\
\text { Temperature } \\
\left({ }_{F}\right)\end{array}$ & $\begin{array}{c}\text { Cooling Reject } \\
\text { Temperature } \\
\left(\mathrm{O}^{\mathrm{F}}\right)\end{array}$ & $\begin{array}{c}\text { Number of } \\
\text { Residences } \\
\text { (resid./bldg) } \\
\end{array}$ & $\begin{array}{c}\text { Number of } \\
\text { People } \\
\text { (people/bldg) }\end{array}$ & $\begin{array}{c}\text { Floor Area } \\
\text { (sq ft/ } \\
\text { residence) }\end{array}$ \\
\hline & $1=$ Suburban & 0.053 & 0.021 & 60.6 & 2560 & .72 & 100 & 55 & 1 & 3.2 & 1620 \\
\hline & $\begin{aligned} 2= & H i g h \text { Density } \\
& \text { Single- } \\
& \text { Family }\end{aligned}$ & ty 0.034 & 0.016 & 55 & 4480 & .72 & 100 & 55 & 1 & 4 & 1000 \\
\hline & $\begin{array}{c}3=\text { Garden } \\
\text { Apts. }\end{array}$ & 1.380 & 0.664 & 3030 & 293 & .72 & 100 & 55 & 60 & 162 & 990 \\
\hline & $\begin{aligned} 4= & \text { Townhouses } \\
& \text { or Row- } \\
& \text { Houses }\end{aligned}$ & 0.900 & 0.392 & 1515 & 373 & .72 & 100 & 55 & 30 & 81 & 1012 \\
\hline & $5=\underset{\text { Apts }}{H i g h \text { Rise }}$ & 1.728 & 1.020 & 5400 & 385 & .72 & 100 & 55 & 108 & 324 & 780 \\
\hline & $\begin{aligned} & 6= \text { Single } \\
& \text { Point } \\
& \text { Demand }\end{aligned}$ & 1.0 & 1.0 & 0 & 1 & 1. & 100 & 55 & 1 & 1 & $N / A$ \\
\hline & $\begin{array}{l}\text { (a) Default peak } \\
\text { (b) Default peak } \\
\text { (c) Sanitary hot }\end{array}$ & $\begin{array}{l}\text { ak heat demand } \\
\text { ak chill deaman } \\
\text { ot water demand }\end{array}$ & $\begin{array}{l}\text { is based on } \\
\text { ignored in }\end{array}$ & $\begin{array}{l}\text { idoor design t } \\
\text { the cooling mo }\end{array}$ & $\begin{array}{l}\text { ature TI } \\
\text { d for a }\end{array}$ & $\left\{\begin{array}{l}=65^{\circ} \mathrm{F}, \mathrm{k} \\
\text { 2) }=78^{\circ} \mathrm{F} \\
\mathrm{e} \text { point de }\end{array}\right.$ & $\begin{array}{l}\text { winter outdoor } \\
\text {, summer outdo }\end{array}$ & $\begin{array}{l}\text { ign temper } \\
\text { lesign temp }\end{array}$ & $\begin{array}{l}\operatorname{DES}(1)=-5 \\
\operatorname{TDES}(2)=\end{array}$ & and a & nd. \\
\hline
\end{tabular}




\begin{tabular}{|c|c|}
\hline $\begin{array}{l}\operatorname{ENSE}(N) \\
=1,8\end{array}$ & $\begin{array}{l}\text { Density of the buildings (buildings/square mile) in district } \\
\text { type } N \text {. }\end{array}$ \\
\hline $\begin{array}{l}\operatorname{DIVF}(N) \\
N=1,8\end{array}$ & $\begin{array}{l}\text { Diversity factor (fraction) for district type } N \text {. The diversity } \\
\text { factor is used to reduce the size of laterals and mains supplying } \\
\text { a district by considering that the peak load for all buildings in } \\
\text { a district does not occur simultaneously. This factor is set to } \\
1 \text { for a single point demand (district type } 6 \text { ). }\end{array}$ \\
\hline $\begin{array}{l}\operatorname{TREJ}(\mathrm{N}) \\
\mathrm{N}=1,8 \\
\mathrm{TREJC}(\mathrm{N}) \\
\mathrm{N}=1,8\end{array}$ & $\begin{array}{l}\text { Temperature }\left({ }^{O} \mathrm{~F}\right) \text { of the return water at the outlet of the } \\
\text { building heating system in district type } N \text {. } \\
\text { Temperature }\left({ }^{O} F\right) \text { of the return water at the outlet of the } \\
\text { building cooling system in district type } N \text {. }\end{array}$ \\
\hline $\begin{array}{l}\operatorname{NRESD}(N) \\
N=1,8\end{array}$ & $\begin{array}{l}\text { Number of residences in a typical building of district type } N \text {. } \\
\text { This parameter is input only in the cooling mode when the cooling } \\
\text { parameter MCOOL is set to } 0 \text { or } 1 \text {. See Section } 3.4 .3 \text { for addi- } \\
\text { tional discussion of this parameter. }\end{array}$ \\
\hline $\begin{array}{l}\text { POPHSE }(N) \\
N=1,8\end{array}$ & $\begin{array}{l}\text { Number of residents in a typical building of district type } N \text {. } \\
\text { This parameter is used only for printout purposes. }\end{array}$ \\
\hline $\begin{array}{l}\operatorname{CRTF}(N) \\
N=1,8\end{array}$ & $\begin{array}{l}\text { Cost (dollars/building) of retrofitting or redoing building } \\
\text { heating (cooling) systems to handle aquifer heating (cooling) in } \\
\text { district type } N \text {. The costs must be input in January, PRINDX base } \\
\text { year dollars as defined in Section } 3.5 .5 .1 \text {, with default value of } \\
\text { January, } 1980 \text { dollars. }\end{array}$ \\
\hline
\end{tabular}

assumed to be $1 / 7$ that of the average daily demand in 24 hours.
If no sanitary hot water heating is desired for the buildings in district type $N$ in the heating mode, the corresponding value of $H W(N)$ for that district type must be input as 0 . No sanitary hot water heating is simulated for a single point demand (district type 6). In addition, no sanitary hot water heating is currently possible in the cooling mode since chilled water is being distributed. Therefore, this parameter is ignored when simulating a single point demand or while in the cooling mode. 


\subsubsection{Distribution System Piping Design}

The layout of a typical, buried piping network in a residential district was illustrated previously in Figure 7 of Section 2.7. Recall that the piping network consists of main, lateral, street pipes, and street-to-house pipes laid out on a rectangular grid system in which a building is associated with each grid point in the rectangular shaped district. The piping network for a single point demand consists only of a supply main and return main. The pipe, insulation, and casing diameters are optimized in the code based on the annualized costs of capital, pumping power, and thermal loss.

Many material and configuration options for the pipes, insulation, and casings can be simulated. The design options include:

- Single-pipe systems (a)

- Several two-pipe system designs

- Use of steel or fiberglass reinforced plastic (FRP) pipes

- Use of calcium silicate, fiberglass, or polyurethane foam insulation

- Use of steel, plastic (PVC), or field-erected concrete casings

If a two-pipe system is used, the piping network has both supply and return pipes in parallel for the main, lateral, street pipes, and street-to-house pipes. If a single-pipe system is used, the return water from the building heating (cooling) systems is disposed through the sewer system.

According to the capital cost models in Appendix B, PVC casing is considerably less expensive than carbon stee 1 casing up to 24 inch diameters. However, the code currently does not simulate the mixing of pipe or casing materials.

For example, using PVC pipes for smaller diameter casing sizes (street to buildings) and carbon steel for larger diameter casing sizes (streets, laterals, and mains), cannot currently be simulated.

The input parameters for selecting the material and configuration options of the distribution piping system are defined below. (a) A single-pipe system would generally not be applicable to the type of
ATES installation depicted in Figure 2 of Section 2.1 . 
Pipe option to design the configuration of the conduit bundle (pipe, insulation, and casing) for the distribution system. The pipe options ${ }^{(a)}$ are:

1. Two pipes, only supply insulated, with supply and return in common casing.

2. Two pipes, supply and return in common insulation and casing.

3. Two pipes, supply and return insulated separately in a common casing.

4. Two pipes, supply and return insulated separately in separate casings.

5. Two pipes, supply pipe insulated only and in separate casing from the return pipe.

6. Single pipe, supply insulated in casing. The return water from the building heating (cooling) system is disposed through the sewer system.

The default is 1 .

(a) The code overrides the input values for the pipe option P0 if the optimized internal pipe diameters are greater than 12 inches and the casing option $\mathrm{CO}=1$ or 2 as follows:

1) $\mathrm{PO}=1$ is reset to $\mathrm{PO}=5$ if the internal pipe diameter is greater than 12 inches.

2) $P O=2$ or 3 is reset to $P O=4$ if the internal pipe diameter is greater than 12 inches.

3) $\mathrm{PO}=4$ through 6 are left unchanged.

This automatic change applies only for the conditions stipulated above. The original input value for PO still applies whenever the internal pipe diameters are less than 12 inches. The reason for automatically switching from common casings to separate casings through the pipe option PO is economic. For internal pipe diameters greater than 12 inches, separate casings are less expensive than common casings according to the capital cost models described in Appendix $B$. 
Pipe material options:

1. Carbon steel, schedule 40

2. Fiberglass reinforced plastic (FRP), schedule 40; FRP pipe is currently limited in subroutine SIZE to pipe diameters $\leq$ 12 in. See Table B-4.

The default is 1 . Insulation options ( 10 is declared a floating-point variable in the AQUASTOR code):

1. Calcium silicate

2. Polyurethane foam

3. Fiberglass

The default is 1 .

Casing options:

1. Prefabricated steel, class A casing

2. Prefabricated plastic (PVC) casing; PVC casing is currently limited in subroutine SIZE to casing diameter $\leq 24$ in. See Table B-6.

3. Field erected poured concrete casing

The default is 1 .

TA

DPTH

Annular air space size (meters). The annular air space is between the insulation and the casing to allow air circulation to dry out the insulation. The default is .0254 meters ( 1 inch). Burial depth (meters) of casing, measured from the top of the casing to the surface of the ground. The default is 0.5 meters (19.69 inches).

CP Thermal conductivity of the pipe (joules/sec-m- ${ }^{0} \mathrm{C}$ ). The default is 3.56 joules $/ \mathrm{sec}-\mathrm{m}^{0}{ }^{0} \mathrm{C}$ or $24.7 \mathrm{Btu} / \mathrm{hr}-\mathrm{ft}^{2}-{ }^{0} \mathrm{~F} / \mathrm{in}$. for carbon steel pipe. This parameter must also be changed if the pipe material parameter PMO is changed from its default value of carbon steel pipe.

CG Thermal conductivity of the ground (joules/sec-m- ${ }^{0} \mathrm{C}$ ). The default is 0.36 joules $/ \mathrm{sec}-\mathrm{m}-{ }^{\circ} \mathrm{C}$ or $2.5 \mathrm{Btu} / \mathrm{hr}-\mathrm{ft}^{2}-{ }^{0} \mathrm{~F} / \mathrm{in}$. 
KINS Thermal conductivity of the insulation around the buried distribution piping (joules/sec-m- ${ }^{\circ} \mathrm{C}$ ). The variable KINS is declared a floating-point variable in the AQUASTOR code. The default values defined in subroutine DIST are:

1. Calcium silicate - .0418 joules $/ \mathrm{sec}-\mathrm{m}-{ }^{\circ} \mathrm{C}$ or $.29 \mathrm{Btu} / \mathrm{hr}-$ $\mathrm{ft}^{2}-{ }^{\mathrm{O}} \mathrm{F} / \mathrm{in}$.

2. Polyurethane foam- .0187 joules $/ \mathrm{sec}-\mathrm{m}-{ }^{\circ} \mathrm{C}$ or $.13 \mathrm{Btu} / \mathrm{hr}-$ $\mathrm{ft}^{2}-{ }^{\mathrm{O}} \mathrm{F} / \mathrm{in}$.

This parameter must also be changed if the insulation material parameter 10 is changed from its default value of calcium silicate.

TG Average year-round ground temperature $\left({ }^{\circ} \mathrm{K}\right)$. The default is $283^{\circ} \mathrm{K}\left(50^{\circ} \mathrm{F}\right)$.

VMBTU Value of one million Btus of heat (chi11) in base year January, PRINDX dollars. This parameter is used in determining the value of lost heat (chill) for optimizing the insulation thickness around the distribution pipes. The default is $\$ 6 / \mathrm{MBtu}$ in January, 1980 dollars.

AGFACT(I) Age factor to increase (multiply) friction losses in distribution $I=1,3$ system pipes due to the increase in relative roughness and the deterioration of pipes with age. Three multipliers are used, depending upon the nominal outer pipe diameters. The default values of the age factor were selected to correspond approximately to a pipe age of 10 years. (a)

The default values are as follows:

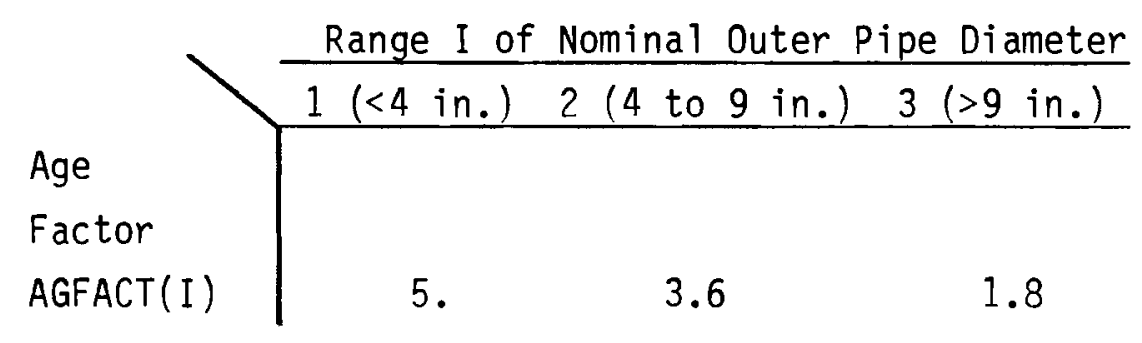

(a) Hydraulic Handbook, Colt Industries, Fairbanks Morse Pump Division, 4th Edition, 1965. 
The estimated pressure drop in a pipe equals the pressure drop calculated for new pipe times the age factor. This factor applies to all distribution system piping: mains, laterals, street, and house pipes.

WLEAK Fraction of fluid lost by accumulative leakage in the transmission and distribution systems. The default is 0.01 .

\subsubsection{Point Demand}

The simulation of a single point demand, i.e., a district consisting of one point of heat or chill demand, is implemented by using district number 1 with its district type set to 6. Recall from Section 3.4.5.2 that district type 6 is reserved for defining a single point demand. The default values defining the characteristics of district type 6 were previously summarized in Table 8 of Section 3.4.5.2.

The two key parameters used to define the annual heating or cooling energy requirements for a single point demand are the peak heat or chill demand and the annual load factor. The peak heat or chill demand is input using the district type parameters $\mathrm{HQ}(6)$ or $\mathrm{CQ}(6)$ expressed in MBtu of heat or chill per hour. Contrary to the simulation of residential districts, the annual load factor for a single point demand is not calculated by the code from climatic data but instead is defined in the input data using the input parameter PF.

AQUASTOR calculates the average heat demand during the year and the annual heat demand for the single point demand as follows:

1) Average heat demand $(\mathrm{MBtu} / \mathrm{hr})=$ peak heat demand $(\mathrm{MBtu} / \mathrm{hr}) *$ annual load factor, i.e., Average heat demand $(\mathrm{MBtu} / \mathrm{hr})=\mathrm{HQ}(6) \star \mathrm{PF}$.

2) Annual heat demand (MBtu/yr) $=$ average heat demand (MBtu/hr) * number of hours per year, i.e., Annual heat demand $(\mathrm{MBtu} / \mathrm{yr})=\mathrm{HQ}(6) * \mathrm{PF} * 24$. * 365.25 .

Several assumptions are present in the code when simulating a point demand. These are as follows:

1) Only one point demand can currently be simulated at a time. 
2) No sanitary hot water heating requirements and no supplemental heating or cooling are simulated for a point demand.

3) No retrofit costs are applied to a point demand.

The parameters described previously for defining the operational mode (Section 3.4.1), optional distribution heat exchanger (Section 3.4.4), and distribution system piping design (Section 3.4.6) also apply to the simulation of a single point demand. Parameters defining climatic data such as heating degree days or cooling degree hours do not apply.

The values that must be input for the geometric and district type parameters to simulate a single point demand are defined below. The district type parameters not mentioned below should be left set to their default values previously defined in Table 8 of Section 3.4.5.2.

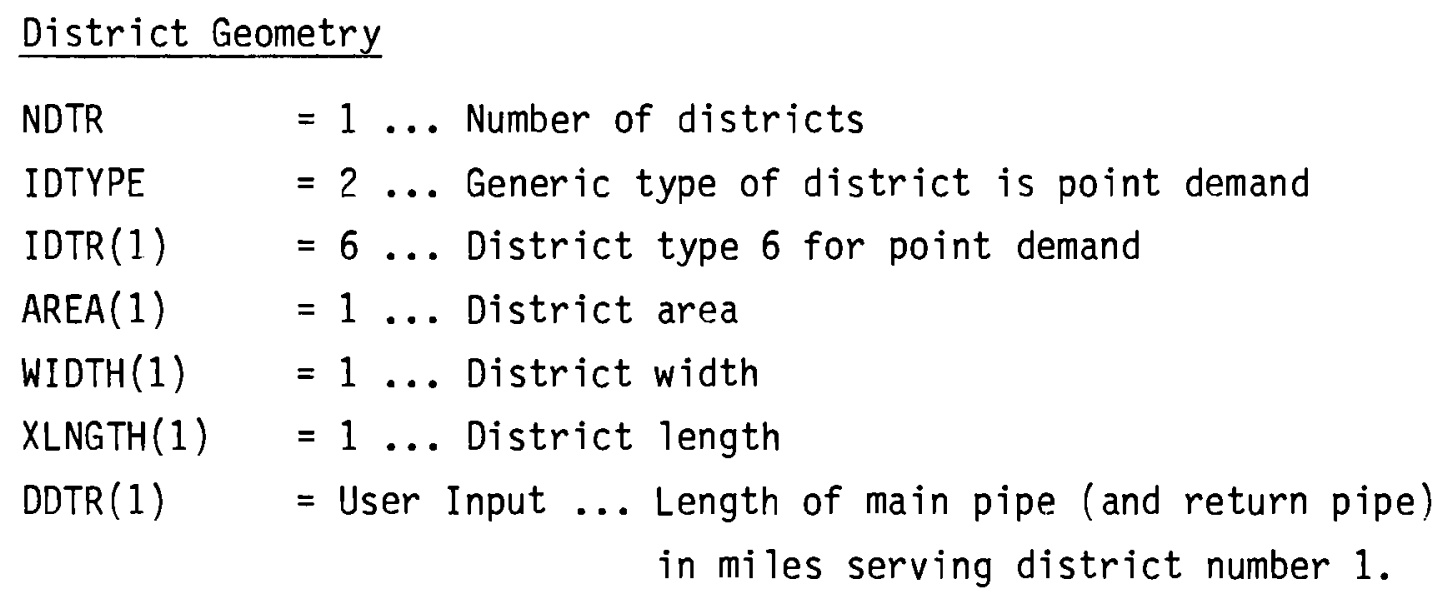

\section{District Type Characteristics}

$\mathrm{HQ}(6) \quad=$ User Input ... Peak heat or chill demand in MBtu/hr for the or $\operatorname{CQ}(6) \quad$ single point demand

PF $\quad=$ User Input ... Annual load factor expressed as a fraction

$\operatorname{TREJ}(6)=$ User Input $\ldots$. Temperature $\left({ }^{\circ} \mathrm{F}\right)$ of the return water at

or the outlet of the point demand heating or

TREJC(6) cooling system.

3.4.8 Branching Mains Network for Multi-Residential Districts

A variety of main configurations can be simulated to service multiresidential districts in AQUASTOR. The configuration of mains is defined by 
means of two matrices: DDTR (District $M$ ), $M=1$ to number of districts (NDTR), and DNET (district $M$, main MM), $M=1$ to number of districts, $M M=1$ to number of mains. The matrices DDTR and DNET are dimensioned 20 and $20 \times 20$ respectively. The Mth element, DDTR (district $M$ ), defines the length (miles) of the main servicing district $M$. Lengths are measured from either the inlet to the distribution system or the last junction in the main to the center of district $M$.

The matrix DNET defines the districts serviced by each main. The element DNET (district $M$, main MM) is set to one of the following values:

2 , if main $M M$ connects directly to district $M$

1 , if main MM transports flow to district $M$ but does not connect directly to district $M$

0 , if main $M M$ does not transport flow to district $M$ in any way.

The procedure for setting up this matrix is defined later in this section. Two options are available for defining the configuration of mains.

Option 1. Each Main Services One and Only One District

Option 1 is used to simulate a simple layout of mains in which each main from the distribution inlet services one and only one district. The configuration of mains is illustrated by sample configuration 1 in Figure 12 . The matrix DDTR (district $M$ ), $M=1$ to number of districts, is used to define the length (miles) of the main serving district $M$. The matrix DNET (district $M$, main $M M), M=1$ to number of districts, $M M=1$ to number of mains, can be left set to its default value of all zeroes. As an alternative approach, configuration 1 can also be simulated using the procedure discussed in option 2 below. Using this approach to simulate configuration 1, the element DNET (district $M$, main MM) is set to 2 whenever main MM connects directly to district $M$ in configuration 1 and set to 0 otherwise.

Option 2. At Least One Main Services More Than One District.

Option 2 is used to simulate more complex configurations of mains in which at least one main services more than one district. With this option, the following main configurations can be simulated. 
- One or more mains service several districts in series, i.e., one or more mains servicing a district continue beyond that district to service additional districts, as illustrated by sample configuration 2 in Figure 12.

- One or more mains branch (subdivide) into two or more mains to service additional districts, as illustrated by sample configuration 3 in

Figure 12.

- Combinations of the above two configurations (combinations of series and branches), as illustrated by sample configuration 4 in Figure 12.

The following steps are suggested for defining option 2:

Step 1. Number a11 districts serviced by a main and all main intersections outside a district, beginning with the districts furthest away from the distribution inlet and proceeding toward the distribution inlet. (a) The number assigned to a given district or main intersection outside of a district must be greater than that assigned to any district or main intersection outside a district further down the main away from the distribution inlet. Figure 12 shows several configurations that illustrate the numbering scheme for districts and main intersections outside a district. In addition, a main intersection outside a district must be defined as a district with zero area and zero heat (chi11) demand in the input data.

Step 2. Number the mains beginning with main number 1 at the distribution inlet and proceeding away from the distribution inlet. At every main intersection that branches (divides) into 2 or more mains, number each branch with a new main number. This numbering scheme for mains is illustrated in Figure 12. Observe that a main that does not divide into 2 or more branches, such as main number 1 in configuration 2 or main number 4 in configuration 4 , can retain the same main number in its next leg.

\footnotetext{
(a) A main intersection may occur inside a district, as number 9 in configuration 4 of Figure 12, or outside a district, as numbers 4 and 8 in configuration 4 .
} 
Step 3. Set up the matrix DDTR (district $M), M=1$ to number of districts (NDTR), defining the distance (miles) from the higher number district on the same main or from the main intersection immediately preceding the district to district number $M$. The sample configurations in Figure 12 illustrate the definition of the lengths of the mains.

Step 4. Set up the matrix DNET (district $M$, main MM), $M=1$ to number of districts (NDTR), MM = 1 to number of mains, defining the districts serviced by each main. Set the element DNET (district M, main MM) to one of the following values:

2, if main MM connects directly to district $M$

1 , if main MM transports flow to district $M$ but does not connect directly to district $M$

0 , if main MM does not transport flow to district $M$ in any way.

In defining the $20 \times 20$ two-dimensional matrix DNET through the NAMELIST input data, the user should be careful to input the array values by columns, i.e., define all rows (district numbers) for the first column (main number 1), next all rows (district numbers) for the second column (main number 2), and so on. The user should also define the entire 20 rows for each column, inputting zeros if necessary to complete the 20 entries for each column. Additionally, zeros should be input if necessary to complete the entries for all 20 columns. This will result in a matrix with values defined for a11 $400(20 \times 20)$ entries.

The matrices DNET (district number, main number), DDTR (district number), and AREA (district number) are set up in Table 9 for sample configurations 2 through 4 in Figure 12 to illustrate the procedure for defining option 2. These matrices are defined for sample configurations 2 through 4 using NAMELIST input data as follows:

Sample Configuration 2

$$
\begin{aligned}
& \text { DNET }=2 * 2,18 * 0,380 * 0, \\
& \text { DDTR }=1_{1}, 1_{2}, 18 * 0, \\
& \text { AREA }=a_{1}, a_{2}, 18 * 0,
\end{aligned}
$$


TABLE 9. Matrix Examples for Branching Mains Network CONFIGURATION 2

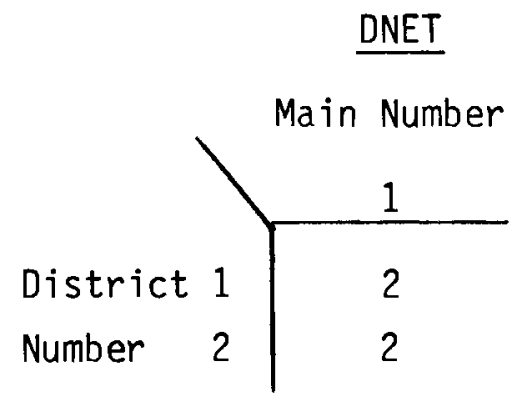

DDTR $\quad$ AREA

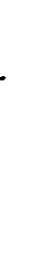


Sample Configuration 3

$$
\begin{aligned}
& \text { DNET }= 1,1,2,17 * 0,0,2,0,17 * 0,2,0,0,17 * 0,340 * 0, \\
& \text { DDTR }= 11,12,13,17 * 0, \\
& \text { AREA }= a_{1}, a_{2}, 0,17 * 0, \\
& \text { Sample Configuration } 4 \\
& \text { DNET }= 8 * 1,2,11 * 0,3 * 1,2,16 * 0,2 * 0,2,17 * 0,2 * 2,18 * 0,4 * 0,3 * 1, \\
& 2,12 * 0,6 * 0,2,13 * 0,4 * 0,2,15 * 0,5 * 0,2,14 * 0,240 * 0, \\
& \text { DDTR }= 1_{1}, 1_{2}, 1_{3}, 1_{4}, 1_{5}, 1_{6}, 1_{7}, 1_{8}, 19,11 * 0,
\end{aligned}
$$

\subsection{FINANCIAL INPUT DATA}

AQUASTOR can simulate a wide range of financial and tax structures through input parameters that vary the rates of return on equity and debt, the debtequity ratios, tax rates, interim capital replacement rates, investment tax credits, property insurance rates, and depreciation schedules. Both private enterprise and municipal utility systems can be simulated. The supply system and the distribution system may have the same or different financial structures and costs of capital. The supply system life and distribution system life can be varied over a long period, currently up to 50 years.

The financial parameters for the supply system are input through the NAMELIST group \$RESVOR. Distribution system financial parameters are input through the NAMELIST group \$DISTRB. Described within Sections 3.5.1 through 3.5.6 are financial data concerning both supply and distribution systems, well drilling costs, trenching costs, and aquifer pre-development, development, and operating activities.

The remaining capital costs of the supply and distribution systems are calculated by the code using the capital cost models described in Appendices $D$ and $B$. The cost of purchased thermal energy was previously defined as the input parameter SHCOST in Section 3.3.1. The cost of thermal energy delivered to the distribution system is calculated by the code. The cost of supplemental heat is defined by the input parameter CSBTU (see Section 3.5.5.3). The 0\&M costs for the supply and distribution system are calculated by the code as fractions of their capital costs, as described in Section 3.5.1 and Appendix B 
respectively. The rates (fractions) for interest, return on equity, tax, capital replacement, property insurance, and maintenance are specified through the input data defined in Sections 3.5.1 and 3.5.3. The pumping electrical costs for the supply and distribution systems are calculated using the parameters ETA and COPUMP, as defined in Section 3.5.5.3.

\subsubsection{Supply System Financial Data}

This section describes the input array $\operatorname{DINPUT}(N), N=1$, to 35 , which is used to define the financial and tax data for the supply system. Other parameters described include the investment tax credit for the supply system and the option to either capitalize or expense all the intangible aquifer predevelopment costs described in Section 3.5.6.

The economic submodels in AQUASTOR use mid-year discounting with the aftertax cost of capital as the discount rate. The discount rate is calculated by the code from the input parameters below as follows:

After-tax discount rate $=$ bond interest rate $*[1-\{$ (federal tax rate $)$ * (1-state tax rate) + state tax rate $\}] *$

fraction of investment in bonds + equity return rate * fraction of investment in equity

The parameters defined below are input through the NAMELIST group \$RESVOR. The values of DINPUT(N) not mentioned below are not input into the code.

$\mathrm{N} \longrightarrow$ Description of DINPUT(N)

4 Fraction of initial investment in bonds; default is 0.42 .

5 Bond interest rate (fraction); default is 0.08 .

6 Earning rate on equity after taxes (fraction); default is 0.15 .

7 Federal income tax rate (fraction); default is 0.46 .

9 Depreciable life of aquifer wells (years); default is 30 years. This value must be less than or equal to the average aquifer well life (AVGWL) defined in Section 3.3.3.

14 Startup year for operation of the distribution system, default is 1990 . The same year must also appear in DINPUT(49) in Section 3.5.3.

15 State income tax rate (fraction); default is 0.07 . 
16 State gross revenue tax rate (fraction); default is 0.

17 Property tax rate (fraction); default is 0.025 .

18 Transmission system interim capital replacement rate, fraction of transmission capital cost; default is 0.0035 .

19 Property insurance rate (fraction); default is 0.0012 .

26 Depreciable life of transmission system (years); default is 15 years. This value must be less than or equal to the transmission and distribution system operating life DINPUT(61) defined in Section 3.5.3.

27 Royalty payments, percentage of supply system annual sales; default is $0 \%$.

28 Transmission system maintenance rate, fraction of transmission capital cost; default is 0.05 .

PIVTCR Percent investment tax credit for the supply system; default is $0 \%$.

IEXPNS Option to capitalize (IEXPNS=0) or expense (IEXPNS=1) all the aquifer pre-development costs described in Section 3.5.6. The default is IEXPNS=0. With the default option, all aquifer predevelopment costs are capitalized and amortized on a straight line basis.

\subsubsection{Aquifer Well Drilling Costs}

Well drilling costs are either input directly or calculated by the drilling model in the code. The option to directly input the drilling costs is described first. This option is implemented by defining the three input parameters described below through the NAMELIST group \$RESVOR.

IDRILL Set to 0 to input the well drilling costs directly. This is the default value. The drilling costs should be input in the same base year dollars in which the capital costs are calculated in the code (January, PRINDX dollars, defined in Section 3.5.5.1, with default value of January, 1980 dollars).

DCPW Total cost (January, PRINDX dollars) of all tasks involved in drilling one aquifer well. The default is $\$ 150,000$ in January, 1980 dollars. 
PERCNT(N) Fraction (not percentage) tangible and intangible parts respec$\mathrm{N}=1,2$ tively of the drilling costs for aquifer wells. The optional breakdown into tangible and intangible parts is provided because of possible differential tax treatment. The tangible part is capitalized with costs recovered through the well depreciation account. The intangible part is expensed immediately. The default values for the PERCNT array are as follows:

$$
\begin{aligned}
& \operatorname{PERCNT}(1)=1 ., \text { fraction tangible } \\
& \operatorname{PERCNT}(2)=0 ., \text { fraction intangible. }
\end{aligned}
$$

The option to calculate the drilling costs using the drilling model (subroutine DRILL) is implemented by setting the parameter IDRILL to 1 and defining four other input parameters through the NAMELIST group \$RESVOR: the fraction of we 11 cased (CASFRC), the well diameter (DIA), the rock hardness to be drilled and the drill depth (NUMTYP, STRATA(M,N), $M=1,2 ; N=1,10$ ). In addition, the drilling costs are also a function of the wellhead temperature, which is calculated by the code. The parameters CASFRC, DIA, NUMTYP, and STRATA(M, $N), M=1,2 ; N=1,10$, were previously defined in Section 3.3.3. A11 input parameters are input through the NAMELIST group \$RESVOR.

IDRILL Set to 1 to let the code calculate the drilling costs using the drilling model in subroutine DRILL. The calcuated drilling costs are automatically updated to the base year dollars (January, PRINDX dollars, defined by the user in Section 3.5.5.1) using drilling price indices obtained from drilling publications. (a) The drilling model also sets the parameters PERCNT(1) and PERCNT(2) described above to 1 and 0 respectively, which represent the fraction tangible and intangible parts of the drilling costs for aquifer wells.

The drilling costs are calculated in subroutine DRILL as the weighted sum of 20 separate categories described below. The

(a) June 1975 report of the Independent Petroleum Association of America (IPAA) Cost Study Committee and February 15, 1981 issue of World 011 Magazine. 
costs in each category are first calculated relative to July, 1969 as the base year. These costs are then brought up-to-date by separate drilling price indices stored in subroutine DRILL for each of the 20 categories. The drilling price indices are defined relative to January, PRINDX as the base year. Currently, the parameter PRINDX cannot be increased beyond its default value of January, 1980 without first updating the drilling price indexes stored in subroutine DRILL for January, 1980. However, this is an easy program modification. The cost calculated in each category is updated by subroutine DRILL using the driliing price index for that category as follows:

Cost of category(I) in January, PRINDX dollars $=$ Cost of category(I) in July, 1969 dollars * Drilling Price Index(I) / 100.

The 20 categories and their drilling price indexes stored in subroutine DRILL for January, 1980 drilling cost updates are as follows:

\begin{tabular}{l} 
Drilling Cost Category \\
\hline 1-Payments to Contractors \\
2-Road \& Site Preparation \\
3-Transportation \\
4-Fuel \\
5-Drilling Mud and Additives \\
6-Well Site Logging \\
7-A1l other Physical Tests \\
8-Logs \\
9-Directional Drilling \\
10-Perforate \\
11-Formation Treating \\
12-Cement \\
13-Casing \\
14-Special Tools \\
15-Drill Bits \\
16-Wellhead Equipment \\
17-Plugging \\
18-0ther Equipment and Supplies \\
19-Supervision \\
20-All Other Expenses
\end{tabular}

Drilling Price Index for January, 1980

378.0

218.9

216.9

488.5

334.4

214.6

262.3

281.8

229.5

231.9

221.4

248.1

323.1

226.1

263.5

292.7

246.4

274.7

239.9

233.8 


\subsubsection{Distribution System Financial Data}

This section describes the input array DINPUT(N), N=36 to 70 , which is used to define the financial and tax data for the distribution system. Other parameters described include the construction time for the distribution system and the investment tax credit.

The after-tax discount rate is calculated by the code from the input parameters defined below in an analogous manner as described for the supply system in Section 3.5.1. The capital investment schedule during the construction time period was described previously in Section 2.9.

The parameters defined below are input through the NAMELIST group \$DISTRB. The values of DINPUT(N) not mentioned below are not input into the code.

39 Fraction of initial investment in bonds; default is 0.59 .

40 Bond interest rate (fraction); default is 0.08 .

41 Earning rate on equity after taxes (fraction); default is 0.12 .

42 Federal income tax rate (fraction); default is 0.46 .

44 Depreciable life of distribution system (years); default is 15 years. This value must be less than or equal to the distribution system operating life [DINPUT(61)].

49 Startup year for operation of the distribution system; default is 1990. The same year must also appear in DINPUT(14) in Section 3.5.1.

50 State income tax rate (fraction); default is 0.07 .

51 State gross revenue tax rate (fraction); default is 0.04 .

52 Property tax rate, fraction of distribution system capital investment; default is 0.025 .

53 Interim capital replacement rate, fraction of distribution system capital investment; default is 0.0035 .

54 Property insurance rate, fraction of distribution system capital investment; default is 0.0012 .

61 Distribution (also transmission) system operating life (years); default is 30 years.

63 Distribution system maintenance rate, fraction of distribution capital cost; default is 0.05 . 
NYC

Number of years to construct the distribution system. The default is 3 years.

PIVTCP Percent investment tax credit for the distribution system. In the first year of operation, the investment tax credit is computed as a fraction (PIVTCP*.01) of the total construction period capital cost and interim capital replacements. In any subsequent year of operation, the investment tax credit is computed as a fraction of the interim capital replacements for that year. The default is $0 \%$.

\subsubsection{Distribution System Trenching Costs}

Trenching costs for the distribution system are calculated by suming five component costs of trenching in a trenching cost model represented by the capital cost equations in Table B-1 of Appendix B. The five components of the trenching cost model are as follows:

1) Excavation

2) Bedding fill, including the purchase and delivery of sifted fill material

3) Back fill, including the purchase and delivery of sifted fill material

4) Finish fill, using the excavated material to fill and pack to grade with a bul1dozer

5) Resurfacing

The physical layout of the trenches used in the trenching cost model for the different pipe and casing options described in Section 3.4.6 is shown in Figure 13.

The trenching cost model assumes vertical slopes with excavation through a dirt and rock mixture. The trenches are assumed to be dug in residential areas, requiring some hand excavation and relocation of existing utilities. Two inches of bedding fill hauled to the site is placed under the pipe casing. Sifted backfill material is hauled to the site and hand filled and tamped in 8 in. lifts until the distribution pipe casing is covered by 2 in. of fill. The rest of the trench is filled and packed by a bulldozer. Resurfacing consists of $2 \mathrm{in.}$ of pavement on top of $2 \mathrm{in.}$ of gravel. The top of the casing is at the specified burial depth DPTH below the surface of the ground as defined in Section 3.4.6. 


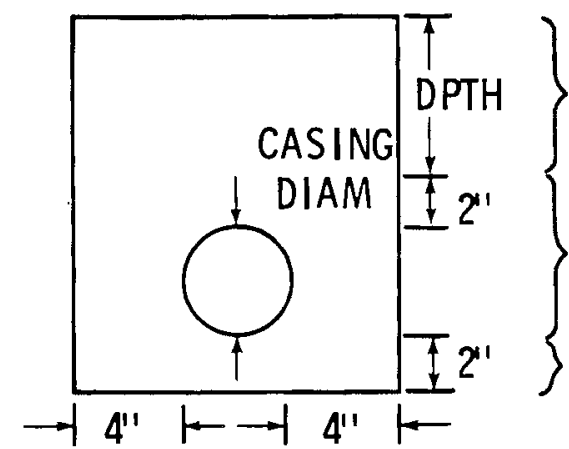

FINISH FILL

BACK FILL

BEDDING FILL

SEPARATE CASINGS

PIPE OPTIONS PO $=4,5$ AND CASING OPTIONS CO $=1,2$

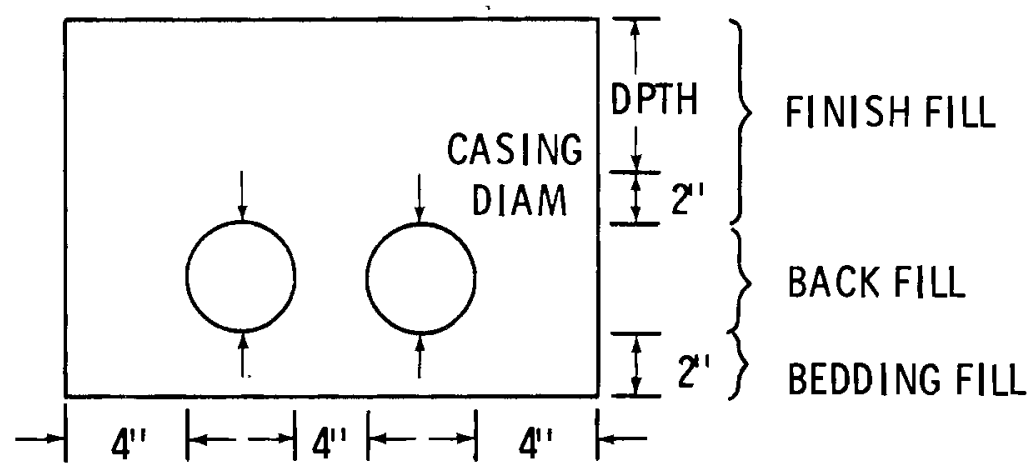

CONCRETE CASING

CASING OPTION CO $=3$

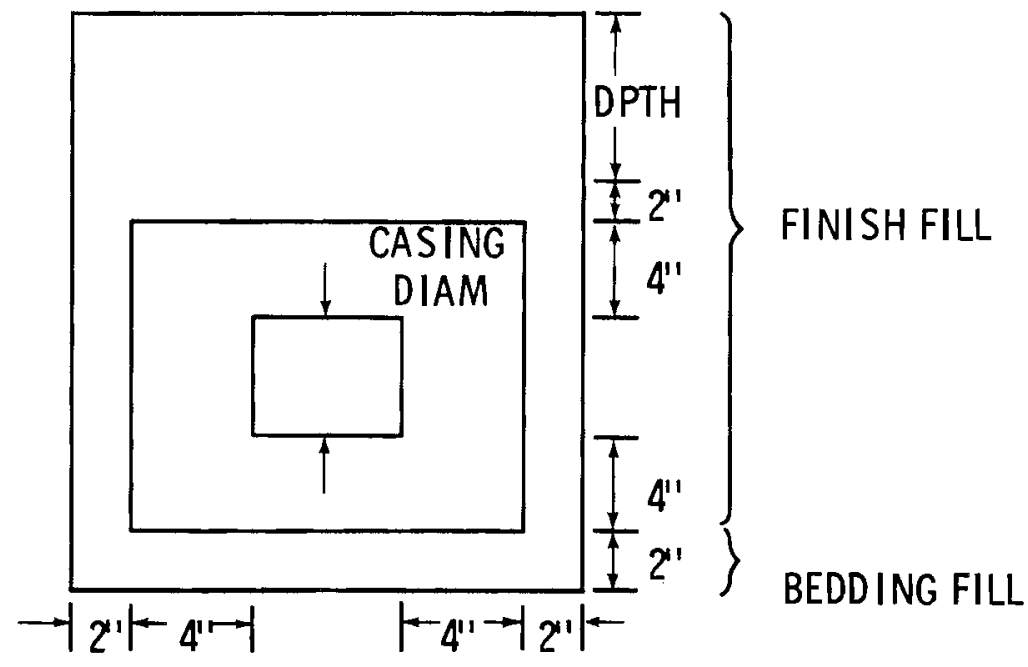

FIGURE 13. Physical Layout of Buried Pipe Trenches Used in the Trenching Cost Model 
The five component costs of trenching can be individually adjusted through the cost parameters defined below. These costs are input in January, 1977 do 11 ars through the NAMELIST group \$DISTRB and then escalated by the code to January, PRINDX base year dollars using the Chemical Engineering Plant Cost Index for the category of "construction labor". Section 3.5.5.1 provides a description of these indices.

EXCC Excavation cost of trenching, \$/meter ${ }^{3}$. The default value of $\$ 26.16 /$ meter $^{3}$ is based on excavation through a dirt and rock mixture. These costs assume union labor and that the trenches are being dug in residential areas, requiring some hand excavation and relocation of existing utilities.

BEDC Bedding fill cost $\$ /$ meter $^{3}$. The default value of $\$ 13.10$ / meter ${ }^{3}$ is based on the use of sifted fill material hauled 10 miles to the site. Two inches of bedding fill is placed in the trench underneath the pipes.

BACKC Backfill cost, $\$ /$ meter $^{3}$. The default value of $\$ 13.10 /$ meter $^{3}$ is based on the use of sifted fill material hauled 10 miles to the site and hand tamped in 8 in. lifts until the top of the pipe is covered by 2 in.

FINC Finish fill cost, $\$ /$ meter $^{3}$. The default value of $\$ 1.30 /$ meter $^{3}$ is based on using excavated material filled and packed to grade with a bulldozer.

RESRFC Resurfacing cost, $\$ /$ meter $^{2}$. The default value of $\$ 8.40 /$ meter $^{2}$ is based on a 2 in. layer of pavement on top of 2 in. of gravel.

TRDF Trenching difficulty factor, used to increase (multiply) the total cost of trenching depending on local conditions at the simulated site. The default value is 1 .

\subsubsection{General Economic Parameters}

\subsubsection{Base Year of Capital and 0\&M Costs and Depreciation Options}

A11 capital and 0\&M cost estimates stored in the internal cost data bases for AQUASTOR or calculated by the capital and 0\&M cost models described in 
Appendices $B$ and $D$ are defined in January, 1977 dollars. This section describes an input parameter PRINDX defined through the NAMELIST group \$DISTRB which automatically updates these costs to January, PRINDX base year dollars. The default value of PRINDX is 1980. This automatic updating is performed using nine Chemical Engineering (CE) Plant Cost indices published monthly in Chemical Engineering magazine and described below.

The following cost parameters must also be input in January, PRINDX base year dollars to operate the code using these base period dollars:

1) The cost of purchased thermal energy from the energy source defined as the input parameter SHCOST in Section 3.3.1.

2) The drilling costs defined as the input parameter DCPW in Section 3.5.2 if the drilling model is not used. If the drilling model is used, AQUASTOR automatically updates the drilling costs it calculates to January, PRINDX base year dollars using the price index adjustments for drilling previously described in Section 3.5.2.

3) The electrical cost of operating the transmission and distribution system pumps defined as the input parameter COPUMP in Section 3.5.5.3.

4) The cost of supplemental heat defined as the input parameter CSBTU in Section 3.5.5.3.

5) The value of supplemental heat defined as the input parameter VMBTU in Section 3.4.6.

6) The building retrofit costs defined as the input array $\operatorname{CRTF}(N), N=1$ to 8 , Section 3.4.5.2.

7) The supply system unit costs defined as the input array UNITO(N), $N=1$ to 39, in Section 3.5.6.

In addition, if the trenching cost parameters described in Section 3.5.4 are changed from their default values, they must be estimated in January, PRINDX dollars and then deflated to January, 1977 dollars using the price index adjustment for the category "construction labor" (see below) before they are input into the code. This is due to the fact that AQUASTOR automatically updates the trenching cost parameters from January, 1977 dollars to January, PRINDX base year dollars.

The capital cost updates implemented through the input parameter PRINDX are programmed in subroutine UPDATE of the code using nine CE Plant Cost Indices. 
Currently, the parameter PRINDX cannot be increased beyond its default value of January, 1980 without first modifying subroutine UPDATE. However, this is an easy programming modification since subroutine UPDATE is a small routine. In addition, if the drilling model is used, the drilling price index adjustments in subroutine DRILL described in Section 3.5 .2 must also be modified if the parameter PRINDX is increased beyond January, 1980.

The nine CE plant cost Indices are defined in subroutine UPDATE as follows:

\begin{tabular}{|c|c|c|c|}
\hline $\begin{array}{l}\text { Generic Cost } \\
\text { Category }\end{array}$ & $\begin{array}{l}\text { CE Index } \\
\text { Jan } 1977 \\
\end{array}$ & $\begin{array}{l}\text { CE Index } \\
\text { Jan } 1980 \\
\end{array}$ & $\begin{array}{l}\text { Index Ratio } \\
\text { (Adjustment) } \\
\end{array}$ \\
\hline $\begin{array}{l}1 \text { - Buildings } \\
2 \text { - Fabricated Equipment (Including } \\
\text { Heat Exchangers) }\end{array}$ & $\begin{array}{l}194 . \\
208.3\end{array}$ & $\begin{array}{l}234.8 \\
274.9\end{array}$ & $\begin{array}{l}1.210 \\
1.320\end{array}$ \\
\hline $\begin{array}{l}3 \text { - Process Machinery } \\
4 \text { - Pipes, Valves \& Fittings } \\
5 \text { - Pumps \& Compressors } \\
6 \text { - Electrical Equipment } \\
7 \text { - Structural Support \& Misc. } \\
\quad \text { (Including Insulation \& Casing) }\end{array}$ & $\begin{array}{l}205.8 \\
236.6 \\
234.6 \\
154 . \\
219.3\end{array}$ & $\begin{array}{l}263.7 \\
317.6 \\
293.8 \\
196.9 \\
285.5\end{array}$ & $\begin{array}{l}1.281 \\
1.342 \\
1.252 \\
1.279 \\
1.302\end{array}$ \\
\hline 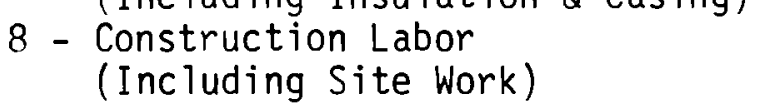 & 178.5 & 199.2 & 1.116 \\
\hline 9 - Engineering \& Manpower & 162.1 & 204.3 & 1.260 \\
\hline \multicolumn{4}{|c|}{$\begin{array}{l}\text { The cost index ratio for each generic category is the ratio of the CE cost } \\
\text { index for the user-specified year PRINDX to the CE cost index for the base year } \\
1977 \text { for that category. Subroutine UPDATE updates the capital cost for a capi- } \\
\text { tal cost item using its appropriate generic cost category and the following } \\
\text { equation: }\end{array}$} \\
\hline
\end{tabular}

Cost $($ Jan, PRINDX $\$)=$ Cost $($ Jan, 1977\$) * CE Cost Index Ratio

As pointed out in Section 3.5 and Appendix B, the 0\&M costs are calculated in the code as fractions of the capital costs. The fractions, such as interim capital replacement rate, maintenance rate, property insurance rate, etc., are specified through the input data. Therefore, updating the capital costs to January, PRINDX base year dollars also automatically updates the O\&M costs to the same base period dollars.

Two depreciation options are available in AQUASTOR for recovering the capital costs and interim capital replacements for the supply and distribution systems: straight line depreciation or double declining balance (DDB) accelerated 
depreciation with switch over to straight line. The switch is made in the year. when the depreciation calculated by DDB depreciation becomes less than it would be by straight line depreciation.

The parameters input through NAMELIST group \$DISTRB to implement the options described in this section are summarized below.

PRINDX January 1 of base year in which AQUASTOR calculates the capital and $0 \& M$ costs of the supply and distribution systems. The default is 1980. Any value beyond 1980 will require modifications to subroutines UPDATE and DRILL in the code.

LL2 Depreciation option for supply and distribution systems. 1 = straight line

3 = double declining balance with switch over to straight line The default is straight line depreciation.

\subsubsection{Inflation and Escalation}

AQUASTOR allows for the effects of inflation and price escalation in calculating the cost of thermal energy from the supply system and the cost of heat (chi11) from the distribution system. Input parameters are provided to define the general inflation rate and price escalation rates for four generic categories in the supply and distribution systems: capital equipment, 0\&M expenses, electricity expenses for pumps, and purchased thermal energy. Another input parameter is provided to define the financial mode of operating the code that permits either current dollar analysis with inflation and escalation or constant dollar analys is without inflation and escalation.

The four escalation rates allow the user to escalate costs in the four generic categories at a compound rate over the project lifetime to reflect a combination of inflation, supply/demand, and other effects such as environmental and engineering considerations. This definition of escalation allows inflation to be just one of several factors that can contribute to price escalation.

The current (inflated) dollar analysis is the default mode of operating the code. This mode calculates the unit costs (\$/MBtu) of energy from the supply system and the unit costs $(\$ / M B t u)$ of heat (chi11) from the distribution 
system for each year of the project lifetime in current dollars. The sale of energy to the distribution system and heat (chili) to the end-users generates the revenues needed by the supply and distribution systems respectively to exactly recover all costs in current dollars, including return on investment, over the project lifetime. Finally, based on the general inflation rate and after-tax discount rate, AQUASTOR levelizes and deflates the year-by-year costs of energy and heat (chill) in current dollars to obtain a lifecycle levelized cost (\$/MBtu) of energy and heat (chili) respectively expressed in January, PRINDX base year dollars. Operation of the code with constant dollars over the project lifetime generates a lifecycle levelized cost (\$/MBtu) of energy and a lifecycle levelized cost (\$/MBtu) of heat (chill) expressed in January, PRINDX base year dollars without inflation and escalation.

The values selected for interest rates and return on equity must be consistent with the financial mode of operating the code and the inflationary assumptions. For example, the default values selected for the interest rate $(0.08)$ and return on equity $(0.15)$ for the financial entity operating the supply system reflect market rates for the current dollar analysis (default mode) based on a default value of $6 \%$ for the general inflation rate (PIFALL = $6 \%$ below). If the code is operated in constant dollars without inflation or in current dollars with a lower general inflation rate, lower interest rates and return on equity should be defined in the input data.

The input parameters needed to simulate the effects of inflation and escalation in the supply and distribution systems are defined below. These parameters are input through the NAMELIST group \$RESVOR.

ICOST

Option to calculate the cost of thermal energy from the supply system and the cost of heat (chill) from the distribution system using either constant dollar analysis or current dollar analysis.

$0=$ Constant dollar analysis. This is the mode used with inflation and escalation rates below set to 0 .

1 = Current dollar analysis. This is the default mode used with the inflation and escalation rates below set greater than 0 . 
PIFALL Percent general inflation rate. The default is $6 \%$.

PIFCAP Percent escalation rate for capital and interim capital

replacement. The default is $6 \%$.

PIFCSB Percent escalation rate for purchased thermal energy. The

default is $8 \%$. This parameter escalates both the cost of thermal energy purchased by the supply system from the energy source (see the definition of the parameter SHCOST in Section 3.3.1) and the cost of supplemental heat purchased by the distribution system (see the definition of the parameter CSBTU in Section 3.5.5.3).

PIFELR Percent escalation rate for electricity needed for operating the pumps. The default is $7 \%$.

PIFOM Percent escalation rate for O\&M. The default is $6 \%$.

3.5.5.3 Cost of Supplemental Heat, Pumping Efficiency, and Pumping Electrical Costs

This section describes the input parameters used to define the cost of supplemental heat, the pumping efficiency, and the pumping electrical cost. Supplemental heating is used by the distribution system to meet two types of heating shortfalls. The first shortfall can arise if the energy source for the supply system can not supply all of the annual thermal energy required by the distribution system. The parameters used by the code in determining the annual thermal energy supply were previously defined in Section 3.3.1. The parameters used to determine the annual heating energy demand were previously defined in Sections 3.4.2 and 3.4.5.

The second shortfall arises when the outdoor temperature falls below the winter outdoor design temperature used in sizing the supply and distribution systems. Recall that the design heating degree days DDGDAY(1) and the winter outdoor design temperature TDES(1) in Section 3.4.2 are usually input to design the system to meet slightly less than the extreme peak heating energy requirements. This undersizing of the capacities of the supply and distribution systems is used to improve the system load factor. In this way, the system is not being sized at a large incremental cost to meet extreme peak heating demands that occur only a small fraction of the time during the winter. As previously 
described in Section 3.4.1, no supplemental cooling is provided by the code for either a residential district or a point demand.

The costs of supplemental heating to meet the heating shortfalls are calculated by the code as the product of the calculated MBtus of heating shortfall times the unit cost of supplemental heating (\$/MBtu). Supplemental heat is included in calculating the annual MBtus of thermal energy sold by the distribution system to the end-users but is also treated as an annual operating expense for the distribution system.

The pumping efficiency and unit cost of electricity to operate the pumps applies to all pumps in the supply and distribution systems including:

- The downhole pumps that provide the vertical lift and restore the frictional pressure losses in the aquifer wells.

- The surface pumps that restore the frictional pressure losses in the surface transmission piping of the supply system.

- The surface pumps at both the tube and shell sides of the heat exchangers located at the energy source and optionally at the inlet to the distribution system.

- The surface pumps that restore the frictional pressure losses in the distribution system piping.

The parameters summarized below are input through the NAMELIST group \$DISTRB.

CSBTU Cost of supplemental heat, expressed in January, PRINDX base year dollars. The default is $\$ 6 / \mathrm{MB} t u$.

ETA Combined motor and pump efficiency (fraction) of supply and distribution system pumps. The default is 0.65 .

COPUMP Unit cost of electricity for operating the supply and distribution system pumps, $\$ / k W h$, expressed in January, PRINDX base year dollars. The default is $\$ .029 / \mathrm{kWh}$. 


\subsubsection{Supply System Pre-Development, Development, and Operation Time Schedules and Costs}

Among the parameters described below are the time arrays used to schedule the times over which the activities comprising the pre-development, development, and operation of the supply system are to take place. The expenditures for these activities are distributed uniformly over the times in which they are scheduled to occur.

This section also describes a cost array used to calculate the costs of all activities comprising the pre-development of the supply system and the annual field operating costs for we 11 abandonment and we 11 maintenance. This array defines costs for these activities on a unit basis, primarily per aquifer site, acre, or we11. The total costs associated with these activities are calculated in the code by multiplying the appropriate unit costs by the number of aquifer sites, acres, or wells calculated for that activity.

The costs of all other activities in the development and operation of the supply system are defined or determined from parameters described in previous sections. This includes the major costs such as drilling aquifer wells, the capital costs of the transmission system and heat exchanger at the energy source, and all other annual operating costs labeled "Computed" in the righthand column of Table 10A.

This section also describes an array that defines the fraction of sites to retain at each of six major decision points in the step-by-step process of reducing the number of prospective aquifer sites during pre-development to one site for development and operation. The size of prospective aquifer sites leased for exploration is also defined below.

The parameters defined below are input through the NAMELIST group SRESVOR. ACRES Size (acres) of aquifer site leased for exploration. This parameter is multiplied by the input unit costs per acre associated with lease cost (UNITO(N),N $=6,7,8$ in Tables $10 \mathrm{~A}$ and 10B) to calculate the lease cost per site. Appendix $A$ gives the cost equations for calculating lease cost. The default value is 500 acres. 


\section{TABLE 10A. Activities and Input Costs for Supply System Pre-Development, Develop- ment, and Operation}

\begin{tabular}{|c|c|c|c|}
\hline $\begin{array}{l}\text { Index for Itemizing } \\
\text { Individual Activities } \\
\end{array}$ & $\begin{array}{l}\text { Index for } \\
\text { Grouping Activities }\end{array}$ & Description of Grouped Activities & $\begin{array}{l}\text { Unit Costs (Dollars) } \\
\text { for Individual Activities }\end{array}$ \\
\hline \multirow[t]{2}{*}{ N } & $I G P=G R O U P(N)$ & AQUIFER EXPLORATION ACTIVITIES & UNITO(N) \\
\hline & & Identification of Targets & \\
\hline 1 & 1 & Literature Search & $100 . / \mathrm{site}$ \\
\hline \multirow[t]{2}{*}{2} & 2 & Preliminary Land Check & $250 . /$ site \\
\hline & & Preliminary Reconnaissance & \\
\hline 3 & 3 & Literature Search & $700 . /$ site \\
\hline 4 & 4 & Geological Reconnaissance & $1000 . /$ site \\
\hline \multirow[t]{2}{*}{5} & 5 & Detailed Land Check & $1200 . /$ site \\
\hline & & Detailed Reconnaissance & \\
\hline $6,7,8(b)$ & 6 & Lease $\cos t$ & $\begin{array}{l}\text { 10./acre, } 10 . / \text { acre/year, } \\
2 . \text { /acre }\end{array}$ \\
\hline \multirow[t]{2}{*}{9} & 7 & Field Geology & $5000 . /$ site \\
\hline & & Environmental Impact Statement & \\
\hline 10 & 8 & Preparation and Publication & $20000 . /$ site $+5000 . /$ we 11 \\
\hline \multirow[t]{2}{*}{11,12} & 9 & Not Used & \\
\hline & & Aquifer Characterization & \\
\hline 13 & 10 & Pump Test & $1000 . /$ site \\
\hline 14 & 11 & Injection/Tracer Test & $3000 . /$ site \\
\hline 15 & 12 & Anisotrophy Test & $5000 . /$ site \\
\hline 16 & 13 & Geophysical Log & $15000 . /$ site \\
\hline \multirow[t]{2}{*}{17} & 14 & Microbiology/Geochemistry & $10000 . /$ site \\
\hline & & Exploration Drilling & \\
\hline $18,19,20,21$ & 15 & Total cost of Drilling to Aquifer Depth & $100 / \mathrm{ft}$ fixed in Subroutine RESVO \\
\hline \multirow[t]{2}{*}{22} & 16 & Not Used & \\
\hline & & FIELD DEVELOPMENT ACTIVITIES & \\
\hline 23,24 & 17 & Aquifer Well Drilling & DCPW/well or drilling model \\
\hline 25 & 18 & Not Used & \\
\hline 26,27 & 19 & Not Used & \\
\hline $28(c)$ & 20 & $\begin{array}{l}\text { Legs } 1 \text { and } 2 \text {, Node } 2 \text {, and Heat } \\
\text { Exchanger at Node } 1\end{array}$ & $\begin{array}{l}\text { Computed in Subroutines INJECT } \\
\text { and TRANS }\end{array}$ \\
\hline \multirow[t]{2}{*}{$29(d)$} & 21 & Legs 3 and 4 and Node 4 & $\begin{array}{l}\text { Computed in Subroutines INJECT } \\
\text { and TRANS }\end{array}$ \\
\hline & . & FIELD OPERATION ACTIVITIES & \\
\hline 30 & 22 & Replacement Well Drilling & Computed - see Appendix A \\
\hline 31 & 23 & Purchased Thermal Energy & Computed - see Appendix A \\
\hline 32 & 24 & Well Abandonment & 1000* No. of Wells/Well Life \\
\hline 33 & 25 & Well Maintenance & 1000./well \\
\hline 34 & 26 & Overhead and Management & Computed - see Appendix A \\
\hline 35 & 27 & Replacement of Downhole Pumps & Computed - see Appendix A \\
\hline 36 & 28 & Source Heat Exchanger Operation & Computed - see Appendix A \\
\hline 37 & 29 & Pumping Electricity Costs & Computed - see Appendix A \\
\hline 38 & 30 & $\begin{array}{l}\text { Legs } 1 \text { and } 2 \text {, Node } 2 \text { and Heat Exchanger } \\
\text { System Maintenance }\end{array}$ & Computed - see Appendix A \\
\hline 39 & 31 & Legs $3 \& 4$ and Node 4 System Maintenance & Computed - see Appendix A \\
\hline $\begin{array}{l}\text { (a) NAMELIST input arr } \\
\text { (b) Activities done at } \\
\text { Lease Cost } \\
\text { 6) Bonus payme } \\
\text { 7) Annual paym } \\
\text { 8) Administrat } \\
\text { (c) Capital costs of } 1 \\
\text { (d) in Section } 2.1 \text { for } \\
\text { Capital costs of }\end{array}$ & $\begin{array}{l}\text { ay -- default values. } \\
\text { the same time that we } \\
\text { nt to leaseholder } \\
\text { ent to leaseholder } \\
\text { ive procurement cost. } \\
\text { egs } 1 \text { and } 2 \text { and node } 2 \\
\text { definition of legs. } \\
\text { egs } 3 \text { and } 4 \text { and node } 4\end{array}$ & $\begin{array}{l}\text { of transmission system and heat exchanger at } \\
\text { of transmission system. }\end{array}$ & It energy source. See Figure 2 \\
\hline
\end{tabular}


TABLE 10B. Activities, Input Times, and Success Ratios for Supply System PreDevelopment, Development, and Operation

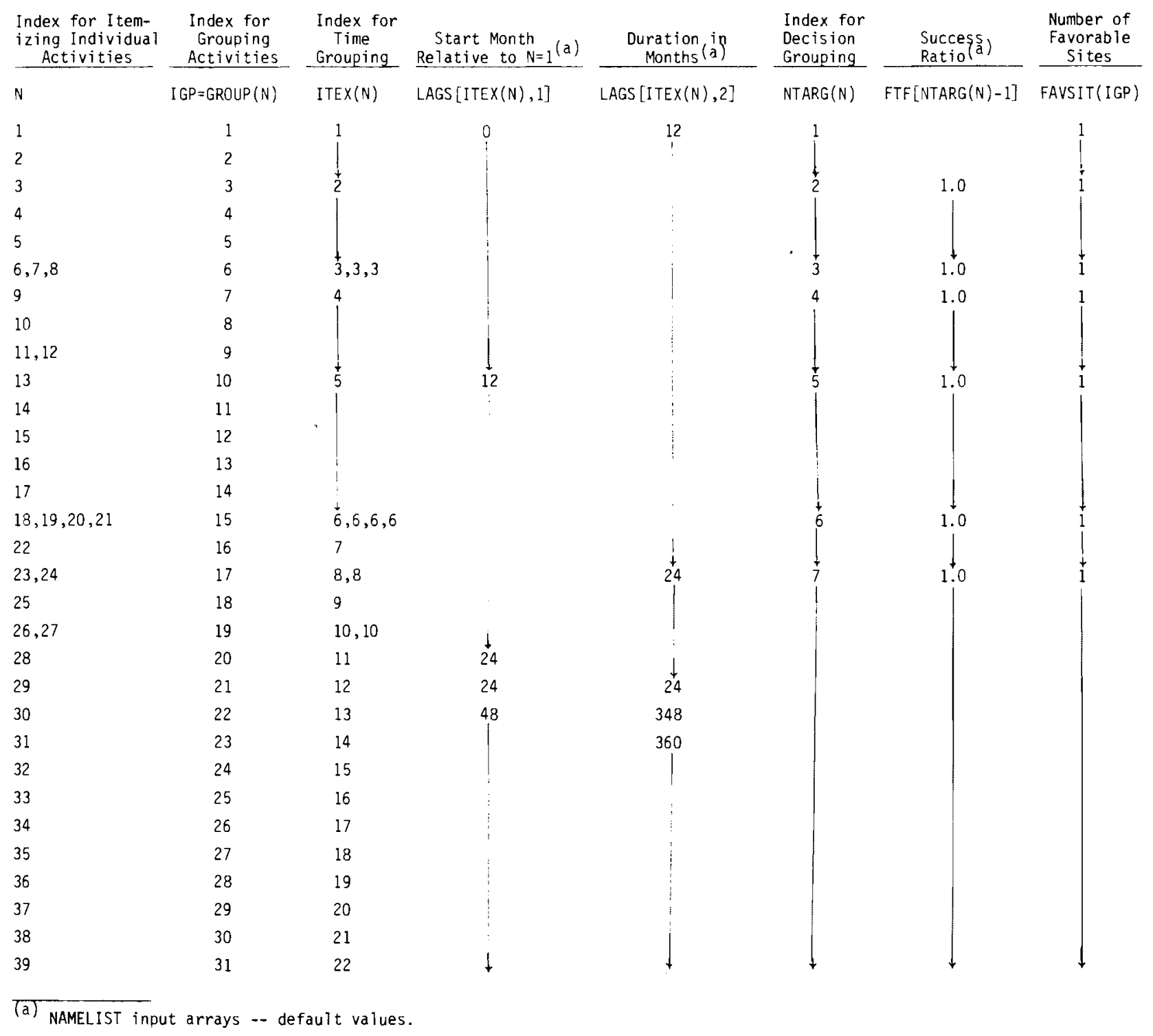

LAGS $(\operatorname{ItEX}(N), K), \operatorname{ITEX}(N)=1, \ldots, 22 ; K=1,2$ - Time array to schedule the expenditures and times over which the activities defining the supply system pre-development, development, and operation in Tables $10 \mathrm{~A}$ and $10 B$ are to take place. An internal array in subroutine RESVOR, ITEX(N), N $=1, \ldots, 39$, currently groups the 
39 activities in Tables $1 O A$ and $I O B$ into 22 subgroups of activities as shown in Table 11. All activities within a given subgroup are presumed to occur parallel in time. However, the user has the flexibility to schedule the different subgroups of activities either sequentially or parallel in time.

The starting month and duration in months $(\geq 1)$ for each set of activities grouped together are defined by means of the input time array $\operatorname{LAGS}(\operatorname{ITEX}(\mathrm{N}), 1)$ and $\operatorname{LAGS}(\operatorname{ITEX}(\mathrm{N}), 2)$ respectively,

TABLE 11. Subgrouping of Supply System Activities Occurring Parallel in Time

Supply System Pre-Development

Task $N$ $\begin{array}{llllllllllllllllllllll}12 & 3 & 4 & 5 & 6 & 7 & 8 & 9 & 10 & 11 & 12 & 13 & 14 & 15 & 16 & 17 & 18 & 19 & 20 & 21 & 22\end{array}$

$\operatorname{ITEX}(N)$

$11-2 \longrightarrow 3$ 4 5 6

$\operatorname{LAGS}[\operatorname{ITEX}(N), 1]$

$$
0
$$

12

$\operatorname{LAGS}[\operatorname{ITEX}(N), 2]$

12

Field Development

TASK $N$

$\begin{array}{lllllll}23 & 24 & 25 & 26 & 27 & 28 & 29\end{array}$

$\operatorname{ITEX}(\mathrm{N})$

$\begin{array}{lllllll}8 & 8 & 9 & 10 & 10 & 11 & 12\end{array}$

LAGS [ITEX (N), 1]

$12 \longrightarrow 24 \quad 24$

$\operatorname{LAGS}[\operatorname{ITEX}(N), 2]$

24 $-24$

Field Operation

Task N

$\operatorname{ITEX}(\mathrm{N})$

$\operatorname{LAGS}[\operatorname{ITEX}(\mathrm{N}), 1]$

$\operatorname{LAGS}[\operatorname{ITEX}(N), 2]$

$\begin{array}{llllllllll}30 & 31 & 32 & 33 & 34 & 35 & 36 & 37 & 38 & 39\end{array}$

$\begin{array}{llllllllll}13 & 14 & 15 & 16 & 17 & 18 & 19 & 20 & 21 & 22\end{array}$

48 48

348360 360 
indexed by the array ITEX. The starting month for each subgroup of activities is defined relative to the first activity, which is given the reference value 0 . The starting date for the first activity, defining the beginning of aquifer pre-development, is back calculated by subroutine RESVOR from the starting date input for the operation of the distribution system using the durations in months for the pre-development and development activities. AQUASTOR schedules the starting date for the operation of the distribution system in January of the year defined in NAMELIST by DINPUT(14) and DINPUT(49). The default value is January, 1990. The back calculation ensures that the last activity in the supply system pre-development and development ends in the month prior to the starting date input for the operation of the distribution system. With the default values, this date is December 1989. Regardless of the duration in months specified for the activities in the supply system operation ( $N=30$ to 39 ), subroutine RESVOR schedules the duration based upon the operating life of the distribution system. Table 11 lists the subgrouping of the activities presumed to occur parallel in time by the array ITEX and the default values of the array LAGS.

The time sequences of the activities corresponding to the default values of the LAGS array and default distribution system startup date of January, 1990, are delineated in the horizontal bar graph of Figure 14. A discussion of the use of these arrays for calculating annual expenditures in subroutine RESVOR is given in Appendix $A$.

UNITO $(N), N=1, \ldots, 39$ - Cost array defining costs (January, PRINDX base year dollars) for the activities in the pre-development, development, and operation of the supply system on a unit basis, primarily per aquifer target site, acre, or well, based upon industry estimates. The total cost associated with each activity is calculated in subroutine RESVOR by multiplying the appropriate unit cost in the UNITO array by the number of favorable aquifer target 


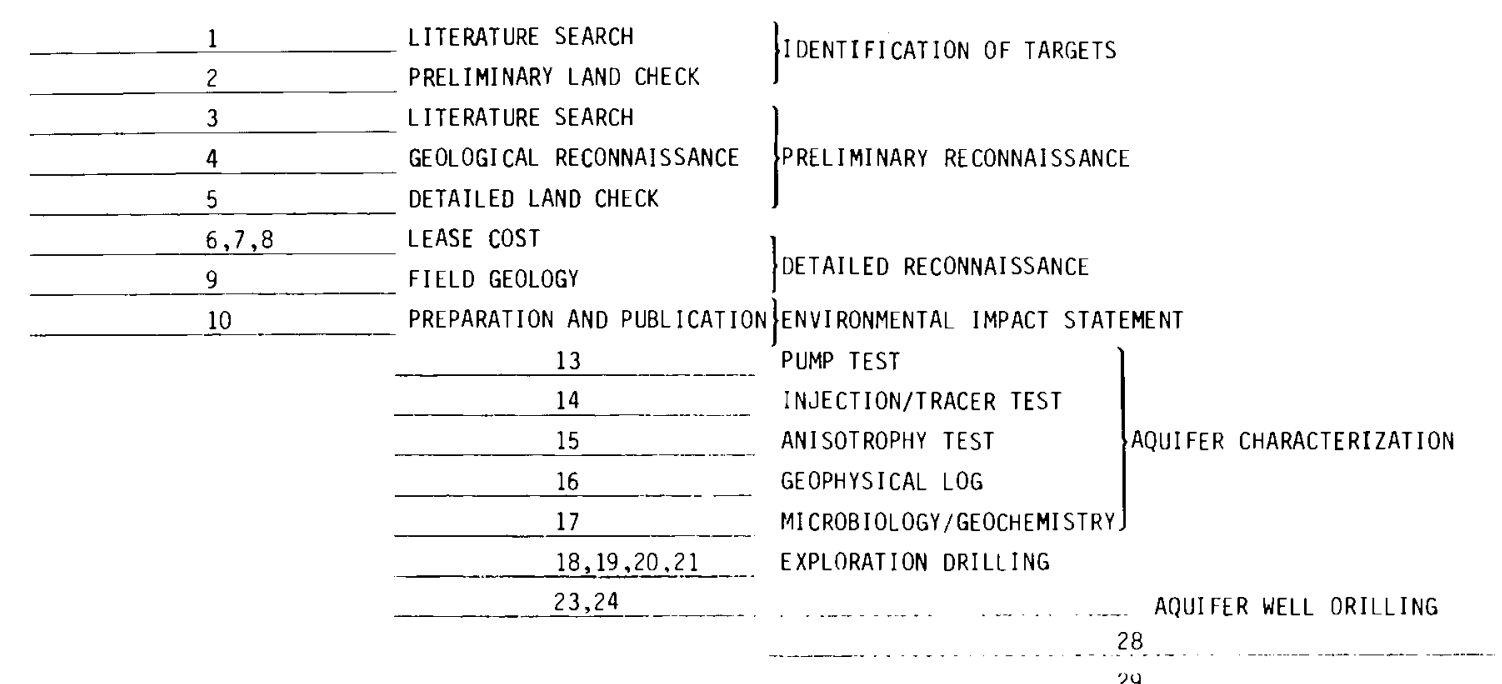

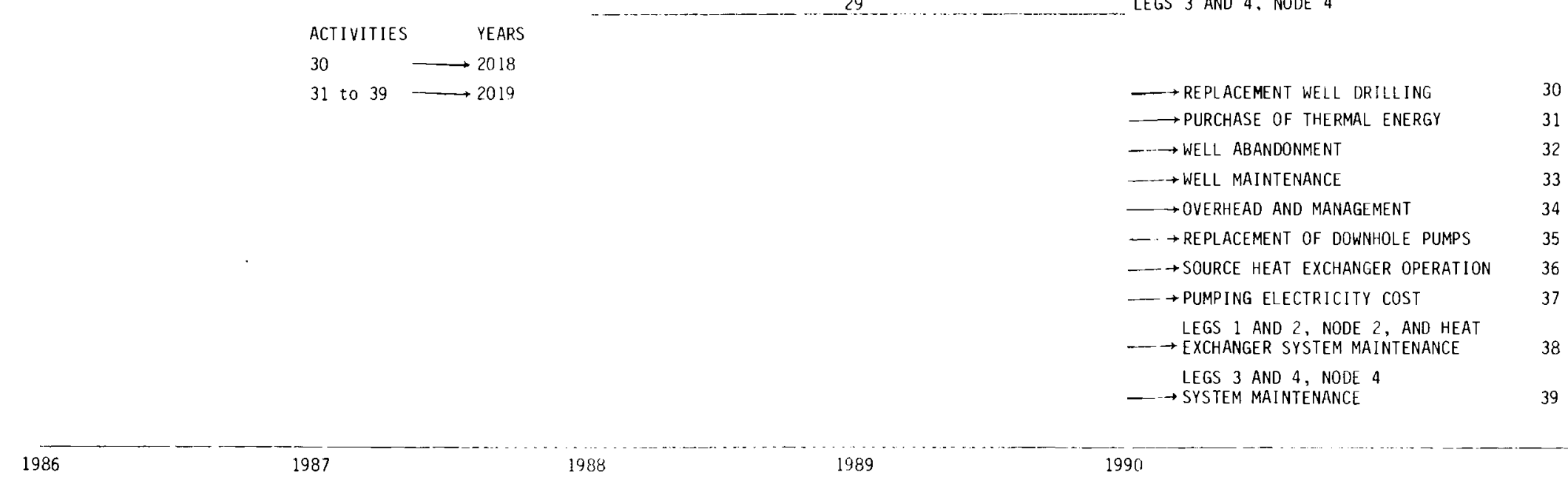

FIGURE 14. Default Time Sequences of Supply System Pre-Development, Development, and Operation Activities 
sites, acres, or wells calculated by AQUASTOR for that activity. The cost equations based on the UNITO array are given in Appendix A. The default values for the UNITO array are shown for each of the supply system activities in Table 10A.

$\operatorname{FTF}[\operatorname{NTARG}(N)-1], \operatorname{NTARG}(N)=1, \ldots, 7$ - Success ratios (fractions), indexed by the array $N$ TARG $(N)$, associated with the major decision points in the step-by-step process of reducing the number of prospective aquifer sites. The process converges on one site for development and operation. An internal variable NUMFTF in subroutine RESVOR currently sets the number of major decision points in the aquifer

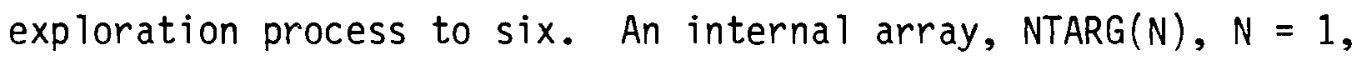
$\ldots, 39$, groups the 39 activities in Table $10 B$ into 7 groups of activities (one more than the number of decision points) according to the major decision points. The calculation of the initial number of aquifer target sites to identify for exploration, and the number of aquifer sites to retain at each decision point for further exploration (based upon the success ratios FTF[NTARG(N) $1]$ ) is described in Appendix A. Table 12A shows the subgrouping

TABLE 12A. Subgrouping of Supply System Activities by Decision Points

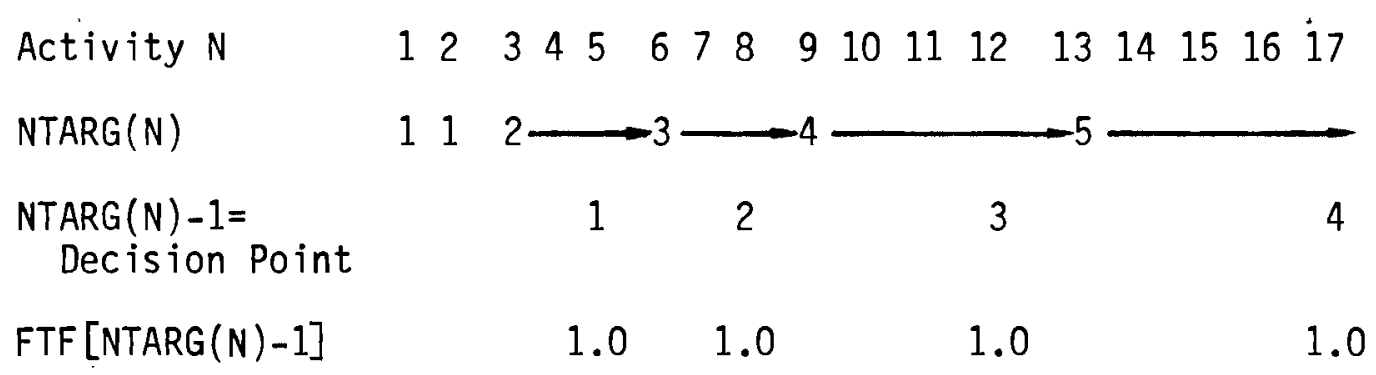

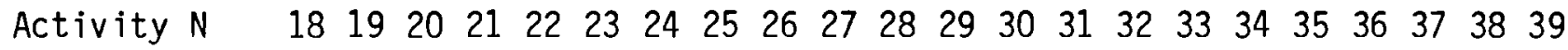
NTARG(N) $6 \longrightarrow 7$

$\operatorname{NTARG}(\mathrm{N})-1=$ 5 Decision Point

$\operatorname{FTF}[\operatorname{NTARG}(N)-1]$ 
of the activities by the array NTARG, the corresponding decision points, and the default values of the array FTF. Table 12B describes the decision points. The default values for the array FTF assume that only one aquifer site is explored.

\section{TABLE 12B. Description of Decision Points}

Decision Point

1

2

3

4

5

6
Description

Fraction of sites to retain for preliminary reconnaissance after identification of target sites

Fraction of sites to lease after preliminary reconnaissance

Fraction of leased sites to retain for detailed reconnaissance

Fraction of sites to evaluate for subsequent exploratory drilling

Fraction of sites to retain for exploratory drilling

Fraction of sites to develop and operate

\subsection{OUTPUT SELECTION OPTIONS}

Several output options (i.e., print switches) are available to select various levels of detail in the printout from the AQUASTOR code. The most detailed printout shows the input data, all technoeconomic iterations between the supply and distribution systems, and full economic output for the supply and distribution systems. This option is generally used only as a troubleshooting guide to debug the code because of the voluminous printout.

- The most condensed printout shows the input data, the input districts and district populations for the distribution system, the distribution system summary, the pre-development, development, and operation time schedules and costs for the supply system, and a technical and financial summary of the simulation results. This option is generally used with multiple production runs to reduce the volume of the printout. 
Other options provide various levels of detail intermediate between these extremes. However, all output options include the input data as part of the printout. The printout generated by the default settings of the output options is intermediate in detail. The default printout is illustrated by the sample case output in Appendix $G$. This includes the input data, the final technoeconomic iteration between the supply and distribution systems, full economic output for the supply and distribution systems, and the technical and financial summaries of the simulation results.

Another printout option allows the user to display printer plots calculated from several of the key capital cost equations described in Appendix $B$ for the distribution system. These plots show in graphical form the capital costs estimated for various components of the distribution piping system, such as pipes, insulation, and casing, over a wide range of pipe diameters. The printer plots are displayed as part of the input data since the underlying capital cost equations constitute an internal data base stored in the code.

Finally, an option is also available to print results from the drilling model when it is implemented by the parameters previously defined in Section 3.5.2. The printer plots and results from the drilling model are not part of the default printout.

The definitions of the print switches generating the various levels of detail in the printout are given below. The print switches LL6, LL11, LL12, IPLOT, IDRPNT, and PRFLAG are input through the NAMELIST group \$RESVOR. The other print switch DFLAG is input through the NAMELIST group \$DISTRB. The description of the output generated by the settings of the print switches is described below in terms of the pages of output generated by the default printout in Appendix G.

LL6 Print switch for selecting the iteration printout between the supply and distribution systems.

0 , suppresses printout of the iterations

1 , prints only the last iteration upon convergence (pages G-15 to G-81)

2, prints all iterations

The default is 1 . 
LL11, LL12 Print switches for selecting the supply and distribution system economic (cash flow) printout.

LL11 = 1 , LL12 = 1 , prints full economic (cash flow) output (pages G-82 to G-94)

LL11 $=1, L L 12=0$, prints an economic summary of the supply and distribution systems, including the breakdown of energy costs from the supply system and heat (chill) costs from the distribution system, but excluding the annual statements of operating costs, cash flow, tax deductible expenses, income, and payout of investments.

LL11 $=0, \operatorname{LL12}=0$, suppresses all economic (cash flow) output.

The default is full economic (cash flow) output.

IPLOT Print switch to display printer plots of capital costs estimated for various components of the distribution piping system, including pipes, insulation, and casing. Costs are plotted as a function of pipe diameter ranging from 1 to 40 inches. The underlying capital cost equations are part of the internal data base stored in the code.

0 , suppresses display of the printer plots

1 , displays the printer plots after the input data The default is 0 .

IDRPNT

Print switch to print the results from the well drilling model which is employed if the parameter IDRILL in Section 3.5.2 is set to 1 .

0 , suppresses printout from the drilling model

1 , prints results from the drilling model

The default is 0 .

DFLAG Print switch for selecting the distribution system printout. The parameter DFLAG is declared logical in the code. The default is .TRUE.

DFLAG = .TRUE., prints the full distribution system output (pages $\mathrm{G}-30$ to $\mathrm{G}-72$ ) 
DFLAG = .FALSE., prints only the first two pages of the distribution system output (pages G-30 to G-32) entitled "Definition of Districts" and "District Populations" and the last page (page G-72) entitled "Distribution System Description".

PRFLAG Print switch to suppress all printout except the input data, the input districts and district populations for the distribution system (pages G-1 to G-14 and G-30 to G-32), the distribution system summary (page G-72), the pre-development, development, and operation time schedules and costs of the supply system (page G-82), and the technical and financial summary of the simulation results (pages G-95 to G-96).

0. , the printout is controlled by the settings of the individual print switches: LL6, LL11, LL12, IPLOT, IDRPNT, and DFLAG

1., overrides all the individual print switches to print only the output described above.

The default is 0 . 


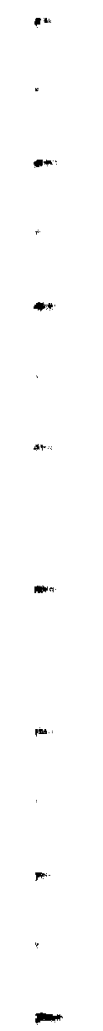

$-$

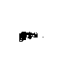




\subsection{DESCRIPTION OF OUTPUT}

Appendix $G$ lists the computer output generated by the sample case for ATES district heating in Richland, Washington (described in Section 3.2 to illustrate the input data using NAMELIST). The 96 pages of printout show the input data, the techno-economic output from the final iteration between the ATES supply system and the distribution system, the annual cash flows for the ATES supply system, the annual cash flows for the distribution system, and the summary of the simulation results. The output results are printed in an easy-toread format with an accompanying description. Table 13 presents an overview of the output, identifying the pages of output generated by the major submodels of AQUASTOR. For the sake of brevity, a more detailed description is provided below only for output results that may require further explanation.

The input parameters to the code are on pages G-1 to G-7. Printer plots of internal equations stored in the code for estimating the capital costs of piping, insulation, and casing for the distribution system are displayed on pages $G-8$ to $G-14$. The equations are defined in Appendix $B$.

The output from the final iteration between the ATES supply system and distribution system is on pages $G-15$ to $G-81$. The output describes the fluid flow rates, pipe diameters, pipe schedules, insulation thickness, thermal losses, pressure drops, pumping requirements, capital costs, and operating costs of the major ATES elements represented symbolically by the nodes and legs in Figure 2 of Section 2.1. The output starts with node 1 and proceeds in the direction of fluid flow to node 4 and leg 4 to complete the cycle around the major ATES elements.

The output for node 1 -- the external energy source, its associated heat exchanger, and pumps -- is on pages G-15 and G-16. Observe that the code has adjusted the peak flow rate from the external energy source (parameter SMFLOW) slightly downward from the input value of $3.565 \times 10^{6} \mathrm{lb} / \mathrm{hr}$ to $3.408 \times 10^{6}$ $1 \mathrm{~b} / \mathrm{hr}$. This adjustment was necessary to match up the annual fluid supply from the storage wellfield with the annual fluid demand by the distribution system for the city of Richland. The annual flow rate of hot water required from the external energy source to heat the circulating water from the supply wellfield 
TABLE 13. Summary of Computer Output from AQUASTOR

AQUASTOR Input Parameters

- ATES Supply System Parameters

G-1

- District Heating (Cooling) Distribution System Parameters

G-2 to $G-5$

- Financial Parameters

G-6, G-7

- Output Selection Options

G-7

- Printer Plots of Internal Capital Cost Equations for Distribution System

G-8 to $G-14$

ATES Supply System

- Node 1 - Fluid Conditions and Capital Costs

G-15,G-16 of External Energy Source and its Heat Exchanger

- Leg 1 - Fluid Conditions and Capital Costs of Transmission Leg 1 from External

G-17 Energy Source to Storage Wellfield

- Node 2 - Entering Fluid Conditions into StorG-18,G-19 age Wellfield

- Node 2 - Storage Wellfield and Aquifer Description

G-20

- Node 2 - Exiting Fluid Conditions from Storage Wellfield and Capital Costs of Node 2

- Leg 2 - Fluid Conditions and Capital Costs of Transmission Leg 2 from Storage We11field to Distribution System

Transmission Leg 3 from Distribution System to Supply Wellfield

- Node 4 - Entering Fluid Conditions into Supply Wellfield 
TABLE 13. (Continued)

Description of Computer Output

- Node 4 - Supply Wellfield and Aquifer Description

- Node 4 - Exiting Fluid Conditions from Supply Wellfield and Capital Costs of Node 4

- Leg 4 - Fluid Conditions and Capital Costs of Transmission Leg 4 from Supply We11field to External Energy Source

District Heating (Cooling) Distribution System (Node 3)

- Heating (Cooling) Requirements and Flow Requirements of Distribution System

- Convergence Test for Flow Requirements Between Distribution System and Storage Wellfield/Aquifer

- Heat Exchanger at Inlet to Distribution System

- Match Up of Annual Fluid Supply from Storage Wellfield/Aquifer with Annual Fluid Demand by Distribution System, Including Supplemental Heating Requirements (if any)

- Definition of Districts

- District Populations

- Piping Network and Fluid Conditions for District $M$

- Capital Costs and Material Requirements to NDTR of Piping Network for District $M$

- Branching Main Network and Fluid Conditions for Each District

- Characteristics and Cost of Distribution Heat Exchanger

- Total Capital Costs, Material Requirements, and Total Operating Expenses of the Distribution System Summed Over A11 Districts 
TABLE 13. (Continued)

Description of Computer Output

Pages

- Summary of District Heating (Cooling) Requirements, Capital Costs, and City Climatic Characteristics

ATES Supply System Discounted Cash Flow

- ATES Supply System Pre-Development, Development, and Operating Costs

- Annual Operating Costs

- Annual Cash Flow Statement

G-84

- Annual Tax Deductible Expense Statement

G-85

- Annual Income Statement

G-86

- Annual Payout of Investments (Capitalization)

- Annual Cost of Energy from the ATES Supply System

Distribution System Discounted Cash Flow

- Annual Operating Costs

- Annual Cash Flow Statement

- Annual Tax Deductible Expense Statement

- Annual Income Statement

- Annual Payout of Investments (Capitalization)

- Annual Cost of Heat (Chill) from the District Heating (Cooling) Distribution System

Simulation Summary

- Technical Surmary

- Financial Summary 
to $307.5^{\circ} \mathrm{F}$ was estimated at $9.8 \times 10^{9} \mathrm{lb} / \mathrm{yr}$. The peak flow rate circulating from the supply wellfield through the heat exchanger and then to the storage wellfield was estimated at $3.439 \times 10^{6} \mathrm{lb} / \mathrm{hr}$. Both flow rates described above for the source heat exchanger are based on a 120 day operating period.

The output describing the design and cost of transmission leg 1 and the fluid degradation during transport from the external energy source to the storage wellfield is on page G-17. Analogous output describing transmission legs 2,3 , and 4 is on pages G-25, G-73, and G-81 respectively. The representation of the transmission legs and wellfields on a nodal basis using rows (I) and columns $(J)$ and the iterative process to calculate the pipe diameters and fluid degradation are explained below in the description of the storage wellfield. For now, note that the output from the first iteration at transmission leg 1 (iteration 1 on page G-17) shows the fluid condition entering the transmission leg. The output from the final iteration (iteration 3 on page G-17) shows the degraded fluid condition exiting the transmission leg. For example, the fluid temperature exiting the heat exchanger at the external energy source is $307.5^{\circ} \mathrm{F}$ and the degraded temperature exiting transmission leg 1 is $306.5^{\circ} \mathrm{F}$.

The degradation of the fluid (temperature and enthalpy) entering the storage wellfield (node 2) is shown on a nodal basis on pages G-18 and G-19. The fluid degradation from storage in the aquifer is shown on page G-20. The fluid degradation exiting the storage wellfield is shown on a nodal basis on pages G-21 to G-23. Although the fluid pressure degradation is also calculated internally by the code on a nodal basis, it is summarized in the printout on page G-23 only from the furthest well in the wellfield (well number 22 in Figure 15) to the outlet of the wellfield. The analogous fluid degradation for the supply wellfield (node 4) is shown on pages G-74 to G-79. For the sake of brevity, only the fluid degradation exiting the storage wellfield is described below.

The layout of the nodes in the storage wellfield for the Richland test case is illustrated in Figure 15. The layout of the supply wellfield is analogous. Twenty three wells are equally spaced on a triangular grid, with the well spacing set to 25 acres in the input data (resulting in a distance of 342 meters between the well nodes). The pipe runs connecting the wells are shown parallel to the horizontal $X$-axis in Figure 15 , joining with one manifold line 
TO DISTRIBUTION

INLET

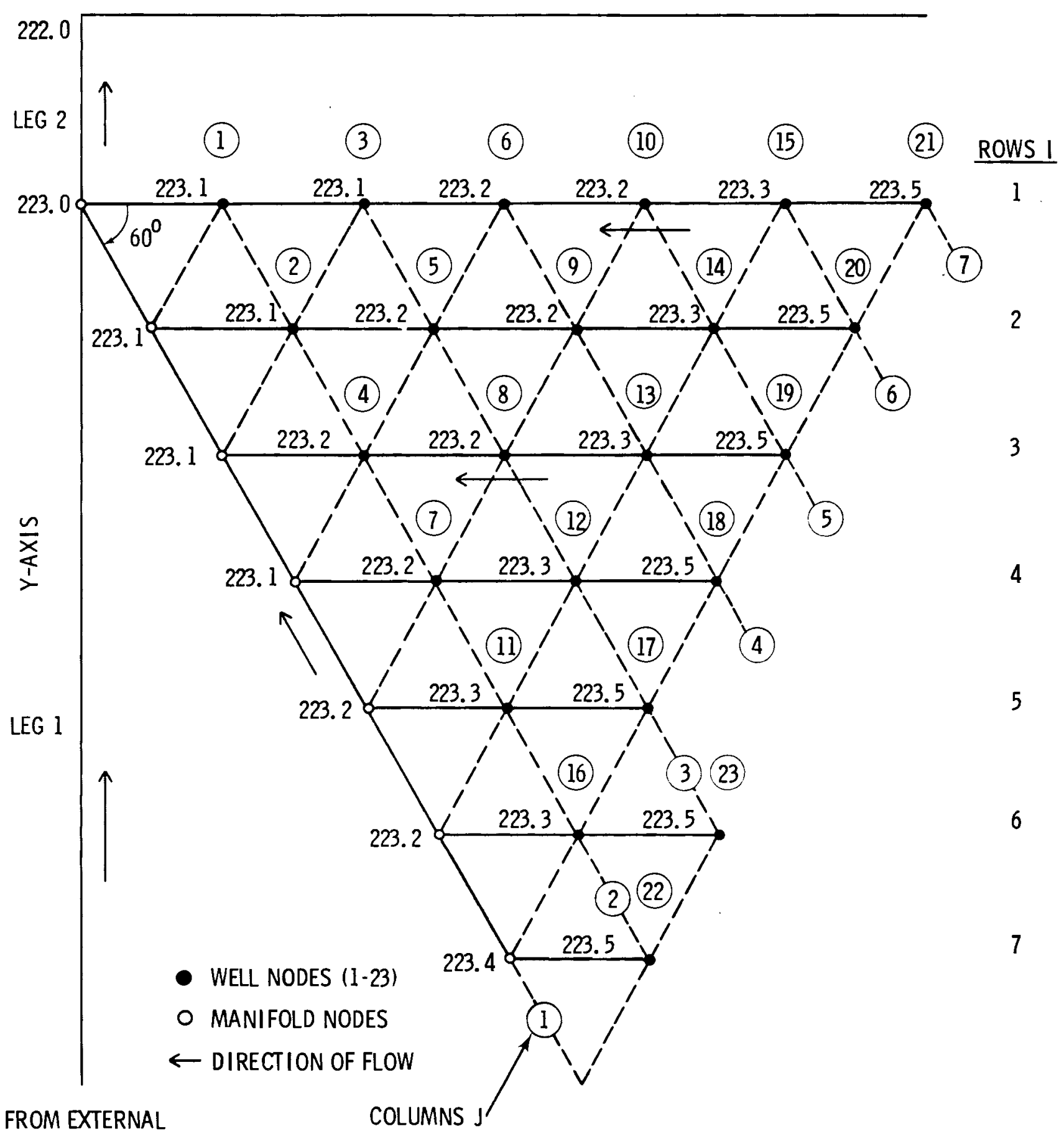

ENERGY SOURCE 
leading to the distribution system. The distance of the manifold line from the first column of wells in the Richland test case was set in the input data to one meter.

The fluid degradation exiting the storage wellfield to the distribution system is calculated in the order shown on pages $G-21$ to $G-23$. Figure $15 \mathrm{i} 17 \mathrm{u}-$ strates the fluid temperature degradation on a nodal basis, corresponding to the output on pages $G-21$ to $G-23$. The calculations begin with the perimeter we 11 node (row $I=7$ and column $J=2$ in Figure 15) and proceed downstream to the outlet of the storage wellfield leading to the distribution system.

The output from the first iteration at a node (iteration 1 on pages $G-21$ to $G-23$ ) shows the condition of the fluid exiting the node. The letter $M$ is used to indicate the mixture of two inlet flows of fluid at a node:

- Fluid exiting a well node ( $J>1$ in Figure 15$)$ is a mixture of fluid from the wellhead and degraded fluid transmitted from upstream well nodes.

- Fluid exiting a manifold node $(J=1$ in Figure 15$)$ is a mixture of degraded fluid from the upstream manifold line and degraded fluid from the row of wells leading into the manifold node.

The exit enthalpy is estimated as the mass-weighted average of the inlet entha1pies. The exit temperature is calculated using the steam library function TPHL for compressed liquid based upon the exit enthalpy and pressure.

The output from the last iteration at a node on pages $G-21$ to $G-23$ shows the degraded condition of the fluid immediately prior to its entry into the next downstream node. Fluid degradation between neighboring nodes is a function of the internal pipe diameter. Inversely, the optimization algorithm used to calculate the internal pipe diameter is a function of the mass flow rate and fluid conditions. The initial estimate of the internal pipe diameter is calculated assuming no fluid degradation between neighboring nodes. The fluid degradation is then calculated as a function of the internal pipe diameter. Using the degraded fluid conditions, the internal pipe diameter is recalculated. The process iterates until the degraded fluid temperature at the entry into the downstream node changes by less than $0.10^{\circ} \mathrm{F}$ from the temperature calculated 
in the previous iteration. The internal diameters of the pipes are shown on a nodal basis on pages $G-21$ to $G-23$.

The annual/peak heating demands and fluid requirements by the distribution system (node 3 ) are on pages $G-26$ and $G-29$. The successful convergence to the annual fluid requirements by the distribution system based on the degraded fluid conditions delivered from the storage wellfield is on page G-27. The characteristics of the heat exchanger and its pumps at the inlet to the distribution system are on page $\mathrm{G}-28$.

The match-up between the annual fluid supply from the storage wellfield/ aquifer and the annual fluid demand by the distribution system is on page $G$ 29. The peak fluid demand by the ATES district heating system in Richland is estimated at $3.298 \times 10^{6} \mathrm{lb} / \mathrm{hr}$; the annual fluid demand from the storage we 11 field/aquifer, after allowing for fluid losses of $1 \%$ (parameter WLEAK = .01 ) in the distribution piping, is estimated at $8.921 \times 10^{9} 1 \mathrm{~b} /$ year. The peak supply flow into the storage wellfield/aquifer is estimated at $3.439 x$ $10^{6} \mathrm{lb} / \mathrm{hr}$; the annual fluid supply into the storage wellfield/aquifer from a source operating 120 days in the year is estimated at $9.904 \times 10^{9} 1 \mathrm{~b} /$ year. The ratio of the annual fluid supply available from the aquifer, after allowing for fluid losses of $10 \%$ (parameter STFREC $=0.90$ ) in the aquifer, to the annual fluid demand by the distribution system is estimated at 0.999, i.e., the ratio: $\left(9.904 \times 10^{9} \times 0.90\right) /\left(8.921 \times 10^{9}\right)$. In the Richland test case, the annual fluid supply was sufficient to meet the annual fluid demand within the convergence ratio of $1 \%$.

The input characteristics to the distribution system submodel (node 3 in Figure 2) defining the residential districts in Richland served by the ATES district heating system are given on page G-30 in English units and on page G-31 in metric units. The district populations are on page G-32; however, the information on population per se is not used in the distribution system submodel.

The design, fluid conditions, capital costs, and material requirements of the piping network are summarized for each district on pages G-33 to G-68. The length of pipe, number of fittings, valves, and expansion loops, and the capital costs of pipes, fittings, valves, insultion, casings, expansion loops, and trenches are summarized by up to 23 categories of nominal outer pipe diameters 
that can be used throughout the piping network. These costs are summed over all pipe sizes and combined with the cost of meters and pumps to give the total capital costs for each district piping system.

The output describing the layout and fluid conditions of the piping network for each district is given in a condensed format. Since the piping network is designed symmetrically by subroutine GRAPH about the main and lateral, output for one house (building), one half-street (above or below the lateral), one half-lateral (to the left or right of the main), and the main is sufficient to summarize the layout and fluid conditions of the entire piping network for the district.

The layout of the piping network for district 7 with 54 multiple-family apartments (corresponding to 54 meters on page G-46) in the sample output on page G-45 is shown in Figure 16. The layout was constructed from the output on page G-45 together with the number of buildings (54) to illustrate the interpretation of the condensed output for the district piping networks. The output on page G-45 summarizes the layout of the piping network and fluid conditions for the following sections of pipe:

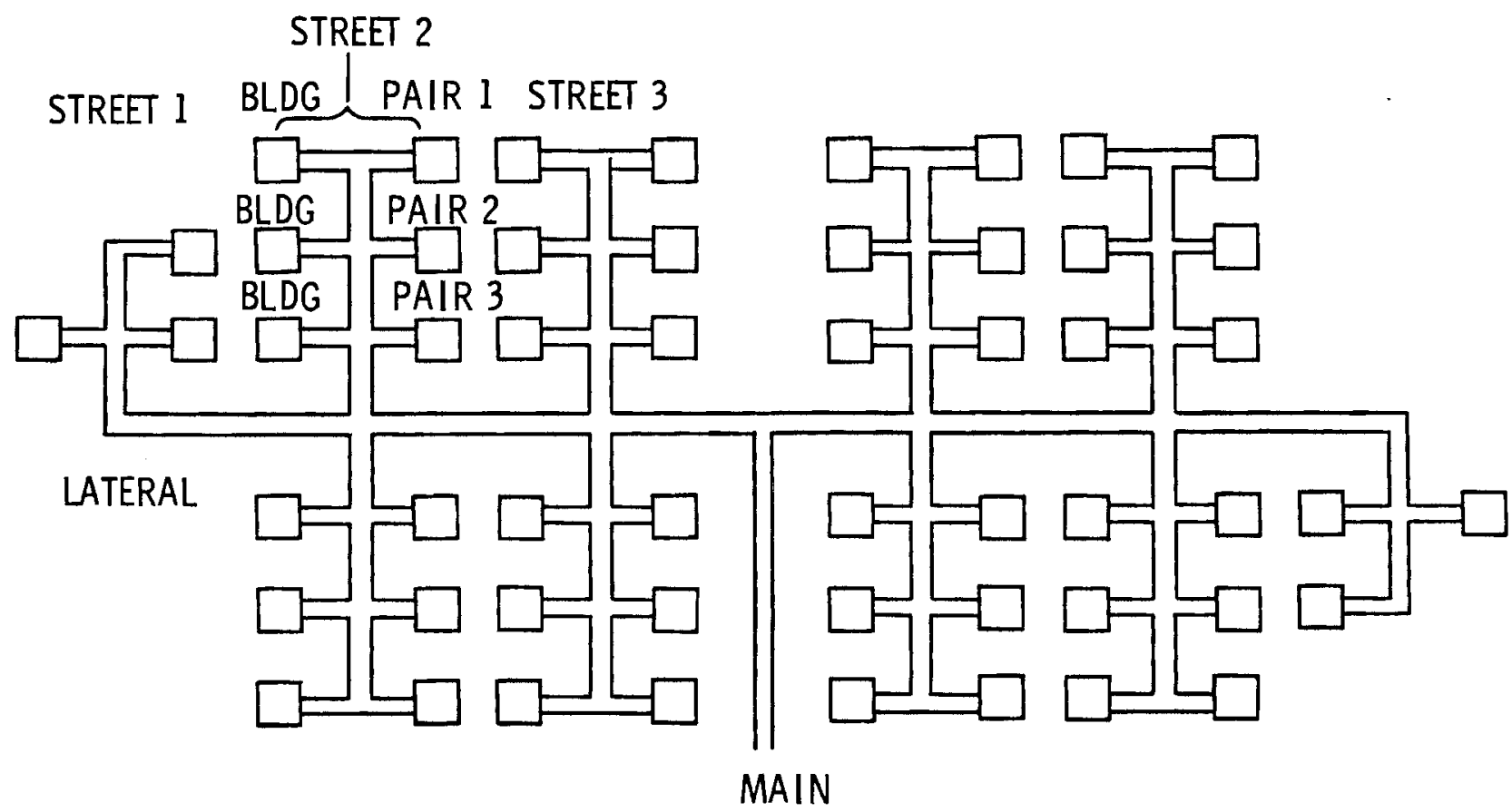

FIGURE 16. Layout for District 7 with 54 Buildings in Sample Case 
- street-to-building pipe for each building

- pipe sections down each half-street connecting building pairs 1-3

- pipe sections across the half-lateral connecting full streets 1-3

- main pipe connecting the midpoint of district 8 with the midpoint of the full lateral in district 7 of Figure 9 .

Note that two short half-streets are used in Figure 16, one on each end of the lateral, to obtain 54 buildings while preserving the symmetry of the piping network about the main and lateral. The 4 full streets account for 48 buildings ( $4 \times 12$ ), leaving a remainder of 6 buildings, which is not enough to fill out a full street.

AQUASTOR uses heat demand data and climatic data to determine the hot water requirements for a typical building in district 7 . Working down the piping network, water requirements are used as the basis for selecting the economic pipe size for each section of the network. Material requirements, thermal losses, and pressure drops are determined for each section of the piping network. Construction costs, material costs, operating costs, and costs for pumps, meters, and control equipment are derived based on the distribution system design. These results are summarized for district 7 on pages $G-45$ and $G-46$.

The output summarizing the design and fluid conditions of the branching mains and the districts served by each main is on page G-69. The total capital costs and material requirements of the piping networks summed over all districts are summarized by up to 23 categories of nominal outer pipe diameters that can be used throughout the piping network on page G-71. The total capital costs summed over all pipe sizes, the cost of meters and pumps, and the total operating expenses of the distribution system are also given on page G-71. The heating requirements and capital costs of the piping network for each district together with the city climatic characteristics are summarized in English and metric units on page G-72.

The output from the discounted cash flow submodel for the ATES supply system is on pages G-82 to G-88. The capitalized and expensed costs associated with the pre-development, development, and operation of the supply system are on page G-82. The times over which these expenditures are uniformly distributed are also shown on page G-82. Page G-83 shows the annual operating costs 
for the supply system. Annual cash flow data for the major supply system expenses are on page G-84; summary accounts of tax deductible expenses are on page G85. A simplified income statement is on page G-86 and the net cash flow and investment position for the supply system are on page G-87.

The cost of thermal energy from the ATES supply system is given on page G-88. Annual costs are given in current dollars for each operating year of the supply system; a single life-cycle levelized cost is given in January base year dollars. The thirty-year levelized cost in January, 1980 dollars for the city of Richland test case is estimated at $\$ 12.51 / \mathrm{mi} 11$ ion Btu of thermal energy delivered to the distribution system.

The output from the discounted cash flow submodel for the distribution system is on pages G-89 to G-94. Pages G-89 to G-93 contain the same cash flow and accounting information for the distribution system as pages $G-83$ to $G-87$ for the ATES supply system. The cost of heat (chi11) from the distribution system to the end-user is given on page G-94. Annual costs are given in current dollars for each operating year of the distribution system; a single lifecycle levelized cost is given in January base year dollars. The thirty-year levelized cost in January, 1980 dollars for ATES district heating in Richland is estimated at $\$ 19.65 / \mathrm{mi} 11$ ion Btu of heat delivered to the end-user.

The technical summary of the simulation results is given on page G-95. The peak heat demand by the ATES district heating system in Richland is estimated at $3.25 \times 10^{8}$ Btu/hour. An estimated $8.8 \times 10^{11}$ Btu/year of heat (annual average demand of 100 MBtu/hour $\times 8766$ hours/year) are used in ATES district heating in Richland.

The financial summary of the simulation results is given on page G-96. The levelized cost of the total capital investment in the ATES supply and distribution systems is $\$ 8.83 / \mathrm{MBtu}$, which accounts for $44.9 \%$ of the total cost of $\$ 19.65 /$ MBtu of ATES district heating to the end-user. The levelized cost of purchased thermal energy from the industrial energy source is $\$ 6.93 / \mathrm{MBtu}$, or $35.3 \%$ of the total cost, even though the purchased cost is only $\$ 3.00 /$ MBtu. This difference reflects the cost of energy lost in the aquifer and pipelines, and also the effect of price escalation. The O\&M cost is $\$ 3.11 /$ MBtu, or $15.8 \%$ 
of the total cost. Finally, the electrical pumping cost is $\$ .78 / \mathrm{MBtu}$, or $4 \%$ of the total cost.

Several approaches which offer the potential to significantly lower ATES district heating costs to the consumer are worthy of mention. The system load factor in the Richland district heating case was calculated to be on 1 y $31 \%$. Since the district heating system is very capital intensive, a higher system capacity utilization throughout the year (i.e., a higher load factor) would lead to lower unit heating costs to the end-user. Combining applications of residential space heating with process heating for industrial demands offers one scheme for increasing the system load factor. The latter, of course, would be most effective if residential space heating and process heating demands occurred during opposite seasons. The increased year-around use of the system, once it has been designed, would then effectively spread the total capital cost over a larger quantity of energy, resulting in a lower unit cost per Btu of energy.

Population density is another important factor affecting district heating costs. Notice that the distribution system piping network accounts for $53.1 \%$ of the initial capital investment of 95 million dollars. Increasing population density reduces district heating costs through reducing the average length of distribution piping runs. With very high population densities, as in large multi-story apartment buildings, economies-of-scale are also realized in the supply and distribution system piping networks through the use of larger diameter pipe. Since piping system costs increase roughly linearly with diameter while capacity increases with the square of the diameter, significant economiesof-scale are achieved with larger pipes. Thus, future growth in high-density developments would make ATES district heating a more attractive option for Rich 1 and.

The four transmission legs in the ATES supply system for the city of Richland are each approximately 6 miles in length. These legs account for $21 \%$ of the initial capital investment of 95 million dollars. Thus, applications of ATES district heating in cities with external energy sources closer to the endusers can significantly lower the capital, 0\&M, and electrical pumping costs. 


\subsection{ACKNOWLEDGMENTS}

The authors gratefully acknowledge the work of C. H. Bloomster, C. L. McDonald, S. C. Schulte, and L. L. Fassbender for their contributions towards the development and application of GEOCITY. GEOCITY, a computer model for geothermal district heating and cooling cost analysis, was a direct predecessor of AQUASTOR. The availability of GEOCITY and its user manual was essential in the development of AQUASTOR and this user manual. 


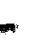

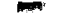

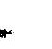

. 


\subsection{REFERENCES}

1. R. W. Reilly, D. R. Brown, and H. D. Huber, Aquifer Thermal Energy Storage Costs with a Seasonal Heat Source, PNL-4135, Pacific Northwest Laboratory, Richland, Washington, December 1981.

2. R. B. MCClintock and G. T. Silvestri, Formulation and Iterative Procedures for the Calculation of Properties of Steam, The American Society of Mechanical Engineers, New York, New York, 1968.

3. C. A. Meyer, R. B. McClintock, G. T. Silvestri, and R. C. Spencer, Jr., 1967 ASME Steam Table--Thermodynamic and Transport Properties of Steam Comprising Tables and Charts for Steam and Water, The American Society of Mechanical Engineers, United Engineering Center, New York, New York.

4. ASHRAE Handbook of Systems, American Society of Heating, Refrigerating, and Air Conditioning Engineers, New York, New York, 1980.

5. CRC Handbook of Tables for Applied Engineering Science, R. E. Boltz and G. L. Tuve, Editors, The Chemical Rubber Co., Cleveland, Ohio, 1970.

6. CRC Handbook of Chemistry and Physics, 50th Edition, R. C. Weast, Editor, The Chemical Rubber Co., Cleveland, Ohio, 1969.

7. ASHRAE Handbook of Fundamentals, American Society of Heating, Refrigerating, and Air Conditioning Engineers, New York, New York, 1977.

8. Op. Cit. ASHRAE Handbook of Systems.

9. Ibid.

10. Op Cit. ASHRAE Handbook of Fundamentals.

11. Chemical Engineers' Handbook, R. H. Perry and C. H. Chilton, Editors, McGraw-Hi11 Book Co., New York, New York, 1973. 


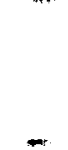




\section{APPENDIX H}

SUPPLY INPUT PARAMETER, DISTRIBUTION INPUT

PARAMETER, AND AQUASTOR SUBROUTINE INDICES 


\section{SUPPLY INPUT PARAMETER INDEX \\ (NAMELIST Group \$RESVOR)}

A11 parameters beginning with the letters I through $\mathrm{N}$ are "integer" except KINS and I0, which are declared "real" in the code. The page numbers listed below for each parameter correspond to the first reference to each parameter in the text. Additional information concerning each parameter may be found in subsequent pages.

\begin{tabular}{|c|c|c|c|}
\hline Parameter & $\begin{array}{l}\text { Page } \\
\text { No. }\end{array}$ & $\begin{array}{c}\text { Default } \\
\text { Value }\end{array}$ & Description \\
\hline ACRES & 3.8 & 500. acres & Size of aquifer site leased for exploration \\
\hline APPHX & 3.7 & $5 .{ }^{\circ} \mathrm{F}$ & $\begin{array}{l}\text { Supply aquifer water temperature approach to } \\
\text { energy source water temperature }\end{array}$ \\
\hline AVGWL & 3.24 & 30. yrs & Average well life \\
\hline CASFRC & 3.24 & 1. & Fraction of each well cased \\
\hline DCPW & 3.8 & $\$ 150,000$. & Drilling cost of one well \\
\hline DIA & 2.13 & 8.75 in. & Well diameter \\
\hline DINPUT (4) & 3.8 & 0.42 & Fraction of initial investment in bonds \\
\hline DINPUT (5) & 3.8 & 0.08 & Bond interest rate \\
\hline DINPUT (6) & 3.8 & 0.15 & Earning rate on equity after taxes \\
\hline DINPUT(7) & 3.8 & 0.46 & Federal income tax rate \\
\hline DINPUT (9) & 3.65 & 30. yrs & Depreciable life of aquifer wells \\
\hline DINPUT(14) & 3.65 & 1990. & Startup year for operation of the supply system \\
\hline DINPUT (15) & 3.8 & 0.07 & State income tax rate \\
\hline DINPUT (16) & 3.66 & 0. & State gross revenue tax rate \\
\hline DINPUT (17) & 3.8 & 0.025 & Property tax rate \\
\hline DINPUT(18) & 3.66 & 0.0035 & $\begin{array}{l}\text { Transmission system interim capital replacement } \\
\text { rate }\end{array}$ \\
\hline DINPUT (19) & 3.66 & 0.0012 & Property insurance rate \\
\hline DINPUT(26) & 3.66 & 15. yrs & Depreciable life of transmission systems \\
\hline
\end{tabular}




\begin{tabular}{|c|c|c|c|}
\hline Parameter & $\begin{array}{l}\text { Page } \\
\text { No. } \\
\end{array}$ & $\begin{array}{l}\text { Default } \\
\text { Value }\end{array}$ & Description \\
\hline DINPUT (27) & 3.66 & $0 . \%$ & Royalty payment percentage \\
\hline DINPUT(28) & 3.66 & 0.05 & Transmission system maintenance rate \\
\hline FLORAT & 3.7 & $\begin{array}{l}500,000 \\
1 \mathrm{~b} / \mathrm{hr}\end{array}$ & Withdrawal well flow rate \\
\hline FRCEPW & 3.24 & 0 . & Fraction excess wells \\
\hline \multicolumn{3}{|c|}{$\begin{array}{l}\text { FTF }[\operatorname{NTARG}(N)-1] \\
\text { (see page } 3.85)\end{array}$} & $\begin{array}{l}\text { Success ratios indexed by the array NTARG(N), } \\
\text { associated with the major decision points in } \\
\text { the process of reducing the number of prospec- } \\
\text { tive aquifer sites }\end{array}$ \\
\hline ICOST & 3.76 & 1 & $\begin{array}{l}\text { Option to use either current dollar or } \\
\text { constant dollar analysis }\end{array}$ \\
\hline IDRILL & 3.66 & 0 & $\begin{array}{l}\text { Option to use drilling model or input directly } \\
\text { the cost of drilling a well }\end{array}$ \\
\hline IDRPNT & 3.88 & 0 & $\begin{array}{l}\text { Print switch to print the results from the well } \\
\text { drilling model, when employed }\end{array}$ \\
\hline IEXPNS & 3.66 & 0 & $\begin{array}{l}\text { Option to capitalize or expense all aquifer pre- } \\
\text { development costs }\end{array}$ \\
\hline IPLOT & 3.8 & 0 & $\begin{array}{l}\text { Print switch to display printer plots of } \\
\text { capital costs estimated for various distribu- } \\
\text { tion system components }\end{array}$ \\
\hline IPUMP & 3.29 & 2 & $\begin{array}{l}\text { Option to employ only surface pumps or a } \\
\text { combination of surface pumps and downhole pumps } \\
\text { in the transmission system }\end{array}$ \\
\hline \multicolumn{3}{|c|}{$\begin{array}{l}\operatorname{LAGS}[\operatorname{ITEX}(N, K)] \\
(\text { see page } 3.81)\end{array}$} & $\begin{array}{l}\text { Time array defining the schedule of expendi- } \\
\text { tures and occurrence of supply system pre- } \\
\text { development, development, and operational } \\
\text { activities }\end{array}$ \\
\hline LL6 & 3.87 & 1 & $\begin{array}{l}\text { Print switch for selecting the iteration } \\
\text { printout between the supply and distribution } \\
\text { systems }\end{array}$ \\
\hline LL11, LL12 & 3.87 & 1,1 & $\begin{array}{l}\text { Print switches for selecting the supply and } \\
\text { distribution system economic printout }\end{array}$ \\
\hline NUMTYP & 3.24 & 1 & $\begin{array}{l}\text { Number of different rock types encountered in } \\
\text { the strata during well drilling }\end{array}$ \\
\hline
\end{tabular}




\begin{tabular}{|c|c|c|c|}
\hline Parameter & $\begin{array}{l}\text { Page } \\
\text { No. }\end{array}$ & $\begin{array}{l}\text { Default } \\
\text { Value }\end{array}$ & Description \\
\hline PERCNT (1) & 3.67 & 1.0 & $\begin{array}{l}\text { Fraction of the well drilling costs considered } \\
\text { tangible }\end{array}$ \\
\hline PERCNT (2) & 3.67 & 0.0 & $\begin{array}{l}\text { Fraction of the we } 11 \text { drilling costs considered } \\
\text { intangible }\end{array}$ \\
\hline PIFALL & 3.77 & $6 . \%$ & Percent general inflation rate \\
\hline PIFCAP & 3.77 & $6 . \%$ & Percent escalation rate for capital \\
\hline PIFCSB & 3.8 & $8 . \%$ & $\begin{array}{l}\text { Percent escalation rate for purchased thermal } \\
\text { energy }\end{array}$ \\
\hline PIFELR & 3.77 & $7 . \%$ & Percent escalation rate for electricity \\
\hline PIFOM & 3.77 & $6 . \%$ & Percent escalation rate for $0 \& M$ \\
\hline PIVTCR & 3.66 & 0.0 & Percent investment tax credit \\
\hline PLMANF & 3.8 & 0.0 & $\begin{array}{l}\text { Distance from the manifold pipe nodes to the } \\
\text { first column of we } 11 \text { nodes }\end{array}$ \\
\hline PLNGTH(1) & 3.8 & $2500 . m$ & $\begin{array}{l}\text { Length of transmission leg } 1 \text { from the energy } \\
\text { source to the storage wellfield }\end{array}$ \\
\hline PLNGTH(2) & 3.8 & $2500 . m$ & $\begin{array}{l}\text { Length of transmission leg } 2 \text { from the storage } \\
\text { wellfield to the distribution system inlet }\end{array}$ \\
\hline $\operatorname{PLNGTH}(3)$ & 3.8 & $2500 . m$ & $\begin{array}{l}\text { Length of transmission leg } 3 \text { from the distri- } \\
\text { bution system inlet to the supply wellfield }\end{array}$ \\
\hline PLNGTH(4) & 3.8 & $2500 . m$ & $\begin{array}{l}\text { Length of transmission leg } 4 \text { from the supply } \\
\text { wellfield to the energy source }\end{array}$ \\
\hline PMLIFE & 3.29 & 10. yrs & Downhole pump service life \\
\hline PRDRAT & 3.24 & 1.0 & $\begin{array}{l}\text { Ratio of injection to withdrawal well flow } \\
\text { rate }\end{array}$ \\
\hline PRFLAG & 3.89 & 0.0 & Print switch to suppress all but summary data \\
\hline SAFLOW & 2.20 & $\begin{array}{l}91,500,000 \\
y r\end{array}$ & Annual water flow rate from the energy source \\
\hline SDFLOW & 3.7 & $\begin{array}{l}000,000 \\
\text { day }\end{array}$ & Daily water flow rate from the energy source \\
\hline
\end{tabular}




\begin{tabular}{|c|c|c|c|}
\hline Parameter & $\begin{array}{l}\text { Page } \\
\text { No. } \\
\end{array}$ & $\begin{array}{l}\text { Default } \\
\text { Value }\end{array}$ & Description \\
\hline SHCOST & 3.7 & $0 . \$ / \mathrm{MBtu}$ & $\begin{array}{l}\text { Cost of purchased thermal energy from the } \\
\text { energy souuce }\end{array}$ \\
\hline SMFLOW & 2.20 & $\begin{array}{l}500,000 \\
1 \mathrm{~b} / \mathrm{hr}\end{array}$ & $\begin{array}{l}\text { Peak hourly water flow rate from the energy } \\
\text { source }\end{array}$ \\
\hline SMXFLW & 3.7 & 1.E99 1b/hr & $\begin{array}{l}\text { Upper bound on the peak hourly water flow } \\
\text { rate from the energy source }\end{array}$ \\
\hline SPAQEF & 3.8 & .8 & $\begin{array}{l}\text { Aquifer thermal efficiency fraction of the } \\
\text { supply wellfield }\end{array}$ \\
\hline STAQEF & 3.7 & .8 & $\begin{array}{l}\text { Aquifer thermal efficiency fraction of the } \\
\text { storage wellfield }\end{array}$ \\
\hline STFREC & 2.20 & .9 & $\begin{array}{l}\text { Aquifer fluid recovery fraction for the } \\
\text { storage wellfield }\end{array}$ \\
\hline $\operatorname{STRATA}(1, N)$ & 3.24 & 3. & $\begin{array}{l}\text { Rock hardness of each strata encountered } \\
\text { during well drilling }\end{array}$ \\
\hline $\operatorname{STRATA}(2, N)$ & 2.3 & $300 . m$ & $\begin{array}{l}\text { Well depth of each strata encountered during } \\
\text { well drilling }\end{array}$ \\
\hline TAQIF & 3.8 & $55 .{ }^{\circ} \mathrm{F}$ & $\begin{array}{l}\text { Discovery (natural) aquifer temperature in } \\
\text { both wellfields }\end{array}$ \\
\hline TENVR (1) & 3.28 & $70 .{ }^{\circ} \mathrm{F}$ & $\begin{array}{l}\text { Average ambient air temperature during } \\
\text { storage of hot water or delivery of cold water }\end{array}$ \\
\hline TENVR (2) & 3.29 & $35 .{ }^{\circ} \mathrm{F}$ & $\begin{array}{l}\text { Average ambient air temperature during } \\
\text { delivery of hot water or storage of cold water }\end{array}$ \\
\hline TRCASE & 3.28 & -1.0 & $\begin{array}{l}\text { Option to de lete the casing or allow the code } \\
\text { to use } 0.016 \text { inch aluminum jacket casing to } \\
\text { cover all transmission system insulation }\end{array}$ \\
\hline TRINSL & 3.28 & -1.0 & $\begin{array}{l}\text { Option to directly input or allow the code to } \\
\text { calculate the insulation thickness on all } \\
\text { transmission system piping }\end{array}$ \\
\hline TSRIN & 2.22 & $200 .^{\circ} \mathrm{F}$ & $\begin{array}{l}\text { In let water temperature entering the heat } \\
\text { exchanger from the energy source }\end{array}$ \\
\hline
\end{tabular}




\begin{tabular}{|c|c|c|c|}
\hline Parameter & $\begin{array}{l}\text { Page } \\
\text { No. }\end{array}$ & $\begin{array}{l}\text { Default } \\
\text { Value }\end{array}$ & Description \\
\hline TSROUT & 2.22 & $80 .{ }^{\circ} \mathrm{F}$ & $\begin{array}{l}\text { Outlet water temperature exiting the heat } \\
\text { exchanger back to the energy source }\end{array}$ \\
\hline UNITO & 3.83 & see pg 3.83 & $\begin{array}{l}\text { Cost array defining costs for pre-development, } \\
\text { development, and operational activities of the } \\
\text { supply system }\end{array}$ \\
\hline WELSPC & 2.38 & 1. acre & Aquifer well spacing \\
\hline
\end{tabular}




\section{DISTRIBUTION INPUT PARAMETER INDEX \\ (NAMELIST Group \$DISTRB)}

All parameters beginning with the letters I through $\mathrm{N}$ are "integer" except KINS and I0, which are declared "real" in the code. The page numbers listed below for each parameter correspond to the first reference to each parameter in the text. Additional information concerning each parameter may be found in subsequent pages.

\begin{tabular}{|c|c|c|c|}
\hline Parameter & $\begin{array}{l}\text { Page } \\
\text { No. }\end{array}$ & $\begin{array}{c}\text { Default } \\
\text { Value }\end{array}$ & Description \\
\hline ACDGHR & 3.43 & $\begin{array}{l}19,571 .^{\circ} \mathrm{F}- \\
\mathrm{hrs} / \mathrm{yr}\end{array}$ & Annual cooling degree-days \\
\hline $\operatorname{ADGDAY}(1)$ & 3.11 & $\begin{array}{l}6500 . \\
\text { days }\end{array}{ }^{\circ} \mathrm{F}$ - & Annual heating degree-days \\
\hline AGFACT(I) & 2.40 & $\begin{array}{l}\text { depends on } \\
\text { pipe dia. }\end{array}$ & $\begin{array}{l}\text { Age factor for increasing the frictional } \\
\text { losses in pipes due to deterioration with } \\
\text { age }\end{array}$ \\
\hline AREA(M) & 2.19 & 1. $m i l e^{2}$ & Area of district $M$ \\
\hline BACKC & 3.72 & $\$ 13.10 / \mathrm{m}^{3}$ & Backfilling cost for trenching \\
\hline BEDC & 3.72 & $\$ 13.10 / \mathrm{m}^{3}$ & Bedding fill cost for trenching \\
\hline CG & 3.56 & $0.36 \mathrm{~J} / \mathrm{s}-\mathrm{m}-{ }^{0} \mathrm{C}$ & Thermal conductivity of the ground \\
\hline $\mathrm{CO}$ & 3.56 & 1.0 & Casing material option \\
\hline COPUMP & 3.78 & $\$ .029 / \mathrm{kWh}$ & Unit cost of electricity for pumping \\
\hline$C P$ & 3.56 & $\begin{array}{l}3.56 \mathrm{~J} / \mathrm{s}-\mathrm{m}-{ }^{\circ} \mathrm{C} \\
\text { (carbon stee } 1 \text { ) }\end{array}$ & Thermal conductivity of the pipe \\
\hline $\operatorname{CQ}(N)$ & 3.39 & $\begin{array}{l}\text { depends on } \\
\text { building }\end{array}$ & $\begin{array}{l}\text { Peak cooling demand of a typical building } \\
\text { in district type } \mathrm{N}\end{array}$ \\
\hline $\operatorname{CRTF}(N)$ & 3.53 & $\begin{array}{l}\text { depends on } \\
\text { building }\end{array}$ & $\begin{array}{l}\text { Cost of retrofitting building heating or } \\
\text { cooling systems in district type } N\end{array}$ \\
\hline CSBTU & 3.64 & $\$ 6 . /$ Btu & Cost of supplemental heat \\
\hline $\operatorname{CSF}(M)$ & 3.51 & 1.0 & Crooked street factor for district $M$ \\
\hline $\operatorname{DDGDAY}(1)$ & 2.19 & $6000 .{ }^{0} \mathrm{~F}$-days & Design heating degree days \\
\hline $\operatorname{DDTR}(M)$ & 3.49 & 1. mile & Length of the main pipe serving district \\
\hline
\end{tabular}




\begin{tabular}{|c|c|c|c|}
\hline Parameter & $\begin{array}{l}\text { Page } \\
\text { No. }\end{array}$ & $\begin{array}{l}\text { Default } \\
\text { Value }\end{array}$ & Description \\
\hline $\operatorname{DENSE}(N)$ & 2.19 & $\begin{array}{l}\text { depends on } \\
\text { building }\end{array}$ & Building density in district type $\mathrm{N}$ \\
\hline DFLAG & 3.88 & . TRUE. & $\begin{array}{l}\text { Print switch for selecting the } \\
\text { distribution system printout }\end{array}$ \\
\hline DIAL & 3.21 & $0.1 \mathrm{ft}$ & Heat exchanger tube inside diameter \\
\hline DIAOL & 3.21 & $0.1104 \mathrm{ft}$ & Heat exchanger tube outside diameter \\
\hline DINPUT (39) & 3.69 & 0.59 & Fraction of investment in bonds \\
\hline DINPUT (40) & 3.69 & 0.08 & Bond interest rate \\
\hline DINPUT (41) & 3.69 & 0.12 & Earning rate on equity after taxes \\
\hline DINPUT (42) & 3.69 & 0.46 & Federal income tax rate \\
\hline DINPUT (44) & 3.69 & 15. yrs & Depreciable life of distribution system \\
\hline DINPUT (49) & 3.69 & 1990. & $\begin{array}{l}\text { Startup year for operation of the } \\
\text { distribution system }\end{array}$ \\
\hline DINPUT (50) & 3.69 & 0.07 & State income tax rate \\
\hline DINPUT (51) & 3.69 & 0.04 & State gross revenue tax rate \\
\hline DINPUT (52) & 2.64 & 0.025 & Property tax rate \\
\hline DINPUT ( 53 ) & 2.64 & 0.0035 & Interim capital replacement rate \\
\hline DINPUT (54) & 2.64 & 0.0012 & Property insurance rate \\
\hline DINPUT (61) & 3.69 & 30. yrs & Distribution system operating life \\
\hline DINPUT (63) & 3.69 & 0.05 & Distribution system maintenance rate \\
\hline $\operatorname{DIVF}(N)$ & 3.53 & 0.72 & Diversity factor for district type $N$ \\
\hline $\operatorname{DNET}(M, M M)$ & 3.60 & must be input & Defines the districts serviced by each mair \\
\hline DPTH & 3.56 & $0.5 \mathrm{~m}$ & Burial depth of the casing \\
\hline ELDIFF (M) & 3.49 & $0.0 \mathrm{ft}$ & $\begin{array}{l}\text { Elevation of district } M \text { above the end of } \\
\text { the transmission line }\end{array}$ \\
\hline
\end{tabular}




\begin{tabular}{|c|c|c|c|}
\hline Parameter & $\begin{array}{l}\text { Page } \\
\text { No. }\end{array}$ & $\begin{array}{l}\text { Default } \\
\text { Value }\end{array}$ & Description \\
\hline ETA & 3.27 & 0.65 & $\begin{array}{l}\text { Combined motor and pump efficiency for } \\
\text { both supply and distribution system pumps }\end{array}$ \\
\hline EXCC & 3.72 & $\$ 26.16 / \mathrm{m}^{3}$ & Excavation cost for trenching \\
\hline FINC & 3.72 & $\$ 1.30 / \mathrm{m}^{3}$ & Finish fill cost for trenching \\
\hline FOULFI & 3.21 & $\begin{array}{l}8.001 \mathrm{hr}-\mathrm{ft}- \\
\mathrm{F} / \text { Btu }\end{array}$ & Heat exchanger inside fouling factor \\
\hline FOULFO & 3.21 & $8.001 \mathrm{hr}-\mathrm{ft}-$ & Heat exchanger outside fouling factor \\
\hline $\operatorname{HDES}(2)$ & 3.38 & $\begin{array}{l}0.0125 \\
1 \mathrm{~b} \mathrm{H}_{2} \mathrm{O} / \mathrm{lb} \text { air }\end{array}$ & $\begin{array}{l}\text { Absolute humidity at the summer outdoor } \\
\text { dry-bulb and wet-bulb temperature for } \\
\text { cooling }\end{array}$ \\
\hline $\mathrm{HQ}(\mathrm{N})$ & 2.19 & $\begin{array}{l}\text { depends on } \\
\text { building }\end{array}$ & $\begin{array}{l}\text { Peak heating demand of a typical building } \\
\text { in district type } N\end{array}$ \\
\hline $\mathrm{HROD}(\mathrm{K})$ & 3.42 & $\begin{array}{l}\text { depends on } \\
\text { interval }\end{array}$ & $\begin{array}{l}\text { Number of hourly temperature observations } \\
\text { per year which lie in each temperature } \\
\text { interval for cooling }\end{array}$ \\
\hline HTEXOP & 3.46 & 0.0 & $\begin{array}{l}\text { Option for a centralized heat exchanger at } \\
\text { the end of the transmission leg from the } \\
\text { storage aquifer }\end{array}$ \\
\hline $\mathrm{HW}(\mathrm{N})$ & 3.51 & $\begin{array}{l}\text { depends on } \\
\text { building }\end{array}$ & $\begin{array}{l}\text { Daily sanitary hot water demand for a } \\
\text { typical building in district type } \mathrm{N}\end{array}$ \\
\hline $\operatorname{IDTR}(M)$ & 3.48 & $\begin{array}{l}\text { depends on } \\
\text { district }\end{array}$ & District type for the Mth district \\
\hline IDTYPE & 3.48 & 1 & $\begin{array}{l}\text { The generic type of district at the } \\
\text { simulated site }\end{array}$ \\
\hline I0 & 3.2 & 1.0 & Insulation material option \\
\hline KINS & 3.2 & $\begin{array}{l}\text { depends on } \\
\text { insulation }\end{array}$ & Thermal conductivity of the insulation \\
\hline LL2 & 3.75 & 1 & $\begin{array}{l}\text { Depreciation option for supply and } \\
\text { distribution systems }\end{array}$ \\
\hline
\end{tabular}




\begin{tabular}{|c|c|c|c|}
\hline Parameter & $\begin{array}{l}\text { Page } \\
\text { No. }\end{array}$ & $\begin{array}{l}\text { Default } \\
\text { Value }\end{array}$ & Description \\
\hline MCOOL & 3.36 & 0 & $\begin{array}{l}\text { Controls option for direct input or } \\
\text { internal calculation of CQ and ACDGHR }\end{array}$ \\
\hline MODE & 3.31 & 0 & $\begin{array}{l}\text { Selection of space heating or cooling } \\
\text { simulation }\end{array}$ \\
\hline NDTR & 3.48 & 1 & Number of districts at the simulated site \\
\hline $\operatorname{NRESD}(\mathrm{N})$ & 3.38 & $\begin{array}{l}\text { depends on } \\
\text { building }\end{array}$ & $\begin{array}{l}\text { Number of residences in a typical building } \\
\text { of district type } N\end{array}$ \\
\hline NTMINT & 3.40 & 10 & $\begin{array}{l}\text { Number of outdoor dry-bulb ambient } \\
\text { temperature intervals used in hourly } \\
\text { calculations of cooling energy requirements }\end{array}$ \\
\hline NYC & 2.63 & 3 & $\begin{array}{l}\text { Number of years to construct the } \\
\text { distribution system }\end{array}$ \\
\hline $\mathrm{PF}$ & 3.58 & must be input & Annual load factor for point demand load \\
\hline PIVTCP & 2.65 & 0.0 & $\begin{array}{l}\text { Percent investment tax credit for the } \\
\text { distribution system }\end{array}$ \\
\hline PMO & 3.56 & 1.0 & Pipe material option \\
\hline PO & 3.55 & 1.0 & $\begin{array}{l}\text { Pipe option for designing the configura- } \\
\text { tion of the conduit bundle }\end{array}$ \\
\hline POPHSE (N) & 3.53 & $\begin{array}{l}\text { depends on } \\
\text { building }\end{array}$ & $\begin{array}{l}\text { Number of residents in a typical building } \\
\text { of district type } N\end{array}$ \\
\hline PRINDX & 3.73 & 1980. & $\begin{array}{l}\text { January } 1 \text { of base year used by AQUASTOR } \\
\text { for calculating capital and O\&M costs of } \\
\text { the supply and distribution systems }\end{array}$ \\
\hline RESRFC & 3.72 & $\$ 8.40 / \mathrm{m}^{2}$ & Resurfacing cost for trenching \\
\hline TA & 3.56 & 1. inch & $\begin{array}{l}\text { Annular air space between the insulation } \\
\text { and the casing }\end{array}$ \\
\hline TAOD $(K)$ & 3.40 & $\begin{array}{l}\text { depends on } \\
\text { interval }\end{array}$ & $\begin{array}{l}\text { Midpoints of the outdoor dry-bulb } \\
\text { temperature intervals for cooling }\end{array}$ \\
\hline $\operatorname{TDES}(1)$ & 2.19 & $-5 .^{0} \mathrm{~F}$ & $\begin{array}{l}\text { Winter design outdoor dry-bulb } \\
\text { temperature }\end{array}$ \\
\hline
\end{tabular}




\begin{tabular}{|c|c|c|c|}
\hline Parameter & $\begin{array}{l}\text { Page } \\
\text { No. }\end{array}$ & $\begin{array}{l}\text { Default } \\
\text { Value }\end{array}$ & Description \\
\hline TDES (2) & 3.38 & $99 .^{\circ} \mathrm{F}$ & $\begin{array}{l}\text { Summer design outdoor dry-butb } \\
\text { temperature }\end{array}$ \\
\hline$T G$ & 3.57 & $50 .^{\circ} \mathrm{F}$ & Average year-round ground temperature \\
\hline $\operatorname{TINDES}(1)$ & 3.33 & $65 .{ }^{\circ} \mathrm{F}$ & Indoor design temperature for heating \\
\hline TINDES (2) & 3.37 & $78 .{ }^{\circ} \mathrm{F}$ & Indoor design temperature for cooling \\
\hline TMIN & 3.32 & $-15 \cdot{ }^{\circ} \mathrm{F}$ & $\begin{array}{l}\text { Minimum winter outdoor temperature for } \\
\text { heating }\end{array}$ \\
\hline TRDF & 3.72 & 1.0 & Trenching difficulty factor \\
\hline $\operatorname{TREJ}(N)$ & 2.49 & $100 .{ }^{\circ} \mathrm{F}$ & $\begin{array}{l}\text { Temperature of the return water at the } \\
\text { outlet of the building heating system in } \\
\text { district type } N\end{array}$ \\
\hline $\operatorname{TREJC}(\mathrm{N})$ & 3.53 & $55 .{ }^{\circ} \mathrm{F}$ & $\begin{array}{l}\text { Temperature of the return water at the } \\
\text { out let of the building cooling system in } \\
\text { district type } N\end{array}$ \\
\hline TWATC & 2.47 & $50 .{ }^{\circ} \mathrm{F}$ & $\begin{array}{l}\text { Cold water temperature in the sanitary } \\
\text { hot water tank }\end{array}$ \\
\hline TWATH & 2.47 & $140 .{ }^{\circ} \mathrm{F}$ & $\begin{array}{l}\text { Hot water temperature from the sanitary } \\
\text { hot water tank }\end{array}$ \\
\hline TWIDTH & 3.40 & $5 .{ }^{\circ} \mathrm{F}$ & $\begin{array}{l}\text { Outdoor temperature interval size } \\
\text { grouping annual hourly temperature data } \\
\text { for cooling }\end{array}$ \\
\hline UAPIN & 3.44 & $5 .{ }^{\circ} \mathrm{F}$ & $\begin{array}{l}\text { Distribution system water temperature } \\
\text { approach to storage aquifer water entering } \\
\text { the distribution heat exchanger }\end{array}$ \\
\hline UAPOUT & 3.44 & $5 .{ }^{\circ} \mathrm{F}$ & $\begin{array}{l}\text { Distribution system water temperature } \\
\text { approach to storage aquifer water exiting } \\
\text { the distribution heat exchanger }\end{array}$ \\
\hline VMBTU & 3.57 & $\$ 6 . / M B t u$ & Value of one million Btus of heat or chill \\
\hline WIDTH(M) & 3.49 & 1. mi le & Width of district $M$ \\
\hline
\end{tabular}




\begin{tabular}{|c|c|c|c|}
\hline Parameter & $\begin{array}{c}\text { Page } \\
\text { No. }\end{array}$ & $\begin{array}{c}\text { Default } \\
\text { Value }\end{array}$ & Description \\
\hline WLEAK & 2.19 & 0.01 & $\begin{array}{l}\text { Fraction of water lost by leakage in the } \\
\text { transmission and distribution systems }\end{array}$ \\
\hline WVELL & 3.23 & 8. $\mathrm{ft} / \mathrm{s}$ & Heat exchanger tube water velocity \\
\hline XLNGTH $(M)$ & 3.49 & 1. mile & Length of district $M$ \\
\hline
\end{tabular}




\section{AQUASTOR SUBROUTINE INDEX}

The page numbers listed below for each subroutine correspond to the first reference to each subroutine in the text. Additional information concerning each subroutine may be found in subsequent pages.

\begin{tabular}{lc} 
Subroutine & Page No. \\
\cline { 2 - 3 } ADATA & 2.9 \\
AGELOS & 2.40 \\
AQIFER & 2.15 \\
AQUASTOR & 1.1 \\
CALQNA & 2.15 \\
CLEAR & 2.59 \\
CONVRT & 2.15 \\
CONVRG & 2.15 \\
COSTEG/COSTEA & 2.65 \\
COSTEQ/COSTQA & 2.60 \\
CPOWER/APOWER & 2.67 \\
DATA & 2.12 \\
DATACK & 2.59 \\
DATAK & 2.65 \\
DATE & 2.13 \\
DEGC & 2.13 \\
DEPREC & 2.60 \\
DESIGN & 2.37 \\
DIST & 2.12 \\
DISTRB & 2.10 \\
&
\end{tabular}

(a) $\operatorname{slash}(/)$ means alternate entry point within subroutine. 
Subroutine

DPREC

DRILL

DWRIT/DWRIT2

ECHO

EQCOST

ESCALT

FACTRS

FEET

FLPROP

FLUID

GRAPH

HCONST

HEAT

HEATEX

HTAREA

HTCOEF

HTLNGH

HXDROP

INCHES

INSUL

LOAD

NODEPR

OHTCOE

OUTPLT
Page No.

2.65

3.67

2.15

2.12

2.39

2.25

2.60

2.13

2.41

2.28

2.45

2.63

2.45

2.15

2.29

2.29

2.29

2.16

2.13

2.40

2.9

2.3

2.29

2.66 


\begin{tabular}{|c|c|}
\hline Subroutine & Page No. \\
\hline OUTPUT & 2.60 \\
\hline PAGE & 2.13 \\
\hline PAYOT & 2.66 \\
\hline PAYOUT & 2.61 \\
\hline PHOTOD & 2.12 \\
\hline PIPE/PIPE 1,PIPE2 & 2.39 \\
\hline PRINT1 & 2.15 \\
\hline PRNTAQ & 2.15 \\
\hline PRNTCQ & 2.16 \\
\hline PRNT12 & 2.42 \\
\hline PROP & 2.45 \\
\hline PUMP & 2.15 \\
\hline PWRCO & 2.60 \\
\hline QAREA & 2.29 \\
\hline RESVOR & 2.9 \\
\hline REYNO & 2.28 \\
\hline SCHEDL & 2.39 \\
\hline SIZE & 2.12 \\
\hline SLEVEL/DLEVEL & 2.10 \\
\hline SPFLOW & 2.40 \\
\hline SPRINT & 2.10 \\
\hline SUBHEX & 2.15 \\
\hline SUMARY / ASUMRY & 2.62 \\
\hline SUPPLM & 2.15 \\
\hline SWITCH & 2.12 \\
\hline
\end{tabular}




\begin{tabular}{|c|c|}
\hline Subroutine & Page No. \\
\hline TARGTS & 2.59 \\
\hline TBCOST & 2.42 \\
\hline TBPUMP & 2.41 \\
\hline TICOST & 2.41 \\
\hline TOLP & 2.12 \\
\hline TPHASE & 2.41 \\
\hline TPRINT & 2.42 \\
\hline TRANS/INJECT & 2.15 \\
\hline TSTRT & 2.39 \\
\hline TUBES & 2.29 \\
\hline UPDATE & 2.25 \\
\hline VELOCY & 2.29 \\
\hline XPHH & 2.41 \\
\hline
\end{tabular}

H. 15 
.
$-\cdots$
$-\cdots$

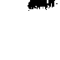

$-$

$-$ 


\section{DISTRIBUTION}

No. of

Copies

\section{OFFSITE}

A. A. Churm

DOE Patent Division

9800 S. Cass Avenue

Argonne, IL 60439

John J. Brogan

DOE Office of Energy

Systems Research

Washington, D.C. 20585

Arnold Epstein

Project Manager

CR-341, Forrestal Building

Department of Energy

Washington, D.C. 20585

T. Levinson

DOE Office of Energy

Systems Research

Washington, D.C. 20585

R. Shivers

DOE Office of Energy

Systems Research

Washington, D.C. 20585

Veronica Rabl

DOE Office of Energy

Systems Research

Washington, D.C. 20585

I. Gyuk

DOE Office of Energy

Systems Research

Washington, D.C. 20585

J. H. Swisher

DOE Office of Energy

Systems Research

Washington, D.C. 20585
No. of

Copies

Fred J. Molz

School of Engineering

Auburn University

Auburn, AL 36830

Donald Langmuir

Department of Chemistry and Geochemistry

Colorado School of Mines

Golden, C0 80401

Louis Stern

Dames \& Moore

6 Commerce Drive

Cranford, NJ 07016

Walter Hausz

4520 Via Vistosa

Santa Barbara, CA 93110

Charles F. Meyer

1141 Cima Linda Lane

Santa Barbara, CA 93108

Chin Fu Tsang

Bldg. 90, Room 1012-H

University of California

Lawrence Berkeley Laboratory

1 Cyclotron Road

Berkeley, CA 94720

Victor E. Hampe 1

Integrated Information Systems

Computation Dept., L-275

University of California

Lawrence Livermore Laboratory

Livermore, CA 94550

L. Lorenz

Internorth

2223 Dodge Street

Omaha, NE 68102

27 Technical Information Center 
No. of

Copies

Matt Walton

Minnesota Geological Survey

319 15th Avenue, S.E.

Minneapolis, MN 55455

National Aeronautics and Space Administration

Asst. Adm. for Energy Programs

Washington, D.C. 20546

National Science Foundation

Division of Advanced Energy

Research and Technology

Room 1140

1800 G Street, N.W.

Washington, D.C. 20550

Director

New York State Energy Research and Development Agency

Rockefeller Plaza

Albany, NY 12223

J. F. Martin

Oak Ridge National Laboratory

PO Box Y

Oak Ridge, TN 37830

Douglas D. Huxtable, Director

Energy R\&D

Rocket Research Company

York Center

Redmond, WA 98052

L. B. Katter

Rocket Research Center

York Center

Redmond, WA 98052

Craig Cooley

Terra Tek

University Research Park

400 Wakara Way

Salt Lake, UT 84108
No. of

Copies

W. G. Wilson

Sandia Laboratories, Livermore

PO Box 969

Livermore, CA 94550

Sandia Laboratories

Technical Library

Division 3141

Albuquerque, NM 87185

Charles Wyman

Solar Energy Research Institute 1516 Cole Boulevard

Golden, C0 80401

Allan Michaels

Solar Thermal Storage Programs

Argonne National Laboratory

Building 362

9700 South Cass Avenue

Argonne, IL 60439

John F. Spencer

Department of Ecology

State of Washington

Olympia, WA 98504

William Waldrop

Assistant Branch Chief

Water Systems Development Branch

Division of Water Management

Tennessee Valley Authority

PO Drawer E

Norris, TN 37828

L. Radosevich

Sandia Laboratories, Livermore PO Box 969

Livermore, CA 94550

Donald L. Reddell

Agricultural Engineering Dept. Texas A\&M University

College Station, TX 77843 
No. of

Copies

U.S. Army Corps of Engineers

Attn: Library

P0 Box 59

Louisville, KY 40202

U.S. Department of Energy

Attn: Chief, APMBR

Division of Energy Storage Systems

Washington, D.C. 20545

U.S. Department of Energy

Attn: Director, Policy and Planning

Office of Conservation and

Solar Applications

Washington, D.C. 20545

U.S. Department of Interior

Attn: Natural Resources

Serials Branch (G/E)

Washington, D.C. 20240

Kevin Billings

Legislative Assistant

Office of Congressman

Sid Morrison

1330 Longworth Building

Washington, D.C. 20515

Robert D. MacNish

District Chief

Arizona District

U.S. Geological Survey

Federa 1 Building

Tucson, $A Z 85718$

Union Carbide Corporation

Nuclear Division

Attn: Library

$Y-12$ Plant

PO Box $Y$

Oak Ridge, TN 37830
No. of

Copies

Stanley N. Davis

Department of Hydrology and Water Research

University of Arizona

Tucson, AZ 85705

W. E. Soderberg

Program Director, ATES

University of Minnesota

200 Shops Bldg.

319 15th Avenue, S.E.

Minneapolis, MN 55455

James W. Crosby II I

Geology Department

Washington State University

Pullman, WA 99164

David L. Schreiber, Ph.D., P.E. Consulting Hydraulic Engineer

PO Box 1087

(\% The Colony)

Coeur d'Alene, ID 83814

ONSITE

DOE Richland Operations Office

H. E. Ransom

46 Pacific Northwest Laboratory

D. E. Blahnik

C. H. Bloomster

D. R. Brown (5)

S. M. Brown

D. B. Cear lock

D. E. Deonigi

T. J. Doherty

P. J. Duetsch

J. R. Eliason

A. F. Gasperino

P. L. Hendrickson

H. D. Huber (5)

C. T. Kincaid 
L. D. Kannberg

W. W. Laity

W. V. Loscutoff

R. P. Marshall

D. A. Meyers

J. R. Raymond

R. W. Reilly (5)

J. A. Stottlemyre

L. D. Willi ams

G. E. Wukelic

STES Library (4)

Technical Information (5)

Publishing Coordination (2) 